\title{
Intertextuality in Kenyan Policy Discourse on the Rights of Women
}

by

George Aberi

A thesis

Submitted to the Victoria University of Wellington in fulfilment of the requirements for the degree of Doctor of Philosophy in Applied Linguistics

Victoria University of Wellington 


\section{Dedication}

To the memory of my late father Elizaphan Aberi, and mother Pricilla Kwamboka for their trust in me

My children, Brian, Agatha and Vivian, whose cause I live to champion. 


\section{Acknowledgements}

Firstly, I would like to thank our loving God and giver of life for seeing me through this $\mathrm{PhD}$ journey.

I would like to thank Derek Wallace, my primary supervisor, for guiding me and giving insightful comments that have seen me go through the thesis process. I am grateful for the knowledge you have imparted in me, and the challenges you have prepared me to overcome. I would also like to extend my vote of thanks to my second supervisor John Macalister, for reading my draft thesis and giving valuable comments.

I would like to acknowledge Victoria University of Wellington for supporting this research through the Equity Grant and the PhD Submission Scholarship. I also wish to thank the Faculty of Humanities and Social Sciences for three Faculty Research Grants that made this research possible.

Thanks to everyone in the School of Linguistics and Applied Language Studies (LALS). I feel greatly honoured to have been part of such a loving, dedicated and enthusiastic community. I have no better words to express my happiness working with you, than to say I wouldn't have come this far without your support. Thanks to my officemates, Douglas Meyer, Ha Pham, Lin He, Ken Smith, and Seyed Hadi Mirvahedi for the lively discussions and ideas we shared.

Thanks to my Master's research supervisor, Associate Felicia Yieke, for encouraging me and introducing me to critical discourse analysis.

A very special thanks goes to Laura Dimock, Senior Student Finance Advisor, who showed me how to manage my limited financial resources through this process.

Finally, my heartfelt gratitude goes to my wife Jane for her love and continued support. For a lack of better words, thank you a zillion times for supporting me to achieve this noble goal. 


\begin{abstract}
The investigative aim of this thesis is to explore the recontextualization of the normative discourse of gender equality in Kenya's policy discourse of women's rights. Its purpose is threefold: Firstly, it attempts to examine the different ways in which policy makers use language in the course of interpreting and implementing gender equality policies. This includes a focus on both the linguistic and rhetorical/discursive strategies that these policy makers employ for such functions as endorsing, negotiating, legitimating, or even contesting given policy proposals. Secondly, the thesis endeavours to bring to light the different and changing conceptions of gender (in)equality espoused by the various policy actors involved in Kenya's policy discourse of women's rights over a critical ten-year period between 1995 and 2005. These policy actors include the Kenyan government; women's non-governmental organizations (NGOs) who actively seek to influence government policy; and the United Nations' organizations with responsibility for ensuring the implementation of women's human rights. Thirdly, the thesis attempts to show the extent to which policy initiatives proposed by the human rights-based women's NGOs in Kenya are taken up in the texts produced by the Kenyan government.
\end{abstract}

In order to gain a better understanding of the discursive interactions between and amongst the policy actors in this study, an intertextual approach to Norman Fairclough's model of critical discourse analysis (CDA) was used. The thesis drew discourse samples for analysis from the Kenyan government's periodic reports detailing progress towards fully meeting the terms of the Convention on the Elimination of Discrimination Against Women (CEDAW); the documents produced by the Committee overseeing the Convention that provided assessment of the Kenyan government's reports; the Kenyan government's official texts on gender policy; and Kenyan women NGOs' annual reports and other texts.

Though many scholars and researchers of women's rights praise the UN Committee's imperatives for bringing about policy changes concerning women's rights globally, the findings from this study confirm that the Committee for CEDAW has only textual power, and that it lacks enforcement powers to ensure the implementation of the universal rights of women within the local milieu. In a similar vein, this study demonstrates that though the women's NGOs play a significant role both in terms of identifying important areas of concern for policy intervention, and in necessitating changes in the genres of the national government, their participation has largely failed to ensure the Kenyan government's epistemological shift 
from its current state of recognizing the existence of women's rights, to the phase of implementing them.

This thesis also establishes that differing conceptions of gender (in)equality and ideological differences between the Committee for CEDAW and the Kenyan government tend to influence both the Committee's and the Kenyan government's use of varied discourses, genres, and styles, with the intent of manipulating to outmanoeuvre one another. This means that both the Kenyan government and the Committee live in different worlds, suggesting a continuing gap between the Committee's normative knowledge of women's rights to gender equality, and the Kenyan government's cultural relativist perspectives concerning such rights. As a solution to these power struggles and political differences that derail policy making on gender equality, this study recommends the need both for the Committee and the Kenyan government to employ a reflexive and pragmatic mix of both the universalist and cultural relativist approaches to gender equality. This will bring forth shared areas of interest concerning women's rights between the UN and the Kenyan government, based on their applicability within the local context. Moreover, such an approach will create a possibility for the Committee to understand the Kenyan government's cultural relativist/competing discourse of women's rights as another way of conceiving gender equality (i.e. productive power-knowledges), rather than viewing them as irrelevant cultural claims that stand in stark opposition to the universal understandings of women's rights to gender equality. Likewise, the aforesaid reflexive and pragmatic mix of approaches will help the Kenyan policy makers to develop a more critical and nuanced view of the universal approaches to gender equality, thereby reducing their varied forms of resistance to gender equality via subtle evasive strategies.

Methodologically, this thesis shows how a comparative intertextual approach to Fairclough's model of critical discourse analysis can be used as a framework for establishing the relations between policy text and context. This framework includes the micro-level of textual/linguistic analysis, the meso level of discursive interactions, and the macro level of socio-cultural practice at the local, institutional, and societal levels. Theoretically, the thesis demonstrates the different ways in which particular philosophical arguments and emancipatory concepts from Foucault's theory of governmentality and transnational feminist rhetorical theory can be combined and exploited by linguists to promote different ways of theorizing and thinking concerning the development of policies for promoting gender equality. 


\section{TABLE OF CONTENTS}

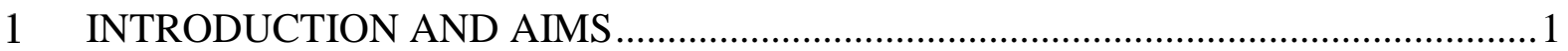

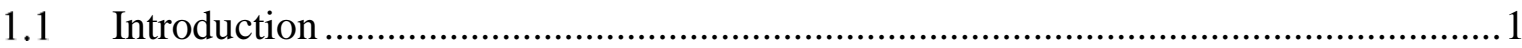

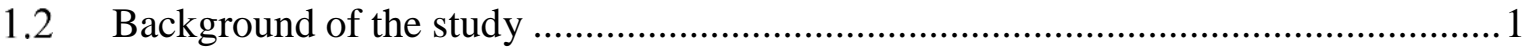

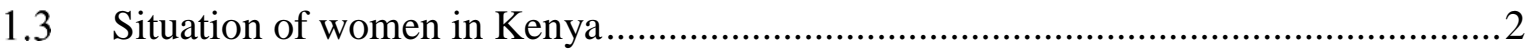

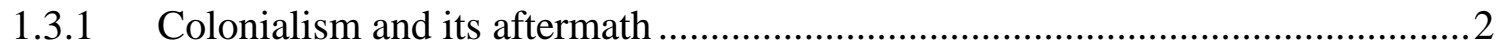

1.3.2 Kenyan people's oppressive cultural practices and traditions ...........................

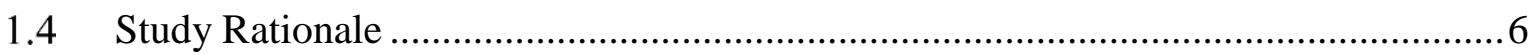

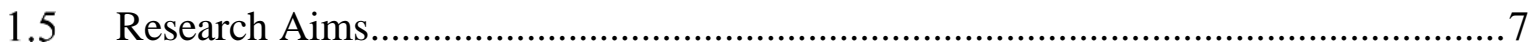

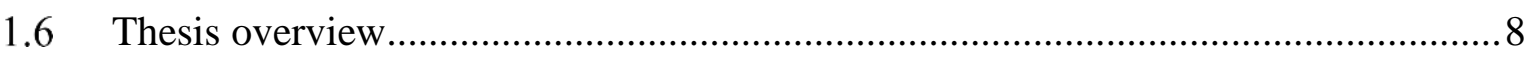

2 LITERATURE REVIEW AND THEORETICAL FRAMEWORK .............................. 10

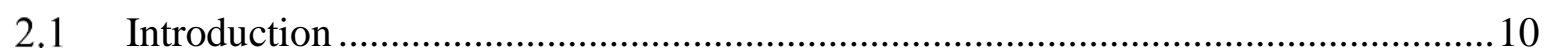

2.2 Universalism and cultural relativism: a brief overview ....................................... 10

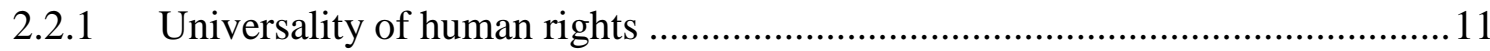

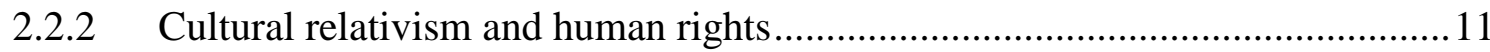

2.2.3 Negotiating the middle level ground between universality and cultural relativity............................................................. 12

2.2.4 Universality of human rights and women's concerns .................................... 14

2.2.5 Challenges in applying the universal approach to women's rights.................... 15

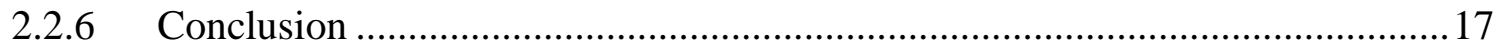

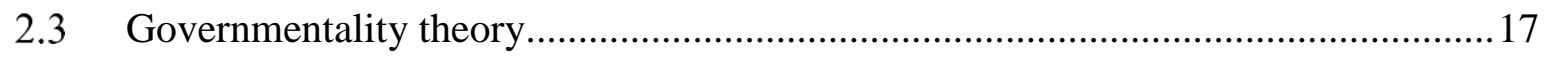

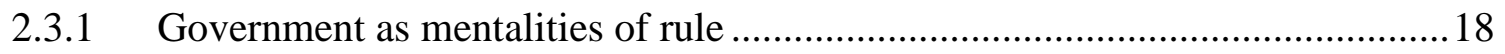

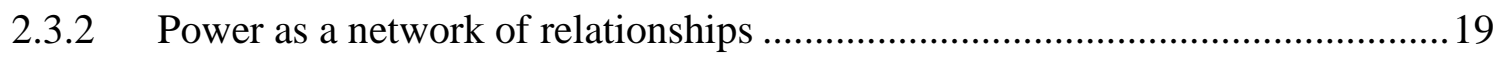

2.3.3 Governmentality and the (neo) liberal rule ..............................................21

2.3.4 Liberal governmentality and authoritative rule ............................................22

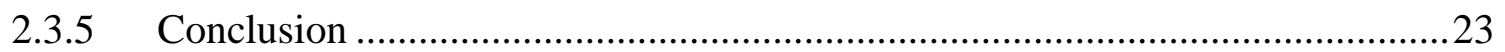

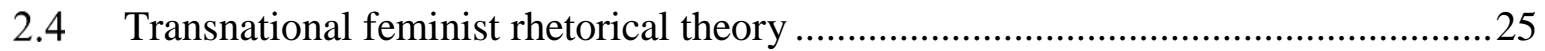

2.4.1 Defining transnational feminist rhetorical analytics .....................................26 
2.4.2 Women's movement and the transnational feminist rhetorical thought .27

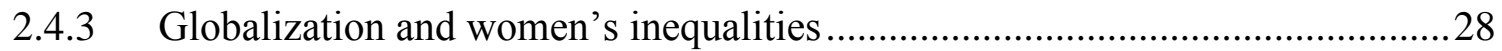

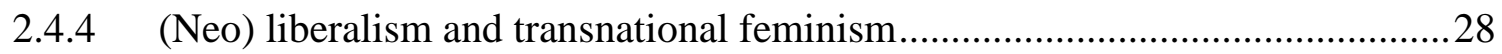

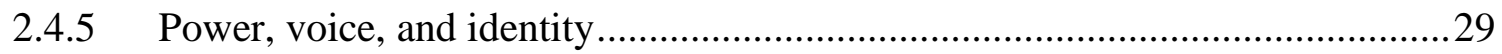

2.4.6 Transnational feminism and gender mainstreaming .....................................2 29

2.4.7 Ways/strategies of mainstreaming women's human rights ............................. 31

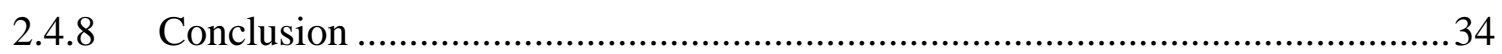

2.5 Governmentality theory and transnational feminist rhetorical theory in this study.. 35

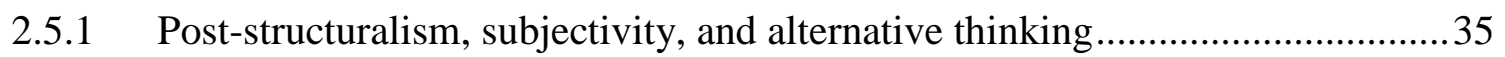

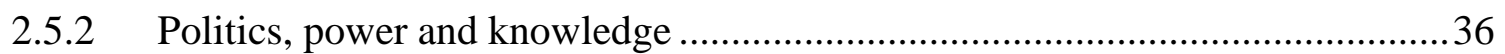

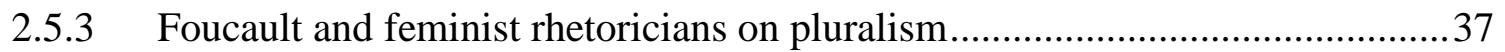

2.5.4 Feminist rhetoricians and the normative concept of human rights ....................38

2.5.5 Feminists and Foucault on sexuality and gender equality concerns ..................39

2.5.6 Complementary aspects of the governmentality theory and feminist rhetorical

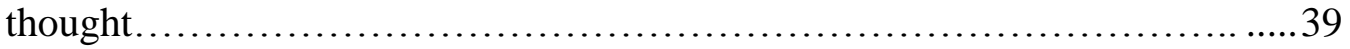

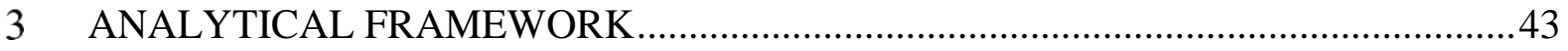

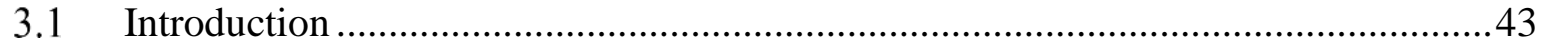

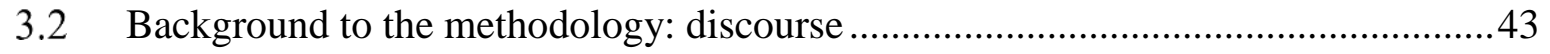

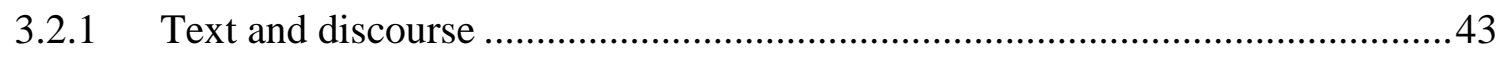

3.2.2 Text as a product of a mediated process ..................................................... 44

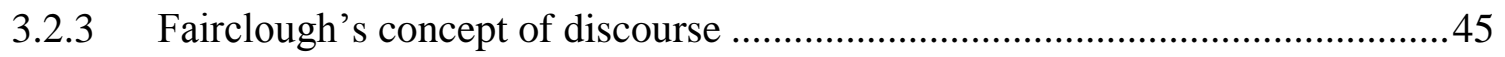

3.2.4 Fairclough and Gramsci's concept of hegemony......................................... 46

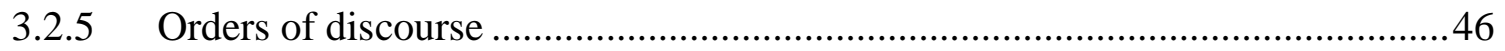

3.3 Analytical framework: critical discourse analysis .......................................... 47

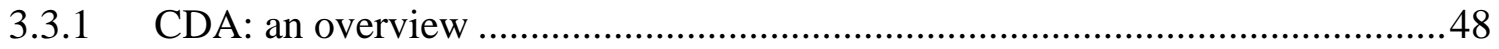

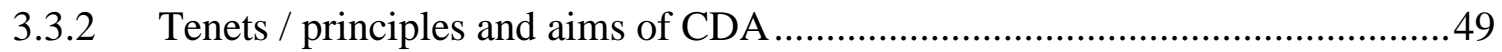

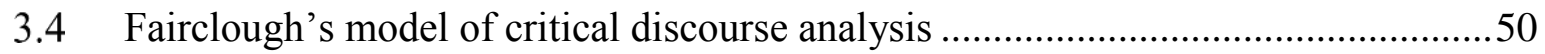


3.5 A three-tier framework of discourse analysis .51

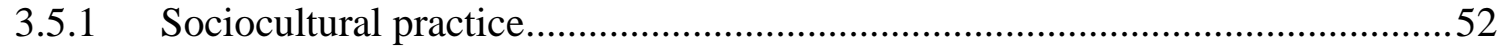

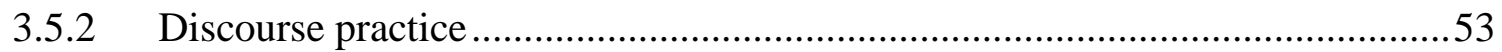

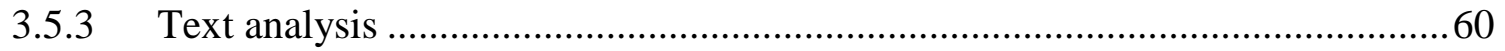

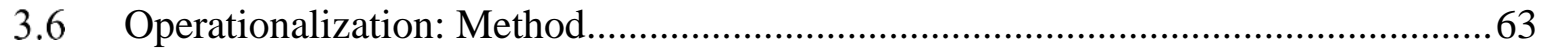

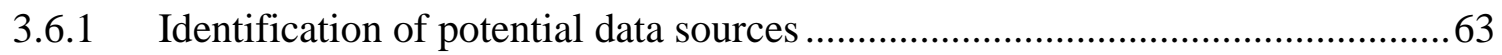

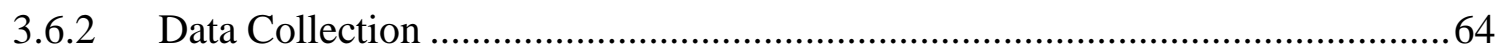

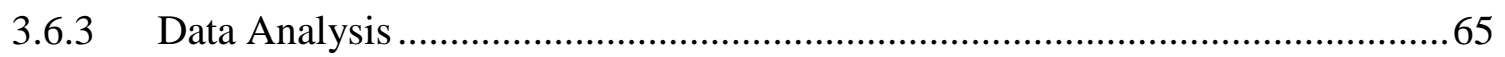

4 UNITED NATIONS' AND KENYA'S DISCOURSE OF WOMEN'S RIGHTS ..........68

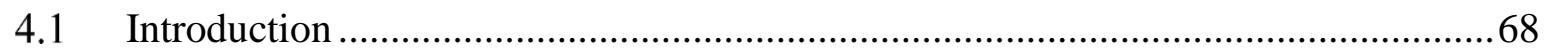

4.2 Summary of the initial exchange between the Kenyan government and the Committee. .70

4.3 Text 1: Consideration of reports submitted by states parties under article 18 of the Convention on the Elimination of All Forms of Discrimination against Women: third and fourth periodic reports of states, Kenya, $14^{\text {th }}$ February, 2000. .72

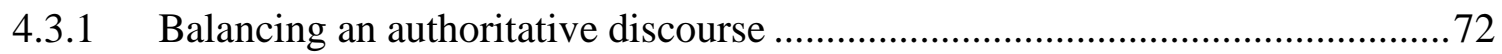

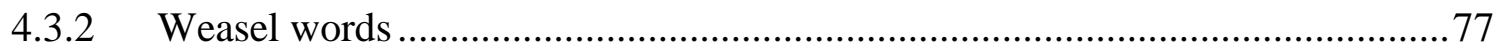

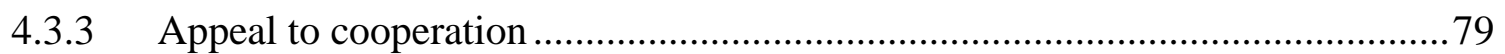

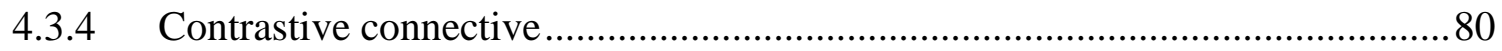

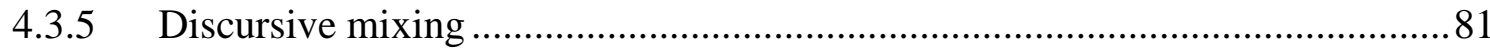

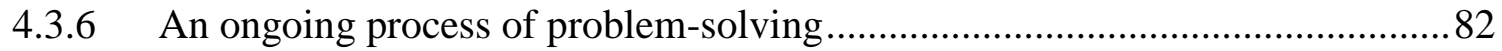

4.4 Text 2: Consideration of reports submitted by states parties under article 18 of the Convention: combined third and fourth periodic report of Kenya, $6^{\text {th }}$ February $2003 \ldots \ldots . .83$

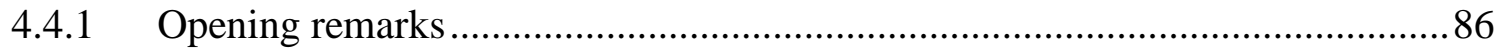

4.4.2 The Committee's opening response and Kenya's reply ..................................90

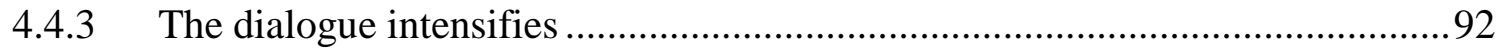

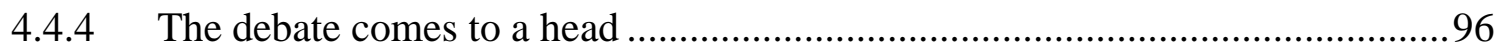

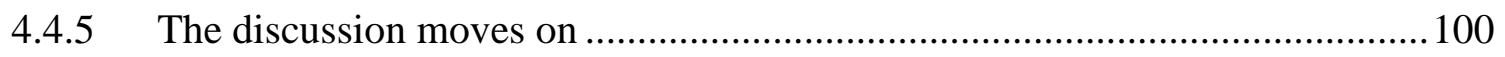


4.5 Text 3: Report of the Committee on the Elimination of Discrimination against Women: official records of the General Assembly, fifty-eighth session, 20 March 2003104

4.5.1 The Convention 104

4.5.2 Customary laws and traditional practices and attitudes .................................. 105

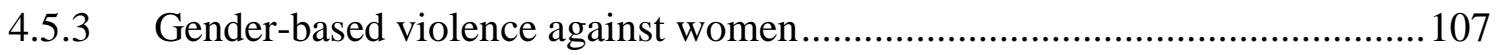

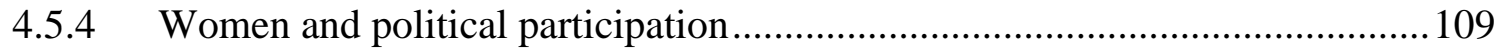

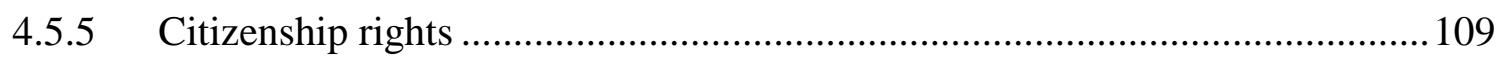

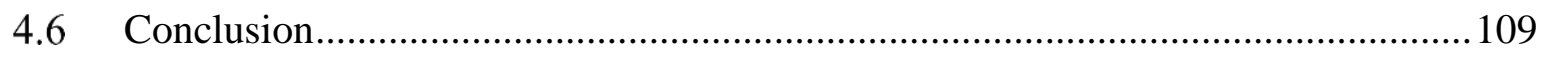

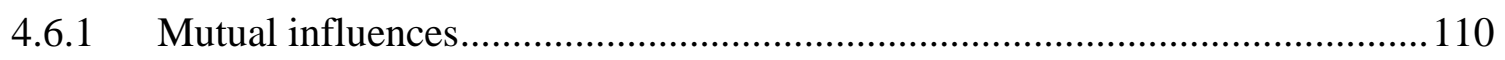

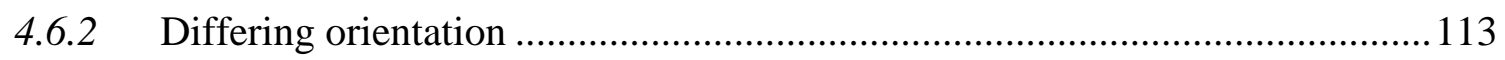

5 KENYAN WOMEN'S NGOS AND THEIR APPROACHES TO INFLUENCE

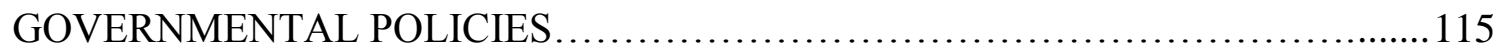

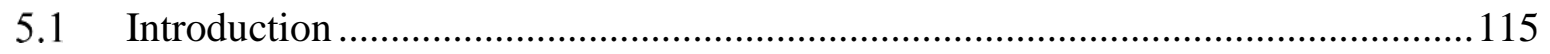

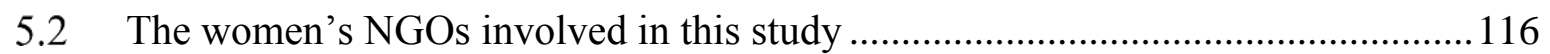

5.3 Constitutional review process and gender equality concerns ................................ 119

5.3.1 Women's political participation and affirmative action policies ....................120

5.3.2 Definition of discrimination in the Kenyan constitution ...............................120

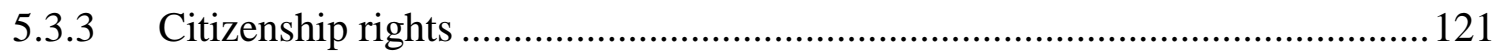

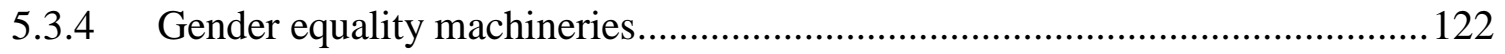

5.3.5 Gender-based violence and sexual harassment against women...................... 123

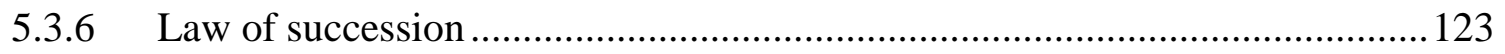

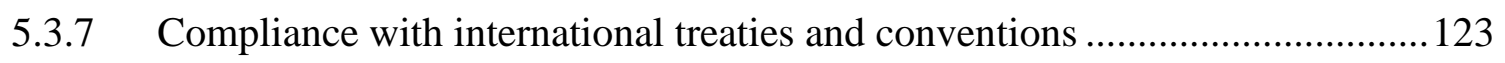

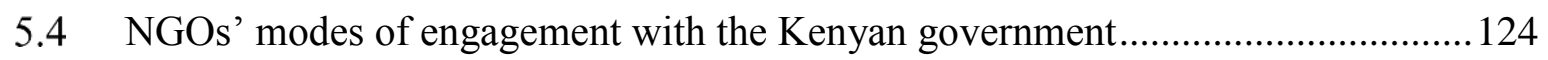

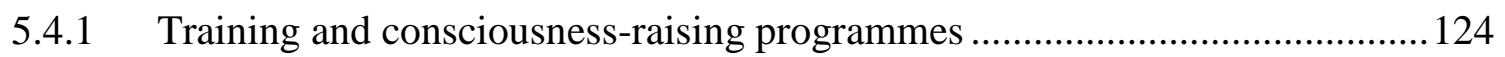

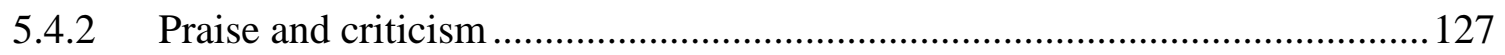

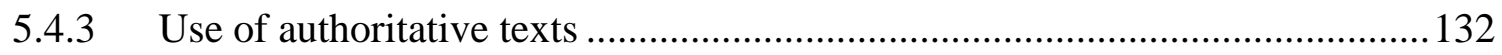

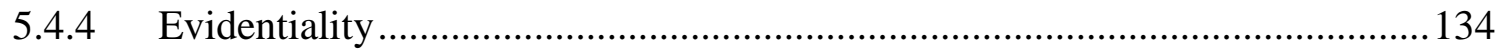




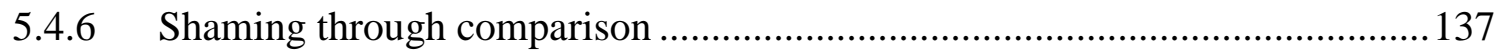

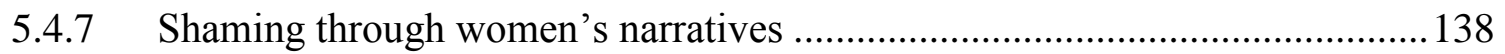

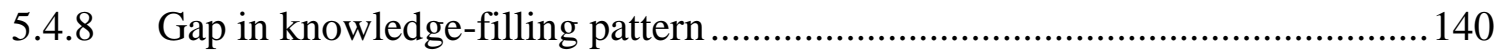

5.4.9 Combating criticism through adversarial forms of address ............................ 141

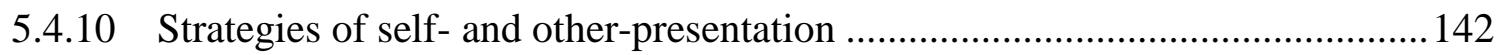

5.5 The Kenyan government's modes of engagement with NGOs ............................. 144

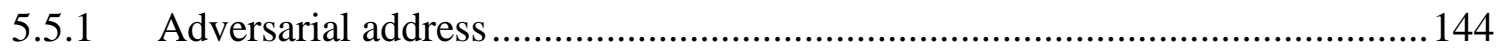

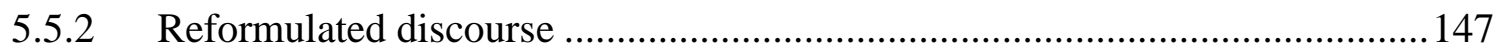

5.5.3 Appealing to emotions via praise and criticism ........................................... 148

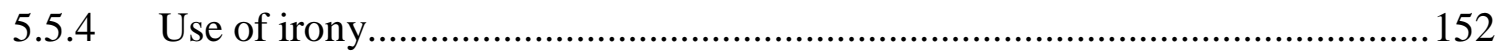

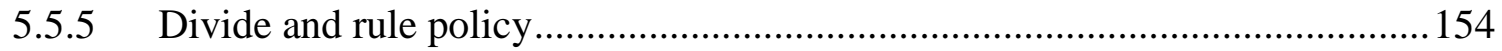

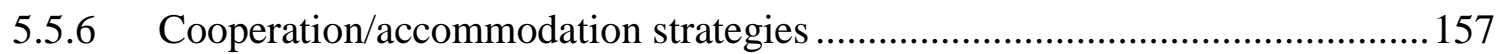

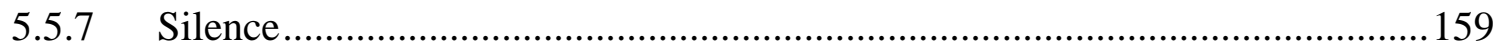

5.6 Women's NGOs' conceptions of gender (in)equality ......................................... 162

5.6.1 Kenyan cultural practices and women's dis-empowerment ........................... 162

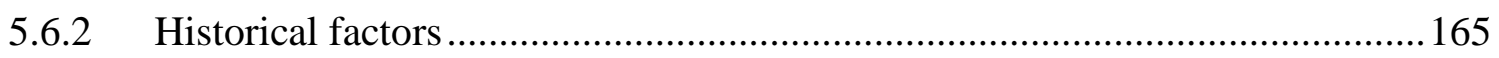

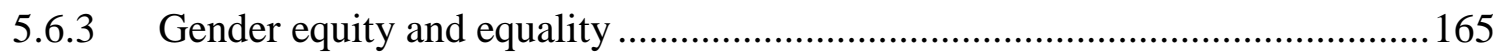

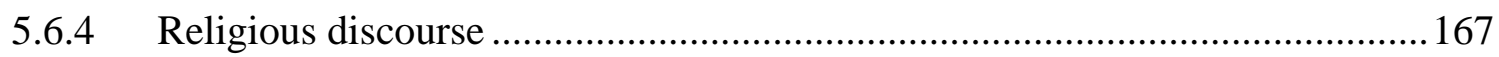

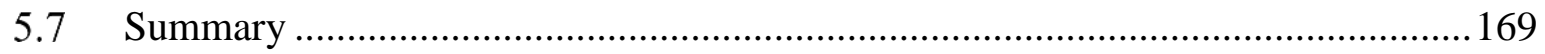

6 OFFICIAL STATE POLICY ON GENDER EQUALITY ......................................... 172

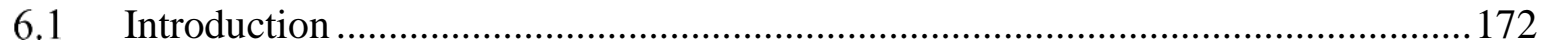

6.2 Establishment of a task force to review laws relating to women .......................... 173

6.3 Text 1: The National Gender and Development Policy 2000, Ministry of Gender,

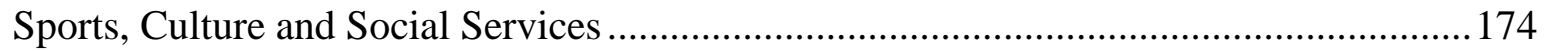

6.3.1 Legitimation through forging solidarity with the United Nations' conventions... 175

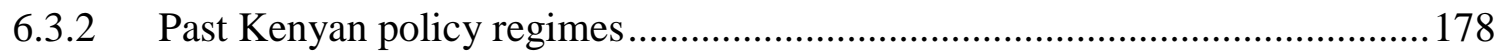


6.3.3 Global economic crises and structural adjustment programmes

6.3.4 Development processes and women's inequality ....................................... 182

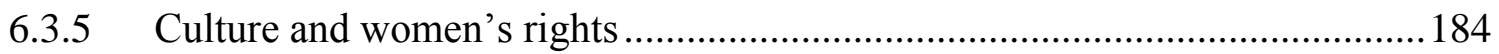

6.3.6 Alternative vocabulary and the characterization of women .......................... 187

6.4 Text 2: Kenya review and appraisal: final report on the implementation of Beijing Platform for Action (Beijing +10) (1994 - 2004), June 2004 ................... 192

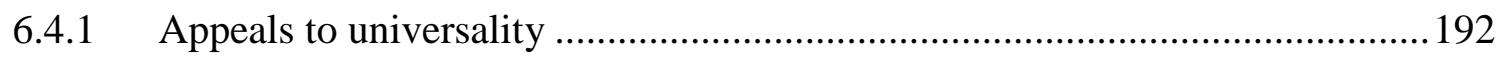

6.4.2 Interdiscursity in the service of competing interests..................................... 193

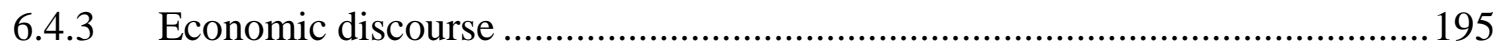

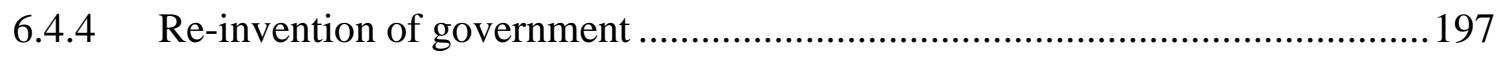

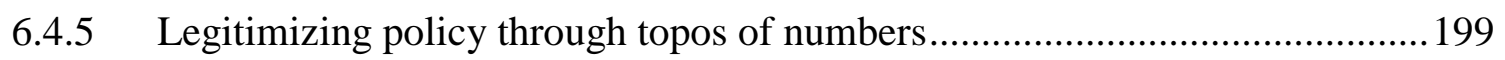

6.4.6 Managing anticipated policy actions through re-stating present and future policy initiatives.................................................200

6.4.7 Governing through the rhetoric of working with NGOs ...............................202

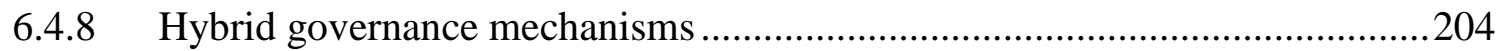

6.4.9 Mixing promotional genres within official discourse ...................................205

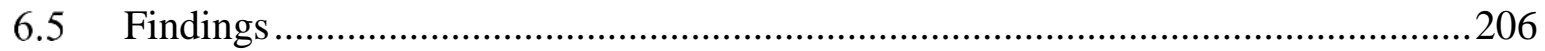

6.5.1 Question 1: Recontextualization of the normative discourse of women's rights to gender equality.............................................. 207

6.5.2 Question 2: Conceptualizations of the notion of gender (in)equality ..............211

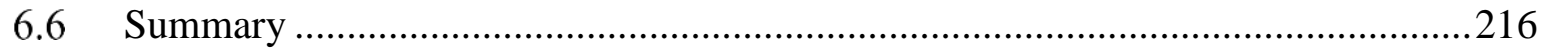

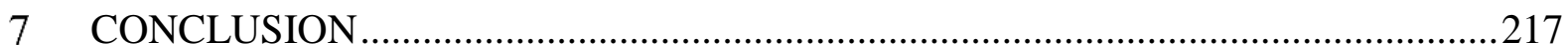

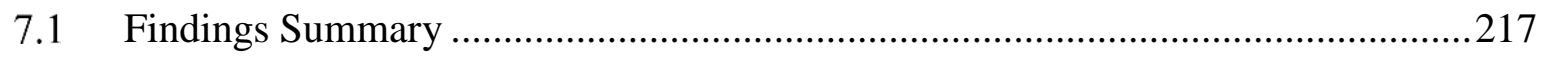

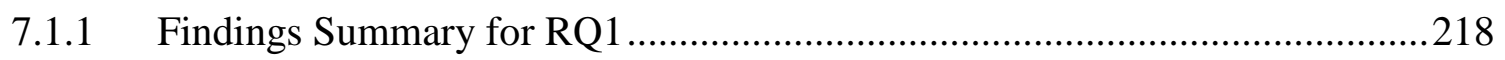

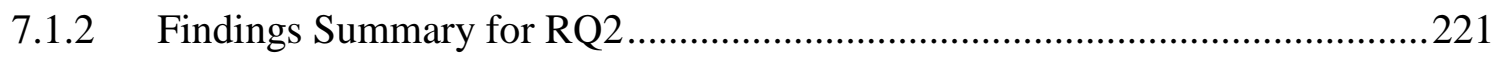

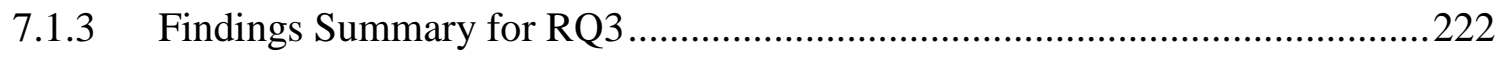

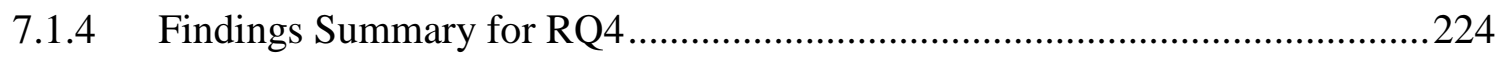

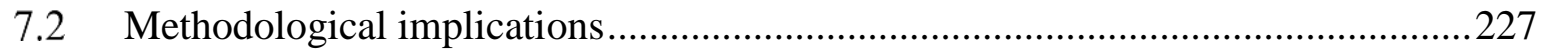




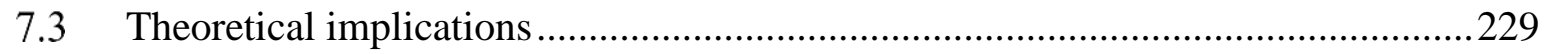

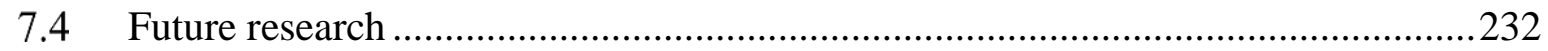

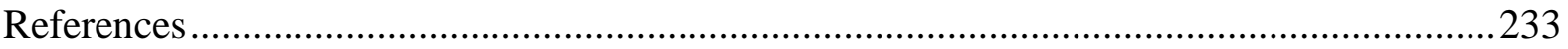




\section{List of tables and figures}

Figure 3.1 Fairclough's (1995) Dimensions of Discourse Analysis ................. 51

Figure 4.1 Intertextual Circuit: Discursive/Intertextual Governmentality............. 84

Table 6.1 Official policy documents on gender equality.......................... 172 


\section{INTRODUCTION AND AIMS}

\subsection{Introduction}

In this chapter, I present the background of the study through a brief account of how my personal experiences led me to study policy discourses of women's rights to gender equality. Next, the chapter introduces the rationale for this study, and then the aims of this thesis. This will be followed with the research questions that this thesis addresses. Lastly, I will conclude this section with an overview of the thesis.

\subsection{Background of the study}

Upon graduating from university as a teacher of English language and literature, I embarked on teaching high school students in Kenya. During my first six years of teaching, I realized that many girls were less motivated to learn and proceed with their studies to higher levels of education. This was particularly reflected from several cases of these girls dropping out of secondary schooling, before completing their expected fourth grade qualification. However, I noted that unlike girls, many boys were always motivated and more concerned with their studies. This motivated my M.A. studies in English Language and Linguistics with a thesis focusing on the "Influence of Gendered Linguistic Images on Girls' Education: A Case Study of Southern Kisii District, Kenya.” The study established that the discursive use of gendered linguistic structures in the Ekegusii language indeed caused the Gusii girls to construct a self-concept and a world view that were incongruous with their educational aspirations. I wondered how this could possibly happen in a modern society, more so in the area of girls' education which we all expect to play an emancipatory role in ameliorating their situation. It was only later that I realised how little I understood the precarious nature of the circumstances that underlie the world of women and girls in Kenya. For instance, it became clear to me that other than the revelations from my research, I knew very little about women's inequality, and the context in which Kenyan girls and women operate. Furthermore, this realization confronted me with the questions:

1. Could Kenyan policies on women's issues offer any solution to women's inequality?

2. What role can I play as a researching linguist in ameliorating Kenyan girls and women from their state of inequality in Kenyan society? 
These questions contributed to my current interest and curiosity to explore the Kenyan government's policy discourse of women's rights to gender equality.

\subsection{Situation of women in Kenya}

Multiple factors affect the current situation of women in Kenya. In this respect, Mutua (2006) identifies four main tensions entrenched in many African states (i.e. Kenya in particular), which continue to constrain women's efforts to achieve their rights to gender equality. These comprise ethnic differences/ rivalry, effects of colonialism, autocratic leadership, and the desire to preserve repugnant cultural norms and practices (Mutua, 2006, p.5). These factors are highlighted under the following two subheadings: (1) Colonialism and its aftermath; and (2) Kenyan people's oppressive cultural practices and traditions.

\subsubsection{Colonialism and its aftermath}

Mutua (2006, p.7) notes that the process of colonialism served to restructure the Kenyan people's socio-economic structures along patriarchal lines. In this context, many scholars of women's rights blame the process of colonialism for women's inequality on the following eight counts.

First, Chege and Sifuna (2006, p.20) explain that colonial settlers introduced monetary economy and imposed taxation in their areas of jurisdiction, thereby forcing African men to leave their homes and begin working for wages in the settler farms in order to pay taxes. This placed considerable burdens on "women who were left behind to perform both their traditional chores" and "the work of the absent men" Chege \& Sifuna, 2006, p.20). This state of affairs, as the scholars note, introduced the ongoing association of women with domestic roles as "household heads" (Chege \& Sifuna 2006, p.21) within the private sphere, which continues to constrict their opportunities to participate equitably with men in politics and other decision-making structures in the public sphere.

Second, the researchers argue that colonial administrators barred women from various "wage employment sectors within government and industry," hence rendering them economically weak and dependent on their husbands (Chege \& Sifuna 2006, p.22). This unequal status of women, as the scholars proceed to argue, was worsened by the Christian missionaries, who encouraged "the exclusion of women from work outside the home" (Chege \& Sifuna 2006, p.27). 
Third, in addition to barring women from the employment sector, the colonial rule restricted their (women's) migration to towns. As Chege and Sifuna (2006, p.22) note, with the gradual development of urban trading centres, many women who defied the aforesaid restrictions and moved to towns became unable to "rent houses for themselves," and were thus circumstancially forced to engage in "commercial sex" with "male workers who lived without their wives." This suggests that the current association of women with prostitution in towns is historically linked with the colonial gendered system of rule.

Fourth, based on the "English imperial ideology of 'female domesticity," " (Chege \& Sifuna, 2006, p.22), colonial masters endeavoured to instil in African women anachronistic values and norms that were designed for the service and pleasure of men, in terms of emphasizing feminine qualities considered desirable for men. Notice that similar values were taught by the Christian missionaries, whose education "ensured female domesticity" "through Christian teaching, to be subservient, and to dutifully combine traditionally feminine chores with hoeing, animal rearing and many other occupations that were traditionally masculine" (ibid, p.27).

Fifth, Chege and Sifuna (2006, p.20) and Presbey (2013, p.286) posit that the colonial legacy introduced land ownership policies/laws that allowed men to become the legal owners of land that was traditionally owned by the family. In this context, as the scholars say, land in pre-colonial times used to be owned by the family, but colonial rule ensured its transition to male ownership. As such, men begun to be issued with title deeds, thereby "masculinizing property" (Presbey, 2013, p.286; Chege \& Sifuna, 2006, p.21). This resulted in a tremendous loss of power for women, as this practice ensured that property continues to be owned and inherited solely by men.

Sixth, Chege and Sifuna (2006, p.27) explain that the colonial administration's educational curriculum for girls was restricted to areas such as "needlework and childcare," compared to "writing, reading and arithmetic" that were considered important for boys. Similarly, the scholars posit that the same system of education was promoted by the Christian missionaries who taught boys such skills as "wagon making and masonry," "while girls were tutored in cookery, food preservation, tailoring and laundry" (Chege\& Sifuna 2006, p.27). This gendered curriculum as Chege and Sifuna emphasise, necessitated the current "persistently low attendance of girls in primary schools," and hindered women's personal development and empowerment necessary for their effective participation in the public sphere (Chege \& Sifuna 2006, p.27).

Finally, Mathai (1995, p.18) emphasises that the process of colonialism served to de- 
culturalize the African people through ways that de-mystify and demean their personality. She argues that this process of de-culturalization and/or alienation engendered a sense of inferiority, and an unclear identity among African people. In a similar vein, she argues that inequalities amongst women are linked to the African people's over reliance on, and "overuse of foreign languages," that alienate people from their cultural values, norms and identity (Mathai, 1995, p.15). By the same token, Fity, Bengtsson and Moraes (2008, p.79) reiterate that, just like the colonial rulers stated above, Christian missionaries trivialized, demonized, and banned many aspects of the local African culture, including various forms of art, initiation rites, and non-christian festivities. Furthermore, the researchers note that Kenyans (i.e. including women) were encouraged to "reject their cultural heritage and cultural means of identification, self-representation and their language," which were essential for "the development of a democratic culture and the establishment of equality" (ibid, p.81).

\subsubsection{Kenyan people's oppressive cultural practices and traditions}

Mutua (2006, p.8) notes that some Kenyan communities wish to preserve their varied socio-cultural beliefs, traditions, and religious norms that embrace a commitment to gender hierarchies that justify women's subordination to men, thereby posing a challenge to women's realization of gender equality. In this context, for instance, the Kenya League of Women (2005, pp.17-35, henceforth LKWV) explains that Kenyan socio-cultural practices continue to emphasize women's subordinate and inferior position, as well as culturally endorsed patriarchal norms that continue to violate women's rights o gender equality. Areas of continued discrimination of women on the basis of cultural practices and traditions include:

-women's lack of rights to property ownership and inheritance rights, where as Kameri-Mbote (2006, p.44) states, a negligible number of Kenyan women own land because property ownership is guided by statutory, customary, and religious laws that favour the dominant patriarchal structures that discriminate against women -The ongoing cases of gender-based violence against women such as wife beating, forced early marriages for young girls, female genital mutilation, and rape (including marital rape) that continue despite the existing Kenyan constitution that guarantees the protection of Kenyans from inhuman and degrading treatment (Kopiyo (1994, p.16 ; Matogo, 2010, pp.26-7; \& Ondicho 2000, p.36). 
- Low enrolment, rentention, and completion of school by girls from some Kenyan communities that see little relevance of formal education for girls (Matogo, 2010, p.13; Soeda, 2008, p.1).

- Paternal thinking and repressive political leadership that has historically marginalized and excluded women's interests from the mainstream politics and decision-making structures (Kamau, 2010, p.10; Mathai, 1995, pp.4-5), including the use of repressive instruments to manipulate, co-opt, and control women's groups such as Maendeleo Ya Wanawake Organization (Aubrey 1995, p.101; Mutua 2006, pp.910).

- The legalization of polygamy (i.e. culture of marrying more than one wife) in Kenya, which according to FIDA-Kenya (2007, p.22) and Matogo (2010, p.16), continue to impede women's ability to exercise their reproductive and sexual rights - Ethnic competition (culturally embedded practice) which as Mutua (2006, p.7) says, socialises women to given ways of reasoning and behaviour that engender a sense of mistrust and suspicion between members from different communities, hence their inability to speak with one voice against the dominant forces that remain reluctant to relinquish and / or change their status quo.

In view of the aforesaid constraints, earnest agitation for women's human rights in Kenya began formally after the deliberations of the first world conference on the status of women held in Mexico. Likewise, following the repealing of section 2A of the then Kenyan constitution in 1991 that ushered in multiparty democracy, Mutua (2006, p.3) and Nzomo (1993, p.62) explain that Kenyan women, feminist activists and scholars of women's rights alike took advantage of the broader democratic space to demand the end of gender discrimination against women, including the need for involving them in defining their own interests in the mainstream policy making processes. However, as Kameri-Mbote and Kiai, (1993), Nzomo (1993), and Jivanjee and (Tebb, 1999, p.33) state, the Kenyan government repeatedly reiterated that there was no discrimination against women in Kenya, hence no need for women's agitation for rights that they already had. As such, FIDA-Kenya (1997) explains that no major gains were made in favour of Kenyan women, until the onset of the 1997 Constitution of Kenya Review Commission, where gender equality issues begun to be part of the central agenda for deliberation. 


\subsection{Study Rationale}

From the foregoing discussion, there is undeniable widespread agreement that gender inequality represents one of the most pressing issues facing Kenyan women and Kenyan society in general. In this context, past studies on women's human rights in Kenya reveal that despite the apparent recognition given to women's rights and equality in recent Kenyan policy discourse, women remain severely subordinated and mistreated at all levels of Kenyan society. Kenyan researchers and scholars of women's rights such as Baraza (2008), CREAW (2007), FIDA-Kenya (2006), Gathigi (2000), Kameri-Mbote (2001), Matogo (2010), Mutgua (2006), Nzomo (1993), and Unterhalter and North (2011) blame these inequalities on the lack of consistent policy actions by the Kenyan government to grant and protect women's rights to gender equality. However, this study contends that gender inequality among Kenyan women could as well be the result of discursive tensions between and amongst the different policy actors involved in the implementation of women's rights to gender equality in Kenya.

Likewise, the majority of the studies on women's rights in Kenya have been done in relation to such matters as: construction of gender identity and gender power relations (Kitetu, 1998; Mulila Matei, 2014; Mwaniki, 2011; Ndambuki, 2010); understandings of gender equality and education (Unterhalter \& North, 2011); role of the law in addressing issues of gender inequality (Baraza, 2008); effects of culture based customs and practices on women's ability to assert their sexual and reproductive rights (Matogo, 2010); impact of civil society groups on Kenyan women's livelihood (Gathigi, 2000; Soeda, 2008); women and political leadership (Kamau, 2010; Ndambuki, 2010; Nzomo, 1997; Walsh, 2005); language use and sexual harassment at work places (Yieke, 2004); the State and abortion discourses (Njagi, 2013); and the women's movement (Kameri-Mbote \& Kiai,1993; Mutua, 2006).

In this way, the majority of the studies in Kenya have tended to blame the rampant cases of gender inequality on institutional structures, and social practices and actions, hence ignoring the fact that in addition to being the result of institutional structures and social practices, the aforesaid problems could as well be the result of how issues are represented or framed in text/language and how power relations operate in and over text/language (Bourdieu \& Wacquant, 2001; Fairclough et al., 2004; Jessop, 2000, cited in Waller, 2006, p.2), hence the need to include discourse as a unit of analysis in finding measures for reforming social life (Waller, 2006, p.2).

Moreover, whereas this study acknowledges that some of the Kenyan scholars mentioned above (e.g. Kitetu, 1998; Mulila Matei, 2014; Ndambuki, 2010; Yieke, 2004) have made insightful interpretations of varied aspects of language use and women's inequality, 
none has addressed the intertextuality in the policy paper trail between and amongst the different policy actors involved in Kenya's policy discourse of women's rights. That is, while there are no doubts many reasons for women's inequality in Kenya, the hypothesis that this study explores is that one significant contributing factor lies in a degree of disconnection in the policy paper trail between the key policy actors on women's human rights in Kenya. These policy actors most importantly include the Kenyan government; the women's nongovernmental organizations (NGOs), who actively seek to influence government policy; and beyond these the United Nations Committee overseeing the Convention on the Elimination of All Forms of Discrimination against Women (CEDAW) with responsibility for women's human rights, on which the NGOs rely for guidance, and to whom the Kenyan government is required to report on its progress in implementing women's rights.

In this way, rather than focusing on the Kenyan government's policy on women's rights per se, this study undertakes to explore how the existing Kenyan policies on gender equality operate in a larger perspective. That is, in examining intertextuality in Kenyan policy discourse of women's rights, I look both at the micro and macro levels of how the policy actors (i.e. Kenyan government, women's NGOs, and the UN/CEDAW Committee) construe and recontextualize the rights of women to gender equality. This approach enables me to explore the discursive processes through which the policy discourses of women's rights to gender equality are articulated, reproduced, and transformed. This is consistent with Fairclough's observation that though "A critical awareness of language and discursive practices" is "a prerequisite for democratic citizenship," this has not yet been achieved (Fairclough, 1995, p.140). Similarly, Mulila-Matei notes that in the process of meaning making, given discursive practices with particular ideological investments are privileged and sustained in place of other alternative practices (Mulila-Matei, 2014, p.2). From these perspectives, it is significant to investigate, for instance, how the policy actors construe the notion of gender equality, and indeed whether there are any power struggles and contestations amongst them that could be constraining women's efforts to realize their rights to gender equality in Kenya.

\subsection{Research Aims}

This thesis aims to understand the discursive relationships between and amongst the different policy actors on women's human rights in Kenya. In this context, the thesis explores the nature of the intertextual relationships amongst the CEDAW Committee, the Kenyan 
government, and women's non-governmental organisations (NGOs) agitating for gender equality policies in Kenya. The primary aim of the thesis is to establish whether (if at all) the texts of women's NGOs in Kenya are being taken up or translated in official government policy documents; and indeed whether such NGOs' policy demands or proposals reflect the women's rights objectives of the UN. With these considerations in mind, my study addresses the following research questions:

RQ1.What are the (changing?) conceptions of gender (in)equality that underlie the Kenyan government's, NGOs' and the United Nations' policy texts about women's rights to gender equality?

RQ2. What strategies/modes of engagement (i.e. linguistic/non-linguistic and rhetorical) do the UN/CEDAW committee, the Kenyan government, and women's NGOs adopt in their policy texts on gender equality?

RQ3. What implications do the intertextual relations between the women's NGOs and government hold for the Kenyan government's policy and practices concerning gender equality for women?

RQ4. What implications do the textual interactions between the UN/CEDAW committee and the Kenyan government hold for the realization of gender equality policies in Kenya?

\subsection{Thesis overview}

This thesis investigates intertextuality in Kenyan policy discourse on the rights of women. This introductory chapter has presented the background of this study, rationale for my research, including an introduction to the research aims. Chapter 2 explores the relevant theoretical arguments, terms, and theories that I draw on to analyse policy texts on women's rights. I situate my study of policy discourse on women's rights in Kenya within a multidisciplinary theoretical framework borrowing from two theories: Foucault's theory of governmentality and transnational feminist rhetorical theory. Chapter 3 highlights the research methodology, highlighting the concept of discourse adopted in this study, and the intertextual approach in Fairclough's $(1992,1995,2003)$ body of work that I developed for selecting, interpreting, and analysing my research data. Moreover, given the centrality of the intertextual approach to the study of gender equality espoused in this research, this chapter also outlines the other methodological approaches (e.g. Reisigl and Wodak's (2001) argumentation theory/topoi, Bakhtin's $(1981,1986)$ theory of dialogism) adopted to 
supplement Fairclough's intertextual approach to critical discourse analysis as the main research method used in this study. Chapters 4 to 6 are the analysis chapters of the thesis. Chapter 4 focuses on the intertextual interactions between the Kenyan government and the UN/CEDAW Committee, with particular emphasis on the discursive strategies employed by the Committee to induce the Kenyan government to adopt gender equality policies. It also explores the linguistic and rhetorical mechanisms deployed by the Kenyan government, either to show compliance with the Committee's imperatives concerning women's rights, or for avoiding to do so by discursively circumventing the UN agenda. Chapter 5 discusses the intertextual interactions between the women's NGOs and the Kenyan government in relation to gender equality policies. This involves a focus on: (1) the type of policy demands or proposals made by the women's NGOs to the Kenyan government; (2) the NGOs' conception of the notion of gender (in)equality in Kenya; and the strategies/modes of engagement used both by the NGOs and the Kenyan government in their policy texts on gender equality.

In chapter 6, the focus shifts to the textual analysis of the Kenyan government's official state policy texts on gender equality. The chapter seeks to show the extent to which the Kenyan government's official policy on gender equality can be said to have emanated from the women's NGOs' demands for women's rights to gender equality in Kenya. The chapter also highlights the Kenyan government's understandings of gender equality, including the varied linguistic and rhetorical strategies it employs to show its readiness to grant or avoid granting gender equality policies. Chapter 7 presents a summary of the core findings of the research, including the possible implications for the realization of gender equality policies in Kenya. 


\section{LITERATURE REVIEW AND THEORETICAL FRAMEWORK}

\subsection{Introduction}

This chapter reviews the literature on the on-going debate between universalism and cultural relativity in the context of human/women's rights. In this context, my review of literature is particularly intended to show how Kenyan policy actors in this study draw on either the cultural relativist or universal approaches to gender equality policies. This will help to clarify the extent to which the prevailing conceptions of women's rights to gender equality support or hinder the realization of women's concerns in Kenya. The chapter also discusses the theoretical background of the research. The study is anchored in a multi-disciplinary theoretical framework borrowing from two theories: Foucault's theory of governmentality and transnational feminist rhetorical theory. The research utilizes the lens of the governmentality theory to problematize Kenya's concept of, and approaches to, the issues of women. The transnational feminist rhetorical theory deals with the appropriation of global ideas and concepts regarding the rights of women (Dingo, 2012), thus providing a link between the global production of ideas and concepts and their consequent recontextualization within the local milieu.

\subsection{Universalism and cultural relativism: a brief overview}

Universalist and relativist theoretical debate about the nature of human rights entail a response to the 1948 Universal Declaration of Human Rights (henceforth UDHR) whose preamble emphasizes that human rights entail a common standard of achievement for all peoples and all nations (United Nations, 1948). In this respect, article two of the declaration states that:

Everyone is entitled to all the rights and freedoms set forth in this Declaration, without distinction of any kind, such as race, colour, sex, language, religion, political or other opinion, national or social origin, property, birth or other status.

Arguments about universalism and cultural relativism are two varying theoretical perspectives on the nature of human rights and their application. As Clapham (2007, p.49) explains, the debate is whether the present day conceptions of human rights are of universal nature and application, or whether they depend on socio-cultural contexts and settings. 


\subsubsection{Universality of human rights}

According to Bunch (2001, p.140), the universality of human rights entails the fact that human rights apply equally to every single person in society, by virtue of being human. Likewise, Delaet (2006, p.44) posits that human rights are indispensable, inalienable, and do not vary in relation to cultural, religious or historical contexts. In other words, universalists believe that human rights are universal and inherent in every individual irrespective of age, ethnicity, race, gender, or culture among other variables. In a similar vein, Brems (2001) states that the universalists' conception of human rights emphasizes individual rather than group (collective) rights, and political rights over socio-economic, and cultural rights. Moreover, Brems emphasizes that the notion of universality ought to be understood as a process or project to be achieved in future (Brems, 2001, p.21). In this context, she stresses that as much as individuals in their countries of the world are still in the process of acquiring political and socio-economic rights (i.e. advocated for in the aforesaid international treaties and conventions), then we could argue that universality is a project and/or process to be achieved at some point in the future. This view is equally shared by Ackerly (2001, p.325) who, in the context of women's rights, observes:

even while some are working to change local practices to enable the realization of women's human rights in specific contexts, activists are also engaged in trying to change international legal norms such that they better recognize women's human rights.

In addition, Brems (2001) stresses that the notion of universality of human rights is only applicable when all states of the world adhere to the international treaties or conventions in which such rights are embedded. In her words, "If international human rights are formally accepted worldwide, their universality is a legal reality...From this formalistic point of view, the universality of human rights might seem rather problematic: a particular human right would not be universal as long as one state exists that does not subscribe to an international text that enounces it" (Brems, 2001, pp.5-6).

\subsubsection{Cultural relativism and human rights}

As Delaet (2006, p.44) explains, cultural relativists discredit the universalist view of human rights, arguing that no rights exist to all human beings by virtue of being human. On 
this basis, Delaet says that cultural relativists dismiss the universalist view of rights, arguing instead that human rights are relative and derived entirely from groups and cultures in which people live. Likewise, Harpur (2009) and Mutua (1995) point out that cultural relativists insist that human rights are not universal, because they are based on western philosophical foundations that reflect western experiences that are at odds with the interests and aspirations of the people in non-western states. A classic example to illustrate the relativists' position with regard to the notion of human rights was given by the American Anthropological Association. This is captured in the excerpt below by Messer (Messer, 1993, p.224):

The American Anthropological Association, when asked to comment on the proposed Universal Declaration, rejected the notion of universal human rights. Instead, they emphasized that different peoples have different rights concepts and that they also refer to different authorities. They criticized the universal international legal framework as ethnocentrically Western.

Similarly, giving the African approach to human rights, Shavji (2004, p. 10) posits that though many scholars from Africa seem to agree on the historical origins of the human rights discourse, they still insist that the universal approach to human rights is consistent with the political cultures of liberal western states which regard persons as distinct and autonomous individuals. This western view of persons as Shavji proceeds to reiterate, stands in opposition to the African concept of human rights as a collective and /or group entity (Shavji, 2004, p. 10).

Notice that the aforesaid African construal of human rights coheres with that of the Asian states, forty-eight of whom, as Harpur (2009, p.58) notes, declared in the Bangkok Declaration on Human Rights that "Western-based international human rights threaten Asia's right to sovereignty..." These observations further endorse Grewal's (1999, p.341) view, that collective/ group rights emerged as a response to the "universalist individualistic ethic" of persons as autonomous beings with rights, and as a means for preserving the cultural values and traditions of the nation states.

\subsubsection{Negotiating the middle level ground between universality and cultural relativity}

Most scholars and researchers of human rights emphasize the need for a compromise between universality and cultural relativism. For instance, Donnelly (2013) and Brems (2001) emphasize that universal human rights could have their origins and philosophical foundations 
in the west, but they remain valid and equally applicable in the African, Asian, and other cultural contexts. In this context, Donnelly (2013, pp.103-104) emphasizes that:

Most defenders of both universality and relativity today recognize the dangers of an extreme commitment and acknowledge at least some attractions and insights in the positions of their critics and opponents.

Arguing against radical or absolute universality or relativism, Donnelly (2013) emphasizes that there exists a multiplicity of different forms of universality and relativity. In his words, "Both relativity and universality are essential to international human rights" (Donnelly, 2013, p.104). Further, Donnelly (2013, p.104) posits that the core issue is to identify the different ways in which "human rights both are and are not both relative and universal - and to avoid either treating the universal as if it were relative or falsely universalizing the particular."

At the same time, Donnelly argues that absolute universality of rights applies fully "only at the level of the concept" (Donnelly, 2013, p.103). He observes that "The ways in which these rights are interpreted and implemented, however, so long as they fall within the range of variation consistent with the overarching concept, are matters of legitimate variation" (Donnelly, 2013, p.103).

With regard to their "recontextualization" (Fairclough, 2005), these variations in interpretation and implementation as Donnelly argues, should not be mistaken to mean the rejection of human rights, but rather be understood as being the result of "differences in human rights practices" (Donnelly, 2013, p.103). As such, advocating for what he calls a "tempered universalism" Donnelly emphasises that human rights can be implemented differently, but with a focus "to leave intact the internationally recognized right to the underlying freedoms and personal dignity" (Donnelly, 2013, p.103).

Donnelly's view is shared by scholars of human rights such as Angle (2002, p.19) and Brown (1997, p.42) who stress that the universal approach to human rights may lose its validity if it continues to be used in isolation from the particular context of situation in which the rights in question are applied. By the same token, Brems (2001, p.72) notes that many Asian governments and scholars of human rights now emphasize the need "for a balance between individual and collective interests within human rights," meaning that they support "collective rights alongside individual rights." The same approach is proposed by scholars and researchers of human rights in Africa. For instance, Ibhavvow (2000), Mutua (1995), and Zeleza (2004) emphasize that the universal application of human rights ought to be enriched 
with some "cross-cultural fertilization of ideas" (i.e. cultural synthesis), drawn both from the African continent, and the rest of the world. Such an approach, as they argue, could help enhance the legitimacy and acceptability of human rights across cultures. This idea is better captured in Zeleza's (2004, p. 43) words below:

In short, trading, sharing, and incorporating human rights experiences, practices, and symbols across cultures and the enduring West-East and NorthSouth divides, can assist in the development of a truly universal human rights discourse and regime, which at the moment does not yet exist.

Furthermore, in their defence of a cross-cultural approach to human rights, Ibhavvoh and Peerenboom dismiss strict cultural relativism, arguing that allowing each state to apply its own brand of rights will permit many oppressive regimes to violate the rights of the people (Ibhavvoh, 2004, p.26; Peerenboom, 2004, p. 13). In addition, the scholars argue that permitting states to apply their own versions of rights will give room for the use of interpretations of cultural values and norms that serve to sustain the existing status quo, while cushioning inequality.

\subsubsection{Universality of human rights and women's concerns}

Scholars and researchers of women's rights credit the universalist approach to women's rights with three major achievements. These are outlined below.

\subsubsection{Visibility and voice}

According to Bunch and Grewal, the universal discourse of human rights serves as a tool for championing women's rights across the globe (Bunch, 2001, pp.137-138; Grewal, 1999, p.338). In this context, they posit that universal rights help feminist activists to question the invisibility of women and their issues, hence the means for moving women's concerns from the margins to the mainstream of policy agenda. In Bunch's words, the universal rights of women provide the means to demand the incorporation of "women- and gender-aware perspectives into all of the ideas and institutions that are already committed to the promotion and protection of a human rights gender perspective" (Bunch, 2001, pp.139-40). 


\subsubsection{Women's social and economic rights}

Basing her argument on the indivisibility of human rights (i.e. the idea that rights are interrelated, and that no right is greater than any other), Bunch (2001) argues that women have been able to challenge the historic bias in favour of civil and political rights over social and economic rights. In this regard, women human rights activists, as Bunch (2001, p.141) emphasizes, insist that political stability cannot be achieved unless "women's social and economic rights are also addressed."

\subsubsection{Women's rights and oppressive cultural practices}

Gould notes that feminist activists and advocates of women's rights emphasize the use of the universal discourse of women's rights to challenge the oppressive cultural practices that subordinate women (Gould, 2004, p.155). The same view is given by the Federation of Women Lawyers-Kenya (FIDA-Kenya, 2006), who emphasize the role of the United Nations' universal treaties and conventions on women's rights in challenging cultural practices that violate women's rights.

\subsubsection{Challenges in applying the universal approach to women's rights}

Despite these stated advantages of the universal approach to women's rights, some puzzles exist that are yet to be resolved. For instance, Gould (2004, p.155) regrets that though the universal language of rights is useful for challenging oppressive cultural practices that violate the rights of women, the universal criteria per se cannot bring about change in women's life experiences, unless such cultural practices are changed and transformed to promote equality between men and women. At the same time, Ackerly (2001, p.325) observes that some policy makers publicly endorse women's human rights, while simultaneously maintaining that what it means to be a human differs for women and men and thus the human rights of women are not the same as those of men. Such an observation endorses Wuerffel's (1998, p. 372) view that because the universal approach to human rights does not clarify which human rights are more important than others, national governments are free to build their own hierarchies of human rights to be pursued, even without seeking ratification from the United Nations. By doing so, Wuerffel stresses that the common understanding of, and respect for human rights enshrined in the UDHR risks being replaced with the states' own understandings that negate the universal principles of human rights. This 
explains the view that "the most significant obstacle to the notion of rights for women is a 'hostile state that is not actually interested in giving them any rights.' " (Singh, 1994, cited in Grewal, 1999, p.340). In other words, as Grewal (1999, p.342) posits, the "women's rights as human rights struggle" seeks to universalize and stabilize the category of 'women', while simultaneously addressing their situations within their local contexts, where their nation states' cultural relativist approaches to their rights prevail.

From another angle, Grewal (1999, p.341) points out that the idea of collective rights discussed above remains problematic in the context of women's rights. In her view, though the emergence of collective rights has helped to galvanise women's agitation for "women's rights as human rights," it remains unclear the extent to which the struggle for women's rights can be viewed "as a group right, since women cannot be seen as one group with a common tradition" (Grewal, 1999, p.341). In other words, attempts to universalize women's rights as human rights tend to presume women as a "coherent group of persons that cuts across class and cultural lines and has an identity of interests" (Grewal, 1999, p.342).

In a similar vein, Manisha (2007, p. 107) insists that the ongoing debates between universality and cultural relativism have contributed to the ongoing violation of the rights of vulnerable groups like women and children. In this regard, for instance, Coomaraswamy (1999, p.168) explains that some radical cultural relativists hold the view that accepting the universality of women's human rights is one way of undermining the cultural framework of their societies. This position as Coomaraswamy (1999, p.168) posits, rests on the strict cultural relativists" view of women as "symbols of a given cultural order" in society. Coomaraswamy (1997, p.1260 stresses that, though the universal discourse of human rights is a powerful tool with which to criticize states,

Nonetheless, insofar as it concerns a woman's private life, it is actually in many societies quite a weak discourse, particularly in the context of family and community relations. While international human rights law moves forward to meet the demands of the international women's movement, the reality in many societies is that women's rights are under challenge from alternative cultural expressions.

Finally, Angle (2002) stresses that the emphasis by some activists on the use of the universal approach to human rights as the only solution to the present day human rights needs ignores the role and motives of those under obligation to guarantee and enforce human rights (i.e. nation states). 


\subsubsection{Conclusion}

This section of the chapter has discussed the universality and cultural relativist approaches to human rights. Insights from these concepts provide insights into how both the universal and cultural relativist criteria are used in the interpretation and implementation of human rights. For instance, in the context of the present study, a number of issues emerged from our discussion that are worth mentioning. First, as noted above, it is stated that the human rights discourse is a dynamic body of knowledge, whose meaning continues to change and expand with time, as we continue to debate our interests and aspirations in relation to it (see 2.2.1). Likewise, it is evident from the foregoing discussion that universal human rights have to be understood as entailing a process, whose interpretation and implementation is dependent on varied contexts of practice. This understanding will be pursued in this study, in relation to the different ways in which different policy actors construct and interpret the notion of women's rights to gender equality.

Furthermore, the realization of universal human rights was seen as being dependent on the interests and aspirations of the state governments that espouse cultural relativist approaches to such rights. From this perspective, it would be interesting to investigate the different ways in which the policy actors in this study navigate their differing ideological aspirations in favour of, or against women's concerns. This view finds further endorsement in Brem's (2001) argument, that though universal human rights originates with the UN, their interpretation, application, and enforcement rests with national governments, which are as well viewed as violators of the same rights.

It is therefore important to demonstrate how the Kenyan government navigates between its cultural relativist approaches to women's rights, and the universal criteria provided by the United Nations in relation to the implementation of women's rights. This is in view of the fact that Kenya has acceded to both the UDHR and CEDAW, which obliges it to implement women's rights using the universal criteria per se (see 5.4.4).

\subsection{Governmentality theory}

In his genealogical study of government, Foucault strives to identify the development of the art of government in sixteenth-century Europe. In this regard, Foucault seeks to answer questions concerning the how of government: "how to govern oneself, how to be governed, how to govern others, who is to govern and how best to govern" (Foucault, 1991, p.87). From this study, Foucault noted some shifts indicative of changes in thinking about political 
rule. As Inda (2005) notes, through his study of Machiavelli's The Prince, Foucault noted the trajectory from a sovereign view of power to an art of government. In Inda's words, the art of government involved three important elements: (1) the conduct of conduct, i.e, calculated ways of thinking and acting that propose to shape, regulate, or manage the conduct of individuals or groups toward specific goals or ends; (2) exercising of political power through the involvement of "a multitude of heterogeneous entities: from politicians, philanthropists, and state bureaucrats to academics..."; and (3) the population and its security, health, prosperity and happiness that are the principle target of governing (Inda, 2005, p.6).

Further, Inda (2005, p.3) notes that Foucault explores the different ways in which power was exercised by examining how rationalities of government and their accompanying governmental technologies were invented and deployed in practice. In Foucault's view, as Inda says, a transformation in the way power was exercised emerged at the onset of the eighteenth century, where life itself (individual bodies and populations) became the centre of interest.

\subsubsection{Government as mentalities of rule}

Lemke argues that through the semantic linking of the act of governing with mentalities (modes of thinking), Foucault seeks to suggest that effective understanding of the nature and mechanics of power is only possible by making reference to the political rationality that undergirds them (Lemke, 2001, p.191). Regarding these mentalities of rule, Dean explains that the concept of mentalities signals the fact that thinking is a collective undertaking which involves issues of knowledge, beliefs and opinions that are part of human existence (Dean, 2010, p.24). Dean adds that the concept of mentalities of government serves to amplify the manner in which the mode of thought involved in the practices of government is explicitly ingrained in language and other advanced tools of rule that are normally ignored and never questioned by those utilizing them (Dean, 2010, p.25). In conclusion, Dean says that these mentalities ought not to be attributed to particular individuals, groups or institutions, but rather be understood as being indicative of the fact that the exercise of power draws upon "expertise, vocabulary, theories, ideas, philosophies and other forms of knowledge" (Dean, 2010, p.25).

Miller and Rose give two ways through which we can ably examine and understand the mentalities and mechanics of government (i.e. problematics of government) (Miller \& Rose, 1992, p.175; Miller \& Rose, 2010, p.273). First, they suggest that problematics of 
government can be explored in terms of their political rationalities, the shifting discursive domain in which power is conceived, as well as the moral basis for its administration. Secondly, they suggest that problematics of government ought to be examined in terms of their governmental technologies, the routine programmes, calculations, techniques, apparatuses, documents and procedures, by means of which authorities endeavour to ensure the realization of given political aspirations (Miller \& Rose, 1992, p.175). This means that it is only by relating the link between political rationalities and governmental technologies that we can begin to gain insights into the diverse and intricate webs that bind people's lives and institutions to the aspirations of the government, in what Miller and Rose term as advanced liberal democracies of the present (Miller \& Rose, 1992, p.176; Miller \& Rose, 2010, pp.2734). As such, a critical examination of the art of government calls for an exploration of the means, techniques and instruments (i.e. technologies of government), through which the rationalities of government are to be achieved.

According to Barry, Osborne and Rose, the notion of technology of government enables us to productively reconnect studies of the exercise of power at the molecular level-in institutions with strategies of programme power at a molar level in such centres of calculation as the Cabinet Office, the War Office, the department of the State, the party manifesto, the government white paper or the enactment of legislation (Barry, Osborne \& Rose, 1996, p.13). In the context of this study, the policy programmes of the various participants can be said to constitute part of the technologies of government that help to problematize the situation of particular individuals, thus rendering their problems thinkable and amenable to given policy intervention measures. The particular role of intertextuality as the locus within which policy programmes emerge is theorised immediately below through the notion of discursive web and developed further in the next chapter.

\subsubsection{Power as a network of relationships}

Foucault recommends that power has to be viewed as a network of relations, where people interact and share with one another as actors in given material circumstances, as well as being the targets of power and its means of articulation. In this respect, Foucault says:

One sees why the analysis of power relations within a society cannot be reduced to the study of a series of institutions, not even to the study of all 
those institutions which would merit the name "political." Power relations are rooted in the system of social networks (Foucault, 1994, p.231).

From this vantage point, Foucault could be suggesting that we can only get to know other people's interests, experiences and expectations, through working together within a given network of power. By the same token, this view of power as a network of relations, as Hartsock (1990) emphasises, is helpful in signalling the different ways in which dominated groups act in their own domination. This is in view of the fact that, by arguing that power is rooted in social networks, Foucault does not discount the possibility of there being a principal player or actor that dominates other social actors within the network of power. This is consistent with Vidovich's (2007) view, that though all actors have space within the network, they are not equally powerful because some actors could be in possession of more resources than others, such as the state that still retains some considerable amount of power relative to other social actors.

Overall, as a means of understanding the chain of relations between the discourses examined in this study, I adopt Foucault's (1994, p.231) view of power as a notion rooted in a system of social networks. In the context of this study, Foucault's view of power leads to a new definition of the policy discourses of women's rights in this study, as a discursive web. Under this metaphor, policy is defined as an ensemble of multiple discourses that interact in a complex web of relationships that enable or constrain social relations. This metaphor highlights that at any given time there are multiple discourses circulating. The discourses circulate in different bodies such as government, professional organisations, authorities and the policy elite, as well as advocates, community organisations and individuals themselves who participate in disseminating and creating discourses. As such, while this definition of policy recognises the important role of the state, it highlights that the state is not the only player as multiple actors can take part in the policy process (Goldberg, 2006, p.82). This as Rensfieldt (2010, p.31) notes, suggests the need to examine the elements of a discursive formation in "plural" by making reference to "different sources and interrelated elements."

Echoing Foucault's advice that power ought to be studied from below, Jessop (2006) explains Foucault's belief that power ought to be examined with specific reference to the diversity of power relations, and across a multiplicity of fragmented sites. This, as Jessop (2006) proceeds to argue, is the point where it becomes possible to unravel the different ways in which various power relations become implicated in creating given states of inequality. From this perspective, it would be interesting for this study to explore how the different 
policy actors involved in the implementation of gender equality policies in Kenya are implicated in constructing women's identity, in addition to conforming to, and/resisting given political forms of conduct.

\subsubsection{Governmentality and the (neo) liberal rule}

When deployed to modern nation-states, governmentality concerns itself with the notions of liberalism as well as the liberal modes of governance. As Dean (2010), and Miller and Rose (1992) argue, liberal governmentality involves governing through the liberal doctrine of freedom, where individuals are viewed as being free and equal to one another, as opposed to existing in a hierarchical relationship of inequality and domination. Further, these scholars argue that the notion of government is strategically aimed at constructing the subjective conditions that enhance mutual co-existence between an individual and other members of society.

Accordingly, liberal modes of governance can be understood as a given logic that functions by moulding and enhancing autonomous and responsible individuals/states, by means of a set of governmental techniques, "including setting standards for appropriate, effective and legitimate behaviour for individual subjects and examining their performances accordingly (Aalberts, 2012, p.246). In other words, liberal forms of rule aim at constructing and functioning by enhancing the agency of self-governing and responsible subjects.

In consequence, as Burchell argues, the governed become the necessary partner and/or accomplice of government (Burchell, 1996, p.23). As Barry, Osborne and Rose put it, "The supposed separation of state and civil society is the consequence of a particular problematization of government, not of withdrawal of government as such" (Barry, Osborne \& Rose, 1996, p.9). They therefore insist that the involvement of civil society in governance has to be understood as entailing a different mode of governance, which remains intrinsic to government.

By contrast, the neoliberal mode of rule involves governing through creating an entrepreneurial spirit by encouraging individuals and institutions to adopt an entrepreneurial attitude towards themselves, as well as the viewing and handling of institutions such as those of health and welfare as enterprises with economic value (Jonathan, 2012, p.13). In other words, through its own programmes and initiatives, neoliberal governmentality seeks to create an environment that fosters what Binkley terms as "voluntaristic, entrepreneurial and self-responsible dispositions," upon which market structures depend (Binkley, 2009, p.68). 
As neoliberalism replaces the naturalism of liberalism, the state takes the initiative of putting into place the necessary conditions for an entrepreneurial and competitive conduct, whereby individuals are encouraged to cultivate an entrepreneurial disposition within their own modes of behaviour. As Barry, Osborne and Rose (1996) argue, this involves the invention of and/or utilization of multiple organizations and technical methods tailored to ensure the realization of the economic rationality of government, in the form of personal autonomy, enterprise and choice.

This approach thus inaugurates a new welfare based approach, with a shift of risk and emphasis on the responsibilitization of citizens. In this respect, the government may intervene to help given social groups, but stress is laid on the rational subject taking individual responsibility (Jonathan, 2012, p.13). As such, Jonathan notes that individuals are obligated to take charge of their welfare, as well as making rational choices and decisions on issues concerning their individual lives, so as to keep at bay the social problems of poverty and unemployment. From the governmentality standpoint, the aforesaid neoliberal mode of rule entails a form of governance based on the metaphor of the market.

\subsubsection{Liberal governmentality and authoritative rule}

Dean argues that the liberal modes of rule/governmentality involve the deployment of autocratic measures as a prerequisite for the liberal effort to govern "free individuals" (Dean, 2002, p.39). This view is revealed in Foucault's assertion that:

Liberalism as I understand it, the liberalism we can describe as the art of government formed in the eighteenth century, entails at its heart a productive/ destructive relationship [with] freedom [...]. Liberalism must produce freedom, but this very act entails the establishment of limitations, controls, forms of coercion, and obligations relying on threats, etcetera (Foucault, 2008, p. 64).

Terming it as authoritarian liberalism, Dean explains that authoritative rule is a lifelong pole of the liberal mode of governance, and one that is based on a free state, and a sound economy (Dean, 2002, p.57). As such, Dean reiterates that though the state may be taken to provide welfare services as a right to those that depend on it, governments are under obligation to adopt an "authoritative policy," to administer "the common obligations of citizenship," and hence reproduce the conditions of obligation that prevail in society (Dean, 
2002, p.39). This as Dean argues, is achieved through the "mechanisms and regulations of civil society," that specify the kinds of freedom and autonomy that are to become the objectives of governmental policies and practices and which, under certain circumstances, will require the use of instruments of coercive authority and legal sanction” (Dean, 2002, p.40). As he puts it, "these authoritarian foldings are enduring features of liberal approaches to government, readily illustrated by episodes from the genealogies of economy, police, poverty and welfare, and subject to certain transformations today (Dean, 2002, p.40).

On these grounds, Dean proposes that in order to ascertain the truth behind his thesis, there is need to undertake research on the actual policy of development and resistance to global liberal norms (Dean, 2002, p.57). From Dean's proposal above, it becomes imperative to examine the different ways the liberal approaches to government under discussion come into play in the acts and practices of the different policy actors involved in the implementation of gender equality policies in Kenya.

\subsubsection{Conclusion}

The view of government as a conduct of conduct hence an activity of leading, guiding and regulating the control of others and oneself, is of great purchase for this study. That is, such an understanding coheres with the core view of this study that sees discourse (e.g. the discourse of women's rights in this study) as an action (Van Dijk, 1997, p.8), and as a social practice/human activity (Fairclough, 1995, p.18; Fairclough, 2003, p.3) to be discussed in detail in the next chapter.

In the context of policy making, Vidovich emphasizes that Foucault's view of power/knowledge as held in a network serves to dissolve the linear approaches to policy (Vidovich, 2007, p.293). That is, Foucault's understanding is significant because it incorporates a multiplicity of policy actors, whose knowledge and values can be tapped through their inclusion in the policy making process, hence their opportunity to contribute to policy programmes with their knowledge (Vidovich, 2007 p.293), thus enhancing the state's capacity to address policy problems. Besides, this inclusion of multiple social actors in policy networks presents the view that all in society have a role in policy making, which in effect helps to win increased societal acceptance of the policy (Vidovich, 2007, p.294). This view of policy networks serves as an alternative option to the view of the nation-state as the central authoritative force steering the policy process (Vidovich, 2007, p.293).

According to Masaki, the network framework signals that the general public is not 
"passively subjugated to the exclusionary nature of policy making" (Masaki, 2007, p.3). As Masaki's chronicles, Foucault's view of power in terms of a system of networked relationships points to the fact that the policy making process is never completely under the control of politicians, bureaucrats, and specialists, but is rather the product of continuous and dynamic interactions and negotiations between various other policy stake holders (elites and non-elites), who collaborate in this endeavour in given situational contexts (Masaki, 2007, p.3). In other words, as Masaki explains, when power is viewed as relational and contingent, it becomes clearer that not just elites but also the entire spectrum of stakeholders exert influence over the course that a policy takes. This signals the greater potential of Foucault's governmentality theory in overcoming "entrenched inequalities" in society (Masaki, 2007, p.13).

As Dean (2010, p.121) advises, Foucault's concept of governmentality is useful, more so, in terms of the approaches employed by states to facilitate the governmentalization of the society. According to Dean (2010), governmentalization entails the emergence of liberal and social forms of rule characterized by the separation and expansion of the art of rule/government by means of law, civil society and market mechanisms. This serves as an eye opener to the manipulative nature of the policy making process, as well as to the means of redressing such tendencies (Masaki, 2007, p.26).

At another level, Foucault's concept of power as not something one group has and exercises over another, but rather as something that circulates between them, may help to account for the ever present micro-power struggles amongst different stakeholders in policy making processes, characteristic of those pursued in this study. Also, unlike other forms of study that look at public statements by government officials, Merlingen notes that governmentality theory examines discourses prevalent in technical policy papers, and which tend to examine modes of governance programmatically (Merlingen, 2010, p.152). That is, governmentality theory assumes that actual policy problems can be programmed, (i.e. made thinkable in ways that render them amenable to "diagnosis, reform, and improvement" (Inda, 2005, p.10).

In a similar vein, as Haahr and Walters (2005) observe, the majority of the studies on government have tended to look at the strategies and arts of government. As such, although Foucault's viewpoints have played an immensely important role in providing tools for exploring many issues of concern in society, they have not been brought to bear on the core issues plaguing women in the Kenyan society. This invites the need to investigate the role of governmentality thought in re-imagining the situation of women in Kenya. As such, using the 
lens provided by the notion of governmentality, this study will be enabled to show the extent to which the various modes of governance espoused by various regimes of power in Kenya can be said to be promoting the implementation of the rights of women or even be blamed for derailing the implementation of such rights.

Most of the analyses referred to above have tended to focus on neo-liberal projects within the institutions of government, while neglecting issues of resistance by oppositional voices that constitute the government. In this way, this study will serve to extend the theorization of the concept of governmentality beyond the government - to other institutions (e.g. women's NGOs and other local and global forces) that continue to contest the status of women in Kenya.

In view of the aforesaid benefits of the governmentality theory in the context of policy making, Larner regrets that the governmentality literature has not paid sufficient attention to the "politics surrounding specific programmes and policies" (Larner, 2006, p.207). This claim is qualified by Dean, who calls for the analyses of actual policy practices to discern what he terms "liberal authoritarianism that characterises contemporary forms of government (Dean, 2002, p.57). This study endeavours to fill this gap.

Finally, with regard to the aforementioned advantages of anchoring this study in Foucault's theoretical and philosophical analytics, Gordon notes Foucault's lack of attention to given power relations concerning global issues (Gordon, 1991, p.4). This explains why the current study combines the lens of governmentality theory and transnational feminist rhetorical theory discussed below, to analyse the recontextualization of gender equality policies in Kenya.

\subsection{Transnational feminist rhetorical theory}

In trying to make sense of the transnational relations affecting women both within and across nations, transnational feminists emphasize the intertextuality of both the local and the global norms, in terms of tracking the global networks and routes along which texts travel and circulate across the globe. Here, transnational feminists, as Dingo (2012) says, are interested in, among other issues, the intersections of class, gender and sexual orientation, so as to uncover the various sources of women's subjugation as well as locating the means to address such inequalities.

The term transnational here means something different from the notion international. In Moghadam's (2000, pp.60-61) words, the term transnational implies a "conscious crossing 
of national boundaries and a superseding of nationalist orientations." According to Dingo (2012, p.8), the term transnational denotes how the process of globalization has impacted on the movement of people, including the production of texts, culture and knowledge across different socio-cultural contexts, thus blurring any marked differences between nations and their national cultures. In view of these shifting interpretations regarding the notion of transnationalism, it is evident that Dingo's (2012) and Moghadam's (2000) definitions above are an addition to the existing frames on the concept, thereby signalling the lack of a fixed meaning and /or definition for the concept of transnationalism. For instance, whereas Moghadam above defines transnationalism from the point of "conceptual shifts," in people's way of seeing things, Dingo's definition embraces both the conceptual shifts in people's way of thinking, as well as their approach to issues in society.

In view of such considerations, there exist general modalities regarding what constitutes transnational activism and/or social movements. These as Desai Manisha notes, include socio-culturally agreed upon normative protest strategies - education, mobilization, symbolic framing, and strategic use of information (Manisha, 2005, p.321).

\subsubsection{Defining transnational feminist rhetorical analytics}

Transnational feminism entails an intersectional set of understandings and practices that can among other things attend to issues of class, capitalist patriarchies and the discursive practices of globalization, including the different ways in which they transform colonial and postcolonial relations of domination and subjugation (Nagar \& Swarr, 2010, p.5). In this regard, Nagar and Swarr differentiate between international feminisms and global feminisms, arguing that whereas international feminisms adhere strictly to nation-state boundaries without giving serious attention to the forces of globalization, global feminisms tend to privilege western feminist agendas and viewpoints, besides homogenizing the women's agitation for socio-political justice. As such, they argue that the term transnational was deployed as an alternative to the questionable use of the terms global and international, employed by the western feminist or Euro-American second-wave feminists and multinational corporations, without due regard for other forms of feminism. For instance, unlike the white hegemonic feminism (global feminism) that creates monolithic assumptions that privilege western feminist agendas/viewpoints, thereby ignoring the histories and struggles of Third World women, including the forces of racism, sexism, colonialism and exploitation, transnational feminism recognizes difference by cultivating informed awareness 
and appreciation of women from diverse socio-cultural backgrounds, thus upholding the individuality and voice of every woman. In this respect, transnational feminists question 'who' has the power to define and construct women's identity, as well as 'whose interests' such constructions represent. Also, Hyndman (2004, p.314) argues that transnational feminist rhetoricians draw on the "feminist poststructuralist and postcolonial approaches" that endeavor to reclaim the agency of marginalized groups, including showing the varied ways in which such groups are "constructed in subordination."

In addition to issues of hegemony and domination, the majority of the transnational feminist rhetoricians concern themselves with a number of issues concerning women. Among other themes, they tend to explore matters related to women's movements; globalization and women's inequalities; neo-liberal governmentality; power, voice, and identity; gender mainstreaming; and strategies of mainstreaming women's human rights. These are explained in the ensuing discussion.

\subsubsection{Women's movement and the transnational feminist rhetorical thought}

According to Friedman (2010), transnational feminist rhetorical theory cannot be said to have evolved in isolation from the struggles of women feminist activists, particularly women's human rights-based NGOs. The notion transnational feminism draws on the global practices of women's NGOs to form transnational advocacy networks that capitalize on the global avenues provided by the United Nations' world conferences on women since 1975. This is evident in Friedman's argument below:

A major element of the opportunity structure for the contemporary transnational women's movement has been the UN conference process, as manifest in conferences from the 1975 conference to mark International Women's Year in Mexico City, to the latest series of " +5 " conferences to evaluate findings from the 1990s conferences... (Friedman, 2003, p.315).

On a similar note, through these transnational networks and interactions between women's NGOs, Friedman argues that certain conceptions of human rights have been constructed as issues of "transnational concern and action" (Friedman, 2003, p.316). 


\subsubsection{Globalization and women's inequalities}

The discursive process of globalization and the growing interests in issues of social justice have necessitated socio-political and cultural connections between and among nations, thereby affecting the ways in which texts are produced, disseminated and used across the globe. These connections have inspired feminist academic scholars from diverse sociocultural backgrounds to think in new ways, both about global politics, and how the modern process of globalization has created a compelling need to examine the movement of "ideas, goods, people, and texts across borders" (Dingo, 2012, p.8). In this respect, many scholars, as Dingo proceeds to argue, have observed and queried the unbalanced impact of globalization upon women's lives.

In this case, Dingo explains that transnational feminist scholars undertake to analyse transnational social spaces and/or connections among political actors across varied geopolitical zones. To meet this objective, Dingo (2012, p.11) observes that transnational feminists emphasize the role of language in establishing the links between political and economic systems that underlie national and global relations. Further, Dingo contends that transnational feminists call for a re-examination, and /or critical reflection regarding who is mandated, and who is not, as a legitimate producer of knowledge, including the institutions and languages to be included or omitted from the practices of knowledge production.

Along similar lines, Dingo notes that transnational feminist scholars deploy the metaphor of networks (i.e. intertextuality in this study) to make sense of the unequal transnational power relationships and their impact on women. For this reason, Dingo (2012, p.11) emphasizes that:

This transnational feminist network model emphasizes that the identity category of "woman" is entangled within a variety of connections.... and to understand women's oppression, feminists must consider not only a woman's local circumstance but how her circumstances relate to and are informed by supranational policies, colonial history, global economic structures.

\subsection{4 (Neo) liberalism and transnational feminism}

According to Dingo, transnational feminists concern themselves with the concept of neoliberalism, with emphasis on the relations that hold between "neoliberal economics and neoliberal governmentality" (Dingo, 2012, p.9). In this context, feminist critics criticize 
neoliberal policies for their indifference to issues of poverty, social development and environmental degradation in the process of extending a market centred capitalist logic that emphasises issues of social welfare, free trade, competition and business dealings that are against women's interests. Dingo (2012, p10) emphasizes that:

transnational feminists tend to trace the economic, social, and political conditions of contemporary neoliberalism, neo-colonialism, and neoimperialism across nations, asking how these sorts of practices link diverse nations and people and shape them in similar and different ways.

Dingo (2012, p.14) notes that the meaning of the concept of neoliberalism has shifted as feminist activists and academic scholars have adopted a more disparaging view of it, to suggest not only its pro-market capitalism embedded in notions of free trade and competition, but also, some political rationality that goes beyond the market dynamics to encompass the management of people. Such an understanding makes it imperative for this research to question how changes in the meaning of the subject under investigation could be attributed to the notion of neoliberal policies mentioned above.

\subsubsection{Power, voice, and identity}

Transnational feminist rhetorical theory examines the relations that obtain between language and power, and seeks to examine both how power operates in given moments, as well as within particular texts. As Nagar and Swarr (2010, p.2) observe, since the 1980s, there have been growing concerns among feminists regarding issues of voice, power, representation and identity. According to Norton (2010, p.350), feminist thought emphasizes the critical role of language in constituting social subjects, subjectivities and identities of persons, their relations, as well as in contesting imposed identities. In this context, she asserts that "language is the place where actual and possible forms of social organization and their likely social and political consequences are defined and contested. Yet it is also the place where our sense of ourselves, our subjectivity, is constructed" (Norton, 1997, p.209).

\subsubsection{Transnational feminism and gender mainstreaming}

With an intertextual reference to the Beijing Declaration and Platform for Action, Dingo reiterates that though the Beijing declaration was meant to harmonise policy strategies 
for addressing women's inequalities, several national policies and programmes end up disempowering women and enhancing gender and global inequalities. In this way, policy makers are under obligation to re-assess policy programmes through the lens of transnational networks to be able to identify the various forms of influence that impact on policy decisions. Thus, using the concept of gender mainstreaming, Dingo demonstrates how despite its universal definition in the Beijing declaration, its meaning continues to shift as it travels across national and international boundaries, and as determined by the contexts in which policy makers deploy it. This explains why feminist academics and other scholars dealing with issues of women must focus on how ideas are interlinked in policies across borders:

By tracing how gender mainstreaming rhetorics circulate within various policies and how they are networked with new and sometimes conflicting ideologies, we can see how rhetorical meaning is not stable. Rhetorics can shift and, thus, have drastically different material effects... Feminist rhetoricians must consider how policy rhetorics are linked - how they are disseminated, received, rewritten, and put into action - in unexpected ways (Dingo, 2012, pp.6-7).

In this regard, Dingo (2012, p.14) continues to insist that if the concept of gender mainstreaming is treated as a single rhetorical moment without tracking the resulting policy processes and initiatives necessitated by the discursive process of globalization, then their material impact on women shall have been overlooked. In other words, by adopting the transnational feminist rhetorical lens, we gain insights into the varied ways in which the policy makers' assumptions regarding women influence the designing and implementation of policy programmes regarding women.

Giving the example of CEDAW and its human rights monitoring mechanisms, Zwingel (2005, p.46) explains how the involvement of local civil society actors in CEDAW's monitoring process creates a situation where governments are given pressure both by an international institution and by civil society groups. Based on this understanding, Zwingel continues to explain that CEDAW serves both as a solid instrument for establishing a transnational civil society and in helping to re-evaluate state sovereignty.

From the above, it becomes evident that transnational feminist activists tend to embed their advocacy for women's rights within the United Nations' conventions and treaties concerning women's lives. Likewise, to achieve their primary objectives, transnational feminist advocates of women's rights use a number of strategies. These are outlined below. 


\subsubsection{Ways/strategies of mainstreaming women's human rights}

As Dingo (2012) and Queen (2008) note, feminist scholars across the globe focus on the interactions among policy makers, feminist academics, feminist activists, women and women's rights-NGOs groups. In this regard, as Queen (2008, p.471) notes, much attention has been given to the political and rhetorical strategies utilized by such organizations to bring the sufferings of women to their government's attention, as well as to highlight the effects of neoliberal policies on the lives of women. Accordingly, transnational feminist rhetoricians emphasize the use of a number of strategies for promoting the mainstreaming of women's rights in varied contexts of policy practice. Among others, these include the following.

\subsubsection{Education and training on women's issues}

One feminist approach for influencing policies on women' rights is the use of gender training and consciousness/awareness raising. As a means to achieve responsiveness to women's issues, feminist activists and advocates of women's rights emphasize the need to train men and women in society regarding gender equality concerns (Ackerly, 2001, pp.316321). For instance, Ackerly (2001, p.318) says of this strategy that activists interested in promoting changes in domestic laws emphasize the need to educate and train law makers/government officials such as judges and police officers to "reorient their thinking, and propose laws" that are gender sensitive. Likewise, Ackerly (2001, p.321) stresses that this strategy is focused on fostering changes in the societal cultural practices and traditions that are oppressive to women.

\subsubsection{Networking/alliance building}

According to Ferree and Mueller (2004, p.593), alliance building is one of the feminist advocacy strategies for networking within and across borders. In this context, transnational women's movements tend to draw on the feminist strategy of networking both as a means for challenging the subordination and social exclusion of women, and as a mechanism for "gaining access and influence within formal, state-centered politics" (Ferree \& Mueller, 2004, p.593). This approach is achieved through working in partnerships amongst organizations in doing research, holding discussions, and exchanging crucial information necessary for generating mutual influence on state policies concerning women's rights 
(Ackerly, 2001, p.322).

Ackerly's view is reiterated by Mohanty (2003, p.530), who argues that transnational feminist activism depends on building feminist alliances "across the divisions of place, identity, class, work, belief, and so on.” For instance, as Zwingel, Keck and Skink argue, NGOs working locally are part of Transnational Advocacy Networks (TANs) that involve the use of a series of tactics to persuade and bring more influential social actors into action. Such strategies include: (1) fast creation and framing of information in credible ways that trigger action; and (2) persuading more influential social actors into the network of other actors to help push for action by monitoring their previously stated policies and /or principles (Keck \& Skink, 1998, p.16; Zwingel, 2005, p.44). Also, Keck and Skink (1998, p.2) stress that these networks help civil society actors (e.g. NGOs in this study) "to mobilize information strategically to help create new issues and categories and to persuade," including pressurizing to "gain leverage over more much more powerful organizations and governments." The significant role of networking as a strategy is reiterated below:

The network model thus provides an effective way for feminist rhetoricians to think through transnational power relationships, especially in light of how rhetorics travel and are dispersed across the globe and how the circulation of rhetorics impacts representation of women and women's material well-being and their ability to speak and be heard (Dingo, 2012, p.14).

\subsubsection{Reinterpretation of official texts}

Transnational feminist activists tend to privilege the strategy of "reinterpretation of legitimate texts as a basis for fostering social change" (Ackerly, 2001, p.324). Also, Ackerly (2001, p.324) says that reinterpretation of official policy texts on women's rights is an ongoing and collective process. In this context, Farrel and MacDermott (2005) point out that advocates of the transnational feminist rhetorical theory have the shared interest in trying to re-read, recover and thus disrupt naturalised ways of thinking that serve to subjugate women.

\subsubsection{Story-telling and personal narratives}

As Ackerly (2001, p.324) observes, women's human rights activists have a tendency of drawing on such strategies as story-telling and "personal narratives," as a means for buttressing and legitimizing their call for "changes in social practices, mores, and norms that 
are necessary to foster women's human rights in practice." Ackerly also notes that the use of story-telling and personal narratives is indicative of their "recognition for greater intracultural plurality" within their approaches to issues of concern to women. Likewise, Zwingel (2005, p.44) emphasizes that the strategy of assembling stories serves a crucial role in terms of promoting broader understanding concerning given situations.

\subsubsection{Diversity/Integration strategies}

Transnational feminist activists also tend to adopt diversity strategies that involve the articulation of women's human rights together with such issues as economic development, health, and environmentalism (Ackerly, 2001, pp.316-317). In Ackerly's view, feminist activists tend to strategically embed their discourse of women's rights within the aforesaid discourses, "where funding is more certain and where attention to women's human rights has payoffs in terms of the increased success of those development, health, and environmental initiatives" (Ackerly, 2001, p.322).

\subsubsection{Politicizing}

Feminist activists, as Ferree and Mueller (2004, p.589) explain, draw on the transnational language of rights to define and criticize given societal structures, such as bureaucratic systems, male dominated politics and formal institutions that serve the interests of men at the expense of those of women. Likewise, Ackerly (2001, p.327) says that women advocates of women's rights draw on the language of rights to define and criticize given societal structures, such as bureaucratic systems, male dominated formal institutions, and other discriminatory social values and practices that violate women's rights and freedoms.

\subsubsection{Theorizing and research}

Arguing that transnational feminist activism emphasizes the notion of "cross-cultural pluralism," Ackerly (2001, pp.324-328) points out that transnational feminist activists propose the need for a cross-cultural theoretical method that uses transnational dialogue to promote interaction among participants from a wide range of perspectives. In this context, noting that universal human rights are aimed at addressing the violations of women's human rights within given socio-cultural contexts, Ackerly (2001, p.327) argues that advocates of 
women's rights emphasize the role of a theoretical framework (i.e. transnational feminist theory), to "engage with the real-life experience of human rights violations of all whose rights are violated." Likewise, Ackerly (2001, pp.326-327) reiterates that such a theoretical methodology is significant for guiding the selection of texts and other relevant sources of information concerning the situation of women and the violation of their human rights in society. On a similar note, Nagar and Swarr (2010, p.2) posit that transnational feminist activists emphasize the need to mix such theories and practices, both as intellectual and political tools for re-examining the existing approaches to issues of voice, authorship and representation in discourses concerning women.

\subsubsection{Knowledge-creation strategies}

According to Ferree (2006, p.15), "Knowledge and its creation," remain "a sustaining aspect of the work of making feminist change." In this context, Ferree (2006, p.14) notes that women's movements have played a major role in producing new words and meanings related to issues of concern to women's rights such as sexual harassment, rape, wife beating, and the double day/shift. The same applies to the establishment of the transnational feminist theory and identity, including the creation of the notion of women's policy machinery of the 1990s (Ferree, 2006, p.14). Other inventions include the notions of gender mainstreaming, and gender budgeting that were invented as part of the feminist knowledge production endeavours, aimed at spurring national governments' policy practices in favour of women (Ferree, 2006, pp.14-15).

\subsubsection{Conclusion}

The above observations are relevant and apply to this study in a number of ways. For instance, using the transnational feminist rhetorical lens, it is important to trace how ideas from the Beijing declaration (and other UN documents concerning women) have travelled across borders to Kenya's policy programmes concerning the rights of women, including the different ways in which such ideas have been interpreted and applied by the Kenyan government and other policy actors championing the implementation of women's rights. This is consistent with Dingo's (2012, pp.6-7) emphasis above, regarding the transnational feminist rhetoricians' concern with 'tracing how gender mainstreaming rhetorics circulate within various policies and how they are networked with new and sometimes conflicting 
ideologies." Likewise, by using the transnational feminist approaches that seek to unravel the varied experiences, aspirations and identities of women across borders, the current study gains in terms of being enabled to make sense of how the complex set of factors that determine the situation of women are communicated across and within texts. In this way, the researcher is enabled to explain how the identity of women has been constructed by a complex web of relationships, besides understanding how their (women's) varied perspectives have been utilized in the production of policies and programmes for women in Kenya.

Significantly, considering that Kenya has ratified CEDAW, it is imperative to understand how CEDAW's transnationally understood imperatives are appropriated to provide the framework for the on-going interactions amongst the Kenyan government, the United Nations and women's NGOs agitating for the implementation of the rights of women in Kenya. This includes getting to know how global influences impact on the NGOs' and the Kenyan government's rhetorical shifts in their policy programmes on the rights of women. This is consistent with Queen's (2008, p.471) view that transnational feminist analytics has the potential to unravel the rhetorical and political acts that converge in policy practices from varied socio-political contexts.

\subsection{Governmentality theory and transnational feminist rhetorical theory in this study}

From the foregoing discussion, there are a number of reasons for choosing the theories adopted by this study. These are, but will not be limited to the following.

\subsubsection{Post-structuralism, subjectivity, and alternative thinking}

The notions of power and subjectivity remain at the core of Foucault's governmentality theory and the transnational feminist rhetorical thought. In this regard, both theories (i.e. informed by poststructuralist theoretical perspectives) embrace poststructuralism which holds a vision of meaning/subjectivity as discontinuous, fluid, fragmented and ever shifting, hence unyoking from the governing dominant centre. This is unlike the Saussurean (Structuralist) perspectives that view meaning as situated/fixed (Norton, 2010, p.350).

The view of meaning as multiple and fluid is crucial, as it allows for the examination of the different forms of relations that hold between the subject, games of truth and power, hence our enhanced capacity to unmask the different ways in which meanings are derived in 
varied socio-political contexts.

Moreover, the poststructuralist thinking embraced by the theories adopted in this study enshrines a political and ethical commitment (i.e. an anti-autocratic ethos) to question the "truth claims of any form of political, social and even textual authority" (Newman, 2005, p.2). In other words, poststructuralism is anchored within the framework of radical and antiautocratic politics, and is focused on disturbing and problematizing the taken for granted truth claims of hegemonic socio-political institutions, discourses and practices that negate alternative thinking (Newman, 2005, p.1).

\subsubsection{Politics, power and knowledge}

As just noted, both the governmentality theory and the transnational feminist theory have the shared goal of wanting to disturb given conventional/established ways thinking embedded in politics and other forms of knowledge in society. Consequently, the poststructuralist ethics espoused by the two theories in this study will enhance our ability to think critically and in ways that not only help us to question the logic behind given truth claims (i.e. unquestioned and naturalised forms of knowledge), but also provide a window of opportunity for reconceptualising the situation of women, as it is constructed in Kenya's policy discourses of women's rights.

To achieve this goal, both theories emphasize the need to focus on the historicity and emergence of social practices. Noting that social practices and understandings are shaped by contestations and power struggles amongst actors, Blain (2005 p.33) argues that a genealogical study never seeks to merely describe the abstract features of members' everyday practices, but rather to destabilize 'truths' and 'subjections' by tracing their history. In this respect for instance, transnational feminist theory emphasizes the need to re-examine the historical and cultural situated-ness of meaning. This as Grosz (2010, p.49) states, involves the social and cultural meanings linked with the notion of gender. That is, transnational feminist thought emphasizes historically contextualized analyses of women's lives, through unearthing of the asymmetrical power relations within different situational contexts, with the aim of theorizing how and why events, practices, knowledges and texts constitute expressions of patriarchal power relations. Similarly, Rose and Rabinow (2003, p.9) note that Foucault repeatedly turns to the past and to the present for an informed view of given practices and the social problems they seek to address. In this context, Rose and Rabinow (2003, p.4) echo Foucault's view that the notion of politics has to be studied genealogically, to gain insights 
into the different ways in which discourses of our everyday are constituted in ways that enhance taken for granted-ness, including how best we can contest and transform them. This approach by both the transnational feminist thought and governmentality theory remains crucial here, as it will help us unearth the genealogical emergence of the subject/social practices as historical phenomena, thereby enhancing our informed understanding of the object of this study.

Also, in achieving these goals, both theories have been noted to emphasise the use of language as an apparatus for rendering reality thinkable (Miller \& Rose, 2010, p.277).

\subsubsection{Foucault and feminist rhetoricians on pluralism}

Though both the governmentality theory and transnational feminist rhetorical thought envision pluralism with regard to the subject, Sawick (1991, p.8) argues that unlike Foucault's 'liberal pluralism, feminist rhetoricians envision "radical pluralism," which differs drastically from the Foucauldian liberal theory of government in many respects. First, radical pluralism tends to politicise social and personal relationships that are usually ignored within the liberal thought. Also, unlike Foucault's model of power that sees power in relational terms, feminist radical pluralism operates with both a relational and dynamic model of identity, that is not only continually in formation within a "hierarchical context of power relations at the micro level of society", but also takes into account the "plurality both within and between subjects" (Sawick, 1991, p.8). In this regard, unlike governmentality theory that concerns itself with the analysis of the different ways in which power is exercised in different contexts, and the techniques through which such power is put into practice (Besley, 2002, p.26), transnational feminist rhetorical theory focuses on such issues as: (1) the situation of women; (2) the existing power relations between men and women in society; and (3) reinterpretation, hence disruption of naturalised forms of knowledge that marginalize women's interests (Ackerly 2001, p.324; Farrel \& MacDermott, 2005). This coheres with Foucault's (1982, p.732) assertion that:

We can say that all types of subjection are derived phenomena, that they are merely the consequences of other economic and social processes: forces of production, class struggle, and ideological structures which determine the form of subjectivity. 
In this matter, Lemke (2010, p.37) notes the fact that the governmentality theory looks at the interplay between the technologies of government, the regulation of the actions of others and the forms of self-governance. In other words, by examining the neoliberal strategies of government, Foucault notes the role of ethics in fashioning individuals' conduct through governing themselves and others according to given norms of civilization, including the concept of human rights, as well as the use of experts to align the capacities of subjects with the aims of the political authorities by means of education, seduction and persuasion among other discursive strategies of advanced liberal government (Miller \& Rose, 1992; Dean, 2010). In this regard, rationalities of government assume a moral character that define the ideals and/or principles such as "freedom, justice, equality, mutual responsibility, citizenship, common sense, economic efficiency, prosperity, growth, fairness" that serve to guide the mode of governance to be adopted (Rose \& Miller, 1992, pp.178-9). In this way, governmentality theory provides a new mode of thinking about the subject in terms of ethics/ morals and norms i.e. as part of the technologies of government that determine how individuals act upon themselves and others (Merlingen, 2010, p.154; Miller \& Rose, 1990, p.8). This understanding is central to the core subject of this study that seeks to understand how issues of women have been constructed by the various participants involved in Kenya's policy practices concerning the rights of women.

\subsubsection{Feminist rhetoricians and the normative concept of human rights}

According to Friedman, Collins et al., transnational feminist rhetoricians have largely focused on issues such as the conceptualization of rights, and the use of the human rights instruments for fostering gender equality, including the influence of national and indigenous cultures on the implementation of the universal human rights to gender equality (Collins et al., 2010, p.305; Friedman, 2003, p.316). This, as Friedman (2003, p.316) argues, has ensured the construction of some conceptions of human rights as a matter of transnational concern and action, including the designing and articulating of transnationally accepted frames (i.e. women's rights are human rights, and the personal is the political), which have both influenced and shaped global understandings concerning women's rights. As noted earlier, transnational feminist rhetoricians have created new terms, which, in addition to the ones mentioned above, include patriarchy, oppression, subjection, as well as dualistic dichotomies like sex/gender, public/private, and subject /object among others (Hughes, 2002). These terms not only express shared beliefs about causes and solutions to contested issues affecting 
women, but have as well the potential to alter the way given concepts are perceived transnationally. Similarly, Foucault's governmentality theory explores such ideas of human concern as choice, freedom, rights, justice, fairness, growth, prosperity, citizenship, mutual responsibility, liberalism, government, knowledge, language, realism, morality and ethics (Miller \& Rose, 2010, pp.276-7). In this way, both the governmentality theory and transnational feminist rhetorical theory offer valuable knowledge regarding the theoretical roots of the key terms and concepts of concern in this study and will thus enable the researcher to understand how given meanings have been created and sustained, rendering intelligible their use.

\subsubsection{Feminists and Foucault on sexuality and gender equality concerns}

Just like feminists that emphasize gender equality and issues of sexuality, Sawick notes that Foucault "made issues of sexual liberation central to his research and political interventions" (Sawick, 1991, p.5). As Rose and Rabinow (2003, p.4) posit, sexuality and gender are equally political issues, and aspects of the different ways in which we are governed, as they not only encompass unequal relations of power, but are prone to contestations. In this regard, both the governmentality theory and transnational feminist rhetorical theory focus on given ideas (i.e. concepts, thematic concerns, categories and theoretical issues) that reveal the overall power structure within a society. In these considerations, McLaren (2002, p.17) observes that unlike Foucault who never takes much interest in issues of representation, transnational feminist rhetoricians emphasize the difference between the sexes. As McLaren puts it, the issue of difference provides us with the opportunity to explain and thus account for the diverse experiences, needs and expectations of women in varied socio-political contexts. This is crucial for a more nuanced analysis and understanding of the different ways in which actors respond to differing power relations in different situations.

\subsubsection{Complementary aspects of the governmentality theory and feminist rhetorical thought}

From the foregoing discussion, it can be asserted that the two theories adopted in this study do complement one another in many respects. For instance, transnational feminist rhetoricians invoke the language of human rights to claim access to the international human 
rights instruments for promoting the implementation of human rights, and for taking action against nations that fail to meet international human rights standards (Coomaraswamy, 1997, p.1257). In this respect, though transnational feminist accounts espouse the normative human rights principles and norms, they never proceed to explain how such universal norms and principles come to be used to control the conduct of others. Here, Foucault's concept of governmentality becomes crucial for transnational feminist rhetoricians, in their efforts to help feminist activists understand the various ways in which their use of the human rights discourse could serve to normalize oppressive ways, as opposed to engendering social justice.

Moreover, though transnational feminist rhetoricians draw on the universal principles of human rights, Merry (2001, p.84) notes that rights are a dynamic cultural concept, ever developing and changing with time in relation to multiple economic, cultural and sociopolitical influences. Similar observations are made by Coomaraswamy (1997, p.1260, who notes that though transnational feminist actors continue advocating for the implementation of the universal human rights of women, the reality on the ground is that "women's rights are under challenge from alternative cultural expressions.” As such, Coomaraswamy (1997, p.1261) advises that:

Unless human rights discourse finds legitimacy in these areas of a country's national life, women's rights and human rights will remain mere words on paper.

According to Phillips and Ochs (2003, p.458), the aforesaid means that policy makers are under obligation to examine the context in both the global and local (borrowing country), to establish both the compatibility and comparability of the concepts to be appropriated, in order to ascertain whether or not to borrow, in view of the differing cultural mores, demographics and the like. This is in view of the fact that we acquire our different ways of talking about ourselves from a given society or culture, with a discursive history (Charlebois, 2010, p.124). In this regard, the analytics of governmentality serves a crucial role in explaining the different ways in which borrowed ideas/discourses are fashioned and transformed to achieve given political ends (Rose \& Rabinow, 2003, p.6), including the political rationality behind given borrowings.

At the same time, using Foucault's concept of political rationality of government, we are enabled to explain the extent to which the universal human rights norms can be rejected on the grounds that they constitute a given directive power unwelcome to the existing relations of authority and subjectivity. Thus, studying the appropriation and 
recontextualization of ideas through the lens of the governmentality theory and the transnational feminist rhetorical thought has the capacity to illuminate the different ways in which knowledges about women are constructed, including their real lived experiences on the ground. Moreover, an analytics of government erases the 'naturalness' and 'taken-for granted' character of how things are done. In so doing, it renders practices of government problematic and reflects that issues of concern are likely to change with time (Dean, 2009, p.49).

Relatedly, Gordon (1991, p.4) notes the Marxists' questioning of Foucault's attentiveness to the specifics of power relations, including given techniques and practices, while ignoring global issues concerning politics, specifically, the relations obtaining between society and the state. This gap is bridged by the transnational feminist rhetorical theory. As noted above, transnational feminist rhetoricians appropriate global ideas and concepts regarding the rights of women, thus providing a link between the global production and the local appropriation of global norms and values. This not only enables us to account for the dialectics between 'the global' and 'the local,' including how human rights law operates in practice, but also provides a window of opportunity for explaining the different ways in which the appropriation and application of the human rights norms locally serve to reconfigure state sovereignty (Vidovich, 2007, p.288). Moreover, the aforesaid means that transnational feminist rhetorical theory offers the much needed methodology for tracing the initiation and dispersal of given global ideas from one context to another, including their recontextualization within policy programmes. This will also enhance our ability to theorize further Foucault's theory of governmentality that encompasses issues of state sovereignty. In addition, governmentality theory plays a significant role here in helping us discern the import of given borrowings, including how such new ideas are recontextualized locally in line with given rationalities of government. For instance, Sharma and Gupta (2006, p.21) argue that the governmentality theory can be used to explain the extent to which the discourses of reform and good leadership can be viewed as part of the circulating global discourse of good governance that is in this context appropriated for refashioning the representations of the government. In the context of this study, such understandings reveal the role of governmentality theory in discerning the difference between practice and rhetoric in given borrowings and recontextualizations within Kenya's policy programmes concerning women's rights.

Likewise, the two theories are important in understanding how ideas (policy borrowings) on given issues flow through the social and political networks, as well as in 
explaining how such circulations have engendered policy reforms locally. The practice of borrowing ideas in the process of policy making has the advantage of reflecting the different ways in which the participants in this study respond to, and even resist given understandings of the subject of the study. Also, the idea of borrowing ideas from other sources, as Laher (2014, p.104) notes, has the advantage of widening the sources of data for analysing networked texts, thereby promoting the analyses and interpretations of such texts. As such, based on the said observations, and on the neoliberal policy of intervention, it will be interesting to investigate how the different policy actors involved in Kenya's discourse of gender equality appropriate ideas from elsewhere, which they strategically use to address the issues of women in their policy programmes concerning the rights of women. In this case, we are also under obligation to look at the varied ways in which both the government and women's NGOs in this study appropriate the language of human rights to regulate the behaviour of women either in ways that serve to liberate them or as strategies of subjugation. This is in view of the fact that texts or talk (e.g. those concerning issues of women in this study) constitute one of the major sources of power/control that can be ably deployed to influence women's minds to behave in certain ways that are for the benefit of those welding power (Van Dijk, 1997, p.17).

Therefore, using Foucault's notion of governmentality and its accompanying philosophical arguments, the current study will be enabled to establish the rationality that directs Kenya's model of governance, and more specifically, the objectives of governmental policy practices concerning the rights of women. In this way, the combination of the two theories will undoubtedly inform our framework for undertaking a comparative intertextual analysis of the relations amongst the different texts that constitute policy discourses of women's rights in Kenya. 


\section{ANALYTICAL FRAMEWORK}

\subsection{Introduction}

This chapter discusses the analytical methodology adopted for the study. The chapter begins with an account of the background to Critical Discourse Analysis (CDA), followed by a detailed discussion of Fairclough's model of CDA as the method of data analysis and interpretation in this study. Subsequently, the method adopted for identifying and selecting data for investigation is described. Given the centrality of the concept of intertextuality in this research, the later part of this chapter (i.e. section 3.5.2) will discuss the process of intertextuality to enhance our understanding of its significance and usefulness as the primary critical analytical tool for making sense of the subject of this study.

\subsection{Background to the methodology: discourse}

The term discourse has been used widely and defined differently by scholars from different academic fields (Wodak \&Busch, 2004, p.109), with some using the word in contradictory ways (Fairclough, 1995, p.18). The concept of discourse originates from the Latin word discursus, which means "to run to and fro," hence the suggestion that discourse moves back and forth between reflecting and constructing the social world (Rogers et al., 2005, p.369). For Gee (1999, p.30), a discourse entails a "characteristic way of saying, doing, and being," while for Rahimi and Riasati (2011, p.107), discourse is a form of language use.

Van Leeuwen and Kress (2011, p.107) define discourses as socially constructed knowledge about some aspects of the world, which serve as a resource for constructing and interpreting the content of texts and communicative events. According to Van Leeuwen (2008), discourse entails a recontextualization of social practices and other discourses.

\subsubsection{Text and discourse}

Talbot (2007) draws a clear boundary between text and discourse. In this context, Talbot (2007, p. 9) defines text as "the observable product of interaction, a cultural object," and discourse as "the process of interaction itself, a cultural activity." This distinction as Talbot argues, presents two significant considerations worth noting. First, it draws attention to the fact that text is the product of discourse, which also bears traces of the production process. Second, it signals the need to view text as a resource (i.e. with meaning potential) 
enmeshed with cues for the interpretation and/or meaning making process (Talbot, 2007, pp.9-14). Along similar lines, Hodge and Kress (1988) argue that text and discourse are always interconnected, with discourse as the social process in which texts are embedded, and text as the concrete material object produced in discourse. In this regard, they emphasize the need for text analysts to adopt a dual understanding of text both as a semiotic process, and as a product, and discourse as dynamic view (Hodge \&Kress, 1988, p.264, cited in Yell, 2005 p.13).

\subsubsection{Text as a product of a mediated process}

Expounding on Hodge and Kress's social semiotic view of text, Yell (2005, p.14) states that social semiotics involves a view of texts as a product of a mediated process, and one that encompasses the production and reproduction of meaning and texts across different socio-cultural contexts. The social semiotic notion of text relates to three core aspects namely: (1) the text /context relation; (2) text as both product and process; and (3) texts and the meaning making process (Yell, 2005, p.13). Thus, Yell posits that a social semiotic view of text emphasizes the dynamic interactive relation between text and context, implying that meanings are produced within given contexts, which constrain or enable the range of meanings that can be made.

Yell (2005 p.14) also claims that a social semiotics approach to text emphasizes an integrated approach, one that views texts as "bearing traces of their contexts of production and of reception." Moreover, text production involves a dialogic process in which texts continually respond to prior texts, as they also anticipate other texts (Yell 2005 p.14). This understanding connects with Fairclough's (1995, p.187) view of text within his three-part model of discourse, which helps to link analysis of texts to analyses of social contexts. Text is the concrete material produced in discourse, and entails "the written or spoken language produced in a discursive event" (Fairclough, 1993, p.138). Consequently, Fairclough (2003, p.3) defines text as "any instance of language use" and an aspect of social events, including visual images and sound systems. This reflects his emphasis on the semiotic nature of texts. Also, stating that text is a product and a process, Fairclough (2001, p. 20) distinguishes between text and discourse. In this context, he uses discourse to denote the entire process of social interaction, of which text is a constituent. In his words, discourse includes text, as well as "the process of production of which the text is a product, and the process of interpretation, for which the text is a resource" (Fairclough, 2001, p.20). In his view, the formal properties 
of a text can be identified from the viewpoint of discourse analysis as "traces of the productive process," and as "cues in the process of interpretation."

Moreover, Fairclough (2003, p.7) emphasizes that texts can bring about change in people's knowledge, beliefs, attitudes and values," thereby shaping their identities. In a similar vein, Fairclough (1995, p.71) holds that it is not possible to 'read off' ideologies from texts," considering that "meanings are produced through interpretations of texts and texts are open to diverse interpretations." It is in this sense that Fairclough (2003, p.128) emphasizes that a text can be viewed as drawing upon a given discourse, even if the realization of that discourse in the text is minimal.

Because of the many and endless definitions of the notion of discourse each reflecting different understandings and manner of usage, this study adopts Fairclough's (1992, 1995, 2003) definition of discourse.

\subsubsection{Fairclough's concept of discourse}

Fairclough's approach to discourse espouses two paradigms. The first view prevalent in language studies (linguistic perspective) sees discourse as a form of social action, wherein people use language to interact in different types of social situations. Secondly, Fairclough (1995, p.18) adopts the poststructuralist view consistent with the Foucauldian notion of discourse, where discourse is seen as a way of construing (i.e. representing and interpreting) areas of knowledge and social practice through language use. In this context, Fairclough (2001, p.14) defines discourse as "language as social practice determined by social structures." Consequently, he defines discourse as the particular view of language in use, and as an aspect of social life that is closely interconnected with other elements (Fairclough, 2003, p.3).

The view of discourse as a social practice has significant implications worth mentioning. First, it suggests that language is not merely an individual activity, but a shared social enterprise. For instance, Fairclough (2001, pp.18-19) explains that linguistic practices are social, considering that any time people talk, listen, write or read, they do so in ways which are determined socially and have social effects. Second, by seeing discourse as a social practice, Fairclough seeks to stress the performative function of language as a form of social activity, which invokes the idea that whenever one says a thing, he is also doing something. This understanding of discourse helps to bring into focus issues of agency (Kress, 2001, p.35), taking into account the dialectical relationship between a given discursive event and all 
the different aspects of the situations, institutions and social structures that constitutes it, as it also shapes them (Fairclough, et al. 2011, p.357; Fairclough \& Wodak, 1997, p. 258). This means that in his view, Fairclough sees discourse as not only being constitutive, but also serving to construct entities and social relations (Fairclough, 1992, p.64; Fairclough, et al., 2011, p.358).

\subsubsection{Fairclough and Gramsci's concept of hegemony}

To account for the constitutive aspect of discourse, Fairclough introduces Gramsci's concept of hegemony to explain how discursive practices are part of the broader social practice encompassing power struggles and ideologies that necessitate the production and reconfiguration of the orders of discourse (Jorgensen and Phillips, 2002, p.76). This means that in his understanding, Fairclough sees discourse not only as reflecting social entities, but also as indexing social relations that obtain between different social actors in different social settings. This understanding is summarized below:

discourse is socially constitutive as well as socially shaped; it constitutes situations, objects of knowledge, and the social identities of and relationships between people and groups of people. It is constitutive both in the sense that it helps to sustain and reproduce the social status quo, and in the sense that it contributes to transforming it (Fairclough, Mulderrig \&Wodak, 2011, p.358).

This study adopts Fairclough's concept of discourse as "a particular way of using language" to construe (represent and interpret) the world (Fairclough, 2003, p.26). In this context, seeing language as a social practice will create a window of opportunity for the researcher to examine the various competing linguistic practices existing within the context of enacting policies on gender equality.

\subsubsection{Orders of discourse}

As part of social practices, Fairclough (2003, p.24) insists that discourses are often networked together in specific and shifting ways, where language (semiotic systems) define given ways of combining certain linguistic elements (possibilities) of networks of social practices, while excluding others. These elements and / or possibilities entail what Fairclough calls orders of discourse, which means the networks of social practices in their language 
aspects. Consequently, he defines an order of discourse or semiotic order as the configuration of discourses, genres, and styles that frame or make up "the discourse aspect/ semiotic moment of a network of social practices" (Fairclough, 2003, p.24 \&220). In his view, these principal elements of orders of discourse /semiotic orders (i.e. discourses, genres and styles) select certain possibilities and / or elements defined by language for inclusion in the text, and exclude others.

In this respect, a genre is a way of acting and interacting (relating) through speaking and writing, viewed in its semiotic aspect, hence helping to regularize interaction (Jessop, 2004, p.166). Fairclough (1995, p.56) argues that a genre entails the "use of language associated with and constituting part of some particular social practice.” Asserting its close link with discursive practices, Palli, Vaara and Sorsa (2009. p.305) define genre as a way to get things done. Citing Fairclough 1992, the authors further define genre as a specific text type and particular processes of producing, disseminating and consuming texts (Palli, Vaara \& Sorsa, 2009. p.305). Discourse appears in different types of genres, including, everyday conversations, interviews, parliamentary debates, news reports in the press, advertisements, research articles (Fairclough, 1995, p.56; Fairclough, 2003, p.17; Van Dijk, 2011, p.5).

In the same vein, styles entail ways of being - personal and social identities (Fairclough, 2003, p.27; Waller, 2006, p.5) in their specifically semiotic aspect (Jessop, 2004, p.166). The three elements of networks of social practices - genres, discourses and styles-are dialectically related. This means that discourses can be enacted in many ways, as genres (ways of interacting / acting /relating), and inculcated as styles (ways of being / personal and social identities), in a broad range of contexts (Jessop, 2004, p.166).

Expounding on Fairclough's view above, Jones explains that the concept of orders of discourses entails the creative use of language to "reproduce, recreate, refashion and recontextualize particular linguistic and cultural resources" in given contexts of use, thereby creating new types of "identities, social practices and relationships of power" (Jones, 2010 p.467).

\subsection{Analytical framework: critical discourse analysis}

This section will present the analytical framework adopted for the study. As Van Dijk (2001, p.353) notes, there are varied strands of CDA with different theoretical and analytical approaches. However, as a school or community of scholars, CDA shares to some degree a number of viewpoints and aims, including theoretical, methodological and conceptual 
frameworks (Blommaert, 2005, p.24; Van Dijk, 2001, p.353). As such, owing to the wide variety of perspectives to CDA, and the methodological approaches espoused by this study, it is impossible to provide a detailed discussion of the different approaches to CDA with material examples. Therefore, a brief account of the origins, aims and common elements of CDA will suffice, before embarking on a detailed discussion of the specific model of CDA adopted by this study.

\subsubsection{CDA: an overview}

CDA is said to have originated from a group of scholars working at the University of East Anglia at the end of the 1970s, by initiating the current focus of CDA on language and discourse (Wodak, 2001, p.5). Further, as Wodak and Busch (2004, p.108) argue, the roots of CDA are traceable to classical rhetoric, text linguistics, sociolinguistics, applied linguistics and pragmatics.

Methodologically speaking, CDA adopts interdisciplinary approaches, through dialoguing with various other disciplines and theories focused on the processes of change in the modern world (Fairclough 2001, p.1). The interdisciplinary approach is useful in helping us to gain a more nuanced understanding of the different ways in which language functions in "constituting and transmitting knowledge, in organizing social institutions, or in exercising power" (Wodak \& Busch, 2004, p.109). This reflects the fact that CDA is an amalgamation of several approaches towards the social study of discourse, which vary in terms of theory, methodology, as well as the topic under investigation. In this frame of reference, CDA adopts both linguistic and sociolinguistic approaches to text and discourse analysis (Fairclough, 1995, p.21), with the core objective of unravelling the socio-cultural contexts. CDA stresses the importance of the context of language use, "the social and historical situativity of the text, and the intertextual/interdiscursive dimension... to identify and analyse discursive strategies, argumentation schemes (i.e. topoi), and means of realization (in verbal as well as in other semiotic modes) (Wodak \& Busch, 2004, p.107).

Accordingly, CDA can be defined as an interdisciplinary approach to the study of discourse, which views language as a form of social practice, (Fairclough, 1992, 1995; Fairclough \& Wodak, 1997). Fairclough (1995, pp.132-133) explains that:

By CDA I mean discourse analysis which aims to systematically explore often opaque relationships of causality and determination between (a) discursive 
practice, events and texts, and (b) wider social and cultural structures, relations, and processes...

For Van Dijk (2001, p.352), CDA is principally aimed at examining "the way social power abuse, dominance, and inequality are enacted, reproduced, and resisted by text and talk in the social and political context." In connection to this position, Blommaert (2005, p.24) emphasizes that CDA has particular interests in power, more so, institutional power.

\subsubsection{Tenets / principles and aims of CDA}

Fairclough and Wodak (1997, pp.271-80) offer a succinct summary of the core tenets and/or principles of CDA as:

(1) CDA addresses social problems

(2) power relations are discursive

(3) discourse constitutes society and culture, meaning that each instance of language use leads to the reproduction and transformation of socio-cultural structures

(4) discourse does ideological work, because it contributes to perpetuating given relations of power and domination in society

(5) discourse is historical, meaning it is linked to a network of other discourses

(6) The link between text and society is mediated by the "orders of discourse"

(7) discourse analysis is interpretative and explanatory, suggesting its accent on systematic methods of data analysis

(8) discourse is a form of social action, signalling the core focus of CDA on agency and the role of ideology.

Based on this vantage point, Blommaert sees discourse as an instrument of power, hence the core aim of CDA to render such power relations "visible and transparent" (Blommaert, 2005, p.25). That is, CDA undertakes to unmask the different ways in which language use/discourse connects with social structures, with a view of locating and disrupting hegemonic forces that engender dominance and inequality (Blommaert, 2005, p.25; Wodak \& Busch, 2004, p.108). The same view is expressed by Fairclough (2005a, p.11), who reiterates CDA's commitment to issues of social justice, social equality and democracy, and in relation to how such concepts are understood and interpreted in different contexts. This explains why Blommaert (2005, p.25) sees CDA as not just being interested in unravelling the social aspects of language use, but also as having a moral and political duty to empower the 
powerless and voiceless, through exposing, and thus destabilizing power abuse and other social evils in society.

Likewise, Fairclough emphasizes that CDA is openly critical, considering its concern to unmask the discursive formation of power relations, as well as its attentiveness to the process of social change (Fairclough 2001, p.230). This understanding is extended by Wodak (2001, p.9), who sees the idea of "critical" as entailing "having a distance to the data, embedding the data in the social, taking an explicit political stance, and focusing on selfreflection."

\subsection{Fairclough's model of critical discourse analysis}

Fairclough (1992, pp.8-10) provides five defining theoretical propositions that frame his approach to CDA. These are: (1) discourse (language use) shapes and is shaped by society, meaning that the use of language is socially determined and varies from one context to another; (2) discourse helps to constitute (and change) knowledge, social relations and social identity, and these three dimensions of the social (knowledge, social relations and social identities), are ever present in every discourse and are simultaneously being constituted or reconstituted; (3) discourse is shaped by relations of power and invested with ideologies, meaning that discourses affect societies in which they are articulated, and are as well shaped by the society in terms of inflecting them with given ideological perspectives; (4) the shaping of discourse is a stake in power struggles, signalling the fact that different discourse practices and conventions held by various groups in society are a powerful device for social control; and (5) CDA seeks to show how society and discourse shape each other.

This study will provide a comparative intertextual analysis of texts produced by the institutions involved in furthering women's human rights in Kenya, i.e. women's human rights-based NGOs, the Kenyan government and the United Nations. This means that existing concepts such as intertextuality and recontextualization are going to be critical analytical tools in this study. Fairclough's model of CDA is in my view the most developed framework available for applying these concepts, as well as being consistent with the theoretical understanding of discourse adopted for this study. Because of the sheer complexity of the network of texts, it is expected that the existing models and understandings of intertextuality will be significantly extended by this analysis. 


\subsection{A three-tier framework of discourse analysis}

Fairclough's framework of discourse analysis reflects his view of discourse as simultaneously incorporating the three levels of text, discourse practice (i.e. text production, interpretation and reception) and sociocultural practice (Fairclough, 1992, p.4). Fairclough's $(1992,1995,2003)$ approach to critical discourse analysis draws on a dialectical theory of discourse, and a transdisciplinary approach to the discursive aspects of social change.

Arguing that text analysis alone is never sufficient for discourse analysis because of its failure to unveil the connections between texts and societal processes and structures, Fairclough (2013, p.94) provides a three-tier framework for carrying out CDA Analysis. The three levels of analysis: the text, the discursive practice, and the social (socio-cultural) practice, involve analysing texts, interactions, and social practices at the local, institutional, and societal levels. In other words, each discursive event has three dimensions: it is a spoken or written text, an instance of discourse practice involving the production and interpretation of texts, as well as part of social practice (Rogers et al., 2005, p. 371). This is shown diagrammatically in Fairclough's (1995) three-tier framework of analysis below:

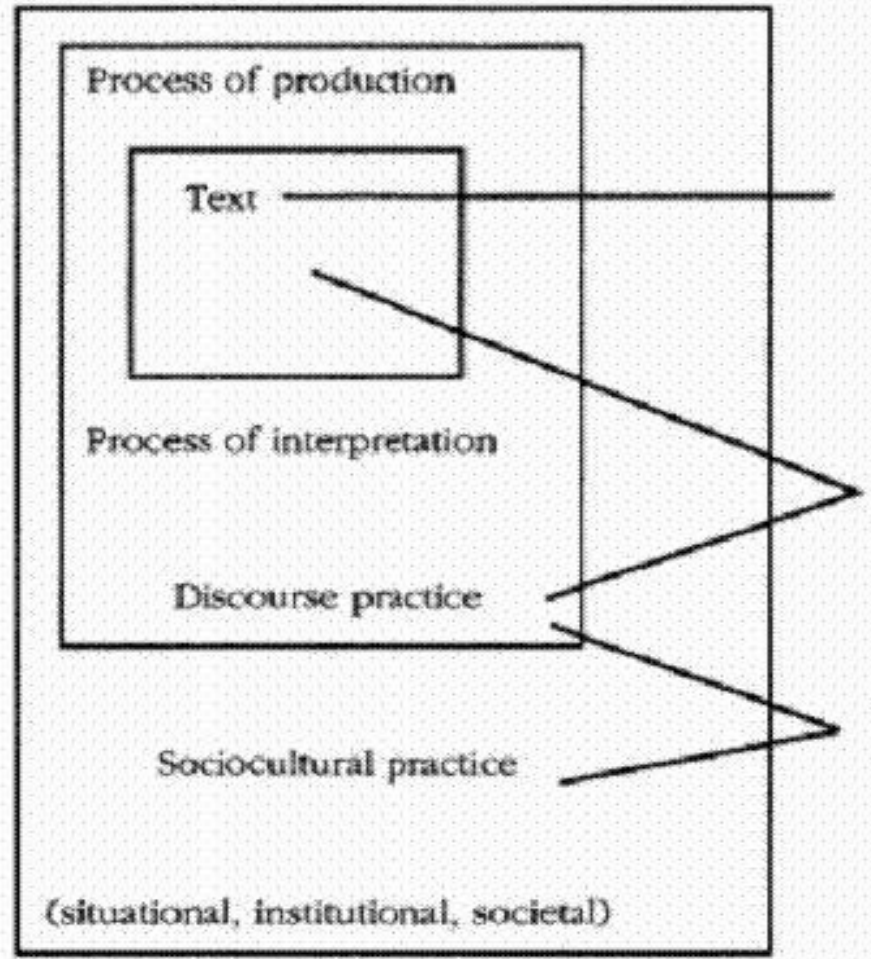

Dimensions of discourse
Description

(text analysis)

Interpretation

(processing

analysis)

Explanation

(social analysis)

Dimensions of discourse analysis

(From Fairclough's (1995) Dimensions of Discourse Analysis) 
Fairclough's model of CDA seeks to link the micro with the macro, by revealing the different ways in which societal knowledge, values, assumptions and ideological beliefs impact the manner in which we speak, write and interact with other members of society. The steps of analysis involve: (1) description, which looks at the formal properties of the text, as well as grammar, vocabulary and textual structures (i.e. textual analysis); (2) interpretation which examines the relations between text and interaction (i.e. discourse/discursive practice); and (3) explanation that is concerned with the relations existing between interaction (discursive practices) and social practices/context (Fairclough, 2001, pp.21-22). These are discussed below in the reverse order, from macro to micro levels of analysis.

\subsubsection{Sociocultural practice}

This entails the broader historical and socio-political context (macro level analysis), within which the text is produced (Smith, 2007, p. 62). From this perspective, Fairclough (2001, p.31) emphasizes that social practice does not just mirror a reality, but is in an active relationship to reality, which it also shapes.

At this level of analysis, Fairclough conceives of discourse as involving both social actors and their varied relations with other social groups in society. As such, analysis at the level of social practice looks at the underlying power relations / hegemonic struggles, with a focus on the extent to which a given text supports or opposes a particular type of discursive hegemony or social practice (Fairclough, 1992, p. 95; Locke, 2004, p. 43). This positioning is identified through the analytical lenses provided by intertextuality and interdiscursivity (see 3.5.2.2 -3.5.2.4 below for more information concerning the concepts of intertextuality and interdiscursivity), which reflect how discourses anticipate and invoke other texts thus bringing to light the "emergence of new orders of discourse, struggles over normativity, attempts at control, and resistance against regimes of power" (Blommaert, 2005, p.30). This will be achieved in the current study, by exploring the historical and socio-political contexts that underlie the texts analysed, given that ideological representations and hegemonic struggles occur in orders of discourse that are the result of past, current and anticipation of future events (Fairclough, 1992, pp. 89-95). 


\subsubsection{Discourse practice}

According to Fairclough (1992, p.85), analysis of discursive practice encompasses a combination of both the micro and the macro analysis. The level of discursive practice serves as a bridge between text and social practice. That is, the discursive practice level (also called meso-level analysis) mediates between the social practice and the text, and addresses itself to how texts are produced, distributed, interpreted and consumed (Fairclough, 1995, pp. 16, 58; Rogers et al., 2005, p. 371; Waller, 2006, p. 62). For Fairclough (1992, p.85), discursive change has to be examined within wider processes of cultural and social changes. According to Jorgensen and Phillips (2002, p.69), "the analysis of discursive practice focuses on how authors of texts draw on already existing discourses and genres to create text, and on how receivers of texts also apply available discourses and genres in the consumption and interpretation of texts." For instance, the Kenyan government's policy texts (see chapter 6) deploy different discourses (e.g. women's NGOs' discourse, and the United Nations' discourse of women's rights to gender equality) and genres such as official gender policy documents and evaluation/assessment reports. The United Nations' and women's NGOs' familiarity with the Kenyan government's gender policy documents/genres shape their interpretation of, and ongoing discussions with, the Kenyan government in relation to gender equality policies.

\subsubsection{Discourse/discursive practice as a process of recontextualization}

Fairclough (2013, p.399) sees a discursive practice as a principle of recontextualization, considering that it assimilates other discursive practices in line with context-specific "recontextualising principles." In a similar vein, Linell observes that the aspects of discourse that get recontextualized include among others "linguistic expressions, concepts and propositions, facts, arguments and lines of argumentation, stories, assessments, values and ideologies, knowledge and theoretical constructs, ways of seeing things and ways of acting towards them, ways of thinking, and ways of saying things" (Linell, 1998, p. 145, in Cox \& Hassard, 2010, p.122). Also, Fairclough and Wodak (2010, p.24) note that recontextualization is often textually realized in the mixing of 'new' recontextualized elements and 'old' elements, such as particular words, expressions, arguments, topoi, and rhetorical devices among other devices.

Recontextualization involves transformations, whereby the appropriated concepts and their representations get inflected by the recontextualizing discourse. As Fairclough (2013, 
p.399) puts it, "recontextualised practices are always transformed, but the particular ways they are transformed depend upon the specific logic, the recontextualising principle of the recontextualising practice.” Citing Bernestein (1990, 1996), Fairclough (2013, p.399) argues that in the process of getting recontextualised, discursive practices are decontextualized from what he calls "their embeddedness in action and transformed into discourses which are articulated together in new ways according to the logic of the recontextualising principle."

By the same token, Blackledge (2006, p.64), Fairclough and Wodak (2010, p.22), and Van Leeuwen (2008, pp.17-18) posit that while being recontextualized, social events are not just repeated, but are transformed in their new contexts, through such mechanisms as "addition of new elements," deletion of some arguments/elements of a given social practice, re-arrangement of events in the new domain, and substitution of some elements of the actual social practice for others. In addition to these considerations given above, Fairclough (1992, p. 82) suggests that analysis of the discursive practice involves use of "mental maps" to interpret texts, and that such mental maps entail "just one interpretation of social realities which are amenable to many interpretations:"

In terms of production, an intertextual perspective stresses the historicity of texts: how they always constitute additions to existing 'chains of speech communication' (Bakhtin 1986: 94) consisting of prior texts to which they respond. In terms of distribution, an intertextual perspective is helpful in exploring relatively stable networks which texts move along, undergoing predictable transformations as they shift from one text type to another (for instance, political speeches are often transformed into news reports). And in terms of consumption, an intertextual perspective is helpful in stressing that it is not just 'the text', not indeed just the texts that intertextually constitute it, that shape interpretation, but also those other texts which interpreters variably bring to the interpretation process (Fairclough, 1992, p.84, my emphasis).

This excerpt foregrounds four categories and /or factors that I find important for the analysis of any discursive event/practice. Such categories (see the phrases/expressions in italics above) underlie Faircough's $(1992,1995)$ analysis of discursive practices. That is: (1) the concept of intertextuality of texts which emphasizes the historicity of texts; (2) the metaphor of intertextual chains, suggesting that our utterances form part of the existing other networks of texts; (3) the process of recontextualization that effects predictable transformations on texts as they travel along the network of other texts; and (4) Bakhtin's 
$(1981,1986)$ concept of dialogism. These categories will be picked up in the course of the following discussion.

\subsubsection{Intertextuality}

Based on Bakhtin's $(1981,1986)$ concepts of dialogism and heteroglossia, Julia Kristeva coined the term intertextuality with emphasis on the social and historical contexts, and defined it as "the insertion of history (society) into a text and of this text into history" (Kristeva, 1986, p.39, cited in Fairclough, 1992, p.101). This means that texts draw on and are built out of other past texts, to which they respond, re-accentuate and rework, thereby making history, and contributing to the larger processes of change, including anticipating and seeking to fashion subsequent texts (Fairclough, 1992, p. 102).

Drawing on Kristeva's view above, Fairclough (Fairclough, 1992, p. 84) defines intertextuality as "the property texts have of being full of snatches of other texts, which may be explicitly demarcated or merged in, and which the text may assimilate, contradict, ironically echo, and so forth." Subsequently, Fairclough defines intertextuality as: "the presence of actual elements of other texts within a text" (Fairclough, 2003, p. 39), and/or "how texts draw upon, incorporate, recontextualize, and dialogue with other texts" (Fairclough, 2003, p. 17).

Fairclough identifies two dimensions of intertextuality - manifest intertextuality and constitutive intertextuality (interdiscursivity) - which shape the interpretation of texts (Fairclough, 1992, p. 271). The two models of intertextuality are discussed under the following sub-headings.

\subsubsection{Manifest intertextuality}

Fairclough (1992, p. 271) defines manifest intertextuality as the explicit presence of other texts in a text, traceable to an actual source in another text. These are overtly drawn upon through the techniques of discourse representation like quotation marks, paraphrase, copying, including other strategies of incorporating, responding to, or anticipating other texts or utterances like irony and presuppositions (Ivanic, 1998, p. 47) which indicate the presence of other texts in a text (Fairclough, 1992, p. 271; Jorgensen \& Phillips, 2002, p. 73).

Manifest intertextuality, or "actual intertextuality" (Ivanic 1998, p. 47), is related to writer identity. For instance, writers have both to situate themselves in relation to the highly 
respected shared conventions in writing, "of quoting from authoritative sources", as well as "echoing the actual voices of people" or institutions they have interacted with, or are aligned with, and wish to be associated with, as opposed to an "abstract social position" (Ivanic, 1998, p. 48).

\subsubsection{Constitutive intertextuality/interdiscursivity}

Constitutive intertextuality (also called interdiscursivity) entails "how a discourse type is constituted through a combination of elements of orders of discourse" (Fairclough, 1992, p.117-118), and "the heterogeneous constitution of texts out of elements (types of conventions) of orders of discourse (interdiscursivity)" (Fairclough, 1992, p.85).

Interdiscursivity entails constitutive intertextuality i.e. the type of macro-discourse that can be invoked, with related elements and thematic concerns (i.e. including conflicting voices) to legitimate one's argument (Atanga, 2010, p.34). In other words as Jorgensen and Phillips (2002, p. 73) note, interdiscursivity arises from instances where different discourses and genres are simultaneously articulated within a given communicative event and they signal the fact that discourses are networked, and coexist with a plurality of other conflicting/oppositional discourses/voices (Atanga, 2010, p. 34).

Constitutive intertextuality (interdiscursivity) denotes the arrangement and/or configuring of the discourse conventions (genres, styles and discourses) in texts and interactions (Grewal, 2008, p. 106; Jianguo, 2011, p. 1313), which characterize the hybrid nature of discourses (Wodak, 2011, p.49). This means that interdiscursivity results from the recontextualization of social practices that are basically linked with other discourses. In this way, Lowndes (2001, p.9) notes that whereas manifest intertextuality is an optional feature for texts, interdiscursivity is omnipresent in every text. This has two significant implications for this study. Firstly, as Atanga notes, interdiscursivity not only makes it possible for the coexistence of competing discourses in a text, but is also in itself a crucial conceptual tool for examining biased discourses, in terms of "traces" drawing from shared discourses within similar and different texts (Atanga, 2010, p.35). Similar sentiments are given by Ainsworth and Hardy (2004, p.166), who argue that the existence of competing discourses provides actors/participants with the flexibility, dialogue, choice of identities to identify with, which eventually give the framework for resistance. This as Phillips and Jorgensen (2002, p. 73) state, is achieved when actors creatively mix different discourses in new and complex ways, thereby creating interdiscursive mixes that serve to disrupt the dominant social-order, thus 
push boundaries that necessitate socio-cultural change.

Second, interdiscursity makes it possible for the examination of "different but related discourses in different genres and texts" (Atanga, 2010, p.34), that feature in different discursive contexts. In Tardy's (2011, p.66) view, interdiscursivity plays a significant role in establishing hybrid genres, or in borrowing conventions from one genre into another. With a focus on the particular network of practices under investigation, Fairclough (2001, p.128) identifies three analytical issues, i.e. dominance, difference and resistance, which underlie the choice and use of particular genres, discourses and styles in different discursive contexts. Fairclough (2013, p.399) emphasizes that discourse analysts ought to do three significant things: (1) considering a discursive practice as a regulative practice, i.e. as one involving the control of interaction between actors, as well as identifying which genres, discourses and styles are dominant, i.e. by looking at which genres regulate action and interaction in given institutions; (2) take into account "the range of difference, diversity, in genres, discourses and styles," including the social structuring and restructuring of that difference, i.e. by looking at such issues as access and power differentials, more so, with a focus on the different ways in which discourses, genres, styles are affected by the imposition of new dominant ones; and (3) with an understanding of a discursive practice as a domain of action, make every effort to identify the various ways in which dominant genres, discourses and styles endeavour to colonize other discourses, including both the manner in which such discourses are assimilated and enmeshed with old forms, and the implicit or explicit forms of resistance at work.

Fairclough's concept of intertextuality is very selective with regard to "what is included and what is excluded from the events and texts represented" (Fairclough, 2003, p.55). From within this frame of reference, Fairclough (1995, p.4) notes that in any representation, the speaker or writer can decide what discourse or aspects of discourse to include and/or exclude, as well as what to foreground or background. This practice points to the differentials in power relations, owing to differential access to various identities and practices associated with different types of statuses and social goods (Gee, 1999, p.30). The exclusion of given discourses/voices involves those discourses being viewed as incorrect/inconsistent, conflicting, inappropriate or even irrelevant in particular settings. It is in this sense that Foucault (1981, pp.54-55) sees knowledge as being interlinked with forms of social control, as institutions have the power to create what they consider as valued knowledge within their own domains. In other words, upon recontextualization, discourses are interpreted differently and oppositional voices within borrowed texts that seem to 
challenge the existing world view are normally omitted.

This scenario confirms why Fairclough presents his concept of intertextuality as involving power relations, hence the explicit association of his notion of intertextuality with Gramsci's concept of hegemony (Fairclough, 1992, p.271) that seeks to reveal the interface between domination and power. Gramsci's (1971) concept of hegemony entails the "systems of practices, meanings, and values that legitimize the dominant society's institutional arrangements and interests" (Kilderry, 2012, p.81). It is in this sense that power analysis is necessary and emancipatory, considering that it "makes us more conscious of reality, because consciousness is the first step towards emancipation" (Fairclough, 2001, p.1, cited in Jorgensen, 2007, p.16).

In addition to Fairclough's (2013, p.399) view of a discursive practice as a regulative practice that involves control of interaction between actors, Fairclough (2005a, p.16) suggests the need to adopt a regulative approach, together with "theories of governance" and aspects of the "cultural theory." Moreover, Fairclough (2005a, p.16) stresses that discourse analysts ought to examine the efforts made to achieve given goals, and the hardships and failures encountered in attaining them. In light of these considerations, I adopt Bakhtin's (1981) theory of authoritative discourse and internally persuasive discourse discussed below.

\subsubsection{Authoritative discourse and internally persuasive discourse}

Bakhtin distinguishes between utterances/texts that are designed to restrict meaning to a single canonical interpretation and those that are left open for varied forms of interpretation. In relation to his concept of heteroglossia (i.e. double voiced discourse), heteroglossic voices can be subdivided into two general categories, depending on the extent to which they are dialogically generative or dialogically restrictive in their "intersubjective functionality" (Feng $\&$ Peter, 2011, p.568). That is, the difference between these two divisions of heteroglossia depends on the degree to which statements actively allow for "dialogically alternative voices (generative), or serves to delimit the realization of alternative viewpoints" (Martin \& White, 2005, p.102, cited in Feng \& Peter, 2011, p.569).

According to Bakhtin (1981), heteroglossia enters discourse through subjects and their languages, which becomes the source of contestations and struggle amongst different actors in society. On the basis of this understanding, Bakhtin invents the concepts of centripetal forces to mean utterances/texts that tend to delimit/centralize meanings, and their direct opposite - centrifugal forces that seek to decentralize meaning. Also, Bakhtin 
differentiates between an "authoritative" utterance /discourse that "demands our unconditional allegiance' (Bakhtin, 1981: pp.270-271), by imposing particular sanctioned perspectives or meanings on the reader or sender (Bakhtin, 1981, pp.293-294 cited in Prior 1995, p.297), and "internally persuasive" discourses that are "half ours and half someone else's" (Bakhtin, 1981, p.345):

Authoritative discourse permits no play with the context framing it, no play with its borders, no gradual and flexible transitions, no spontaneously creative stylizing variants on it. It enters our verbal consciousness as a compact and indivisible mass; one must either totally affirm, or totally reject it. It is indissolubly fused with its authority - with political power, an institution, a person - and it stands or falls together with that authority (Bakhtin, 1981, p.343).

As such, Bakhtin insists that authoritative discourses demand that they be acknowledged and assimilated as they are, whilst internally persuasive discourses remain open to dialogic interactions with other viewpoints. An internally persuasive utterance can be questioned, resisted and "put in a new situation in order to expose its weak sides" (Bakhtin, 1981, p.348). An internally persuasive discourse is one that is:

tightly interwoven with "one's own word." In the everyday rounds of our consciousness, the internally persuasive word is half-ours and half-someone else's. Its creativity and productiveness consist precisely in the fact that such a word awakens new and independent words, that it organizes masses of our words from within, and does not remain in an isolated and static condition. It is not so much interpreted by us as it is further, that is, freely, developed, applied to new material, new conditions; it enters into interanimating relationships with new contexts (Bakhtin, 1981, pp. 345-346, cited in Cooper \& Selfe, 1990, p. 859).

Further, Bakhtin says that authoritative and monologic meanings occur in a number of forms such as: "authority of tradition; religious decrees; generally acknowledged scientific truths, or an official ideology" (Bakhtin, 1981, pp.342-343, in Tuler, 2000, p.4). On the contrary, generative or "internally-persuasive" utterances are dialogic/polyphonic and subject to transformations through "reflective engagement of meanings" (Tuler, 2000, p.4). According to Bakhtin, such internally-persuasive utterances are endless, considering the 
unfinalizability of human creativity and freedom. Sullivan (2012, p.140) provides another key for drawing a boundary between an authoritative discourse and an internally persuasive discourse:

A discourse is 'authoritative or internally persuasive' depending on how it is appropriated. If a discourse is echoed, with little questioning, then one could argue that it is authoritative for the author. If it is actively questioned or appeals to logical coherence, which in turn can be open to question, then it is more likely to be 'internally-persuasive.' Nonetheless, these are fluid boundaries and discourses do shift between 'authority' and internal persuasiveness.

In Lowndes' (2001, p.22) view, Bakhtin's concepts of authoritative and internally persuasive discourses are useful in theorizing both stability and change in discourse (Lowndes, 2001, p.22). In this way, Bakhtin's theory offers a way of identifying intertextual evidence of contestations and hegemonic struggles, which according to Fairclough need to be isolated for further analysis. Likewise, Bakhtin's $(1981,1986)$ concept of dialogism that allows for the co-existence of contradictory discourses of our everyday life, and his metaphors of answerability, addressivity, polyphony, authoritative and internally persuasive discourses can be stretched to augment Fairclough's $(1992,1995,2003)$ theory of intertextuality.

\subsubsection{Text analysis}

According to Fairclough (2003, p.3), text analysis involves both linguistic analysis as well as an examination of the different discourses, genres and styles articulated simultaneously in a text (i.e. interdiscursive analysis). Fairclough (1995, pp.187-8) insists that textual analysis facilitates discourse analysis, and helps to give factuality to the conclusions made in the study.

\subsubsection{Textual analysis using Halliday's systemic functional linguistics}

Analysis at the textual level involves use of Halliday's systemic functional linguistics and the three domains of ideational, interpersonal, and textual analysis. The ideational metafunction is usually unveiled through a transitivity analysis with the main focus on what 
occurs in the text and the agents/participants that trigger this process. The various categories of the process of transitivity are "action (the process of doing); thinking (mental process); saying (verbal process); states of being (relational process); and states of behaving (behavioural process)" (Halliday, 1985, cited in Ahmad, 2012, p. 152).

Our focus on ideational and interpersonal functions of language use will include a focus on the various ways in which language and other semiotic resources are used to construct social relationships and identities enacted. This will be achieved by examining the speech roles of various policy actors in given intertextual interactions.

Textual analysis deals with micro analysis of the selected texts, and it focuses on the textual organization (rhetorical structure) of the text (Blommaert \& Bulcaen, 2000, p. 448; Fairclough, 1995, pp. 57-58), including the language structures used in a discursive event (Fairclough, 1995, pp. 57-58; Rogers et al., 2005, p. 371). This involves the choice and use of vocabulary, grammar, semantics, cohesion and sound patterns from which the discourses and genres are realized linguistically (Jørgensen \& Phillips, 2002, p. 69). From the perspective of grammar, textual analysis pays special attention to the choice of modality.

Identifying between two types of modality (i.e. epistemic and deontic), Fairclough (2003, pp.165-170) defines epistemic modality as entailing "the question of what people commit themselves to when they make statements, ask questions, make demands, or offers." Further, seeing it as being part of knowledge exchange, Fairclough (2003, p.167) reiterates that epistemic modality entails the utterances that speakers make (i.e. assertions) to signal their commitment to truth. Likewise, he defines deontic modality as involving the use of such modal verbs as can, will, may, must, would and should to express one's commitment to obligation/necessity (Faircough, 2003, p.168).

In addition, modal adverbials such as definitely, importantly, surely, certainly, probably, allegedly, possibly are common markers of epistemic modality. Other markers of modality include participial adjectives such as required, supposed and allowed, modal adjectives like probable, necessary, possible, uncertain, evident, imperative (Fairclough, 2003, p.170-171; Rivitoi, 2008, p.41), including mental processes such as I know, think, concerned, feel, wonder, alarmed and suspect among others. These modals as he argues are used for such functions as eliciting information, making demands/requests, making assertions or denials, and asking questions. Moreover, Fairclough (2003, p.167) posits that modality choices play a role in making judgements and/or evaluation, by reflecting what speakers consider "desirable or undesirable, good or bad." As such, modal choices involve both the expression of attitudes (i.e. use of an utterance to signal factuality, degrees of certainty or 
uncertainty, vagueness, possibility, necessity, permission, and obligation, as well as the texturing of both self-identity and social relations (Fairclough, 2003, pp.165-166). Along similar lines, Livnat (2012, p.17) argues that modality choices can be used to articulate an attitude towards a given proposition, given that speakers can express differing attitudes toward the truthfulness of a given message or source of some voice. Further, Livnat (2012, p.17) states that such attitudes can be classified as being neutral, negative or positive, or even irrelevant to given contexts.

Moreover, because this study involves different policy actors, it is assumed that their framing practices could be having persuasive intent. As such, to provide additional perspectives and understandings to textual analyses of the subject under investigation, the rhetorical techniques deployed in the policy texts will be unveiled. This will include the use of topoi.

\subsubsection{Topoi}

Reisigl and Wodak define topoi as "content-related warrants or conclusion rules that connect the argument or arguments with the conclusion, the claim" (Reisigl \&Wodak, 2001, p.75; Wodak, 2011, p.42). Likewise, Hart defines topoi as lines of arguments used to "justify the transition from the premise to the conclusion" (Hart, 2013, p.201). In other words, topoi serve to give a justification for the movement/transition from an argument or arguments to a given conclusion or claim.

In a similar vein, Wodak (2011, p.43) notes that topoi are deployed to justify and thus legitimize particular views by giving what she calls "common places, instead of substantial evidence." Further, citing Kwon, Clarke and Wodak (2009), Wodak (2011, p.42) states that topoi are commonly deployed in debates or meetings for such purposes as negotiating a given agenda, or to convince the audience towards embracing one's viewpoint or vision of reality. In this context, Reisigl and Wodak (2001, pp.76-81), and Kwon, Clarke and Wodak (2009, p.280) identify different types of topoi used by interactants, such as the topos of justice, topos of finances/cost, topos of threat/danger, topos of numbers, topos of definition or nameinterpretation, topos of equality, topos of responsibility, topos of burdening or weighing down, topos of culture, topos of abuse, topos of history and topos of numbers among others.

Analysis of topoi in this study will be done against the background of the list of topoi stated above, and in relation to the different ways in which they are used to justify and thus legitimize or delegitimize particular policy decisions 


\subsection{Operationalization: Method}

This study employs a comparative intertextual approach to explore the interactions between different policy actors, their strategies of engagement (linguistic/non-linguistic, and rhetorical), including their construal of the notion of gender equality.Considering that "there is no single approach to analysing the complex phenomena of intertextuality in written texts" (Wang 2008, p.363), the researcher drew on the key analytical categories in Fairclough's $(1992,1995)$ three-dimensional approach to critical discourse analysis (interdisciplinary approach) discussed in 3.5 above. This was based on the fact that Fairclough's (1992, 1995, 2003) three-tier approach to CDA offers a wide variety of categories/concepts (e.g. genre, hybridity, interdiscursivity, orders of discourse, semiosis, hegemony, and heterogeneity) for describing intertextual relations between and across texts.

Likewise, Fairclough's (2005b, p. 66) approach to discourse analysis involves borrowing particular concepts and categories from different theories and disciplinary fields, and reworking them to enhance the interpretation and analysis of the subject of study (Fairclough, 2005b, p. 66). As Bellier confirms, different methods and theories present a multiplicity of tools with different qualities and impact on the findings of the research (Bellier 2005, p.244). As such, to explore the nexus amongst the three levels of analysis ( i.e. textual practice, discourse practice, and sociological practice), this study will employ the principle of triangulation, i.e. the integration and combination in the analysis and interpretation of a given discourse phenomenon, a multiplicity of methods and approaches, and data from varied empirical sites, including the available historical/background knowledge of the issue under investigation (Fairclough \& Wodak, 1997, p.226;Van Leeuwen \& Wodak,1999, p.92). The interdisciplinary approach enables the researcher to make informed interpretations of his research findings, using information from multiple empirical sites. This is demonstrated in the analysis chapters 4,5 , and 6 , which pay particular attention both to action at macro and micro levels of analysis.

\subsubsection{Identification of potential data sources}

This study is based on qualitatively gathered data from publicly available documents written by the primary discourse communities/policy actors (Kenyan government, women's NGOs, and the United Nations Committee in charge of women's rights) that are actively involved in the implementation of gender equality policies in Kenya. This was based on the expectation that the combination of different data sets from the aforesaid discourse 
communities could provide "a variety of analytic entries that will answer the proposed research questions" (Akerstrom, Yakhlef \& Basic, 2015, p.35).

Fairclough (1992, p.227) provides a formula for investigating changes in a discourse. In this context, he recommends that the selection of texts/data for analysis depends on such factors as the nature of the research questions to be answered, and the nature of the research project. Likewise, Fairclough (2005a, p15) suggests that any investigations involving transitions ought to include texts that mirror: (1) the emergence of a discourse; (2) the hegemonic struggles and/or "moments of crisis" (Fairclough, 1992, p.230) relating to significant discursive events linked with the issue/discourse under investigation; (3) the different ways in which a discourse is recontextualized; and (4) the operationalization of a discourse within varied contexts of practice. On these grounds, the present study selected the period 1995 to 2005 as its primary focus for three main reasons. First, the years 1995 - 2000 mark moments of crises in the history of the discourse of women's rights in Kenya, when, as will be shown in the following chapters, the discursive acts of different actors in the policy process triggered and responded to significant actions that prompted changes in the policy text. Also, the rights of women were declared human rights in the 1995 fourth world conference on women at Beijing, thereby affording them the prominence that triggered the agitation for women's rights in Kenya. Second, the year 2000 is the time when Kenya signalled her commitment to implement and promote the rights of women by enacting the national gender and development policy 2000. Third, the study covers the period from 2000 to 2005 , to allow time for mutual interaction between the policy texts under investigation, i.e. from the date of adopting the national gender policy.

According to Leitch and Palmer (2010, p.1199), "given the heterogeneous nature of both CDA and organization studies, there is room for debate as to the basis for inclusions and exclusions" from a given database. Based on this criteria, only texts addressed to women's rights and making reference to the implementation of women's rights in Kenya were selected for the current study.

\subsubsection{Data Collection}

The above said time period for the study imposed a limitation on the amount and type of data, in terms of the texts to be included or excluded for analysis. In this context, the selection of texts for analysis was done in five steps as follows. First, I did electronic searches 
on the key policy actors' institutional websites for information about documents concerning women's rights/gender equality. Second, I listed the relevant body of documents identified through electronic searches as meeting the study criteria. Third, I printed the identified documents, and read them in full for a general idea concerning the prevailing understandings regarding gender equality. This was followed with a critical reading of the key policy actors' chain of related documents from the perspective of intertextual relations (Fairclough 1992, 1995), to establish the semantic relations and intertextual links between texts. This helped to deepen my understanding of the social practices that underlie the context of study. Finally, texts reflecting the principal policy actors' interpretation of, and responses to, gender equality policies were selected.

Following from the above said process for identifying data for analysis in this study, a total of 30 documents/articles were selected as reflecting interactions typical of policy making process between and amongst the different policy stakeholders in Kenya. The dataset include, the Kenyan government's official gender policy documents, NGOs' annual reports, NGOs' evaluation/assessment reports, speeches by NGOs' representatives, transcripts from the Kenyan parliament (Hansard reports), and newspaper commentaries. In this context, precise reference was made to 24 texts. These texts were taken to be representative of the numbers of each type of interaction that did occur (Mcenery \& Hardie, 2012, p.9) between policy actors, and that were relevant to the researcher's topic of study.

\subsubsection{Data Analysis}

Consistent with Fairclough's $(1992,1995,2003)$ three tier approach to discourse analysis discussed above, the researcher used a combination of the methods of linguistic analysis, intertextual/interdiscursive analysis, and socio-cultural analysis to analyse the data for this research. In this context, data analysis was carried out in three stages as highlighted below.

First, using Fairclough's (1992, 1995) concepts of intertextuality (i.e. manifest intertextuality and constitutive intertextuality/interdiscursivity) as the guiding principle, I identified the semantic relations and shared themes between policy texts written by the principal policy actors in this study. This was achieved by looking at the different ways in which policy actors' texts draw on and are built out of other past texts through such techniques of discourse representation as quotation marks, paraphrase, copying/imitating, 
including the use of irony, and presuppositions among other strategies (Fairclough, 1992, p. 271; Jorgensen \& Phillips, 2002, p. 73) (see chapters 4, 5, and 6). For instance, analysis of data in 5.5.2 shows how the Kenyan government uses the linguistic feature of irony through imitating/reformulating feminist discourses of gender equality, as part of its oppositional strategies for questioning the power and legitimacy of those championing gender equality policies in Kenya.

The second stage of data analysis involved exploring the linguistic and rhetorical strategies used in texts to position policy actors in relation to gender equality policies. In this context, I identified the use of linguistic categories such as mental processes (see 4.4.3 and 4.5.2), comparison (see 5.4.6), negation (see 4.4.4 and 5.5.7), contrastive connectives, and modality (see 4.4.4, 4.4.5 and 4.6.1) used to describe women and their rights to gender equality. For instance, in my analysis of modal choices (deontic and epistemic modality) (see 4.4.6) made in the policy texts, I looked at the different ways in which modal auxiliary verbs (e.g. must, should, will/would be) are used to express levels of intimacy/affinity, involvement or commitment to given events and actions. This included a focus on the manner in which policy actors could be using modality to distance themselves from the propositions they make (Baker \& Galasinski 2003).

Finally, policy actors'conceptualization of gender equality was examined by looking at the different ways in which policy actors' linguistic choices manifest their differing conceptualizations of gender equality policies, including power differentials and control over given meanings. For instance, in 4.4.4 and 6.3.6, efforts were made to identify the particular elements of vocabulary deployed to present new norms and principles that define how issues of women are to be understood. This is in line with Fairclough's (1992, p.191) advice that whenever we introduce or change the wording in a text, we also change and introduce new meanings and lexical structures. Moreover, using Fairclough's (1992, 1995) analytical categories of intertextuality and interdiscursivity, the policy actors' differing conceptualizations of gender equality were determined by examining their creative mixing of varied discourses concerning gender equality (e.g. 5.5.1-5.5.4, 6.3.3, 6.3.5).

Likewise, analysis of the policy actors' interpretation and understanding of gender equality in this study involved examining how the UN's/CEDAW's gender equality policies are cued, negotiated, and responded to (Prior, 1995, p.295) by Kenyan policy makers (see chapters 4, 5, and 6). In this context, the categories/metaphors of polyphony (see 4.4.3), authoritative and internally persuasive discourses that underlie Bakhtin's $(1981,1986)$ notion of dialogism (see chapter 4) were used for making sense of the different ways in which the 
policy actors understand the notion of gender equality, including the strategies they use to endorse or challenge the monologism of universal views and normative discourses being emphasized by the United Nations/CEDAW. 


\section{UNITED NATIONS' AND KENYA'S DISCOURSE OF WOMEN'S RIGHTS}

\subsection{Introduction}

This chapter is the first of three to investigate through concrete textual analysis whether the policies relating to women's rights and gender equality initiated in Kenya between the years 1995 and 2005 should be attributed to the United Nations' leverage (i.e. following the Beijing imperatives), or in addition truly reflected Kenya's policy makers' own willingness to pursue social justice-oriented reforms. This question is based on the premise that the United Nations' discourse of human rights has had immense influence on governments' policy choices regarding the implementation of women's rights to gender equality (Bunch, 1990; Coomaraswany, 1999).

In this context, the analysis in this chapter highlights: (1) the discursive strategies employed by the United Nations to induce Kenya's adoption of a gender perspective with regard to issues of women; and (2) the linguistic and rhetorical mechanisms employed by the Kenyan government, either to show compliance with the Beijing imperatives and implement women's rights or avoid doing so by discursively circumventing the United Nations' agenda. This will shed some light on the nature of the discursive relationship between the United Nations (henceforth UN) and the Kenyan government, by reflecting the extent to which Kenya's policy choices, and implementation of women's rights could be due to its intertextual interactions with the UN's bodies in charge of women's human rights. The next chapter will focus in a similar way on the nature of the intertextual relationship between the Kenyan government and women's non-governmental organisations (NGOs) in relation to the universal discourse of women's rights being proposed by the UN/CEDAW. The chapter following that will explore intertextual links and historical developments visible in the government's own official texts over the period studied.

To make sense, then, of the relations between the UN and Kenya between the years 1995 and 2005 that are the focus of this study, this chapter will consist of an in-depth analysis of the textual exchanges between the UN's organization in charge of women's rights and the Kenyan government. This involves, first, analysing the different ways in which the questions asked by the UN through such genres as assessment reports and interviews are cued, understood and responded (Prior 1995) to by the Kenyan government. And secondly, analysis will be made of the assessment by the Committee on the Elimination of Discrimination Against Women (henceforth the Committee) of Kenya's periodic reports to the UN's bodies 
in charge of women's rights.

To briefly recapitulate the background provided in chapter four, Kenya as a signatory to the Convention on the Elimination of Discrimination against Women (CEDAW) is required to regularly report on progress it has made towards enacting the recommendations issuing from the Committee. Because the convention is non-binding, this is effectively government by textual forms of persuasion and response, of conduct and counter-conduct, involving, in principle, textual exchange and dialogue. So the following analyses focus on the following three texts as exemplary of this ongoing process of exchange:

- The combined third and fourth reports of the Kenyan government, due in 1998 but not delivered until February 2000 (a lateness on Kenya's part that has been typical of its reporting conduct and is of rhetorical significance in itself).

- The official UN report of the face-to-face meeting between the Kenyan government's delegation and the Committee, held in New York in February 2003, to allow the Committee to seek further information and insights concerning the situation of women in Kenya.

- The Committee's formal written assessment of Kenya's progress including recommendations for further action by Kenya, issued in March 2003.

Moreover, to get the gist of the historical context of Kenya's intertextual interactions with the UN, I will include a brief summary of texts dating from 1993, when the Committee released its assessment report of Kenya's combined first and second periodic reports to the UN. This means that the information provided in section 4.2 below is specifically designed to provide an intertextual background to Kenya's past understandings and history in aligning its discourse of women's rights with the universal human rights norms.

In order to interrogate the impact of the discursive interactions between the UN and the Kenyan government in terms of the effects of their actions and strategies on the understandings of gender equality, I give particular attention to Bakhtin's theory of authoritative discourse and internally persuasive discourse (Bakhtin, 1981) introduced in chapter three of this study. In my view, concepts of authoritative and internally persuasive discourse are very relevant for making sense of the discursive interactions between the UN and the Kenyan government with regard to the implementation of women's rights. 


\subsection{Summary of the initial exchange between the Kenyan government and the Committee.}

This section summarises Kenya's initial and second periodic reports to the CEDAW Committee (abbreviated as Kenya 1993) combined into a single submission as a result of Kenya failing to meet the deadline for the first report. Because of our interest in the trajectory of textual exchanges between the Committee and the Kenyan government, the discussion in this part includes a brief description of the thematic areas of concern at the centre of their interaction.

In its combined report, the Kenyan government identified cultural attitudes, women's low educational and economic status, and discriminatory laws governing marriage and divorce as some of the factors hindering women's rights to gender equality (Kenya, 1993, p.1). The report went on to state that the Kenyan government had instituted a number of policy measures to implement the Convention. These included the introduction of the 8.4.4 system of education, which "did away with the stereotyped roles of men and women", as well as the ongoing plans to enact "a gender and development policy" to facilitate equality between men and women in Kenya (Kenya, 1993, p.1).

In its assessment, the Committee pointed out that the Kenyan government's reports failed to provide sufficient statistical data, and had not complied with the general guidelines regarding the form and content of reports (Committee 1993, p.2). Specifically, the Committee claimed that the Kenyan government's reports lacked information regarding "the specific problems met by women," and "the policy interventions" designed to curb them, including explanations as to "why the Government had not undertaken special measures" to solve them (Committee, 1993, p.5).

Concerning women's discrimination, the Committee acknowledged that Kenya's report had to be assessed "against a background of specific cultural attitudes," which in its view had a significant effect on the situation of women (Committee, 1993, p.2). However, insisting that the Kenyan government was fully aware of the particular "discriminatory provisions" given in the Kenyan constitution, because the word "sex" was not included in the article defining discrimination (Committee, 1993, p.3), the Committee asked: (1) whether the concept of discrimination based on the grounds of gender could be added to the Constitution; and (2) for an explanation concerning how the Convention was being applied in Kenya.

As appertains to women's representation in decision making structures, the Committee noted that though women constituted a higher percentage of voters, "they were hardly represented in higher political office" (Committee, 1993, p.2). The Committee pointed 
out that "It would be difficult for women to promote themselves if they could not participate in the planning and development of the country" (Committee, 1993, p.2), and stated that in order for the Kenyan women to effectively participate in decision making structures, the Kenyan government was under obligation to ensure their literacy, considering that "half of the female population was illiterate" (Committee, 1993, p.3). In this regard, the Committee sought further elucidation concerning: (1) whether the Kenyan government had put into place any "special temporary measures" to improve the status of women; (2) whether affirmative action policies had been discussed in the Kenyan parliament; and (3) whether the Kenyan government had received any requests from the "women's groups for positive measures," to promote the status of women (Committee, 1993, p.4).

Regarding gender-based violence against women, the Committee asked the Kenyan government to provide additional information appertaining to laws on rape, female genital mutilation (FGM)/circumcision of girls and women, domestic violence, and trafficking of women (Committee,1993, p.5), including whether the aforesaid laws were being enforced in line with the dictates of the Convention (Committee, 1993, p.5). Moreover, emphasizing discrepancies in the report, the Committee argued that it consisted of contradictions regarding the education of boys and girls (Committee, 1993, p.8). In this context, the Committee sought information as to why many girls were dropping out of school, including the steps that the Kenyan government had taken to correct the situation (Committee, 1993 pp.7-8)

On women's health and reproductive rights, the Committee asked for further explanation concerning whether the Kenyan government was offering "sexual education" and awareness campaigns on contraceptive use as part of the nation-state's efforts to stop the spread of HIV/AIDS among women. In addition, the Committee requested the Kenyan government to provide additional information concerning: (1) the presidential decree banning female genital mutilation, including its effects and implementation process; (2) legislation and statistics on abortion; and (3) whether Kenyan women were entitled to paid maternity leave, and job security after such a leave (Committee, 1993, p.9).

In addition, the Committee asked whether Kenyan women were aware of their rights, including their entitlement to property ownership, disposal and inheritance rights on equal basis with men. And citing insufficient data concerning land ownership, the Committee sought clarification as to whether there were any legal provisions guaranteeing men as the sole owners of land (Committee, 1993, p.11). 


\subsection{Text 1: Consideration of reports submitted by states parties under article 18 of the Convention on the Elimination of All Forms of Discrimination against Women: third and fourth periodic reports of states, Kenya, $14^{\text {th }}$ February, 2000.}

This section analyses the Kenyan government's formal written report (henceforth Kenya 2000) to the Committee, as a response to the Committee's queries summarised in the previous section. It is also worth noting that this report formed the basis for the Committee members' questions (see 4.4 below) to the Kenyan delegation to the United Nations headquarters in New York, USA. For reasons of limited space, this particular analysis, rather than working consecutively through the report, will identify and illustrate what appear to be the main linguistic strategies informing the government's presentation. It is acknowledged that this approach runs the risk of "cherry-picking" linguistic elements that support the conclusions favoured by the researcher. However, one of the benefits of conducting an intertextual study is that analysis of a single text can be tested for its consistency with other texts in the chain. And to that end, the analysis of the report of the oral meeting between the Committee and the Kenyan government delegation in the following section will follow closely the trajectory of the discussion and this can be expected to expose accurately the tenor of the relations between the parties and therefore help to confirm the more selective approach adopted in the current section.

\subsubsection{Balancing an authoritative discourse}

It soon becomes clear that the Kenyan government, while prepared to claim a commitment to women's rights, is unwilling to surrender sovereignty to an international agency. In evoking the common law to underwrite its actions, the government lays claim to an authoritative discourse that ultimately supersedes its commitment to the notion of universal rights and even results in presuming to tutor the UN committee rather than attempt to foster an internally persuasive dialogue.

The groundwork for this manoeuvre is laid in the preamble to its report, when the Kenyan government uses manifest intertextuality to reiterate its unquestioned commitment to the promotion of issues of women, but discloses at the same time an overriding national imperative:

The government of Kenya has remained committed to the advancement of women, as is reflected in progressive inclusion of women's agenda in the 
national development plans and projects. The Key national documents, both sectoral and multi-sectoral, categorically outline the government's development approach from a gender perspective (Kenya, 2000, p.2, my emphasis)

In this text, the government seeks to establish good interpersonal relations with the Committee, hence secure its confidence as a concerned and willing partner in implementing women's rights. This is enacted through manifest intertextual references to the notions of "commitment," "advancement of women" and a gender perspective attributed to articles 1-38 of the Beijing Declaration and Platform for Action (United Nations, 1995) that obliges the $\mathrm{UN}$-member states to dedicate their efforts toward the empowerment of women by implementing national policies espousing a gender dimension. That is, in addition to emphasizing the need to ensure "The empowerment and advancement of women," through their "full and equal participation" in "economic and social development," the Beijing Declaration and Platform for Action asks governments of the world to adopt and commit themselves to "implement the Platform for Action, ensuring that a gender perspective is reflected in all our policies and programmes of the world to reaffirm their determination" (Art.12-38, United Nations 1995). In this context, the intertextual linking of the Kenyan government's policies of gender equality to the UN's normative discourse of women's rights seeks to establish a sense of compliance to the UN's norms, thereby affording them (policies) some legitimating authority. Interesting though, is the manner in which the government's text is interdiscursively framed to accommodate other discourses such as those of "national development plans and projects," pointing to the existence of other competing voices in its discourse of women's rights. Indeed, it is telling that these populist discourses are accorded the priority of being the container in which the women's agenda is to be included.

Subsequently, the Kenyan government informs the Committee, which does not need to be told, that in line with "the common law doctrine" being used in Kenya, matters of international law do not affect the national law, unless the government enacts and /or legislates their incorporation into the Kenyan law (Kenya, 2000, p.2). This is better captured in the Kenyan quotation below:

In the common law doctrine, which is in operation in Kenya, International law does not affect the municipal law of the country unless parliament has specifically enacted or in some other legislative way incorporated it as the law of Kenya (Kenya, 2000, p.2). 
This statement was in response to the Committee's raising the issue of the Kenyan government's non-compliance with the Convention in its 1993 assessment, to which the report being analysed here is the direct response. That is, the Committee had sought clarification concerning how the Convention's rules and regulations were being applied in Kenya, in addition to asking for detailed information regarding any significant changes that the Kenyan government had instituted to align its laws with CEDAW's imperatives (Committee, 1993, p.12). According to Bakhtin, authoritative meanings occur in a number of forms such as: 'authority of tradition; religious decrees; generally acknowledged scientific truths, or an official ideology" (Bakhtin, 1981, pp. 342-343, cited in Tuler, 2000, p.4). Also, echoing Bakhtin, Matusov notes that authoritative discourse can be based on such factors as "authority of power, imposition, tradition, and ignorance" (Matusov, 2007, pp.229-233). Thus, in Bakhtinian terms, by invoking "the common law doctrine, which is in operation in Kenya," the Kenyan government can be said to be wanting to exercise exclusive authority over the manner in which meanings of gender equality ought to be defined in Kenya, thereby defying the alternative ways of thinking being proposed by the Convention. This means that though the Kenyan government's introduction to these reports initially espouses a dialogic mode of interaction (i.e. internally persuasive) by making manifest intertextual references to the notions attributed to the UN's discourse of women's rights, it is as well authoritative in as far as it seeks to exercise exclusive authority over how issues of women ought to be defined within its national boundaries. This understanding can be deduced from the text "unless parliament has specifically enacted or in some other legislative way incorporated it as the law of Kenya" in the extract above. In this context, the connective "unless" in the phrase "unless parliament..." introduces not only the "argumentative character" of the policy text under discussion, but also the underlying ambivalent feelings towards the universal rights of women. That is, it serves to explain the reason for the existing incoherence between the Kenyan law and the "International law," including the institutional restrictions (local orders of discourse) that make it hard for the aforesaid Kenyan law to comply with the international law concerning women's rights. As (Van Eemeren et. al., 2007, p.4) argue:

Argumentation is put forwad as a response to, or in anticipation of, a difference of opinion, and serves a function in the regulation of disagreement. In principle, the argumentation that is advanced is geared to resolving a difference of opinion by providing a justification - or refutation - of the 
standpoint under discussion, thus ending any doubts about the acceptability of this standpoint

This demonstrates an underlying refusal to engage in the dialogue that Bakhtin (1984) emphasizes in expressing the need to move away from the authoritative discourses of control, to internally persuasive critical discourses that embrace collaborative thinking towards locating lasting solutions for problems in society:

in an environment of...[excessive] monologism the genuine interaction of consciousness is impossible and thus genuine dialogue is impossible as well. In essence... [excessive monologism] knows only a single mode of cognitive interaction among consciousnesses: someone who knows and possesses the truth instructs someone who is ignorant of it and in error; that is, it is the interaction of a teacher and a pupil, which, it follows, can be only a pedagogical dialogue (Bakhtin, 1984, p.81, cited in Matusov, 2007, p.235).

Upon defining government as the conduct of conduct (Foucault, 1982), Foucault emphasizes that a more nuanced understanding of power relations demand an analysis of the "system of differentiations which permits one to act upon the actions of others" (Foucault, 1994, p.230). In this context, Foucault stresses the need to look at differentiations based on and/or determined by such factors as "the law," or "traditions of status and privilege," including cultural differences with which they are articulated (Foucault 1994, p.230). On these grounds, the invocation of "the common law doctrine" above can be said to signal the existing discursive tensions between the universalist perspectives of women's rights held by the Committee, and the cultural relativist viewpoints being espoused by the Kenyan government. In this context, the mentioning of "the common law doctrine" can be argued to symbolize a form of protest being played out by the Kenyan government, one that is against the normative rules trying to frame how it (Kenya) ought to conduct itself in dealing with women and their issues.

Along with this early move to an authoritative discourse, which can be said to anchor the text, the government draws on all the textual resources available to it in an attempt to reassure the Committee that it is genuinely dedicated to change and the advancement of women. Using the topos of history (Kwon, Clarke \& Wodak, 2009; Chang and Mehan, 2008; Reisigl \& Wodak, 2001), the Kenyan government's report proceeds to list the policy initiatives that have been put into place by the Kenyan government in favour of women, 
without acknowledging, it should be noted, the largely unfinished status of these initiatives. These include: (1) the 1998 tabling of the Draft National Policy on Gender and Development; (2) the ratification of the Convention by the Kenyan government in 1984; (3) the 1993 creation of the task force to review laws relating to women; (4) the 1998 initiation of the Constitution of Kenya Review Commission (henceforth CKRC); (5) the 1976 establishment of the Women's Bureau as the national organ for the advancement of women, which in the government's view was "a clear determination to improve the status of women" (Kenya, 2000, p.3). Evidently, the tabling of the aforesaid "Draft National Policy on Gender and Development" draws from the Committee's interactions with the Kenyan government concerning its (Kenya's) Combined Initial and Second Periodic Report (see 4.2 above). In this context, the Kenyan government could be said to have "recognized the need for a gender and development policy" (Committee, 1993, p. 1), to provide a national framework for mainstreaming gender issues into the national development process. Returning to Bakhtin's concept of internally persuasive discourses (Bakhtin, 1981, 1986), the listing of various initiatives to promote gender equality can be argued to be a rhetorical strategy, and an internally persuasive move to influence the Committee's perception of Kenya, as a committed government in implementing the UN's mode of women's rights. This rhetorical import comes to surface when the government asserts that:

Taken together, the setting up of the Task Force to review all the laws relating to women and children, the ongoing Constitution Review Process, the Proposal to establish the national Gender Policy and proposed National Council for Gender and Development are far reaching legislative, political and administrative developments which augur well for the establishment of institutionalized mechanisms for ongoing and dynamic implementation of the measures provided for in the convention (Kenya, 2000, p.5, my emphasis).

From Bakhtin's perspective as Matusov contends, dialogical authority can be garnered through combining "reified past and anticipated" future internally persuasive discourses (Matusov, 2007, p.234). Thus, ideologically speaking, these propositions are aimed at promoting the government's ideological aspirations, as one that has historically supported matters concerning women.

But the anchoring authoritative discourse soon returns to the surface as the report gives a tutorial regarding the various feminist strategies - Women in Development (WID), and Gender and Development (GAD) in the development process, including their failures 
(Kenya, 2000, p.4). The intertextual reference to the feminist notions of WID and GAD concerning women's involvement in the development process appears in context to be intended to demonstrate the policy makers' presupposed grasp of the feminist perspectives informing their national policies, hence their claim to authority based on expertise in feminist viewpoints regarding women and their issues. This enables the government to assert its status of being knowledgeable about gender equality policies.

\subsubsection{Weasel words}

In response to the Committee's request in the previous reports for detailed information concerning the laws discriminating against women and how the Convention was being applied in Kenya, the Kenyan government acknowledged that though amendments to the Kenyan constitution had been made to include sex as the basis for discrimination, the existing legal definition in the Kenyan law did not embrace all the rules and norms of the Convention (Kenya, 2000, p.5). In addition, using the topos of definition (Reisigl \&Wodak, 2001), the government stated that the discriminatory clause in the Kenyan constitution had been identified and amended in November 1997. In this context though, the government asserted that:

It is significant to note that sections $82(4)(\mathrm{b} \& \mathrm{c})$ of the constitution reserves the right to discriminate in matters of adoption, marriage, divorce, burial, devolution of property of death, customary and personal law, areas of law that more affect women. However, this must be seen in context since Kenyan society is composed of various ethnic groups with different customs and practices (Kenya, 2000, p.5, my emphasis)

The use of the intensifying adjective "significant," and deontic modality "must," associated with authority (Fairclough, 2003) in the text above, point to the government's ideological aim of wanting to legitimize its claims. Such framing style positions the Kenyan government as having an upper hand, hence its authority to decide unilaterally what it considers appropriate for Kenyan women. Subsequently, the Kenyan government proceeds to list a number of institutions that had been set up, which in its terminology "had been deliberately formed" and constituted "a strong force in reacting to discriminatory laws, policies and practices violating women's rights" (Kenya, 2000, p.6). The phrase "deliberately formed" is, as an unnecessary tautology, rhetorically used to stress the government's active 
agency in addressing the situation of women. A similar effect is created through the use of evaluative language, "a strong force". However, the phrase "a strong force" (intensifier) entails an example of the weasel terms (i.e. words that seem to say something important but fail to do so in the real sense (Lapakko, 2014), that characterize the Kenyan government's discourse of women's rights. Further examples can be seen in the extract from the report given at the end of the previous section, featuring the self-regarding booster terms "far reaching" and "dynamic." According to Bhatia (2006, p.190), such use of language without having to explain the intended meaning entails an evasive strategy, one that is aimed at controlling the type and extent of information given while interacting with others concerning particular issues of concern in society.

With an intertextual reference to the Kenyan constitution, the Committee inquired how the Law Succession Act of 1981, (i.e.law governing inheritance, ownership, management, and control of property/estates of deceased persons, Republic of Kenya, 2010, pp.7-8), relates to the Kenyan women and its effectiveness in enhancing ethnic diversity (Committee, 1993, p.3). In its words, the Committee stated that:

With regard to article 2, the Committee noted that the Law of Succession Act of 1981 was mentioned in the report, and wished to have more detailed information on that Law in relation to women and how effective it was in the context of ethnic diversity (Committee, 1993, p.3).

Answering the Committee's question in the text above, the government reiterated that the enactment of and operationalization of the Law of Succession Act in July 1981 "has been a major step towards equality as is envisioned by the Convention" (Kenya, 2000, p.6, my emphasis). Also, the government stated that the law had offered a standard framework for property ownership, disposal and inheritance rights on equal basis between men and women (Kenya, 2000, p.6). The repeated use of formulations relating to the Convention above such as: (1) "has been a major step towards equality as is envisioned by the Convention"; (2) "furtherance of the state's obligations under the Convention"; and (3) "implementation of the measures provided for in the Convention" (Kenya, 2000, pp.2-5) points to the requirements in place for the Kenyan government to reproduce, and thereby sustain the existing UN's conventions on the rights of women.

Chilton and Schaffner note that "boasting about performance" and "positive selfpresentation are part of the techniques that actors can use to legitimize given actions" (Chilton \& Schaffner, 2006, p.213). Within this frame of reference, "a major step" in the 
phrase "has been a major step towards equality" above serves to legitimize the government's claims regarding the success of the law in question. A similar feeling is enhanced through the use of the present perfect tense marker in the verb phrase" has been" above, to suggest that the law in question has historically been in force. Again, from Lapakko's (2014) perspective of weasel terms, the bit "a major step" can be explained in terms of weasel phrases that are evaluative in nature. This means that phrases such as "a major step" and a "strong force" as discussed above cannot be quantified in order to demonstrate the extent to which the law of succession has helped the Kenyan government towards promoting the rights of women. Additionally, the text as "envisioned by the convention" is an aspect of "simulated equalization" (Fairclough, 1989, p.184, cited in Machini and Mayr, 2012, p.45), whereby the government's text is framed in ways that seek to present the state policy practices as operating on an equal footing with the Committee's understandings.

\subsubsection{Appeal to cooperation}

The government states that it was working in collaboration with other policy actors to eliminate stereotypes on "women and men" (Kenya, 2000, p.12, my emphasis):

The Government, NGO, Religious Organization and Civil Society have been involved in programmes targeted to remove stereotyping on women and men... However, such efforts meet hindrances impacted by traditional practices, lack of men's involvement, illiteracy and poverty.

This statement was in response to the Committee's request for more information regarding "the results and obstacles that the legislation was encountering, and the other measures that had been taken to change stereotyped images of women" (Committee 1993, p.6, emphasis added). In this context, for instance, the government identifies FIDA-Kenya as one of the women's NGOs that it was working in collaboration with, to train police officers about the rights of women (Kenya, 2000, p.12). This was in response to the Committee's query as to whether the Kenyan government was working in collaboration with the women's NGOs in implementing gender equality policies. Also, the Kenyan government's text regrets that the efforts to foster the realization of women's rights were, "however" (note contrastive connective to be discussed in the next sub-section), being hindered by "traditional practices, lack of men's involvement, illiteracy and poverty" (Kenya 2000, p.12), probably to suggest the complexity of other issues impeding its efforts to promote gender equality. 
From Bakhtin's notion of dialogism, the language of collaboration points to the significance of working together when creating meanings and understandings concerning a given issue. However, as Skilling (2010) advises us below (see 4.4.1), the use of language that appeals to cooperation entails a rhetorical strategy to suggest shared goals. This implies that the government's emphasis on working with NGOs and other policy makers could be part of its ideological aspirations of wanting to project gender equality as a shared objective between the government and other policy stakeholders.

What is also of considerable interest about the section of the government's text just referred to is how the Kenyan government introduces the notion of "men" in its language of working with other policy actors to eliminate stereotypes on "men and women" (Kenya 2000, p.12). In effect, this borrowing from the African human rights system that emphasizes collective/people's rights (i.e. rights for all persons in society) (Delaet, 2006, p.20; Ness, 1999, p.9), without regard for individual rights and the rights of women, dislodges women as the centre of focus for policies to eliminate cultural stereotypes impeding the realization of women's rights.

\subsubsection{Contrastive connective}

Taking Bakhtin's perspective of polyphony (i.e. the co-existence of a plurality of voices/points of view in one and the same utterance, Bakhtin 1984,1986), Didriksen and Gjestedal argue that the use of argumentative connectives involves a discursive logic, as they carry traces of a plurality of voices (Didriksen, Gjestedal \& Muller, 2013, p.87). Describing argumentative connectives as rhetorical tools for texturing texts, they identify different types of connectives. These are: (1) causal connectives such as "because," "due to," and "as a result of," which enact the textual representation of shared values by presenting arguments as given, hence their role in naturalizing states of affairs in ways that conceal underlying controversies and contestations; (2) contrastive connectives such as "but" and "however," which signal concession and contrast, thereby reinforcing the discursive representation of the opposition between two discourses as expressed in the text; and (3) conclusive connectives such as therefore, thus, and so, used to summarise preceding arguments, as well as to introduce new ideas (Didriksen, Gjestedal \& Muller 2013, pp.97-108). In their conclusion, the authors emphasize that for a more nuanced understanding of the rhetorical role of argumentative connectives such as "naturalization and the discursive representation of shared identities," discourse analysts are under obligation to unveil the underlying semantic elements 
of these argumentative connectives in the texts under investigation (Didriksen, Gjestedal \& Muller, 2013, p.108). From this perspective, the use of the contrastive connective "however" in the extract: "However, such efforts meet hindrances impacted by traditional practices, lack of men's involvement, illiteracy and poverty" (see 4.3.3, para. 1), introduces the discursive polyphony in the government's text, that of wanting to attribute the situation of women to given sources such as “traditional practices, lack of men's involvement, illiteracy and poverty."

A related rhetorical function of contrastive connections involves the effects of the subordination achieved by it. Through manifest intertextuality (Fairclough, 1992, 1995) to the Committee's claims concerning the issue of girls dropping out of school, as well as any special measures/affirmative action measures initiated to curb the problem (see 4.2 above), the Kenyan government states that it had noted a decline in the enrolment of girls in public universities, and that it had introduced affirmative action policy by "lowering the entry points for female students by one point" (Kenya, 2000, p.11). Further, the government argues that the aforesaid affirmative action was in response to its recognition of the centrality of education both to women's economic status, and the nation-state in general (Kenya, 2000, p.11). In a similar vein, the government informs the committee that no affirmative action policies had been introduced in other sectors of government (Kenya 2000, p.11). Despite these positive remarks, with a contrastive argumentative connective "however," the government regrets that the introduction of "cost-sharing" in the Kenyan system of education had compelled many girls from poor families to drop out of school (Kenya, 2000, p.23). The use of the contrastive connective "however" in the text under discussion is significant, as it subordinates a failure to meet the Committee's demands concerning equality in education to what the government takes to be a significant achievement, thereby hoping to minimise and even compensate for the failure.

\subsubsection{Discursive mixing}

Through manifest intertextual reference to its national constitution, the Kenyan government argues that "the law relating to violence against women in Kenya is covered under the penal code that deals with offence against the person," and that "This law is applicable to all persons in Kenya including prostitutes" (Kenya 2000, p.13). Further, the issue of violence against women is interdiscursively framed with other discourses relating to rape, child prostitution, morality and women's sexual services among others (Kenya, 2000, 
p.13). Noticeably, the above said penal code is meant for a genderless individual i.e. "the person." This can be said to be one example of the strategic use of vagueness/strategic uncleanness (Chovanec, 2012) that enables the Kenyan government to deny the lack of a law with a clearly defined focus on countering violence against women. Chovanec warns that implicit denials do promote the reproduction of inequality (Chovanec, 2012, p.70). Such an understanding endorses Fairclough's (1995) emphasis on the need to scrutinize aspects that are often excluded from actions and events in texts. According to Wodak (1997), framing practices that tend to combine multiple discourses, including a change in topics, entail a discursive strategy of seeking to assert some power. This means that through the concept of interdiscursivity (Fairclough, 1992, 1995, 2003), the Kenyan government's text above invokes the issue of violence against women by mixing it with other discourses such as rape, child prostitution, morality and women's sexual services, thereby rationalizing and depoliticizing the issue of gender-based violence against women. This interdiscursivity enables the government to navigate through the committee's queries without having to mention that the Kenyan national laws are not focused on the issue of violence against women, but rather, offences against "the person."

\subsubsection{An ongoing process of problem-solving}

In addition, while responding to the Committee's recommendations discussed above, the Kenyan government uses numerous "un-headed excerpts" (Fairclough, 2001, p.180) from its national policy texts, detailing its previous, present and proposed future policy actions in favour of women. These details are presented in "bullet points" and "numbered points," (Fairclough, 2001, p.180) accompanied with a series of tables that occupy a substantial space of the reports. Very often, the presentation seems designed to produce the effect of much activity, but on closer inspection, what has actually been achieved are decisions which merely set in train processes which are ongoing and of uncertain resolution. For instance, the Kenyan government informs the committee that it had initiated a national commission composed of both men and women mandated:

-To conduct and facilitate civic education in order to stimulate public discussions...

- To collect and collate the views of the people of Kenya on proposals to alter the constitution...

-To carry out or cause to be carried out such studies, researches and evaluations ... 
-The commission is mandated to inter alia:

(i) Examine and recommend improvements to the existing constitution.

(ii) Examine and recommend improvements to the electorate system in Kenya

(iii) Examine and review the place of property and land rights...

(iv) Examine and review the right to citizenship and recommend...

(v) Examine and review the socio-cultural obstacles that promote various forms of discrimination... (Kenya, 2000, pp.8-9).

In this context, by presenting its policy plans by listing the identified areas of concern and scheduling them for a review process, the Kenyan government can be said to be constructing gender equality policies as a managerial process of "problem-solving" (Fairclough, 2001, p.180) through demonstrating a willingness to find solutions to already established problems (but without committing to solutions as they have been requested to do by the Committee). According to Lombardo, Meier and Verloo, transnational feminist activists and scholars of women's rights reject deterministic approaches that present gender equality issues as a fixed concept, and instead emphasize the need for a relational-dialectic conception, one that recognises gender equality as an ever expanding body of scholarship subject to different interpretations and critiques (Lombardo, Meier \&Verloo, 2013, pp.1\& 187).

\subsection{Text 2: Consideration of reports submitted by states parties under article 18 of the Convention: combined third and fourth periodic report of Kenya, $6^{\text {th }}$ February 2003.}

The text under discussion in this section is the report of the oral discussion between the CEDAW committee and the Kenyan officials (hereafter Committee 2003a, and Committee 2003b, reflecting the fact that the morning and afternoon sessions of this meeting were reported independently). The discussion draws from the Committee's initial consideration of the Kenyan government's third and fourth periodic reports submitted to the committee on $14^{\text {th }}$ February 2000 which were discussed in the previous section.

As part of its consideration of these reports, the Committee invited Kenyan policy makers for a meeting at the UN headquarters in New York, on Wednesday 15th January 2003. The meeting (oral presentation session) was principally devoted to discuss Kenya's progress towards granting women full equality, and in line with the Convention's 
imperatives. From the Foucauldian perspectives, the face to face meeting can be said to have been aimed at controlling and steering the on-going policy practices concerning women in Kenya, hence an attempt by the Committee to conduct the conduct of Kenyan policy makers towards promoting the realization of the universal rights of women.

Notice that the face to face interaction involving a question and answer session between the Committee and Kenyan policy makers is part of an intertextual chain of texts and events, meaning that their discussions are to be understood as being "intertextually related to other events and texts" (Fairclough, Pardoe \& Szerszynski, 2006, p.106). That is, it is evident that the face to face meeting is part of a chain of genres, i.e. Kenya's combined initial and second periodic reports to the Committee, and the Committee's assessment of those reports; Kenya's actual written report as a response to the Committee's recommendations emanating from its assessment of Kenya's combined initial and second periodical reports to the Committee; and the present face to face meeting, a "generic device" (Fairclough, 2003, p.30) and managerial means for accessing the government's viewpoint concerning gender equality policies. The chain of communication between the Committee and the Kenyan government discussed in this study follows the sequence summarised in the diagram below:

\section{Figure 2. Intertextual Circuit: Discursive/Intertextual Governmentality}
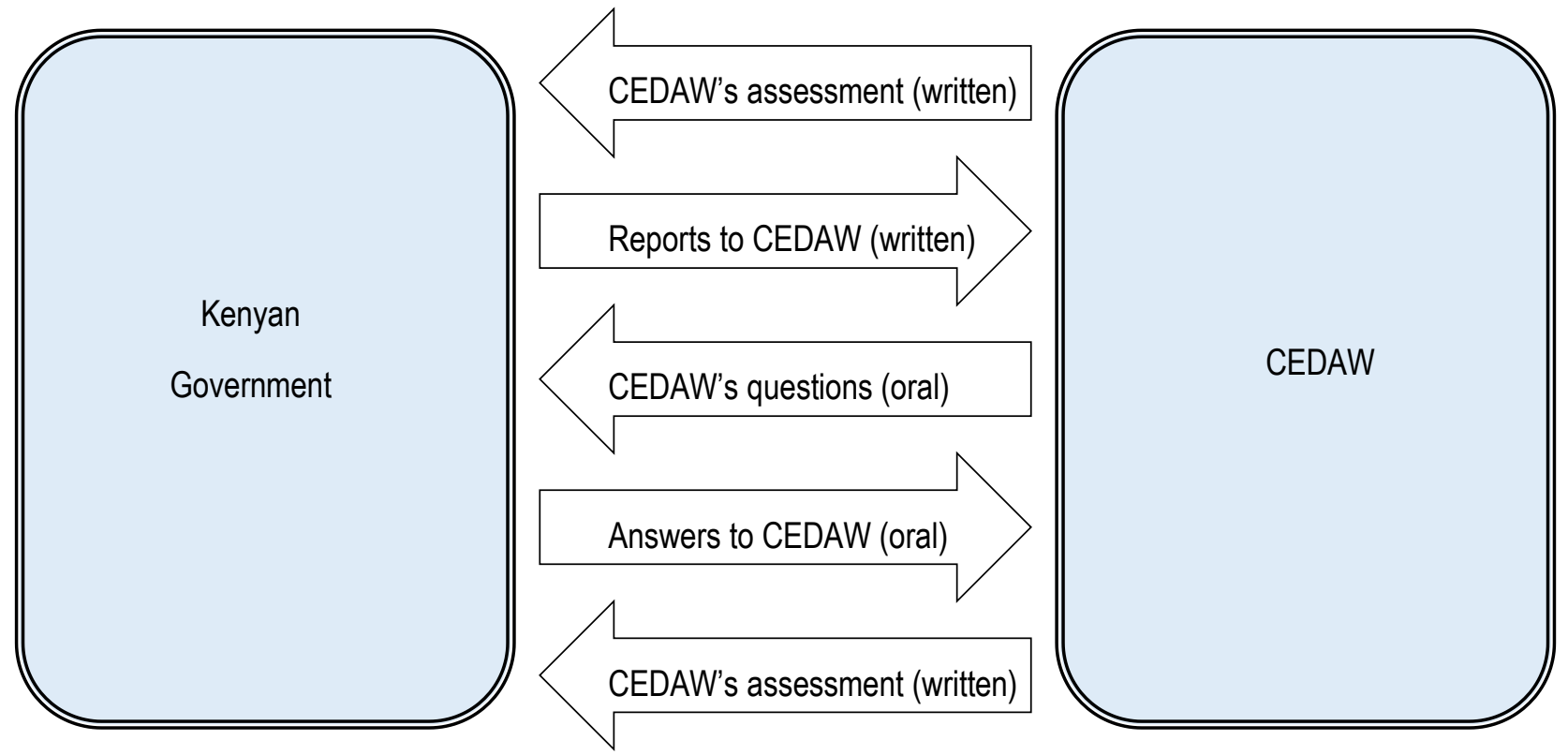

As the arrows in this model illustrate, information on gender equality produced by CEDAW in the form of requests to the Kenyan government involves a series of response rounds of communication. These include the Kenyan government's periodical reports to 
CEDAW, CEDAW's assessment of the Kenyan government's periodical reports to CEDAW, and a face to face meeting involving a question and answer session between the CEDAW committee and Kenyan policy makers.

With regard to questions, Prior argues that modes of interaction that involve questions and answers constitute part of the institutional tools for gauging one's alignment and grasp of given institutional understandings (Prior, 1995, p. 303). Similarly, Livnat notes that questions constitute a significant component of dialogism (Livnat, 2012, p.110). Citing Bakhtin, Livnat points out that questions belong to persuasive genres, and are used as a strategy of dialogism to forge or create rapport (i.e. intimacy and solidarity), thereby enhancing the dialogic involvement of actors in an interaction (Livnat, 2012, p.110). Therefore, the face to face interaction involving questions from the Committee and answers from the Kenyan officials can be argued to constitute an institutional test meant to measure the Kenyan policy makers' disciplinary engagement in terms of how their interpretation of gender equality as expressed both in their past reports and policy texts relate to the actual practices on the ground. In this context, the Committee uses the face to face meeting sessions to check whether the government officials are getting conversant with the norms and principles of the UN's human rights, signifying its authority over the human rights practice. Furthermore, in Bakhtinian terms, such a face to face meeting between the Committee and the Kenyan government's officials signals the Committee's realization that meaningful dialogic interactions had to be based both in authoritative and internally persuasive discourses. That is, the Committee can be said to have initiated a non-authoritative discourse/approach tailored strategically to stimulate a shared attention between the Committee and the Kenyan officials, with the sole aim of winning the Kenyan government's support and trust. This understanding is consistent with Matusov, who contends that more fulfilling dialogical communication commences with a non-authoritarian discourse, that is necessary for winning some trust, thereby laying "a foundation of temporal authority that acts as a precursor for future internally persuasive discourse" (Matusov, 2007, pp.233-234).

It is important to note at this juncture that the written text issuing from this meeting is not a full transcript of what was said, but a third-person summary produced by the Committee. That said, the summary is a very extensive one that approaches paraphrase, and therefore I believe I am justified in treating it as an accurate record sufficient for useful analysis. Ideally, one would have a verbatim record, but none such is available. Therefore, rather than continually remind the reader that a particular speaker "is reported as having said, in the Committee's words" (which would very soon become extremely tedious), I am going 
to make direct reference to the speakers' statements, except in those cases where the analytical point being made relies on attention being given to the exact words used. Since the meeting was conducted as an unfolding conversation, I will maintain that sequential focus in the analysis rather than extract meta-categories from it in an abstract way.

\subsubsection{Opening remarks}

The session opened with Ms Ongewe's (Kenyan official) summary presentation of Kenya's third and fourth periodic reports to the Committee. In her introductory remarks, Ms Ongewe gave particular emphasis to the fact that the Kenyan government was working in partnership with "non-governmental and community-based organizations (CBOs) in implementing the provisions of the Convention" Committee, 2003a, p.2). As Skilling says, mouthing the rhetoric of partnership by parties in an interaction seeks to present given items or ideas as a shared significant goal (Skilling, 2010, p. 39). As such, Ms Ongewe's rhetoric of working with NGOs here can be said to be aimed at presenting women's rights as a shared important objective. Notably, espousing the language of partnership presupposes that gender equality policies are made collaboratively between the Kenyan government and women's NGOs, who work collectively to promote such policies in Kenya.

Continuing, Ms Ongewe stated that a new government had been sworn in which was to be guided by "the principles of democracy, good governance and the promotion and protection of human rights" (Committee, 2003a, p.2). Rhetorically speaking, by seeking to merge Kenya's professed values of democracy with the UN's core values of democracy and human rights, Ms Ongewe can be said to be wanting to image her government in a new light, as one that respects human rights norms that underlie the UN's strategic objectives.

Ms Ongewe then enumerated the government's progress in championing the rights of women, by stating what can be said to be the principal initiatives for bringing about gender equality policies. Among other things, she outlined: (1) adoption of affirmative action policies in favour of women; (2) the elevation of the Women's Bureau (i.e. national machinery for the advancement of women) to a fully-fledged department within the Ministry of Gender, Sports, Culture and Social Services; (3) the 2001 enactment of a poverty reduction strategy paper to provide a framework for eradicating poverty; (4) formation of a thematic group to guide national development and collaborative efforts; (5) publication of a new draft constitution, which "represented a milestone for the women of Kenya because it contained provisions to empower women and eliminate discrimination"; (6) proposal of the Domestic 
Violence (Family Protection ) Bill 2002 to address the issue of violence against women; (7) proposed creation of a fund to offer financial aid, shelter, counselling and legal services to the women victims of domestic violence; (8) increase in the number of women participating in politics and decisionmaking; and (9) the introduction of free primary education policy that had helped to boost the enrolment of girls in school (Committee, 2003a, pp.2-3). These initiatives are stated in the exerpt below:

Kenya recognized that gender inequalities persisted and was committed to ensuring that gender equality was promoted as a necessary precondition for national development and the realization of the full potential of each and every Kenyan. It undertook to ensure the removal of social, cultural and legal obstacles faced by women, including through affirmative action, and would encourage participation of non-governmental and community-based organizations. Accordingly, the National Machinery for the Advancement of Women, or the Women's Bureau had been elevated to a full Department of the new Ministry of Gender, Sports, Culture and Social Services. The challenge facing Kenya was to reduce poverty and achieve sustainable economic growth. A Poverty Reduction Strategy Paper (PRSP) had been prepared in 2001 with a view to implementing the National Poverty Eradication Plan in a series of three year instalments. A gender theme group had been formed... A new draft Constitution had been published on 27 September 2002 and was awaiting consideration by the National Constitutional Conference before being introduced in Parliament... In order to address the problem of domestic violence against women, the Domestic Violence (Family Protection) Bill 2002 proposed the establishment of a fund to provide financial assistance, shelters and counselling and legal services for victims of domestic violence. There had been a gradual increase in the number of women participating in politics and decisionmaking...The increasing visibility of women in key positions was indicative of the trend towards the elimination of gender stereotyping and increased awareness of women's issues. A policy of free, compulsory primary education had been instituted leading to an unprecedented increase in enrolment of girls in primary schools (Committee, 2003a, pp.2-3, my emphasis). 
What is significant here rhetorically, is the listing and sequencing of accumulated evidence of initiatives to enact the government's intervention to alleviate gender inequality. According to Chang and Mehan (2008), Reisgil and Wodak (2001), and Kwon, Clarke \& Wodak (2009), the topos of history (i.e. event sequencing in this discussion) entails an argumentation strategy commonly used in political discourse, and one that is often laden with a manipulative intent. Similarly, Tardy (2011, p.66) stresses that references to past accomplishments represent one of the rhetorical strategies for gaining credibility for one's stated actions and plans. Based on these accounts, Ms Ongewe's manner of presenting ideas (i.e. policy claims followed with listed evidential policy actions/events) above, can be said to constitute a rhetorical strategy tactfully tailored to persuading the Committee to embrace an understanding that projects the Kenyan government as being committed to fulfilling its mandate of granting equality rights, thereby raising its (the Committee's) comfort level. In other words, these initiatives and the manner of their presentation constitute a persuasive device for anaesthetizing and diffusing the Committee's radical call for change in Kenya.

Also, deploying the topos of change (Reisgil \&Wodak, 2001), Ms Ongewe argued that the aforesaid "new draft constitution" had been enacted as part of the legislative measures to curb injustices being meted out against women, thereby enhancing the realization of women's rights (Committee, 2003a, p.2). In this respect, Ms Ongewe explained that in addition to conferring citizenship rights and access to health care and reproductive rights among other rights, the new draft constitution had an expanded definition of discrimination that included "race, sex, pregnancy, marital status, ethnic and social origin" (Committee, 2003a, p.2):

In the new Constitution the definition of discrimination had been expanded to include race, sex, pregnancy, marital status, ethnic and social origin, colour, age, disability, religion, conscience, belief, culture, language and birth

In other words, in relation to the Convention's call for the elimination of discrimination against women on the basis of sex (Article1, CEDAW, 1981), the Kenyan government responds by bringing on board other discourses, such as those of race, pregnancy, and marital status, ethnic and social origin, which are simultaneously articulated with that of "sex."

Van Leeuwen and Wodak (1999, p.96) argue that recontextualization involves transformation, in which case the social practices that get transformed hinge on the "interests, goals and values" of the recontextualizing context. In this respect, Van Leeuwen and Wodak (1999, pp.96-98) identify typical forms of transformation such as deletion of given social 
practices, and addition which involves adding other elements to a given representation. Based on this understanding, the Kenyan government's professed broad definition of discrimination above creates a new version of gender equality policies and identity for Kenya, one that supports diversity and collective/solidarity rights (see explanation of collective rights in section 2.2.2), rather than the broader goal of gender equality for women. This state of affairs brings to the fore Foucault's view that "where there is power, there is resistance", and that "this resistance is never in a position of exteriority in relation to power" (Foucault, 1978, pp.95-96). That is, the Kenyan government's broad definition of discrimination can be said to signal the idea that Kenya had protested against the Convention's universality view of discrimination, hence the need for an alternative way of defining it. Said otherwise, the Kenyan government's definition of discrimination above serves to evade or resist the regulative perspectives of the universalist view of equality, by reifying its cultural relativist perspectives that stand in opposition to the Convention's imperatives. In doing so, the Kenyan government can be said to be resisting the Committee's act of wanting to conduct the conduct of others (i.e. Kenyan government and its policy practices concerning women), hence its call to be governed differently, i.e. based on shared understandings drawn both from the universalist and cultural relativist perspectives of women's rights. This points to the view that there is no one size fits all approach to gender equality policies. Instead, as Zeleza (2004, p. 43) recommends (see 2.2.3), there is an urgent need for the universal application of human rights to be enriched with some "cross-cultural fertilization of ideas" concerning women's rights to enhance both their legitimacy and acceptability across cultures where they are implemented. What is more, this recommendation seems to connect fittingly with that of the transnational feminist scholars of women's rights. That is, transnational feminist rhetoricians, as Nagar and Swarr (2010, p.2) note (see 2.4.1), stress not only the need for a collaborative mix of theories and practices of knowledge formation on issues of voice, authorship and representation in matters of women's rights, but also the adoption of transnational feminist approaches that are critically aware of their historical, political, and geographical locations, owing to the dialogic and self-reflexive processes of knowledge production. Further, this state of affairs attests to the view of transnational feminist activists and academic scholars of women's rights, that though the Beijing imperatives provide a framework for a common understanding of human rights, it fails to provide for how such rights ought to be interpreted and applied within the local context.

Furthermore, this scenario as Ness (1999, p.13) and Wuerffel (1998, p.370) argue (see 2.2.5), permits nations of the world to continue implementing human rights according to the 
prevailing local contexts, thereby hindering the attainment of gender equality. More significantly, this state of affairs raises queries regarding the ability of the Convention to achieve gender equality policies.

\subsubsection{The Committee's opening response and Kenya's reply}

On its part, the Committee praised the Kenyan government for its commitment to eradicate discrimination against women, as well as advancing the rights of women (Committee 2003a, p. 3). Moreover, the Committee stated that the large delegation of the Kenyan officials constituting solely of women, and the inclusion of NGOs in preparing the reports, "testified to Kenya's commitment to women's rights" (Committee, 2003a, p.4). It should be noted here that representatives of the women's NGOs (e.g. FIDA-Kenya) were included in the Kenyan delegation.

Similar comments were given with regard to the elevation of the Women's Bureau to the level of a department within the Ministry of Gender, Sports, Culture and Social Services.

Having congratulated the Kenyan government, the Committee deploys the topos of history (Kwon, Clarke \& Wodak, 2009, p. 280) anchored in evidentiality, "a form of intertextuality" (Van Dijk, 2000, p.93), to criticize the Kenyan government's periodic reports. The Committee argues that despite acceding to the Convention nineteen years back, the Kenyan government had shown no progress in applying the Convention, as well as in eliminating discrimination against women (Committee, 2003a, p.4). In a way, these comments index the committee's evaluative stance, as the global women's rights enforcement agency. Brown notes that arguments, praises, admonitions and/or criticisms are part of the "rhetorical forms and strategies" that characterize authoritative discourses, and whose use is to persuade someone to given ways of thinking (Brown, 2008, p.77). According to Wodak (1997, p.183), framing practices that espouse topic shifts entail a discursive strategy for asserting and maintaining authority. As such, the Committee's mixing and dialogical shift of frames (i.e. from praise to criticism) can be said to be a persuasive strategy, one that is authoritatively tailored at wooing the Kenyan officials toward embracing the Convention's approach to women's rights.

In like manner, the Committee took the Kenyan government officials to task, by asking for clarification regarding how the proposed constitutional reforms could change the relations that hold between the international and domestic laws. Further, the Committee "wondered whether treaty law would in fact take precedence over domestic law" (Committee, 
2003, p.6, my emphasis). According to Saarinen (2008, p.342), whatever we presuppose serves as a guiding light both to what we choose to say and how we wish to be understood. Arguably, the use of the mental process verb "wondered" in the extract "the Committee wondered whether treaty law would in fact take precedence over domestic law" signals the Committee's desire for the Kenyan government to adopt and apply international laws concerning women's rights to gender equality. In Bakhtinian terms, the Committee can be said to be solely pre-occupied with the need for the Kenyan government to embed its discourse of women's rights within the monologic normative framework of women's rights. This is realised through the Committee's inclination to the UN's treaty laws.

In response, Ms Nkoroi from Kenya asserted that:

the Kenyan Constitution recognized that international law was a source of national law and that it took precedence over domestic law. However, Kenya's national legislation was derived in part from the body of uncodified customary law, which had tended to discriminate against women, particularly with regard to marriage and inheritance. The Task Force set up in 1993 by the Attorney General to review all laws relating to women had conducted a survey of Kenyan women and other relevant stakeholders to ascertain the areas in which they felt discriminated against, and had made a series of recommendations for legislative intervention to rectify matters (Committee, 2003a, p.8).

Citing Bakhtin (1981), Ball and Freedman argue that our struggles with an authoritative discourse hinge on the relationship holding between us and such a discourse (Ball \& Freedman 2004, p.7). Further, Ball and Freedman reiterate Bakhtin's advice, that when different voices interact, a struggle ensues with regard to how to assimilate both the authoritative discourse, and the internally persuasive discourse, owing to their differing properties (Bakhtin, 1981, pp.342-343, cited in Ball \& Freedman, 2004, p.7). In Bakhtin's words, the authoritative word/discourse entails "the word of the fathers. Its authority was already acknowledged in the past. It is a prior discourse. It is therefore not a question of choosing it among other possible discourses that are its equal" (Bakhtin 1981, p.342-343, cited in Ball \& Freedman, 2004, p.7). In this sense, Ms Nkoroi's utterance "the Kenyan constitution recognized that international law was a source of national law and that it took precedence over domestic law" above can be said to have come into contact with the authoritative word (international law) that demanded her unquestioned allegiance. In this way, Ms Nkoroi draws dialogically upon the Committee's points to elaborate her point of 
view that endorses the superiority of the international law over the domestic laws. In effect, her utterance gives the Committee the power as agent of the international law, to control and continue questioning the Kenyan delegation. Consequently, the use of the contrastive connective "however" in her text introduces the existing conflict in terms of the differing perspective upon which the Kenyan law was founded, hence her "struggle against various kinds and degrees of authority" (Bakhtin, 1981, p.345). According to Bakhtin, such a struggle occurs due to the fact that "the authoritative word demands that we acknowledge it, that we make it our own; it binds us, quite independent of any power it might have to persuade us internally; we encounter it with its authority already fused to it" (Bakhtin, 1981, p. 342).

\subsubsection{The dialogue intensifies}

Making manifest intertextual reference to Kenya's draft constitution and the bills pending in the Kenyan parliament, the Committee reprimanded the Kenyan government, arguing that though it had presented an encouraging list of bills and initiatives, all such bills were pending or incomplete, hence "no evidence of real progress" (Committee, 2003a, pp.46). Moreover, the Committee lamented that all the aforesaid bills and initiatives had not led to any tangible results in the actual sense (Committee, 2003a, p.4). Hence, the committee told the Kenyan government, that it is "“"urgent that the new government should act decisively and meet its commitment to enact the new constitution" (Committee, 2003a, p.4, my emphasis).

According to Fairclough (1996), changes in the grammar of a language are traceable to shifts in the orders of discourse happening both in response to, as well as constitutive of socio-cultural change. Also, modality entails "the speaker's judgement of the probabilities, or the obligations, involved in what he is saying" (Fairclough, 2003, p.165; Machini \& Mayr, 2012, p.13). This means that modality is an indicator of self-identity, and one way of communicating judgement and attitude towards some shared intertextual knowledge, by expressing one's complete or reserved commitment to "one thing or another" (Waterton et al.2006, p.345) (see also 3.5.3.1). In this context, the use of the deontic modality "should" (i.e. modality of necessity and obligation) (Fairclough, 2003, p.219), and the lexical item "urgent" attributed to authoritative discourses (Fairclough, 1995) reflect Kenya's unfulfilled role in bringing about gender equality policies, hence the Committee's authoritative role in pushing the Kenyan government to accept the UN's mode of rights. The use of negation in the phrase "no evidence of real progress" in the excerpt above serves to bolster the Committee's claim to the effect that the Kenyan government has not met its UN mandated 
duty to bring about gender equality in Kenya.

Regarding discrimination against women, the Committee argued that Kenyan laws were explicitly discriminatory. In this context, the Committee lamented the lack of progress in applying the Convention toward enhancing the realization of women's rights. In its terms, the Committee:

wondered whether the Government had considered measures to change social stereotypes about women, as the report contained no information in that regard (Committee, 2003a, p.4, my emphasis).

Assuming an advisory role, the Committee recommended that Kenya's adoption of the Convention had to be accompanied by comprehensive public education regarding the rights of women. In this context, the Committee enquired from the Kenyan officials regarding whether the Kenyan government had initiated plans to have the Judiciary officials educated about the Convention, and as to whether university courses in Kenya addressed matters of the Convention. In response, Ms Nkoroi from Kenya argued that a number of bills concerning gender equality were awaiting consideration by the Kenyan parliament, which "would also be required to enact new legislation to enforce the provisions of the new constitution expressly prohibiting the use of cultural and traditional practices" (Committee, 2003a, p.8, my emphasis). In this context, the verbal phrases "were awaiting," and "would also be" may be said to signal the fact that Kenya's policy initiatives to bring about gender equality entail an agenda for the future, hence not something to be expected in the present moment. According to Van Dijk (1997, p.17), political discourses tend to espouse a future oriented language. On these grounds therefore, we may argue that Ms Nkoroi's future oriented language is aimed at triggering the Committee's positive hopes with regard to the future policy actions that the Kenyan government has promised to accomplish.

Furthermore, the Committee acknowledged the upgrading of the Women's Bureau to a department, but criticized the government, and "lamented the lack of de facto change, and stressed the Committee's desire to see genuine progress" (Committee, 2003a, p.4, my emphasis). However, as Bhatia notes, the use of technical terms (e.g. "de facto change" above) serves to exert power asymmetry between actors, which in a sense constitutes a political register (Bhatia, 2006, p.190).

With respect to public service, the Committee enquired about the actual number of people working in the Bureau, emphasizing the need for collaborative efforts between the different policy actors dealing with the issues of women (Committee 2003a, p.4). Within this 
frame of reference, the Committee's repeated use of mental process verbs is worth examining. Fairclough and Morley define mental process verbs as verbs involving the mind and mental behaviour (Fairclough, 2003, pp.170-171; Morley 2000, p.96) (see also 3.5.3.1).

Moreover, Fairclough states that mental processes are enacted in texts through the use of such mental process verbs as suspect, think, wonder (see emphasised examples above), feel, concerned, alarmed, etcetera (Fairclough 2003, p.170-171). Additionally, Morley and Mulila note that mental processes involve the processes of sensing, perception and affection (Morley, 2000, p.95; Mulila, 2014, p. xiv). In this sense, the Committee's reported use of the mental process verb "lamented" above introduces the Committee's disappointment with the lack of progress in the Kenyan government's efforts to bring about gender equality. This feeling is enhanced through the Committee's use of the normative expression "de facto change," signalling its authoritative role in persuading the Kenyan officials to resolve the outstanding issues concerning Kenya's discourse of gender equality. Also, the use of the noun phrase "genuine progress" in the clause "the Committee's desire to see genuine progress," presupposes that no tangible progress had been made by the Kenyan government towards implementing the normative rights of women. This claim was aimed at countering the government's accumulated evidences above, with regard to its policy initiatives for promoting gender equality.

Faced with this challenge, Ms Ambwere, another Kenyan official, argued that the head of the newly created Ministry of Gender, Sports, Culture and Social Services was a man, which in her view signalled both the Kenyan government's commitment to issues of women, as well as its willingness to involve men in this endeavour (Committee, 2003a, p.5). Further, Ms Ambwere stated that the national machinery for the advancement of women had representatives from every Ministry and non-governmental organization, who had the requisite expertise for use in this area. Ms Ambwere's conclusion however reveals the argumentative stance underpinning her discourse. That is, she emphasized that:

The move to upgrade the Women's Bureau from a division within the Department of Social Services to a separate Department would help mainstream the gender issue in all sectors of society...The existing institutional machinery, the Government, the gender desks, the Ministries and non-governmental organizations would all work in a collaborative manner. That, together with the proposed National Council for Gender Development 
and the draft Constitution, would help mainstream the gender issue (Committee, 2003a, p.5, my emphasis).

This excerpt demonstrates a similar textual pattern noted above (see 4.4.1), of listing policy initiatives adopted by the Kenyan government to support its claims, no doubt in an attempt to raise the Committee's comfort level. Bhatia and Zhengrui (2012, p.200) note that policy framing practices that tend to sum up particular "claims, facts and reasons, and opinions" point to the argumentation strategies deployed by policy makers to support the truth claims in their policy propositions. Based on this viewpoint, it could be argued that Ms Ambere's listing of the above stated policy initiatives points to the Kenyan government's interdiscursive efforts to neutralise the Committee's demands for immediate change with regard to gender equality issues. This is evident in her conclusive remark that "That, together with the proposed National Council for Gender Development and the draft Constitution, would help mainstream the gender issue". Fairclough notes the verb help as being one among other linguistic features/verbs such as promote, advance and sustain, which are used to trigger value assumptions, i.e. "assumptions about what is good or desirable" (Fairclough, 2003, p.55) As such, the use of "help" in the future oriented verb phrase "would help" above can be said to signal what Ms Ambwere considers desirable. However, the fact that her language foregoes the idea of implementing gender equality in the present moment in favour of an unknown future time reflects the Kenyan government's aim of wanting to manage the structural conditions under which the actions of women occur, rather than ameliorating them from their situations. Further, this suggests Ms Ambwere's rhetorical intent of wanting to persuade the Committee to given conclusions in favour of the Kenyan government.

Using manifest intertextuality, Ms Ongewe reinforced Ms Ambwere's argument above, by stating that "The new Government was now in place, and Kenya was committed to achieving real progress." (Committee 2003a, p.5, my emphasis). As Fairclough argues, when it comes to recontextualizing the voice of the other, the notion of framing is at issue (Fairclough, 2003, p.53). In his words, "when the voice of another is incorporated into a text, there are always choices about how to 'frame' it, how to contextualize it, in terms of other parts of the text - about relations between report and authorial account" (Fairclough 2003, p.53). As such, the phrase "real progress" in Ms Ongewe's statement is an evident borrowing from the Committee's remarks, "no evidence of real progress" (see the first paragraph of this subsection). This "parodic stylization" (Bakhtin, 1981, p.292) reveals the fact that Ms Ongewe's discourse is not only "manifestly intertextual” (Candlin \& Marley 1997, p.218), 
but also dialogically laden with some rhetorical intent, i.e. of seeking to raise the committee's comfort level with regard to the Kenyan government's progress towards bringing about gender equality. From Bakhtin's notion of polyphony, Patrona advises that the tendency of repeating others' phrases can be used as a strategy for evading obligations to adopt a given agenda or perspective (Patrona, 2013, p.36). On these grounds, repeating the Committee's phrase "real progress," through embedding it in her utterance, Ms Ongewe's words can be argued to be a doctored response, one that is ironically meant to negate adopting what is demanded of her by the Committee.

\subsubsection{The debate comes to a head}

A central issue, and perhaps the most defining issue of the dialogue in which the two parties are engaged, concerns the Committee's interpretation of the notion of equality. Assuming the stance of an expert who knows the logic of how the implementation of gender equality policies ought to be done, the Committee urged the Kenyan officials to ensure that the Kenyan government implements "gender equality, not merely gender equity, by means of "a true rights-based approach to women's issues in all areas" (Committee, 2003a, p.4, my emphasis). This signals the Committee's evaluation of those elements of the Kenyan policy that it finds undesirable. In this respect, the word "true" in the clause "a true rights-based approach to women's issues..." presupposes that the Kenyan government does not espouse the normative approach to gender equality. As mentioned earlier (see 3.5.2.1), Fairclough and Wodak insist that whenever a discourse is recontextualized in a new setting, its meaning is subject to change depending both on the needs and nature of the relationships existing between the different contexts within which such a discourse gets recontextualized (Fairclough \&Wodak, 2010, p.22). On these grounds, though article 14 of the Beijing Declaration declares that "women's rights are human rights" and calls upon nations of the world to implement such rights "on the basis of equality" (United Nations, 1995, p.3), the Committee's queries above presuppose that the Kenyan government has adopted the cultural relativist and/or equity model in place of the universal/equality criteria, as its framework for implementing gender equality policies.

According to Martin and Rose, negation constitutes a resource for introducing competing voices into a text (Martin \&Rose, 2007, p.53). As such, from the Foucauldian perspective of power, the negation "not merely" means that the government's voice exists in an opposing relationship to that of the Committee, hence a challenge to the UN's mode of 
women's rights.

In Foucault's view, any analysis of power relations ought to consider "forms of institutionalization" in terms of their principles of regulation, their defined hierarchical structures, and their autonomous functioning that seeks to take everything under their control (Foucault, 1994, pp.230-231). As such, the Committee's insistence on the need for the Kenyan government to implement equality rather than equity points to its oppositional stance against alternative and/or cultural relativist viewpoints that stand in opposition to the universal perspectives of women's rights. In other words, in its interpretation regarding the notions of equity and equality above, the Committee can be said to have protested against the Kenyan government's view of equality from the perspective of equity (i.e. relativist stance), which in its view was not sufficient and necessary for engendering the realization of the universal rights of women in Kenya. However, transnational researchers of human rights (including feminist scholars of women's rights) such as Coomaraswamy (1997); Donnelly (2013); Ibhabow (2000); Mutua (1995); and Zeleza (2004) among many more do emphasize the need for the application of the universal rights of women with reference to the particular contexts of practice, where different interpretations abound. This suggests that the Committee's approach to gender equality ignores the particular contextual factors that come into play as gender equality issues get interpreted and implemented within the local milieu.

Notice too that the Committee's advice to the Kenyan government to implement "gender equality, not merely gender equity" and "by means of a true rights-based approach to women's issues in all areas" (Committee, 2003a, p.4) constitutes a subtle strategy for reminding the Kenyan officials of their expected appropriate conduct and/or obligation to adhere to the normative approaches to gender equality, hence its protest against the Kenyan government's inappropriate conduct of implementing gender equality policies from the perspective of equity.

Rai notes that the distinction between equality and equity has been part of the ongoing debates amongst the advocates of gender justice, concerning the relevance of either the language of equality or that of equity (Rai, 2003, p.16). In this context, Rai explains that the equality approach is privileged over the equity approach, because it is both anchored in universal human rights norms, as well as seeks to "erase the differences between women and men," thereby ensuring that the concept of sameness becomes the centre of focus, rather than the emphasis on the "different needs and interests of women and men" (Rai, 2003, p.16). Further, Rai elucidates that the language of equity is anchored in a subjective criterion (i.e. cultural relativist stance), one that is focused on the dignity of women, but does not include 
the normative dignity and worth of the human person with inalienable rights on the basis of being human (Rai, 2003, p.16). However, as McLaren and Ransom note, Foucault dismisses totalizing discourses and/or exclusionary language (i.e. language use that imposes a given way of thinking/worldview that excludes alternative perspectives), arguing that universal forms never fashion people's actions, as conflicting human viewpoints mediate all social practices in society (McLaren, 2002, p.29; Ransom 1997, p.112). In this context, for instance, the aforesaid scenario about equity and equality approaches to women's rights is indicative of the ongoing "definitional struggles over the contested meanings" (Solin, 2004, p.290) of the notion of gender equality, with the Committee emphasizing the universal rights of women that seem to stand at odds with the cultural relativist version of such rights espoused by the Kenyan government. That is, though the universal discourse of women's rights can be authoritatively attributed to the Committee, Kenya's choice of the equity approach to women's rights instead of the Committee's equality model above reflects the fact that the Committee does not have "sole definitional power" (Solin, 2004, p.290) in the context of interpretation and application of concepts underlying the discourse of women's rights at the national government level.

Notably, the Committee's proposal to the Kenyan government officials in the extract above demonstrates three very important points worth cataloguing here. First, it shows that the Committee's face to face interaction with the Kenyan officials is not just a matter of dialoguing and asking questions that require answers, but also a device for giving policy advice regarding what the UN considers desirable or undesirable in its discourse of women's rights. Second, the advice to the Kenyan officials to implement gender equality rather than merely equity, presents the Committee as being thoroughly aware of how the Kenyan government operates, including its view of and approaches to gender equality policies. Finally, and more importantly, from Bakhtin's notions of authoritative and internally persuasive discourses (Bakhtin 1981, 1986), the committee's use of "discipline-specific terms" (Ivanic, 1998, p.301) (i.e. equity, equality, and true-rights based approach) points to the ultimately non-dialogic nature of the UN's discourse of women's rights. That is, through its use of terms associated with the UN's discourse of women's rights (i.e. gender equality, gender equity, and rights-based approach), it is arguable that though the Committee is operating dialogically in interacting with the Kenyan policy makers, its arguments remain authoritatively anchored in the normative discourse of women's rights.

Following the Committee's challenge above, Ms Koome (i.e. another Kenyan official) responded that the new constitution would embrace a rights-based approach to gender 
equality. Further, Ms Koome bolstered her arguments by stressing that the new constitution would ensure the eradication of customary laws that were at odds with the individual rights. In conclusion, Ms Koome emphasized that:

The individual's human rights must be respected, and, if those rights were infringed, the individual concerned would be able to seek redress in the courts (Committee, 2003a, p.5).

From this text, it can be said that Ms Koome is exercising her "epistemic authority," (Kim, 2011, p.437) to 'co-tell' the norms underlying the universal discourse of women's rights, including her factual experience regarding how such knowledge can be applied to claim justice in favour of women. Epistemic authority entails "the legitimate power to define, describe, and explain bounded domains of reality" (Gieryn, 1999, p.1). In other words, the text above projects Ms Koome's agreement with the universal approach to women's rights, while simultaneously thematising her first hand knowledge and experience regarding how such rights ought to be understood and put into practice.

From the governmentality perspective as Miller and Rose (2010, pp.276-7) contend, political rationalities have a moral character, meaning that political discourses have a tendency of seeking to formulate and justify particular schemes using a morally coloured language, and one that is based on knowledge focusing on issues of human concern such as freedom, equality, justice, prosperity, growth, mutual responsibility, citizenship and fairness among many more. In this context, drawing on Fairclough's concept of interdiscursivity (Fairclough1992, 1995, 2003), Ms Koome creatively uses the language of rights borrowed from the normative discourse of human rights, probably to show that she shares the same viewpoint with the Committee towards equality policies, thereby enacting credibility for her claims, with the aim of both wanting to raise the Committee's comfort level, as well as reaching some agreement with it.

Bazerman argues that a text can invoke other texts at different levels of intertextuality, and through various mechanisms of intertextual representation (Bazerman, 2004). As such, Bazerman states that texts can invoke other texts for such purposes as identity and/or identification through the use of language/terminology associated with a given genre (i.e. such as the human rights vocabulary (Bazerman, 2004, pp.86-9). From this perspective, Ms Koome can be said to have embedded her utterance within the language of human rights associated with the UN's epistemic domain, probably to register her affirmative acknowledgment of the significance of the normative discourse of women's rights, thereby 
suggesting a shared perspective in dealing with matters of women's rights. This feeling is reinforced through the use of the deontic modality must (Fairclough, 2003) above, attributed to authoritative discourses, as well as the reference to the courts (legal discourse), probably to authenticate her truth claims as well as future policy obligations.

\subsubsection{The discussion moves on}

Concerning timelines for achieving particular policy actions, the Committee deploys the deontic modality "should" (see 3.5.3.1) that characterizes authoritative discourses (Fairclough 2003) to demand that "Deadlines should be set for achieving the objectives of the Beijing Platform for Action.” (Committee, 2003a, p.7, my emphasis). In addition, the Committee recommends that technical help from the United Nations is necessary to meet the aforesaid objective (Committee, 2003a, p.7). According to Livnat (2012), statements framed to suggest the need for help in interactions are indicative of the existing unequal power relations between or amongst the actors. From this perspective, by insisting on the need for the Kenyan government to seek assistance (i.e. technical help from the United Nations), the Committee can be argued to be levying its power and authority over the Kenyan government, by positioning itself in a position of power while placing the Kenyan government in a state of powerlessness that requires help from the UN.

In a similar vein, the Committee sought clarification concerning: (1) the deadlines for passing laws relating to equality rights; (2) the time-frame for creating the National Commission on Gender and Development; (3) whether the government was committed to adopt temporary special measures; (4) the budget allocated to the Ministry of Gender, Sports, Culture and Social Services; and (5) whether the government intended to take a human rights approach with regard to the laws on property rights and succession that were yet to be adopted (Committee, 2003a, p.7).

In her response to these series of questions above, Ms Ambwere responded that "the new Government was committed to enacting the bill," that will allow for the creation of "the National Commission on Gender and Development" (Committee, 2003a, p.8). Chilton and Schaffner argue that commissives (i.e. promises and offerings) are part of the speech acts that serve the role of reassuring (Chilton \& Schaffner, 2006, p.220). From this line of thought, it can be argued that Ms Ambwere's utterance under discussion is rhetorically aimed at reassuring the Committee of Kenya's commitment to the normative discourse of women's rights. 
Appertaining to the concept of "gender budgeting", Ms Ambere informed the Committee that "Kenya was still in the early stages of introducing the concept, but a committee had been formed within the Treasury to ensure that the budgeting process was gender responsive" (Committee, 2003, p.8). According to Patronas, avoiding to answer given questions, providing partial answers, or even delaying to answer particular questions entail one of the discursive strategies that governments can strategically deploy to evade their obligation in implementing a given agenda, more so when there is a general feeling that such an agenda is being imposed on their ideological convictions (Patrona, 2013, p.14). In other words, the exclusion of given discourses/voices from the events and actions in a text points to those discourses being viewed as incorrect/inconsistent, conflicting, inappropriate or even irrelevant in particular settings. Arguably, it is on such grounds that Ms Ambwere may have chosen to avoid giving answers for the other questions, such as the one relating to whether the government was intending to adopt a human rights approach with regard to the laws on property rights and succession that were yet to be enacted.

Foucault, as Rose and Rabinow (2003) note, and as I have already mentioned in recent pages, but it bears repeating here, dismisses totalizing discourses because of their tendency of wanting to conduct the behaviour of others (see chapter 2), thereby marginalizing alternative realities and experiences in society (Rose \& Rabinow, 2003, p.6). In this context, Ms Ambwere's avoidance of answering the Committee's question as to whether the Kenyan government was planning to adopt a human rights approach with regard to gender equality policies points to the Kenyan government's continued efforts to avoid being conducted by the Committee towards wholesale adoption of the universalist perspectives to gender equality. This could be said to be an act of "counter-conduct" (Foucault 1982) against the processes implemented by other regimes of power (i.e. proponents of the universal rights of women) "for conducting others" (Foucault 2007) to particular ends. This understanding can be inferred from Ms Koome's response to the Committee seen in 4.4.4 above, whereby she informs the Committee that the new Constitution would embrace a rights-based approach to gender equality (Committee, 2003a, p.5, my emphasis). In this case, her future oriented language could be said to signal the fact that universal rights of women are an issue for the future, hence a technique and/or strategy of circumventing the Committee's call for the universal rights of women in the here and now.

As noted in chapter two, and as already discussed earlier in this section, there is an ongoing debate between universalism and cultural relativism, in which case as Clapham, Delaet, and Selby argue, whereas universalists hold that human rights are universal and 
applicable to all humans by virtue of being human and regardless of their cultures, the cultural relativists insist that human rights are cultural entities, hence relative and/or variable according to the people's religious, socio-cultural and historical contexts (Clapham, 2007, p.49; Delaet, 2006, p.44 ; Selby, 1987, p.8). In view of these understandings, and considering that power plays a key role in the production of discourses of knowledge and truth that serve to legitimate given asymmetrical power relations between given actors (Rayner 2007, p.105), it is arguable that Ms Ambwere's reluctance to address the Kenyan government's view of a "human rights approach" to women's rights above is indicative of the Kenyan government's reluctance to embrace a purely universalist approach to gender equality policies.

\subsubsection{Competing futures}

What follows is the final substantial point arising from my analysis of the ongoing exchanges between the Committee and Kenyan officials. Ms Mutinda from Kenya told the Committee that her government was committed to restructuring the system of education. In this context, Ms Mutinda said that the Kenyan government had already made tremendous progress in terms of reforming the school curriculum, including the vetting of text books for use in schools, to help combat the stereotyping of women (Committee, 2003a, p.5). In conclusion to her contribution, Ms Mutinda commented that "a strategic plan would be formulated in an effort to address gender stereotypes in the sector," and that "it was hoped that process would be strengthened once the government had changed the educational structure to respond to people's needs" (Committee 2003a, p.5).

Patricia Dunmire provides a reliable methodological device through which we can gain insights into the ongoing intertextual interactions between the Committee and the Kenyan government's officials. According to Dunmire (2005, p.483), the use of future oriented language has to be understood as being ideologically motivated. As such, Kenya's approach that seeks to project gender equality as being in the pipeline has to be seen as serving both a rhetorical and ideological function in the text. In relation to the notion of deontic modality discussed in section 3.5.3.1 above, Dunmire asserts that:

We can understand representations of the future as being articulated in and as operating through two modalities: deontic and epistemic. Deontic modality is the modality of 'ought' and 'should' and is concerned with future action and policy, and expresses obligation, conviction, and permission. Epistemic modality is the modality of 'will'. It is concerned with knowledge, belief, and 
truth about the future and expresses judgements as to the status and/or certainty of that knowledge, belief, and truth. This distinction between deontic and epistemic futures is important because it emphasizes that political discourse includes not only arguments about actions and policies that 'we have it in our power to set going'. It also comprises claims to knowledge of the future, that is, knowledge about what will be at some future moment (Dunmire, 2005, p.484).

Arguing that the future constitutes a principal 'ideological site for exercising political and institutional power," Dunmire (2005, p.485) emphasizes the need to reconceptualise the proposed futures by critically examining the present that builds hope in those proposed predictable future outcomes. Thus, Ms Mutinda's use of future oriented language points to the Kenyan government's neoliberal technique of rule, one that seeks to manage the conduct of others through building expectations of their anticipated futures. In this respect, prioritizing what the state of women "will/would be" in the presupposed future, overrides their state of inequality at the present moment. In effect, this affords Ms Mutinda the power and authority to imagine herself as one person that is fully aware of the situation of women, and in control of what it takes to ameliorate them in future. In a way, the Kenyan government's future oriented language is an evasion strategy, one that helps it (government) to avoid accounting for women's present unequal status, by seeking to raise the Committee's comfort level and expectations regarding the anticipated future gender equality policy initiatives.

Notice that from their discussion, competing futures are presented within the existing question and answer mode of interaction. That is, whereas the government officials espouse a privileged future framed through the use of the absolute modality "will/would be" that derives from "evidence, history and reason", the Committee's oppositional future (i.e. as a counter strategy) is projected through "verbal and mental process clauses" (Dunmire, 2005, p. 502) such as, "the committee lamented,", "the committee hopes,", "the committee believes,", "the committee is concerned,", as well as through deontic modalities "should" and "must", that encode its message and/or questions as urgent and compelling, in addition to signalling the government's unfulfilled obligation. The aforesaid Kenyan government's privileging of futurological language through the use of "will/would be," and the Committee's use of deontic modalities "should" and "must" can be located in the context of Foucault's notion of conduct of conduct (Foucault, 1982, p.237) discussed in chapter two, as well as the 
mentalities of protest and resistance/counter conduct, i.e. "a struggle against the processes implemented for conducting others" (Foucault, 2007, p 201, cited in Death, 2010, pp.239240). In other words, we could say that the Kenyan government's use of a future oriented language above signals its protest against the Committee's aim of wanting to deploy the United Nations' human rights principles to guide and conduct it towards embracing the universal discourse of gender equality. As such, whereas the Committee seeks to influence the conduct of Kenya towards accepting equality policies, the Kenyan government's use of "will"/ "would be" entails a strategy for persuading the Committee to remain hopeful of the anticipated future, when such policies will be implemented. In this context, the use of a future oriented language serves as a means for challenging and countering the Committee's call for gender equality in the here and now, hence an act that is characteristic of Foucault's (2007) notion of counter conduct mentioned above.

\subsection{Text 3: Report of the Committee on the Elimination of Discrimination against Women: official records of the General Assembly, fifty-eighth session, 20 March 2003}

This section discusses the Committee's report to the UN Secretary General (henceforth General Assembly 2003), arising from the chain of interactions between it (the Committee) and the Kenyan government analysed above. As such, it is the final link in the chain for the round of texts centring on Kenya's combined third and fourth reports, presenting the Committee's final conclusions and its recommendations to the Kenyan government. The analysis below follows the structure of the report by beginning with a discussion of the Committee's comments centring on the convention itself and then focusing one-by-one on the policy themes singled out by the Committee. The most important point to take from the description below is that, in spite of the dialogic framework within which the relations between the two parties are formally conducted, the Committee makes absolutely no concessions to the exigencies exposed by the prior exchanges. It is as though the dialogue had never taken place.

\subsubsection{The Convention}

In the introductory part of its report, the Committee applauded the Kenyan government for its declared political will to implement gender equality policies, including the 
enactment of the draft constitution, and the elevation of the women's Bureau to the level of a department within the Ministry of Gender, Culture and Social Services (General Assembly, 2003, p.35).

Making a shift to what it calls the "principal areas of concern and recommendations" (General Assembly 2003, p.35), the Committee noted that though the Kenyan government's draft constitution could allow for the implementation of the Convention for the Elimination of Discrimination against Women, once ratified, it (the Convention) had neither been incorporated into Kenya's national laws, nor applied in courts as required by the Convention (General Assembly, 2003, p.36). In consequence, the Committee asked the Kenyan government to ensure the adoption of the CEDAW imperatives into the Kenyan law without delay, and with a further request for the Kenyan government to ensure that such provisions are reflected in the Kenyan constitution, as well as in all legislation. In this way, it becomes evident that the Committee uses its UN sanctioned authority to praise the Kenyan government (i.e. by applauding its declared political will to implement gender equality, and for enacting the draft constitution), before tendering its requests. That is, from the perspective of Fairclough's concept of interdiscursivity, as Ho (2011, p.2542) notes, the genre of praise is normally used as a rhetorical tactic to convince someone to do something. Based on this understanding, by imbuing its recommendations with the intertextual element of praise, the Committee can be said to be seeking to convince the Kenyan government to accept its requests.

\subsubsection{Customary laws and traditional practices and attitudes}

Using mental processes, the Committee reiterated that it was "concerned that legislative provisions as well as customary laws and practices" discriminative of women in such areas as marriage and divorce were still being condoned by the Kenyan government (General Assembly 2003, p.38). Accordingly, the Committee asked the Kenyan government to ban discriminatory laws, practices and traditions that violate women's rights to gender equality. Aso, in addition to recommending the need for the Kenyan government to work in partnership with civil society and nongovernmental organizations to facilitate law reforms supportive of gender equality, the Committee demanded among other things:

speedy enactment of the relevant bills, including the Domestic Violence (Family Protection) bill of 2002; the Equality bill of 2001; the National 
Commission on Gender and Development bill of 2002 (General Assembly, 2003, p.38, my emphasis).

The Committee's manifest intertextual references to the Kenyan government's policy initiatives, as illustrated in this extract, point to its detailed knowledge regarding what is going on in Kenya with regard to the implementation of gender equality policies. The Committee's argument in the excerpt above underscores Foucault's (1988) notions of liberalism and the liberal modes of governance that sit at the centre of his theory of governmentality. As mentioned in chapter two, liberalism is based on the general idea of individual freedoms and equality, whereby individuals are seen as being equal and free to make their own choices in life, beyond any forms of domination. This could partly be the reason why the Committee emphasizes the need for the Kenyan government to enact "the Equality bill of 2001" and other bills mentioned above, probably as the means for ensuring Kenyan women's acess to their individual freedoms and equality that underpin Foucault's notions of liberalism and governmentality.

The Committee regrets the prevalence of "cultural practices and stereotypical attitudes" concerning the particular roles and responsibilities of women, which in its words, "undermine the rights of women" (General Assembly, 2003, p.38, my emphasis). In this context, the Committee asked the Kenyan government to mount campaigns aimed at educating the Kenyan public on the need to change stereotypical attitudes and discrimination against women and girls (General Assembly, 2003, p.38). Moreover, the Committee recommended the need for the Kenyan government to involve the media in presenting a positive image of women, as well as their equal status with men in both the public and private domains of their existence. In addition, the Committee requested the Kenyan government to continue making periodical assessments of its efforts to eliminate barriers to gender equality, including the measures taken to correct such barriers (General Assembly, 2003, p.38). Chilton and Schaffner (2006) posit that actors can use arguments about an individual's or groups' wants to legitimize their claims. This implies that the Committee's text above regarding the existing cultural practices that undermine the rights of women was strategically framed to help legitimize women's claims, thereby exerting pressure on the Kenyan government to rethink its position regarding such discriminatory laws. This feeing is heightened through the Committee's emphasis on the need for the Kenyan government to enact "appropriate legislation on all forms of violence against women, including domestic violence," (General Assembly, 2003, p.38). In this context, the committee's call for 
"appropriate legislation" in the extract above suggests the lack of proper laws to ensure the realization of women's rights in Kenya.

According to Van Dijk, groups may use "experts, teachers, leaders and other ideologues" to inculcate and ensure the reproduction of given ideologies, through such mechanisms as education and training (Van Dijk, 2006, p.119). As such, the Committee's emphasis on public campaigns to teach the public in the extract above is indicative of its (committee's) need of wanting to enhance the acquisition of the universal values and norms underlying the normative discourse of women's rights in Kenya. This resonates with Foucault's view that knowledge is closely linked with forms of social control, as institutions use the powers within their reach to create what they consider to be valued knowledge within their own fields (Foucault, 1981, pp.54-55). Moreover, the term undermine in the excerpt "undermine the rights of women" above foregrounds the notion of morality that is at the centre of Foucault's concept of government. This understanding is made clear by Dean (2010, p.19) when he argues that:

one can approach the morality of government in a number of ways. It is moral because policies and practices of government, whether of national governments or of other governing bodies, presume to know, with varying degrees of explicitness and using specific forms of knowledge, what constitutes good, virtuous, appropriate, responsible conduct of individuals and collectives.

From this perspective, the term "undermine" in the extract "undermine the rights of women" under discussion spells out the Committee's awareness of the particular forms of knowledge, values, and norms that are considered morally good/correct, including better ways of managing individuals' conduct to particular ends.

\subsubsection{Gender-based violence against women}

A further argument made by the Committee concerns the specific issue of violence against women. Here, the Committee used mental processes (i.e. concern) to argue that "The Committee expresses concern at the continued prevalence of violence against women" (Committee, 2003, p.38, my emphasis). The use of the mental process verb "concern" here serves to register the Committee's dissatisfaction and demand for further action in dealing with sexual harassment cases against women in Kenya. In this context, among other related 
issues, the Committee (2003, pp.38-39) recommends the Kenyan government to: (1) enact laws to curb violence against women in line with article 19 of CEDAW; (2) train all public officials to enhance their awareness of gender equality policies; (3) establish shelters and counselling services for women victims of violence and sexual harassment; and (4) combat the sexual exploitation of women involved in prostitution. These suggestions can be inferred from the Committee's statement below:

The Committee urges the State party to accord priority attention to the adoption of comprehensive measures to address violence against women and girls, taking into account its general recommendation 19 on violence against women.The Committee calls on the State party to enact or review, as appropriate, legislation on all forms of violence against women, including domestic violence, as well as legislation concerning all forms of sexual harassment, in order to ensure that women and girls who are victims of violence and sexual harassment have access to protection and effective redress and that perpetrators of such acts are prosecuted and punished. The Committee also recommends gender-sensitive training for public officials, particularly law enforcement personnel, the judiciary and health services providers. It also recommends the establishment of shelters and counselling services for victims of violence and sexual harassment.... The Committee requests the State party to study the phenomenon of prostitution and to take appropriate measures to combat the exploitation of prostitution in urban areas (General Assembly, 2003, pp.38-39, my emphasis)

As previously noted, Bakhtin states that authoritative meanings in a text can occur through the invocation of "authority of tradition; religious decrees; generally acknowledged scientific truths, or an official ideology" (Bakhtin, 1981, pp.342-343). As such, the Committee's demand for Kenya to enact laws in line with article 19 of the Convention stated in the extract above points both to the authoritative nature of its (Committee's) discourse of gender equality, as well as its pre-occupation with the human rights approach to gender equality. 


\subsubsection{Women and political participation}

Building on their earlier point on the participation of women in public service, the Committee asked the Kenyan government to enact policies to: (1) raise the number of women appointed to the primary decision-making structures; and (2) adopt temporary special measures to bolster women's elevation to positions of power (General Assembly, 2003, p.39). Arguably, demanding the increase of women in public service presupposes the committee's dissatisfaction with the Kenyan government's professed efforts to increase women's participation in politics. Also, asking for temporary special measures (affirmative action) here signals the Committee's view of the Kenyan government's modes of affirmative action as being incapable of ameliorating women.

\subsubsection{Citizenship rights}

Concerning citizenship/nationality rights, the Committee asked the Kenyan government to make the Kenyan laws consistent with both the provisions of the draft constitution and the Convention, and report such policy adjustments to the Committee in its next periodic report (General Assembly, 2003, p.39). By asking to see such policy changes in the Kenyan government's next report, the Committee can be said to have tacitly confirmed its own lack of power to dictate terms and/or direction of Kenya's promised future policy actions. This affords the Kenyan government some "deontic authority" (Stevanovic \& Perakyla, 2012, p.308) with regard to how and when such policies can be implemented.

\subsection{Conclusion}

This chapter has examined the intertextual interactions between the Kenyan government and the CEDAW Committee with regard to the implementation of gender equality policies in Kenya. The primary aim of the chapter was to highlight the discursive strategies employed by the Committee to induce the Kenyan government's adoption of the transformative gender equality policies. This included a focus on the impact of such strategies on the Kenyan government's approach to, and concept of women's rights to gender equality. The chapter also sought to discuss the linguistic and rhetorical strategies deployed by the Kenyan government, either to signal its compliance with, or rejection of the United Nations' imperatives concerning women's rights to gender equality. This as well involved an exploration of the effect of these strategies on the Committee's view of the Kenyan 
government in relation to the implementation of gender equality policies in Kenya. These are discussed under the headings below.

\subsubsection{Mutual influences}

As confirmed in this chapter, the Committee's monitoring/benchmarking practices served to re-awaken Kenya's consciousness towards embracing a gender perspective in its policy practices concerning women. This is evidenced through the enactment of the various Kenyan government's policy initiatives noted above, toward addressing matters of women. For instance, in the same year as the Committee released its assessment report for Kenya's combined initial and second reports, the Kenyan government through its principal legal advisor, attorney-general Amos Wako, commissioned a Task Force mandated to investigate and report on all the laws and practices that discriminate against women in Kenya (Hansard, April 24th 2002).Though not explicitly stated, the timing of the commissioning of the task force suggests that it was motivated by the Committee's demands that the Kenyan government explain "the specific problems met by women," and "the policy interventions" put in place to solve them; including the reasons as to "why the Government had not undertaken special measures" to curb the problems faced by women (Committee, 1993, p.5).

At the same time, Kenya's decision to outlaw discrimination on the basis of sex can be attributed to the Committee's pressures upon the Kenyan government to implement gender equality from the perspective of a human rights-based approach to equality. As noted above (see 4.2), when emphasizing the omission of sex in the Kenyan constitution, the Committee asked whether the Kenyan government was considering amending its constitution and adding the notion of "sex" in its definition of discrimination (Committee, 1993, p.3). In this context, it can be argued that the Kenyan government's adjustment of its constitution to include "sex" entails one of the direct effects of the Convention on policy making concerning women's rights in Kenya. Furthermore, the Committee's repeated call for the inclusion of NGOs in the implementation of gender equality policies in Kenya leads to the Kenyan government's increased manifest intertextual references to the NGOs' involvement and participation in the Kenyan government's policy discourse of women's rights.

Other policy initiatives introduced in Kenya that are attributed to pressures from the Committee include the enactment of the gender and development policy 2000, and the adoption of the quota system to secure women's increased participation in the public sphere, such as the affirmative action policy of lowering the entry points for female students joining 
university education by one point (Kenya, 2000, p.11).

This chapter also sought to unveil the discursive strategies and rhetorical choices that are used both by the Kenyan government and the UN to achieve their rhetorical and political goals. In this context, the discussion above reveals how both the Committee's and the Kenyan government's use of particular discursive strategies seem to have influenced their behaviour towards one another. That is, the Committee's and Kenyan government's differing ideological perspectives seem to have impacted on their choice and use of both linguistic and rhetorical strategies. For instance, due to its allegiance to the transformative notion of gender equality which Kenya appears to be reluctant to adopt, the Committee seems to opt for the use of deontic modalities that seek to manipulate and dictate terms. For example, in their textual exchanges above, the Committee seems to privilege the use of strong modal auxiliary verbs "must" and "should," including lexical terms attributed to power and authority (Fairclough, 1995) such as "urgent," "speedy" and "without delay," with the aim of persuading the Kenyan government to accept and implement gender equality in the here and now as a given fact. Indirectly, this can be said to mirror the fact that the Committee has only the textual power and authority to instruct governments on how to implement gender equality policies. Such observations are consistent with Clapham's view that the enforcement of human rights laws takes place at the national level, where national laws reproduce or give force to the international human rights (Clapham, 2007, p.47).

It is worth mentioning here that the Committee's insistence on the need for the Kenyan government to implement women's rights from a purely human rights perspective seems to have made the Kenyan government adopt a future oriented language, characterized with the use of will/would/would be. This could be an evasive strategy, to circumvent the Committee's demands. Similarly, Kenya's use of a future oriented language in its interactions with the Committee appears to have influenced changes in the Committee's use of language. That is, it is arguable that the Kenyan government's repeated use of a future oriented language may have necessitated the Committee's adoption of mental processes as a counterstrategy to the government's anticipatory discourse. In addition to several other instances, this framing practice on the part of the Committee is evidenced in section 4.4.6, where mental process are extensively exploited as a counter-strategy to the Kenyan government's policy formulations privileging future actions. As noted earlier in the ongoing analysis, Mulila notes that mental processes are processes of sensing and are expressed by verbs that involve cognition, reaction and perception (Mulila, 2014, p. xiv). This suggests that the Committee's repeated use of mental processes such as "hoped" and "concerned" in its interactions with the 
Kenyan government, is a reaction to the Kenyan government's repeated use of language with futurological policy orientations. In other words, the repeated use of a future oriented language points to the use of "influence and power" (Bhatia, 2006, p.180) which the Kenyan government deploys so as to predetermine the Committee's future behaviour. For instance, in its concluding remarks to the Kenyan government (i.e. during their oral discussion discussed in section 4.4), the Committee stated that it "hoped that the Committee would in future receive good news from Kenya regarding the implementation of the Convention, and that the new Constitution would bring about the elimination of discrimination against women" (Committee, 2003b, p.7), my emphasis). Taking note of the Committee's use of the future oriented mental process verb "hoped" above, it is arguable that the Committee acquiesces to the government's future policy actions, hence the fact that both the government and the Committee are in a state of "deontic congruence" (Stevanovic \& Perakyla, 2012, p.303). This is in view of their shared action frame in the anticipated future policy actions. In other words, by accepting through mental process to see changes in the Kenyan government's policy practices, the Committee can be said to be as well committing itself to the government's stated future policy actions. But it needs to be stressed that this is because the Committee effectively has no choice but to accept promises, on account of its lack of the power to enforce.

At the same time, however, it should be noted that the Committee does not ultimately retract its demands. This is an important point, because in its assessment of the Kenyan government's combined initial and second periodic reports, the Committee had stated that it recognized the fact that Kenya' reports had to be assessed "against a background of specific cultural attitudes," that had a huge impact on the situation of women in Kenya (Committee, 1993, p.2). It might appear, therefore, that the Committee is open to being influenced by the different ways in which Kenyan policy makers frame aspects of culture in their periodic reports, hence its shift from a purely authoritative stance, to a more accommodative and/ or internally persuasive discourse that considers the cultural relativist ideas of the Kenyan government. This influence was temporary, however, as the Committee in its subsequent assessment of the combined second and third reports, consistently and firmly calls upon the Kenyan government to eliminate cultural values that violate the rights of women, thereby realigning its (Kenya's) cultural relativist perspectives of women's rights with the universalist viewpoints about gender equality. One is led to conclude that the earlier accommodation was a rhetorical concession for the purpose of aiding Kenya's induction into the compliance process at that early stage of her participation in the convention. 
A further important issue is that differing ideological controversies were found to influence both the Committee's and the Kenyan government's choice and use of a diversity of discourses, genres, styles with manipulative tendencies, pointing to power struggles and political differences. For instance, the Committee's formulations that seek to impose universalist understandings of equality with a "normative charge" (Nash, 2002, p.9), seem to have moved the Kenyan government to adopt recontextualizing strategies cleverly deployed to serve a gatekeeping role of preventing the state's gender policy from being colonized by the normative discourse of women's rights. For instance, this is noted in 4.4.1 above, where the Kenyan government defines discrimination against women discursively to include "race, pregnancy, marital status, ethnic origin and sex", thereby displacing gender as the core focus of the normative gender equality policy. This formulation as I continue to argue, is one example of the subtle forms of evasion deployed by the Kenyan government to avoid making total commitment to secure the rights of women.

\subsubsection{Differing orientation}

This chapter sought to determine whether there are any (mis) translations by the Kenyan government of the initiatives coming from the United Nations. In the light of this inquiry, the core issue emerging from this discussion is that as both the Kenyan government and the Committee seek to outmanoeuvre one another, at issue are power struggles and ideological controversies underlying their understandings of gender equality policies. For instance, whereas the Committee from the perspective of change emphasizes the implementation of gender equality policies through inclusion of women in politics, and the elimination of gendered structures in society, i.e. "by means of a true rights-based approach to women's issues in all areas" (Committee, 2003a, p.4), the Kenyan government espouses inclusion and diversity, with emphasis on the improvement/ advancement of women's situation. This is noted above, for instance, when the committee advised the Kenyan government to implement "gender equality", and "not merely gender equity..." (Committee, 2003a, p.4). The Committee's viewpoint here seems to draw from the United Nations' statute which states that:

A human rights-based approach ensures that human rights standards, as established in international law, are applied as a criterion for policy orientation and for the solution of problems in specific areas. It introduces a normative 
basis, which is obligatory for States Parties, and thus requires a legislative response at the State level. A rights approach implies that "beneficiaries" of policies and activities are active subjects and "claim holders" and stipulates duties or obligations for those against whom such claims can be held (duty bearers) (United Nations, 1998, cited in Powell, 2005, p.607).

This distinction is the bone of contention between the Committee and the Kenyan government (see 4.4.4). That is, in the light of the Committee's views examined above, Kenya's privileging of the equity approach over the equality approach to gender equality policies can be said to constitute a mis-translation of the Committee's initiatives to promote gender equality, which emphasizes the use of a gender equality criterion and "a true rightsbased approach to women's issues in all areas" (Committee, 2003a, p.4). 


\section{KENYAN WOMEN'S NGOS AND THEIR APPROACHES TO INFLUENCE GOVERNMENTAL POLICIES}

\subsection{Introduction}

The previous chapter focused on the intertextual interactions between the United Nations and the Kenyan government in relation to gender equality policies. The current chapter discusses the intertextual interactions between the women's NGOs and the Kenyan government. This involves an examination of the women's NGOs' conceptualizations of gender (in)equality. The chapter opens with a brief description concerning the women's NGOs involved in this study and the reasons for their inclusion. This will help to unravel the context within which these NGOs frame their discourse of women's rights in Kenya. Section two of this chapter discusses the actual intertextual interactions between the women's NGOs and the Kenyan government. To achieve this purpose, the study undertakes to answer the questions:

(1) What policy demands or initiatives do the women's NGOs advance to the Kenyan government in their texts on gender equality? To what extent do these demands or proposals reflect the women's rights objectives of the UN?

(2) What modes of engagement (i.e. linguistic/non-linguistic and rhetorical) are adopted or referred to by the women's NGOs in their texts addressed to or intended for the Kenyan government?

(3) What modes of engagement (i.e. linguistic/non-linguistic and rhetorical) does the Kenyan government adopt in its responses to the NGOs' policy proposals and/or demands regarding gender equality?

(4) What (changing?) conceptions of gender relations underpin the women's NGOs' policy texts concerning gender equality?

Answers to these questions will help us ascertain the extent to which the women's NGOs in this study influence, or get influenced by the Kenyan government's policy decisions concerning gender equality. This claim draws on the available transnational feminist literature, which emphasizes the ability of the women's NGOs to exert pressure on national governments, thereby influencing their policies on gender equality (Manisha 2005; Dingo 2012). In this context, each of the above said questions will be answered on its own right as follows. 
As a means to establishing the context for the study, section 5.2 will present the women's NGOs involved in this research. Section 5.3 will discuss the women's NGOs' policy proposals or demands to the Kenyan government. This will include a description of how these policy proposals relate to the CEDAW Committee's convictions discussed in the previous chapter. Then, in section 5.4, I examine the NGOs' modes of engagement with the Kenyan government. Next, section 5.5 presents a discussion of the Kenyan government's modes of engagement with these NGOs, in terms how it responds to their policy demands. Finally, section 5.6 will explore the NGOs' conceptualization of gender (in)equality in Kenya.

\subsection{The women's NGOs involved in this study}

For a more inclusive and holistic perspective concerning gender equality policies in Kenya, this chapter includes the analysis of works from various women's NGOs. According to Weldon and Htun, "any impact on policy depends on the presence of a strong, autonomous women's movement" (Weldon \& Htun, 2012, p.240). In this context, the study purposefully selected only those NGOs that: (1) are focused on the human rights-based approach to gender equality; and (2) stand out as exceptional cases championing women's rights to gender equality, as opposed to the other NGOs that avoided political engagement with the Kenyan government in matters relating to the transformative gender equality policies. Moreover, the majority of the NGOs included in this study have established partnerships with the Kenyan government to address gender inequality issues among Kenyan women. These are briefly outlined below.

The Green Belt Movement (GBM) was set up in 1977 as an offshoot of the National Council of Women of Kenya (NCWK). Under the auspices of Professor Wangari Mathai, the Green Belt Movement strives to foster women's empowerment through civic education, including such issues as democratic governance, justice, women's rights, and environmental management.

The Association of Media Women in Kenya (AMWIK) was established in 1983 as an NGO for women journalists and communicators. It seeks to use the media to create public awareness concerning matters affecting women in society, including helping to construct a positive image about women. Moreover, AMWIK provides training programmes for journalists regarding women's rights, including empowerment programmes for women to enhance their capacity to influence public policy and decision-making structures. 
The African Women and Child Information Network (henceforth AWC) was established in 1994 with the aim of helping to mainstream gender equality in and through the media (AWC 2004). In this context, focused on both women and children (i.e. girl child), AWC undertakes to promote such issues as gender equality, gender equity, and social justice through the media, training and research.

The Federation of Women Lawyers-Kenya (FIDA-Kenya) was established in 1985 following the 3rd UN conference on women held in Nairobi. It endeavours to provide legal services for women, enhance public awareness on the rights of women, including research and training programmes on gender and legal conventions. Also, as the autonomous NGO with both the observer status, and special consultative status with the United Nations' conventions and treaties, FIDA-Kenya lobbies for continued implementation of laws and policies concerning the rights of women.

Founded in 1992, the League of Kenya Women Voters (hereinafter LKWV) champions women's rights in the areas of political leadership and decision-making. In this context, the LKWV lobbies for legislative reforms in favour of women, including doing research and advocacy on matters appertaining to women's empowerment and gender equality policies.

The Women's Political Alliance Kenya (WPA-K) was formed in 2001 as an umbrella organization for women members of parliament, women civic leaders, and women professionals. It seeks to enhance the implementation of gender equality policies, as well as promoting women's capacity for participation in politics, leadership positions, and other decision-making structures.

With the core aim of championing the expansion and actualization of women's rights in Kenya, the Centre for Rights, Education and Awareness (henceforth CREAW) was founded by women lawyers in 1998. In this respect, as a women's NGO, CREAW seeks to enhance public awareness concerning women's rights through education, training and research, including lobbying for policies that uphold women's rights to gender equality.

The following analyses draw on the texts listed below as a representative range for illustrating the NGOs' part in the ongoing intertextual interactions between the women's NGOs and the Kenyan government.

-Bottle-Necks of Development in Africa, Speech presented by Professor Wangari Mathai, Chairlady, the Green Belt Movement, at the 4th United Nations' Conference for Women in Beijing, China, August 30th -15th September 1995 
-Bado Mapambano-Kenyan Women Demand their Rights: The 1997 FIDA (K) Annual Report on the Legal Status of Kenyan Women

-The Women's Reforms Initiative: A Document of the Kenya Women's Political Caucus, 1997

-Engendering the Political Process in Kenya Using the Media, paper presented by Ms Rita Mainga, the Programme Assistant, AMWIK, at the East African Women's Leadership Institute of Akina Mama Wa Africa, September 22nd -3rd October 2003, Entebe Uganda

- Kenya Human Development Report, 1999

-Women Political Participation in Kenya" paper presented by Faith Kasiva, Programmes Coordinator, WPA-K, at the East African Women's Leadership Institute of Akina Mama Wa Africa, September 22nd -3rd October 2003, Entebe Uganda

-The constitution of Kenya, 1998, 2001, Republic of Kenya

-Women's Rights As Human Rights in Kenya: A Contradiction between Policy and Practice. Occasional Paper Number 01/2004, AWC

-Parliamentary Survey Report, 2004, FIDA-Kenya

-The Cracked Mirror, 2004, Mathai, Chairlady, the Green Belt Movement

-The Kenya Women's Manifesto, 2005, LKWV

-Towards the Promise of Gender Equality...Will the Millennium Development Goals take us there? : 2005 Annual Report, FIDA-Kenya

- Report of a Baseline Survey on the level of awareness and impact of CEDAW on Rural Women in Kenya, 2006, FIDA-Kenya

- Status of Women and Girls in Kenya: Urgent Need to Uphold Human Rights, 2007, CREAW)

- Beijing +15-How Far Have We Come, How Far to Go?: Assessing the Implementation of the Beijing Platform for Action in Kenya, November 2009, Association of Media Women in Kenya, African Women's Development and Communication Network, Centre for Rights Education and Awareness, Federation of Women Lawyers, Kenya, Girl Child Network, GROOTS Kenya, and Maendeleo ya Wanawake Organization. 
- Beyond Numbers: Narrating the Impact of Women's Leadership in Eastern

Africa. Nairobi: The African Woman and Child Features Service (AWC 2010)

\subsection{Constitutional review process and gender equality concerns}

The discussion in this section draws on the textual interactions between the women's NGOs and the Kenyan government during the Constitution of Kenya Review Process. As explained in the next chapter, demands for women's rights to gender equality in Kenya began to capture the Kenyan government's attention in 1993, hence the formation of the "Task Force to Review Laws Relating to Women” (see 6.2). However, the Kenyan government never acted on the recommendations of the aforesaid task force, thereby fuelling women's NGOs' continued agitation for gender equality policies. In this context, FIDA-Kenya notes that the 1997 Constitution of Kenya Review Commission provided the representatives of the women's NGOs and other interested parties a window of opportunity to tender their proposals as well as to negotiate for gender equality policies. As stated in its report titled: "Bado Mapambano-Kenyan Women Demand their Rights: The 1997 FIDA-Kenya Annual Report on the Legal Status of Kenyan Women," FIDA-Kenya explains that:

1997 marks a watershed year in respect of pressing for woman friendly law reform in Kenya. 1997 is the year in which Kenyan women finally collectively articulated their demands for inclusion in the constitutional reform process...women have been excluded from several of the emerging constitutional dialogue mechanisms... (FIDA-Kenya 1997, pp.22-26).

In Faircloughian terms, the year 1997 can be said to involve the "moments of crisis" (Fairclough 1992, p.230) in the history of the discourse of women's rights in Kenya. This is in view of the fact that the women's NGOs seized the forum provided by the Kenyan government's constitutional reform process to have their voices included in the mainstream policy making agenda. Taking this into account, in what can be termed "a broad-based collective resistance" (Ganesh, Zoller \& Cheney, 2005, p.175) against the Kenyan government's lack of gender equality policies, the women's NGOs made their demands to the constitutional reform process. As FIDA-Kenya explains, these demands were jointly made by all NGOs under the umbrella organization of the women's NGOs in Kenya, the Kenya Women's Political Caucus. As FIDA-Kenya proceeds to explain, the NGOs' demands were made in the form of a document titled: "the Women's Reforms Initiative: A Document of the 
Kenya Women's Political Caucus" (FIDA-Kenya, 1997, p.22), through the Inter-Parties Parliamentary Group (IPPG). Also, FIDA-Kenya notes that on May $11^{\text {th }} 1998$, it presented a document titled "Women as Partners within the Constitution Review Process," to the Parliamentary Committee on the Constitutional Review Process at Bomas of Kenya (FIDA2004, p.11). In this context, FIDA-Kenya notes that through these documents, they made a number of demands to be addressed in the constitutional review process in favour of women. These are analysed in detail below.

\subsubsection{Women's political participation and affirmative action policies}

Drawing attention to several areas concerning women's rights to political participation, the NGOs made a series of demands to the Kenyan government. First, as FIDAKenya notes, the NGOs demanded that the constitutional reform process had to include women's issues as part of the review agenda (FIDA-Kenya, 1997, p.22). Second, FIDAKenya says that the NGOs requested that the process of amending the constitution of Kenya and other laws be inclusive of women (FIDA-Kenya, 1997, p.22). These demands can be inferred from FIDA-Kenya's text below:

The Kenya Women's Political Caucus' raised the issue of the exclusion of women from the evolving dialogue mechanisms... The Caucus demanded that: At least half of all persons sitting on bodies involved in reviewing and reforming the Constitution, be women. That women be represented in the constitutional reform process in their heterogeneity i.e. across lines of race, class, religion, age, ability etc (FIDA-Kenya 1997, p.23)

Third, with an intertextual reference to Article 4 of the Women's Convention, FIDAKenya reports that the NGOs proposed the need for the Kenyan government to adopt and legalise affirmative action policies to promote women's participation in the public sphere of their lives, including the request to "reserve at least $30 \%$ of the seats in parliament for women" (FIDA-Kenya, 1997, pp.21-26).

\subsubsection{Definition of discrimination in the Kenyan constitution}

As part of their proposals, the NGOs demanded that section 82 (3) of the Kenyan constitution be adjusted to include the word "sex" in its definition of the term discrimination. 
As FIDA-Kenya (1997, p.24) puts it "Women wanted section 82(3) to be amended to include the word sex to ensure that sexism was recognized, under the Constitution, as a form of discrimination." It must be emphasized that the NGOs' proposal here echoes the CEDAW committee's view that Kenyan laws are explicitly discriminative against women, hence the call on the Kenyan government to amend the constitution and add the word "sex" to its definition of discrimination (see section 4.2). This is in line with article 2(g) of CEDAW, which calls upon national governments to "To repeal all national penal provisions which constitute discrimination against women" (United Nations 1981).

\subsubsection{Citizenship rights}

With refrence to article 9 of CEDAW that obligates national governments to grant women and men their citizenship rights on equal basis (United Nations 1981), the NGOs demanded that sections 90 and 91 of the Kenyan constitution be amended to guarantee Kenyan women their citizenship rights on equal basis with their male counterparts (FIDA-Kenya, 1997, pp.22-28). This proposal is better captured by Ms Judy Thongori, head of litigation, and deputy executive director, FIDA-Kenya. In her submission to the Constitution of Kenya Review Commission, Thongori (2003, pp.184-187) argued that:

Sections 90 and 91 discriminate against women in not giving them a right to bequeath citizenship to their foreign husbands or children born out of those unions. Sections 90 and 91 generate the continuation of sexist immigration policies...The current discrimination in the citizenship rules should be removed and discrimination on the basis of sex in politics or laws specifically outlawed.

Tracing the source of Thongor's text above, I find it in Sections 90 and 91 of the Kenyan constitution that states:

A person born outside Kenya after 11th December, 1963 shall become a citizen of Kenya at the date of his birth if at that date his father is a citizen of Kenya. A woman who has been married to a citizen of Kenya shall be entitled, upon making application in such manner as may be prescribed by or under an Act of Parliament, to be registered as a citizen of Kenya (Republic of Kenya, 2001, p.48). 
Consequently, FIDA-Kenya (1997, p.24) notes that the NGOs demanded that section 91 of the Kenyan constitution be amended and re-written in a gender neutral language to read "A person married to a citizen of Kenya shall be entitled, upon making application in such manner as may be prescribed under an Act of Parliament, to be registered as a citizen of Kenya." Remember that the CEDAW committee continues to demand that the Kenyan government amends its laws relating to women's citizenship rights in line with the Convention (see 4.5.5).

\subsubsection{Gender equality machineries}

On the particular issue of gender equality machineries i.e. "formal government structures assigned to promote gender equality and/or improve the status and rights of women" (McBride \& Mazur, 2012, p.4), the NGOs demanded that the Kenyan government set up a Gender Commission to monitor the implementation of gender equality policies (FIDA-Kenya, 1997, pp.22-28). In this context, as FIDA-Kenya (1997, p.26) states, the women's NGOs argued that:

In order to ensure that the Government does not renege on promises made in respect of woman-friendly international human rights instruments, the Women's caucus recommends... That there be a Gender Commission set up under the Constitution, the purpose of which shall be to monitor Government's implementation of legal and policy measures necessary to ensure the equality of women and men.

Though not explicitly stated in the NGOs' text above, this proposal draws intertextually on the1995 Beijing Declaration and Platform for Action (United Nations, 1995), which emphasized the need for the UN member states to establish national machineries to help provide the framework for adopting and implementing gender equality policies. This includes the recommendation that the women's NGOs should work in collaboration with the "national machinery for the advancement of women," in the designing and implementing of programmes that promote the rights of women (art. 245, United Nations 1995). 


\subsubsection{Gender-based violence and sexual harassment against women}

With implicit intertextual reference to article 29 of the Beijing Declaration and Platform for Action that calls on national governments to "Prevent and eliminate all forms of violence against women and girls" (United Nations, 1995), the women's NGOs asked the Kenyan government to enact "A bill explicitly and specifically prohibiting domestic violence" (FIDA-Kenya, 1997, p.27). In a similar vein, FIDA-Kenya (1997, p.27) notes that as a means of curbing early marriage of girls, the NGOs demanded that a law be introduced in Kenya specifying "a uniform minimum age for marriage," and that that age "be 18 years of age."

\subsubsection{Law of succession}

In relation to women's rights to own and inherit property, the NGOs drew on the topos of disadvantage (Reisigl \&Wodak, 2001) to argue that Cap. 160 of the Succession Act denies Kenyan women the right to own and inherit property on equal terms with men. The Law of Succession is an Act of Parliament that relates to the inheritance, control, management, and ownership of estates and/or property of deceased persons (Republic of Kenya, 2012, p.7). In this regard, as FIDA-Kenya reiterates, the NGOs recommended the need for the Kenyan government to amend "the Succession Act Cap. 160 of the Laws of Kenya," both to grant daughters the right to inherit property, as well as allowing wives/women to inherit their husbands' property whenever they (husbands) die (FIDAKenya, 1997, p.27). Notice that though the committee had questioned the Kenyan government's legal system that continues to allow men as the sole owners of land and other forms of property (see 4.2), the Kenyan constitution is yet to be amended to grant women their equal rights to property ownership.

\subsubsection{Compliance with international treaties and conventions}

On the issue of the Kenyan government's compliance with international treaties and conventions, the women's NGOs made three major demands. First, they demanded that the international human rights conventions and treaties concerning women's rights be incorporated into Kenya's domestic law. Second, the NGOs demanded that Kenya should comply with its obligation under international law and submit reports to the treaty body for the women's convention. Finally, drawing on the topos of advantage (Reisigl \&Wodak, 2001; 
Kwon, Clarke \& Wodak 2009), the NGOs demanded that the Kenyan government should accede to Article 13 of the women's convention, so as to promote Kenyan women's socioeconomic rights (FIDA-Kenya, 1997, pp.22-28). These demands are evident in the excerpt below:

The Women's Caucus recommends that international human rights instruments pertaining to women's human rights be incorporated into Kenya's domestic law...That Kenya comply with its requirements under international law and report to the treaty body for the Women's Convention, the Committee on the Elimination of All Forms of Discrimination Against Women (hereinafter CEDAW) ... In order to further enhance the socio-economic rights of Kenyan women, the Government, should ratify Article 13 of the Women's Convention (FIDA-Kenya 1997, p.24-26).

It must be recalled that the CEDAW committee continues to emphasize the need for the Kenyan government to adopt the Convention (see section 4.5.1), including submitting periodical reports detailing its (Kenya's) progress in implementing gender equality.

From the foregoing discussion, it is evident that the NGOs' policy demands to the Kenyan government draw on the United Nations' imperatives concerning the implementation of gender equality (see illustrations in sections 5.3.1 to 5.3.7). The following section addresses the NGOs' strategies for engaging with the Kenyan government. The Kenyan government's response to the NGOs' policy proposals can be evidenced from the discussion below.

\subsection{NGOs' modes of engagement with the Kenyan government}

In an effort to have their policy demands listened to and/or adopted by the Kenyan government, the NGOs in this study adopted different modes - mainly but not exclusively textual - of interacting, and/or engaging with the Kenyan government. These are described in the ensuing discussion.

\subsubsection{Training and consciousness-raising programmes}

In response to the existing lack of political will and negative attitudes towards women's participation in politics and other decision-making structures (see 1.3), the women's NGOs drew on the transnational feminist advocacy strategies of training and consciousness 
raising to propose ways of sensitising the Kenyan government's officials and aspiring women politicians about gender equality policies. This was particularly in relation to the existing gendered stereotypes of women, and the different ways in which political leaders used such stereotypes to position women. In this context for instance, with the intent of bringing about increased women's representation in politics and decision-making positions, AMWIK designed a broad based training programme to educate aspiring women politicians about how to articulate their political interests as a right. This is reiterated in a transcript from a speech titled "Engendering the Political Process in Kenya using the Media," presented by Ms Rita Mainga, the Programme Assistant, Association of Media Women in Kenya, at the first Eastern African Women's Leadership Institute of Akina Mama Wa Africa on 22 September 2003, at Entebe, Uganda. As Mainga explains, training and awareness programmes involved not only the aspiring women politicians, but also educating news editors in the Kenyan government's mainstream media houses about their role in promoting a good image of women in society. Following these training and awareness raising programmes, Mainga explains that a number of women were able to articulate their interests as demonstrated through their consequent ascendance to leadership positions within the government (Mainga, 2003, pp.82-83). This is explained in the extract below:

The Association trained 148 women out of the targeted 160. AMWIK also profiled various women both in the print and electronic media through radio programmes and newspaper articles. Three women that the Association trained were elected into parliament. They include: Linah Jebii Kilimo, MP Marakwet West, Alicen Chelaite, MP Rongai and Cecily Mbarire, nominated MP. Hon Kilimo is a Minister in the Office of the Vice President, while Hon. Chelaite is an Assistant Minister in the Ministry of Gender and Sports. All the three women were first entrants in parliament (Mainga, 2003, pp.82-83).

According to Dejaeghere and Wiger (2013, p.557), the feminist advocacy strategies of training and consciousness raising entail a discursive arena where members of subordinated social groups circulate counter-discourses. Taking this argument into consideration, AMWIK's training of aspiring women politicians can be interpreted as being part of its attempt at creating "counter-spaces" (Dempsey, Parker \& Krone, 2011, p.213) within which women can begin to articulate their resistant politics against the Kenyan government. This includes ensuring women's active participation in restructuring the existing unequal power relations between men and women that are the main source of their unequal status in society. 
Following a similar line of action as AMWIK's, FIDA-Kenya initiated collaborative processes between itself and Kenyan government officials, as a means of influencing national policies on gender equality. In this case, FIDA-Kenya (2004, p.41) details its engagements with Kenyan MPs through training and awareness raising seminars and workshops. This involved sponsoring the Kenyan government's MPs' tour of Scandinavian Countries (Norway and Sweden), to learn the application of laws and policies concerning women's rights to gender equality. These seminars and training programmes as FIDA-Kenya continues to state, were aimed at influencing Kenyan MPs to support legislative and policy changes in favour of women. This is stated in its publication titled "Parliamentary Survey Report 2004," which stresses that:

FIDA expects the MPs to use the knowledge, attitudes and skills gained to initiate gender sensitive motions, articulate gender dimensions of parliamentary Bills, make gender responsive public pronouncements, press for domestication of international instruments into national law and mainstream gender in party structures, legislation and their routine activities (FIDAKenya, 2004, p.11).

According to Gelb (2003, p.13), policy actors can pursue insider or outsider strategies to affect policy making processes. Within this context, Gelb (2003, p.13) states that NGOs can gain access to those entrusted with the task of making decisions, educate the public and mobilise them to support a particular policy agenda. In effect, as Gelb (2003, p.13) notes, their efforts may bring about more radical structural transformative ideas "inside" the policy agenda. This includes allowing feminists to gain greater legitimacy and enter public discourse, thus altering policies. Based on this approach for instance, FIDA-Kenya (2004) argues that after familiarising MPs with gender equality issues and legal conventions between the period 1998 and 2004, great changes were noted. That is, FIDA-Kenya (2004, p.20) explains that a working relationship was established between it and the Kenyan parliamentarians. Further, FIDA-Kenya (2004, p.20) reiterates that a change of attitude to issues of women was noted amongst these MPs, as "evidenced in their greater appreciation of the need for gender mainstreaming," including their reduced hostility towards FIDA-Kenya, and willingness to "vote for gender responsive Bills.".

Likewise, as the training and awareness-raising architect, FIDA-Kenya (FIDA-Kenya, 2005 , p.17) pioneered the sensitization and training programmes on gender and human rights for the Kenyan police. In this regard, FIDA-Kenya chaired a series of meetings with the 
police officers to teach them about gender issues and women's rights. As a result, FIDAKenya (2005, p.17) argues that the training of police officers at Kiganjo Police Training College culminated in the production of a Police Training Manual on Gender and Human Rights. In addition, FIDA-Kenya (2004, p.17) states that more than ten thousand police officers have been trained since the inception of this programme in 1996, and that the training project has been extended to several police units and training colleges across Kenya.

These training programmes and awareness-raising campaigns were not only focused on the Kenyan MPs and police officers per se, but also Kenyan women and the general population. For instance, with manifest intertextual reference to the civic education efforts of the League of Kenya Women Voters (i.e. another women's NGO), FIDA-Kenya invokes the verbatim report by Beatrice Konya, an employee of the League of Kenya Women Voters. The following is a transcript from her recorded statement with FIDA-Kenya:

We had just sent out invitations to our monthly teas and we were due to start collaborating with Maendeleo Ya Wanawake on civic education... (Konya, 1997, cited in FIDA-Kenya, 1997, p.8).

This extract illustrates that as part of their commitment to bring about gender equality policies in Kenya, NGOs (e.g. the League of Kenya Women Voters and Maendeleo Ya Wanawake Organization mentioned above) provided Kenyan women and other members of the public with civic education concerning gender and women's rights.

\subsubsection{Praise and criticism}

As part of their discursive strategies for engaging with the Kenyan government from a variety of angles, the NGOs' texts under discussion use praise in combination with an overriding critique. Focusing first on the critical tone of the texts, repeatedly, and sharply, NGOs criticise the existing contradictions between the official gender policy and practice. For example, the LKWV (2005) criticizes the Kenyan government's inability to enforce laws abolishing discrimination on the basis of sex. As such, with intertextual reference to the Kenyan constitution, the LKWV (2005, p.11) notes that while there are laws against discrimination on grounds of gender in Kenya, "the treatment meted out to women and girls is in practice determined, not by what the Constitution or the written laws say, but by the traditions and attitudes of Kenyan communities." In this context, the LKWV gives a number of examples to prove its claims. First, it argues that though the Marriage Act specifies that a 
man and woman can only get married after attaining the age of 18 years, the Kenyan government permits customary laws that "allows a man to marry as many wives as he wishes, while Islamic law allows a man to marry four wives at any time" (LKWV, 2005, p.32).

On its part, FIDA-Kenya criticises President Daniel Moi, the Kenyan president, with regard to his remarks concerning civic education for women. In this particular case, FIDAKenya indicts president Moi for his negative remarks about the NGOs' civic education activities for women as a "waste of money," and his advice that instead, such money should be used "to educate the street boys" (LKWV, 1997, cited in FIDA-Kenya, 1997, p.8). Paradoxically, President Moi's remarks run contrary to the stipulations of the Kenya Government Sessional Paper No. 2 of 1992, which as FIDA-Kenya argues, "proposes policy measures designed to incorporate gender concerns in civic education as well as raising gender awareness in all sectors of the economy" (FIDA-Kenya, 2006, p.15).

As regards violence against women, FIDA-Kenya criticizes the Kenyan government for its reluctance and lack of political will to address gender-based violence against women. In this case, FIDA-Kenya blames domestic violence against women on the existing culture of impunity among Kenyan police officers for harassing women victims of violence. On a similar note, FIDA-Kenya indicts the Kenyan government for failing to put in place policies to curb the ongoing violence against women.

Similarly, in its report titled "Report of a Baseline Survey on the level of Awareness and Impact of CEDAW on Rural Women in Kenya, 2006," FIDA-Kenya (2006, p.35) notes that the main hindrance to curbing violence against women remains the "lack of adequate laws to protect women against domestic violence and sexual abuse." In this context, FIDAKenya criticises the Kenyan government's concept of rape on several accounts. First, FIDAKenya (2005, p.37) emphasizes that the Kenyan constitution does not conceive of rape as being possible in marriage, because "a husband cannot rape his wife as consent is implied." Second, with manifest intertextual reference to the Kenyan constitution, FIDA-Kenya (1997, p.41) argues that "under the Penal Code Chapter 63 of the Laws of Kenya, rape, incest, sexual harassment and other forms of sexual assault are considered offences against morality, and not offences against the person.” As a consequence, FIDA-Kenya (2005, p.37) points out that the Penal Code interprets the perpetrator as "any person," rather than "any man."

Furthermore, FIDA-Kenya (1997, p.41) stresses that the concept of "offences against morality," exposes the underlying Victorian moral philosophy of Chapter XV of the Penal Code which is more about controlling sexuality than protecting women and girls from sexual assault. From within this frame of reference, FIDA-Kenya (1997, p.41) criticizes the Kenyan 
government's concept of rape, arguing that as an act of violence, rape is literally equated with a consensual sexual activity defined as "carnal knowledge against the order of nature." Notice that FIDA-Kenya's criticism of the Kenyan government's policies under discussion is akin to the transnational feminist strategy of "reinterpretation of official policy texts" (Ackerly, 2001, p.324) (see section 2.4.7.3), as a means of disrupting naturalised ways of thinking that marginalize women's interests (Farrel \& MacDermott, 2005). According to Nylund (2011, p.125), reinterpretation (i.e. infusing texts with preferred meanings) is an aspect of recontextualization, and an act of control by the speaker or writer aimed at blocking "dispreferred meanings" in particular contexts. For instance, as discussed above, FIDAKenya (2005, p.37) reinterprets the Kenyan government's use of “any person” (i.e. dispreferred meaning), to describe a perpetrator of violence against women, and instead argues for the use "any man."

According to Fairclough (1989, pp.88-89), "having the power to determine things like which word meanings or which linguistic and communicative norms are legitimate or correct, or appropriate," is a significant aspect of social and ideological power, hence a pointer to underlying ideological struggles. That is, in line with Fairclough's (1992) concept of hegemony, FIDA-Kenya's criticism of the Kenyan government's conceptualization of rape can be read as pointing to its intent of wanting to exercise some power and control over the expected meaning of the concept of gender equality under discussion.

From the point of view of Foucault's (1991) notion of governmentality, FIDAKenya's criticism of the Kenyan government's concept of rape entails an act of resistance against the Kenyan government's interpretation of gender equality concepts.

Turning to the issue of women's treatment in Kenya's criminal justice system, the women's NGOs criticise the Kenyan judicial system as being discriminatory against women, judging from the "low percentage of female judges" appointed by the Kenyan government to serve in law courts (AMWIK et al., 2009, p.34). In a similar vein, the NGOs criticise the Kenyan government's judges for their "little knowledge of gender issues and international standards on women's rights" (AMWIK et al., 2009, p.34). Extending this view, FIDAKenya (1997) blames the Kenyan government's male magistrates for promoting cultural stereotypes that continue to violate the rights of women. In this context, FIDA-Kenya (1997, p.37) indicts the male magistrates not only for treating women as "minors," but also for supporting cultural practices that endorse violence against them. For instance, FIDA-Kenya (1997, p.37) criticises the conduct of Mr G.M Njuguna, the Senior Magistrate Kiambu District, Kenya. In this case, FIDA-Kenya (1997, p.37) alleges that while making a ruling in 
court, Mr Njuguna stated that men's violence against women is "the African man's way of disciplining his wife."

Shifting its focus to formal education, FIDA-Kenya criticises the Kenyan government's Millennium Development Goals (MDGs). MDGs were adopted by the United Nations' General Assembly, through the United Nations Millennium Declaration of September 2000, with a focus on eight time-bound goals to be achieved by 2015 (United Nations, 2000). These goals included a call on the national governments to promote gender equality and women's empowerment; ensure boys and girls receive universal education; and improve maternal health among many more (United Nations, 2000). As such, with implicit reference to articles 10 and 14 of CEDAW that obligates national governments to take the necessary steps to "eliminate discrimination against women in all areas to ensure their equal access to education" (United Nations 1981), FIDA-Kenya (2005) criticizes the Kenyan government's MDGs' approach to girls' and boys' education on two accounts. First, FIDAKenya (2005, p.20) claims that the MDG approach sees boys' and girls' education as an end in itself rather than as a means to an end, i.e. achieving "gender equality and social justice." Then, FIDA-Kenya (2005, p.20) claims that the MDG approach targets "numbers," rather than the unequal power relations that hinder equal access to quality education for both boys and girls. In conclusion, FIDA-Kenya (2005, p.20) declares that:

In essence the MDGs have failed to take into account the de facto situation of girls and boys, women and men and to address the gender imbalances that impact on efforts towards achieving gender equality.

In a similar vein, FIDA-Kenya's dismisses the Kenyan government's MDG approach to women's reproductive rights. FIDA-Kenya (2005, p.21) argues that the Kenyan government focuses on reducing maternal mortality rates, as opposed to achieving women's reproductive rights. Likewise, FIDA-Kenya (2005, p.21) states that the Kenyan government's MDG approach to reproductive rights promotes the view of women primarily as "mothers and care givers," as opposed to persons with rights to their "own health and wellbeing." These criticisms against the Kenyan government's approach to gender equality policies can be said to be an aspect of the feminist strategy of politicizing (see 2.4.7.6), which as Ferree and Mueller noted, is used for mainstreaming women's rights through criticising institutional structures and policies that marginalize women's interests (Ferree \& Mueller, 2004, p.589).

However it is clearly evident that the NGOs' criticisms of the Kenyan government's approach to gender equality are articulated simultaneously with praises for the same 
government's efforts to implement gender equality policies. For instance, whereas the texts examined above show several instances of the NGOs' criticism against the Kenyan government's approach to, and position with regard to equality policies, other texts, or even the same texts, bear traces of remarks that seem to contradict this position. For example, in its annual report titled "Towards the Promise of Gender Equality...Will the Millennium Development Goals take us there: 2005 Annual Report,” FIDA-Kenya (2005, pp.22-23, emphasis added) states that:

In Kenya the Ministry of Planning is spearheading the programs towards the realization of the MDGs whereas traditionally issues to do with gender equality and women's empowerment were seen as the preserve of the Women's Bureau and now of the Department of Gender within the Ministry of Gender Culture Sports and Social services. The potential thus of the MDGs to mainstream gender equality in mainstream ministries is evident but only if the MDGs goals embrace the principles of equality as contained in the BPFA, CEDAW and ICPD among others...

This text expresses FIDA-Kenya's acknowledgement of the Kenyan government's progress towards implementing gender equality policies. This understanding is evident in the extracts "the Ministry of Planning is spearheading the programs towards the realization of the MDGs," and "The potential thus of the MDGs to mainstream gender equality in mainstream ministries is evident..." These statements contradict FIDA-Kenya's criticisms discussed earlier, alleging the ineffectiveness of the Kenyan government's MDGs approach to gender equality policies.

Whilst these contradictions may be argued to characterise FIDA-Kenya's texts per se, I wish to emphasise that the same is true for other NGOs' texts as well. For instance, contrary to the above stated allegations about the Kenyan government's police officers' reluctance to record cases of women victims of gender-based violence, AMWIK et al. et al., (2009, p.17, my emphasis) explain that:

The police Department has made some efforts to react more appropriately to $V A W$. In response to rising incidences of rape and carjacking, the police department set up a special police unit called "the Spider Squad...

The extract "The police Department has made some efforts to react more appropriately to VAW" above expresses AMWIK et al.'s praise for the Kenyan government's 
police department with regard to their efforts to address violence against women (VAW).

Arguing that criticisms and praise are "carefully managed strategies," Hyland (2004, p.45) points out that whereas giving praise implies an authority to make judgements, criticisms entail a form of evaluation of the existing knowledge, and have significant interpersonal consequences as a face threatening act. Similarly, Hyland (2004, p.45) explains that praise and /or compliment conveys support and interest, demonstrating solidarity between participants. From these perspectives, we may argue that the aforesaid contradictions and/or inconsistencies in the NGOs' texts above are part of their deliberate mitigation strategies to soften the force or effect of their criticisms, hence navigate any tensions that may constrain the interpersonal relations necessary for working collaboratively towards implementing gender equality policies.

This means that the existing contradictions or inconsistencies in the NGOs' texts entail a temporary textual strategy (i.e. use of contradictory logics), one that is both aimed at securing the Kenyan government's support for, as well as serving as a bargaining tool for alternative ways of implementing gender equality policies. My argument here finds teeth in Brown's view seen in the previous chapter (see 4.4.2), where he emphasized that praise and criticism are part of the "rhetorical forms and strategies" aimed at persuading someone to given ways of thinking (Brown, 2008, p.77).

\subsubsection{Use of authoritative texts}

As part of their discursive efforts to challenge the Kenyan government's cultural relativist approach to gender equality, NGOs' texts tend to invoke the normative discourse of women's rights. For instance, against the ongoing cases of gender based violence against women in Kenya, FIDA-Kenya (2005, p.38) emphasizes that:

The basic platform for launching the war against sexual violence is the Universal Declaration of Human Rights... In respect of the protection of the rights of women, the Convention on the Elimination of All forms of Discrimination Against Women (CEDAW), is the key document of reference.

Rhetorically speaking, the alleged limitations on the part of the Kenyan government's concept of violence against women entails a strategy for endorsing the need for the Kenyan government to adopt equality policies. In other words, the alleged Kenyan government's limited conceptualization of the key concepts underlying gender equality becomes a strategy 
for recommending the need for the adoption of the universal rights of women.

Similarly, in its publication titled "Women Rights as Human Rights in Kenya: A contradiction between Policy and Practice, Occasional paper Number 01/2004," the African Woman and Child Information Network draws on the Beijing Declaration to defend the need for women's political participation. This is reflected in the inclusion of the excerpt below from the Beijing Declaration and Platform for Action:

"Women's equal participation in decision making is not only a demand for simple justice or democracy but can also be seen as a necessary condition for women's interests to be taken into account. Achieving the goal of equal participation of women and men in decision making will provide a balance that more accurately reflects the composition of society and is needed in order to strengthen democracy and promote its proper functioning." Beijing Platform for Action (AWC, 2004, p.12).

According to Maguire and Hardy (2006, p.18), actors can strategically draw on authoritative texts that promote particular meanings to legitimate their claims for particular considerations. This could precisely be the reason behind the above stated NGOs' intertextual references to the United Nations' imperatives.

Likewise, as part of its efforts to promote women's rights to equality through policy reforms, the LKWV's texts make repeated intertextual references to the United Nation's treaties and conventions concerning the rights of women. For instance, in its publication titled “The Kenya Women's Manifesto, 2005," the LKWV (2005, pp.30-31, my emphasis) posits that:

Kenya is also a signatory to CEDAW, the Convention on the Elimination of all Forms of Discrimination Against Women (CEDAW) of 1979, which is the only human rights convention that is gender specific, and the Convention on the Rights of the Child [CRC (1989)]. The former is a useful instrument for achieving equality between women and men, due to its concern for women's equal access to, and equal opportunities in political and public life.

According to Van Leeuwen (2007, p.102), terms like "useful" and "effective" are themselves legitimatory, and are used to argue for "purposefulness, usefulness and effectiveness as criteria of truth and foundations" for conforming to given norms and ethical behaviour. In view of this argument, the use of the term "useful" above is suggestive of 
LKWV's efforts to legitimize the importance of the universal discourse of gender equality in Kenya. In this context, the NGOs' regular references to the United Nations imperatives (e.g. CEDAW and the Beijing declaration) that emphasize the transformative discourse of gender equality can be interpreted as pointing to the NGOs' call for the Kenyan government to revisit and/or return to the origins of the normative discourse of gender equality, as "the primary points of reference" for its policy practices on women, and develop "a new way of reading them" (Mona \& Stellan 2014, p.117).

From a rhetorical perspective, the NGOs' invocation of both the normative discourse of gender equality and the other NGOs' texts can be taken to mean that the Kenyan government could not argue further, or negotiate regarding the meaning of internationally agreed conceptions and approaches to gender equality.

\subsubsection{Evidentiality}

NGOs' texts examined in this study were seen to privilege "evidentiality" (Hyland, 1999, p.101; Hart, 2011, p.758) as a mode or attitude of interaction aimed at bolstering their claims and policy demands to the Kenyan government. Hyland (1999, p.101) defines evidentiality as "a writer's assessment of possibilities and indicates the degree of confidence in what is said, ranging from uncertain potentiality to categorical assurance." In addition, Hart (2011, pp.756-758) observes that evidentials serve not only to indicate how the speaker has come to know what he or she is claiming, but also play a legitimizing function in discourse. In this context for instance, the NGOs texts analysed in this study were found to be drawing on the other NGO-authored texts championing the same course, as a means of confirming the credibility of their claims to the Kenyan government. A good example to demonstrate this approach is FIDA-Kenya's invocation of “the Women's Reforms Initiative: A Document of the Kenya Women's Political Caucus," mentioned in section 5.3 above. As noted, FIDA-Kenya explained that this document was jointly produced by the women's NGOs working under the umbrella of the Kenya Women's Political Caucus, and presented to the Kenyan government via the Inter-Parties Parliamentary Group (FIDA-Kenya, 1997, p.22).

Likewise, commenting on its publication titled "Report of a Baseline Survey on the level of awareness and impact of CEDAW on Rural Women in Kenya, 2006," FIDA-Kenya (2006, p.14) emphasises that the "findings and analysis" in the report were the product of "the Principal Researchers whom FIDA-Kenya contracted from the Association of African Women for Research and Development (AAWORD-Kenya).” As Hart (2011, p.760) argues, 
invocation of "expert knowledge" attributed to a particular person, individuals or organization, is a legitimation strategy that utilizes what the "speaker assumes the hearer will consider authoritative." As a consequence, this helps to bolster the reliability of the evidence given in their text (Hart, 2011, p.760).

A similar expression of evidentiality can be inferred from AMWIK's text below. In this context, Ms Rita Mainga, the Programme Assistant, the Association of Media Women in Kenya (AMWIK) makes manifest intertextual reference to another NGO's text (i.e. the Kenya Women Political Caucus) by arguing that:

In a publication by the Kenya Women Political Caucus, $A$ Women's Political Manifesto indicates that Kenya continues to lag behind sister countries like Uganda, Tanzania, Rwanda and South Africa in women's political consciousness and effective participation. There is no doubt that Kenyan women need to continue working on defining common interests that can unite them across ethnic, religious or economic divides (Mainga, 2003, p.83).

It can be noted in advance here that this recurring tendency of making manifest intertextual references to the texts of other NGOs is one characterizing feature of the women's NGOs' texts that appears to be absent in the texts produced by the Kenyan government analysed in the next chapter.

This framing style of invoking other NGOs' texts may be explained from two perspectives. First, drawing upon the texts of other NGOs can be said to be rhetorically tailored at signalling the NGOs' level of commitment and shared aims and interests in gender equality policies. Second, this could be a mechanism for maintaining interaction with other policy actors through "building a convincing argument" concerning particular issues of interest to them all (Hyland, 1999, p.99).

\subsubsection{Cooperation}

The best example to illustrate the use of cooperation as a mode of interaction is the NGOs' willingness to engage in dialogue with the Kenyan government through the InterParties Parliamentary Group mentioned above.

Another example of the NGOs' use of cooperation as a means of interacting with the Kenyan government is the coming together of the NGOs under the umbrella organization of the women's NGOs in Kenya, the Kenya Women's Political Caucus, and their jointly 
produced document “the Women's Reforms Initiative: A Document of the Kenya Women's Political Caucus" (FIDA-Kenya, 1997, p.22) (see 5.3). This was part of the NGOs' collective efforts to win the Kenyan government's attention to their cause. As noted above, this approach enabled them to secure their place in the policy making process through the appointment of women to participate in the Constitution of Kenya Review Commission.

Also, the above said FIDA-Kenya's training of the Kenyan government's MPs and police officers entail part of the NGOs' use of cooperation strategies to lobby the Kenyan government's support for gender equality policies.

The same approach was seen during the face to face discussions between the CEDAW committee and the Kenyan government's officials (see 4.4.2). In this context, for instance, it can be noted that some of the Kenyan government's officials engaging the CEDAW Committee were representatives of the Kenyan women's NGOs (i.e. FIDA Kenya and Maendeleo Ya Wanawake Organization).

However, contradictions are noticeable in the NGOs' rhetorical positions while interacting with the Kenyan government and the CEDAW committee. That is, in their interactions with the Kenyan government witnessed above, the NGOs' texts are largely characterised by blame and criticisms alleging the Kenyan government's failure to implement gender equality policies. To the contrary, during their face to face discussions with the Committee, the same NGOs' representatives working in partnership with the Kenyan government's officials were noted to be defending the Kenyan government's efforts towards implementing gender equality (see 4.4.3). Nevertheless, rhetorically speaking, such contradictory logics could be part of the NGOs' bargaining strategies for engaging with the Kenyan government.

On top of the above mentioned examples, using the topos of history (Reisigl \&Wodak, 2001), FIDA-Kenya (2005, p.20) explains that upon noticing that the Kenyan government "has no comprehensive law enforcement programs targeting trafficking in persons," they began a network of sharing information. In this context, FIDA-Kenya (2005, p.32) says that in January 2005, while working in partnership with the Association of Media Women in Kenya (AMWIK), and Women and Law in East Africa (WLEA), they began a network of sharing information and referrals regarding the trafficking of persons. As a consequence, FIDA-Kenya explains that a number of the Kenyan government's Ministries joined this endeavour.

From these arguments, it can be argued that the NGO's training programmes and awareness-creation campaigns with the government officials were part of their discursive 
tools for shaping the Kenyan government's view of women's issues, thereby ensuring its compliance with gender equality policies.

\subsubsection{Shaming through comparison}

In what can be taken to signpost the NGOs' realization of the Kenyan government's lack of political will to adopt affirmative action policies wholesale, the NGOs resort to shaming strategies through the use of comparison and/ or relational approaches (DeJaeghere, Parkes \& Unterhalter, 2013, p.543). In this case, to show how the Kenyan government's gender policies deviate from the norm, the NGOs' texts regularly compare Kenya's gender policy practices with those of the neighbouring countries. This approach is for instance utilized by Ms Mainga of AMWIK mentioned elsewhere in this discussion (see 5.4.4), whose quote we have seen above and which I repeat here. In this regard, with manifest intertextual reference to another NGO's text, Ms Mainga (2003, p.83) says that:

In a publication by the Kenya Women Political Caucus, $A$ Women's Political Manifesto indicates that Kenya continues to lag behind sister countries like Uganda, Tanzania, Rwanda and South Africa in women's political consciousness and effective participation. There is no doubt that Kenyan women need to continue working on defining common interests that can unite them across ethnic, religious or economic divides.

From this extract, we can argue that by comparing the Kenyan government's policy actions with those of other countries, Ms Mainga could be wanting to shame, and hence soften the Kenyan government's position towards embracing a transnational approach to gender equality policies. This line of thinking can also be inferred from CREAW's (2007, p.29) text below concerning affirmative action policies:

borrowing from the Somalia experience, Kenya needs to entrench affirmative action into the current constitution so that the prejudices that have existed against the minorities and women can be remedied and overcome

In a way, we could argue that just like AMWIK, CREAW's text above draws on the policy experiences of other countries with the strategic objective of seeking to construct facts about the Kenyan government's lack of concern for equality policies. In other words, by drawing upon the examples of Kenya's neighbouring countries, the NGOs position the 
Kenyan government negatively, in terms of being in constant breach of the universal human rights norms.

\subsubsection{Shaming through women's narratives}

In giving public voice and expression to women victims of gender-based violence, NGO's texts intertextually incorporate narratives from Kenyan women as part of their shaming strategy. That is, as a means of contesting and publicly exposing the Kenyan government's complicity with regard to the ongoing violations of women's rights, NGOs use narratives from the women victims of gender-based violence. For instance, in its annual report titled "Bado Mapambano-Kenyan Women Demand their Rights: The 1997 FIDA (K) Annual Report on the Legal Status of Kenyan Women," FIDA-Kenya draws on several narratives from women victims of gender-based violence. One example involves a story from Agnes Siankoi, who is said to have been married off by her father to his friend, thereby becoming a victim of early marriage and domestic violence:

I have suffered for a very long time. I was married as a child in 1984 just after I had finished standard 7. Even though I had been accepted to high school. I couldn't go because I was married. I was married as a second wife. I never felt free because I had married an old man. He was 40 and I was 18 years old. I was not happy. I was married into a home where there were girls my own age. I was not allowed to style my hair because it was assumed that I was looking for a man. In 1985 I had my first child... I had a baby girl. I was beaten very badly by my husband. He even hit my 2-month old baby girl who I was carrying. She still has a scar... (FIDA- Kenya, 1997, p.34).

From Fairclough's (1992) view of discourse as action, FIDA-Kenya's use of women's experiences (narrative intertextuality) in the text above can be said to be part of its textual strategies for shaming the Kenyan government by exposing the problems Kenyan women are going through as a result of the Kenyan government's failure to implement women's rights to gender equality. Terming it mythopoesis (i.e. legitimation achieved through the telling of stories), Van Leeuwen and Wodak argue that stories are not only taken as evidence for a particular norm of behaviour (e.g. gender based violence against women in this study), but are also a significant strategy in anti-discrimination discourses in informal settings (Van Leeuwen \& Wodak, 1999, p.110). Similarly, Fregoso explains that mobilizing shame is a 
powerful instrument for intervening politically on behalf of the "powerless against despotic and authoritarian power" (Fregoso, 2006, p.118). This suggests that FIDA-Kenya could be deploying narratives of women's lived experiences (i.e. intertextually oppositional discourse) as a discursive resource for political intervention, through putting the Kenyan government in an emotionally uncomfortable situation (i.e. shaming strategy).

By the same token, the NGOs draw on the everyday stories (i.e. "goings-on", Fairclough, 1989) as part of their strategies to shame the Kenyan government for failing to grant and protect women's rights to equality. For instance, with reference to newspaper reports, the LKWV (2005, p.33, my emphasis) argues that:

Gender based violence continues to be a serious problem in this country...Newspaper coverage indicates that cases of rape, sexual assault and defilement are increasing at alarming proportions, with the victims varying from babies to grandmothers.

From this excerpt, it is arguable that by invoking babies and grandmothers as victims of gender-based violence against women, the LKWV could be drawing on a shaming strategy, aimed at projecting the Kenyan government's failure to enact laws to address gender-based violence against women. Drawing on her studies on the impact of ideologies through persuasive rhetoric, Wodak (Wodak, 2006, p.11) posits that "ideologies are connected to and make use of emotions." Therefore, we may argue that the LKWV's use of babies and grandmothers in their text is aimed both at arousing emotions and shaming the Kenyan government, thereby exerting pressure on it. This is achieved through placing it in an “interactionally uncomfortable situation" (Patrona, 2013, p.19), with the aim of heralding its acceptance of gender equality policies.

Similarly, AWC (2004, p15-16) adopts a shaming strategy, by arguing that:

Young women and girls in some parts of Kenya, especially in the rural areas are still forced to marry suitors who are in most cases older than them by decades. This takes place for a number of reasons from bride price to repaying debt...They are not consulted at all, and their pleas not listened to. Being married off automatically means that the girls and women lose any rights in their parental homes. It also means that they are reduced to commodities, as their suitors pay for them. 
It has to be kept in mind that the use of this narrative and other stories under discussion also serves as an expression of evidentiality discussed above (see 5.4.4). According to Keats (2009, p.183), narratives play a crucial role in validating arguments, as we are "prone to respect the teller's truth and attest to the validity of its reality." This view coheres with that of Ackerly (2001) and Zwingel (2005) (see 2.4.7.4), who identify storytelling and personal narratives as one of the major devices used by women's human rights activists (e.g. NGOs in this study) both to support and legitimize their call for policies in favour of women.

\subsubsection{Gap in knowledge-filling pattern}

Beyond the strategies identified above, the NGOs' texts examined in this study were found to adopt a "gap in knowledge-filling pattern" (Hoey, 2001, p.160) as part of their textual strategies for engaging the Kenyan government. In this regard, the NGOs' texts tend to identify the gaps in the Kenyan government's existing knowledge of gender equality, in terms of specifying the areas of weakness, and then providing a solution to fill such gaps (i.e. in the form of a recommendation). For instance, mobilizing around the existing discrimination against women in Kenya, the LKWV (2005, pp.11-35) claims that women's inequality emanates from the Kenyan government's failure to establish "a mechanism for monitoring and evaluating instances of de facto discrimination in law." On these grounds, the LKWV (2005, pp.11-35) recommends that "the Government must implement the recommendations of the Beijing Platform For Action," including the "recommendations of the Task Force for the Review of Laws Relating to Women."

In the same breath, the LKWV (2005, p.33) points out that though statutory laws such as the Land Acquisition Act and the Land Adjudication Act exist to govern access to and ownership of land, the patriarchal nature of the Kenyan communities "favours the male lineage.” As such, using the topos of numbers (Reisigil \&Wodak, 2001), the LKWV (2005, p.33) stresses that the existing situation in Kenya has ensured that men continue to own $95 \%$ of the land. Further, the LKWV claims that this state of affairs is precipitated by the lack of enforcement mechanisms, hence why majority of the Kenyan women continue to be denied the right to own and inherit land and other forms of property. As a solution to this alleged anomaly, the LKWV (2005, pp.11-35) recommends the need for the Kenyan government to implement the law of succession to grant men and women equal rights to property.

Subsequently, the LKWV (2005, pp.11-35) emphasizes that the Kenyan government should 
not only formulate gender responsive policies, but "must be ready" as well to enforce them in practice.

It must be emphasised at this point that the arguments under discussion point to the LKWV's realization that women's inequality may not be addressed solely through the application of the universal rights of women, but also, through the Kenyan government's willingness to enforce laws concerning the implementation of such rights. This view can be inferred from the repeated use of the deontic modality "must" (Fairclough, 2003) in the LKWV's texts above.

\subsubsection{Combating criticism through adversarial forms of address}

FIDA-Kenya posits that in response to President Moi's criticism against the NGOs' civic education programmes (see section 5.5 .4 below), the Chairlady of the League of Kenya Women Voters, the Honourable Martha Karua criticised President Moi as having "set an unfortunate precedent as it is clearly anti-women" (FIDA-Kenya, 1997, p.11). In addition, describing President Moi's words as “disappointing and unwarranted," Mrs Karua argued that "dissemination of information on civil rights was the first step to development," and that "the League operates within the law and will continue furthering its aims and objectives without fear or favour in spite of the obvious and unwarranted intimidation by the Head of State" (FIDA-Kenya, 1997, p.11).

Also, the following text from Professor Wangari Mathai, the Chairlady, the Green Belt Movement, presents a typical example of this use of adversarial forms of address by the women's NGOs. That is, in response to her criticisms against the Kenyan government for its corrupt practices and lack of respect for democracy and human rights, the Kenyan president and parliamentarians are reported to have dismissed her as "a frustrated divorcee who had no credentials to challenge a state decision" (Muthuki, 2006, p.88). In addition, Muthuki (2006, p.88) says that some parliamentarians proceeded to threaten her with female genital mutilation/circumcision. Reacting to the Kenyan president's and the parliamentarians' threats above, Mathai is said to have dismissed their claims by arguing that:

I'm sick and tired of men who are so incompetent that, every time they feel the heat because women are challenging them, they have to check their genitalia to reassure themselves. I'm not interested in that part of the anatomy. The issues I'm dealing with require the utilisation of the anatomy of whatever lies 
above the neck. If you don't have anything there, leave me alone (Mathai 2004, cited in Muthuki, 2006, p.88).

As this excerpt demonstrates, using adversarial address, Mathai contests the Kenyan leaders' treatment of her based on her sex. This understanding is demonstrated from the extract "The issues I'm dealing with require the utilisation of the anatomy of whatever lies above the neck" above. Mathai's view here seems to draw on the feminist thought about patriarchal thinking, which as Salleh (1988) argues, tend to associate women with the body, nature and emotions, while characterising men with the mind and reason. This means that she contests being ascribed her identity based on her sex, hence the need to be treated on equal terms with the male members of the Kenyan society.

Other practical examples of the NGOs' use of adversarial address as a means of engaging the Kenyan government can be read from their varied responses to President Moi's abuse of women discussed in section 5.5.1 below.

\subsubsection{Strategies of self- and other-presentation}

In engaging the Kenyan government, NGOs also draw on the strategies of "positive self-presentation and negative other-presentation" (Reisigl \& Wodak, 2001, p.46). This includes representing the NGOs positively as championing women's rights to equality, while at the same time linguistically constructing the Kenyan government negatively as the one that constitutes a hindrance to women's realization of their equality rights. The following extract from FIDA-Kenya (1997, pp.36-38, my emphasis) is a classic example of this particular strategy:

Women's human rights groups in Kenya have consistently asked to have domestic violence specifically criminalised because of the complexities that arise out of prosecuting a domestic violence case. Unfortunately, the State has been resistant to instituting such legislation...failure by Kenya to enact the Women's Convention into its domestic law leaves women extremely vulnerable to all manner of human rights abuses.

From this excerpt, the extract "Women's human rights groups in Kenya have consistently asked to have domestic violence specifically criminalised" represents the NGOs positively as those seeking the passing of laws by the Kenyan government to protect women against gender-based violence. To the contrary, the extract "Unfortunately, the State has been 
resistant to instituting such legislation," presents the Kenyan government negatively as the one blocking the NGOs' efforts to ensure the passing of laws that promote the protection of women's rights. This view is reinforced through the selective use of the terms "Unfortunately" and "resistant," which cues the Kenyan government as being against the interests and well-being of Kenyan women.

The same strategy is evident in the following excerpt from AWC, which presents women positively as seeking what is desirable to them (i.e. political positions), while simultaneously representing the Kenyan male society negatively (i.e. as those discriminating and working against women's political interests):

The right of Kenyan women to participate in politics, leadership and the governance of their country has been elusive in post independent Kenya. Those who have sought political positions have been seen as rebels attempting to break the traditional and cultural tranquillity. They have met fierce hostility and rejection from proponents of discrimination against women (AWC, 2004, p.5, emphasis added).

Blain (2005, p.35) argues that "victimage rhetoric" can be used to categorize actors as “enemies," "victims," and "villains." Moreover, Blain (2005, p.35) states that social actors "construct villainous and heroic subjects by mobilizing antonyms known to the audience." In this context as Blain (2005, p.35) continues to argue, the adversary is identified with the negative, with "the antagonists struggling to make themselves synonymous with the positives and their opponents synonymous with the negatives." Based on this perspective, AWC's use of the term "rebels" in the proposition "rebels attempting to break the traditional and cultural tranquillity," above, connotes women activists as "enemies" of the Kenyan government, and as a minority rebel group that stands in stark opposition to the values and norms of the male dominated leadership. This stance is reinforced through the use of the proposition "They have met fierce hostility and rejection from proponents of discrimination against women" above. In this context, the phrase "fierce hostility and rejection" negatively cues the Kenyan male dominated leadership as being barbaric and uncivilized, for deliberately denying women's rights to equality. Notice that by throwing the Kenyan leadership on the defensive as hostile and/or hateful of women activists and their call for equality, AWC's text under discussion projects women positively as being supportive of women's interests. 


\subsection{The Kenyan government's modes of engagement with NGOs}

As part of its efforts to respond to the women's NGOs' policy demands stated above, the Kenyan government deployed a number of textual and rhetorical strategies, some of which mirror those used by the women's NGOs. These modes include the use of adversarial address, categorical assertions, imitative/reformulated discourse, irony, praise and criticism, including the neo-liberal technique of governance. These are explained below.

\subsubsection{Adversarial address}

According to Patrona (2013), "adversarial address" constitutes part of the discursive practices deployed by actors to levy their power and authority upon others, with the aim of fashioning their thinking to particular ends. To illustrate this point, we draw on the example of the Kenyan President, Daniel Moi's abusive statement towards women. That is, in March 2001, while opening a women's seminar in Nairobi, Kenya, President Daniel Moi is noted to have argued that: "you women can achieve more, can get more but because of your little minds, you cannot get what you are expected to get" (Human Rights Watch, 2003, p.14). The impact of president Moi's utterances on the women's NGOs' behaviour is reflected in the coverage below by Judith Achieng, the news editor/correspondent, Inter Press Service News Agency (hereinafter IPS). In her article titled: "Politics-Kenya: President Moi’s Remarks Spoil Women's Day," Inter Press Service News Agency, March 8 ${ }^{\text {th }}$, 2001," Achieng (2001, p.1, my emphasis) reports:

Kenyan President Daniel Arap Moi's remarks that women have not excelled because of their "little minds" have spoilt this year's International Women's Day celebrations in Kenya. In a broadcast statement this week, Moi said women "should have gone very far" but because of their "little minds" they "have not made much progress." The remarks made to a group of women travelling to New York as part of the Kenyan delegation to the on-going United Nations Commission on the Status of Women (CSW) meeting, has enraged women groups in Kenya. "What gains are we celebrating if the gains are being taken away?" wonders Adelina Mwau, who runs tdelinahe Nairobibased Coalition on Violence Against Women (COVAW), a non-governmental organisation (NGO). "I can't believe that in this age and time, the president can say women have small minds. He is not recognising that women support 
Kenya's economy"... Mwau, who has been campaigning for stronger legislation against gender violence, a serious problem in Kenya, says Moi's remarks only reinforces the myth in her native Kamba in eastern Kenya that "women think like squirrels." "We can't accept the head of the nation to abuse us in public when we are already suffering abuses in private," she told IPS. The International Federation of Women Lawyers (FIDA) Kenya Chapter also has described Moi's remarks as "offensive" and "disappointing" at a time when women are keen to work for the expansion of their equal participation in politics and decision making... On its part, the League of Women Voters representatives, attending the 45th session of the UN Commission on The Status of Women in New York, said 'the president's statement is characteristic of the government's inconsistency, lack of clarity and commitment on the integration of women in politics and decision making process." "The government's presence at this meeting is, therefore, a facade and an exercise of public relations, lacking in any commitment and meant to hoodwink the international community and the people of Kenya," the League said in a statement faxed to IPS on Thursday.

In line with Fairclough (2003, p.8), texts have causal effects upon, and contribute to change in, people's actions, social relations, and the material world. In a similar vein, Phillips and Hardy (1997, p.169) emphasize that "invoking a discourse has consequences for the speaker as well as for the various receivers of the text." In this context, President Moi's reference to women as a people with "little minds" has causal effects upon, and contributes to the NGOs' criticisms against him. The tension that characterises the textual exchanges between President Moi and the NGOs endorses Wodak's (2001, p. 11) view that texts are "sites of struggle in that they show traces of differing discourses and ideologies contending and struggling for dominance."

According to Van Dijk (1997, p.32), "language use and thought typically and functionally manifest themselves in discursive social interaction." From this perspective, the lexical choice of "little minds" reflects President Moi as one not to be taken seriously, for the phrase little minds semantically cues him as one who lacks respect for women and their issues. It must be remembered that President Moi's statement, and the above said Kamba myth, are part of the larger /macro-level discourses/social practices that govern how Kenyan men think and respond to issues concerning women. 
From Fairclough's (2003, p.17) view of genre as a particular way of using language (i.e. way of acting and interacting) through speaking, President Moi's alleged reference to women as a people with "little minds" and the aforesaid Kamba myth can be argued to constitute the particular choices of genre (i.e. given ways of acting and interacting in the Kenyan society), that seek to regularize and naturalize how women and their issues ought to be perceived. This scenario explains why as Nietsche argues, Foucault emphasizes that it is "the practices, or the way someone acts, that allow the analysis of power or counterconducts" (Foucault 2007, cited in Niesche, 2013, p.148).

The use of adversarial address is also noted with regard to President Moi's remarks concerning women's political participation and affirmative action policies. As AWC (2010, p.85) explains:

On April 23, 1997 Hon Phoebe Asiyo brought to Parliament a motion that sought to allow Affirmative Action in assigning Parliamentary seats to women. The motion was rejected because many of the male members did not understand what Affirmative Action meant... The then head of state, Daniel Arap Moi, refused to yield to pressure from female Parliamentarians and the public to sign the Affirmative Action Bill into law. Instead he was quoted in the Media as saying, "Those women who have made it do so because of merit: they are not favoured. You know I do not believe in Affirmative Action for women. This I have said openly."

From this excerpt, one significant issue worth mentioning emerges. That is, just like the Kenyan government's written policies that declare the government's unilateral decision to grant affirmative action policies selectively without reference to any universally agreed on standards or criteria (see section 6.4.4), President Moi also exercises his power to decide and declare that affirmative action policies are not welcome as they may cause social upheavals. This is evident in the proposition "You know I do not believe in Affirmative Action for women. This I have said openly" above.

Likewise, it must be remembered that Mr Njuguna, the Court Magistrate's remark (see section 5.4.2 above) that men's violence against women is “the African man's way of disciplining his wife" (FIDA, Kenya, 1997, p.37), is yet another case demonstrating the Kenyan government's use of adversarial forms of address as a means of engaging the women's NGOs. From these examples, it can be asserted that despite the ongoing contestations by the women's NGOs with regard to the lack of state policies to grant and 
promote women's equal participation in politics and decision making structures, the Kenyan government is yet to grant their demands.

\subsubsection{Reformulated discourse}

In some instances, the Kenyan government's policy texts addressed to the women's NGOs tend to reformulate the NGOs' claims in ways designed to counter them. An illustrative example to show this mode of recontextualizing the NGOs' claims concerns again the court Magistrate, Mr Njuguna's discriminatory behaviour and argument that men's violence against women entails "the African man's way of disciplining his wife" (FIDA Kenya, 1997, p.37) (see section 5.4.2). That is, while contributing to a motion titled "Increase of Rape/defilement Cases in Mumias District, Kenya,” Mr Kariuki, the assistant Minister in the office of the President had this to say:

If I may comment about issues of defilement and courts, we have had serious problems with women magistrates... it is the women magistrates who are setting these suspects free ... On the part of the Government, we encourage the NGOs to continue creating awareness and criticising outdated cultural practices which make our girl child become a victim of defilement (Hansard, 2005, pp.146-147).

This excerpt is significant in that though the report under discussion (FIDA-Kenya, 1997) allocates blame on the male magistrates as the ones promoting the use of stereotyped language and violence against women, Mr Kariuki's statement above that attributes the continued violence against women to the women magistrates (i.e. for freeing male rapists) can be said to represent a form of response to the women's NGOs that utilizes an imitative and/or reformulated discourse that uses the reversed form of FIDA Kenya's claims.

As such, Mr Kariuki's imitative statement serves as a means of responding to, as well as countering any allegations against the behaviour of male magistrates. In other words, $\mathrm{Mr}$ Kariuki's "imitative discourse" (Junefelt, 2007) is a form of interdiscursivity that occurs between the recontextualized (i.e. reformulated discourse), and FIDA-Kenya's claims in the form of accusations against male magistrates.

Mr Kariuki's statement entails part of Fairclough's (2003) notion of genre chains mentioned in chapter three. In this context, Mr Kariuki's statement is part of a chain of meanings that are transformed as they get moved and recontextualized in new contexts, 
where it functions as "a sort of 'social technology", (Fairclough, 2003, p.68). Furthermore, it must be borne in mind that Mr Kariuki's reversed blame and/ or imitative statement is characteristic of Foucault's (1982) notions of power and reversal discourses (Mona \& Stellan, 2014, p.115), in that it helps to create the impression that women themselves are to blame for the continued cases of violence against them.

Similarly, Mr Kariuki's reformulated discourse constitutes part of the Kenyan government's oppositional strategies for enacting the Kenyan leaders' open questioning of the legitimacy of women magistrates, including their ability, knowledge, and power to serve in managerial posts within the public sphere. In line with Deem (1999, p.73), questioning or challenging women's legitimacy to serve in decision making positions constitutes acts of resistance to women's roles in the public sphere. Further, Deem $(1999$, p.73) argues that such challenges are aimed at pushing women to conform to given male/patriarchal norms that characterise managerial posts.

According to Fairclough (2003), genres are selective and involve filtering devices that selectively control aspects of meaning. From this perspective, considering the context from which Mr Kariuki speaks (i.e. Kenyan Parliament), it is arguable that his imitative discourse seeks to regulate and hence control how issues of women ought to be interpreted and understood.

Extrapolating further from the extract above, it ought to be stated that Mr Kariuki's statement stresses the independent role of the women's NGOs through the use of "we," symbolizing the "authoritative and distant" (Saarinen, 2008, p.186) government that assigns roles to those wanting to promote the implementation of women's rights (i.e. NGOs) in Kenya. To the contrary, though, this rhetorical strategy limits the collective efforts to achieve the broad goal of gender equality, considering that the government, as the executor of policy, is much of the time missing and unwilling to work with the women's NGOs.

\subsubsection{Appealing to emotions via praise and criticism}

Just like the women's NGOs' texts examined above, the Kenyan government also uses praise as its mode of engaging with the women's NGOs agitating for gender equality policies. This strategy can be observed in the following statement by the Attorney General, Mr Amos Wako while contributing to a parliamentary debate on the Domestic Violence (Family Protection) Bill: 
I know that FIDA-Kenya contributed quite much to the drafting of this bill. I think it is a good example of the collaborative consultative process that can happen between the government and the Non-Governmental Organizations which are genuinely seriously committed to the objectives of their constitutions (Hansard, April $24^{\text {th }} 2002$, p.730).

From this excerpt, the phrase "the Non-Governmental Organizations which are genuinely seriously committed ..." is illustrative of Mr Wako's use of praise for FIDAKenya. However, judging from the alleged continued reluctance by the Kenyan government to grant gender equality, it is arguable that Mr Wako's praise for FIDA-Kenya is an example of staged intertextuality (Kotthoff, 2002), probably to appease its (FIDA-Kenya's) representatives by raising their comfort level. "Staged intertextuality" (Kotthoff, 2002) in this study entails a rhetorical strategy of invoking a particular discourse to demonstrate shared values, attitudes, and knowledge pertaining to an issue of political significance, while simultaneously distancing oneself from making a commitment to a particular proposition. This can be said to be the case with the Attorney General, Mr Amos Wako's text above, that seeks to praise FIDA-Kenya for collaborating with the Kenyan government in championing the rights of women, yet, as seen in the foregoing discussion, the Kenyan government remains non-commital in bringing about gender equality policies.

Another good example to illustrate the Kenyan government's use of praise for the NGOs concerns material discussed in section 6.4.7 of the next chapter. As noted, with reference to the lobbying campaigns by the women's NGOs, the Kenyan government argues that:

To address the poor media portrayal of women, the media in Kenya, through lobbying by various women organizations such as Maendeleo ya Wanawake Organization (MYWO), the National Council of Women in Kenya (NCWK), the Federation of Women Lawyers (FIDA) and the Association of Media Women in Kenya (AMWIK), religious organizations and the Government, have developed media programmes in support of the key roles women play in the society. Generally the campaigns against bad practices that impact negatively on participation of women in development are undertaken through advocacy and awareness creating activities using television and radio programmes and the print media. The campaigns undertaken by AMWIK are already yielding positive results. It is engaged in programmes that train 
women to involve the media in disseminating realistic information on their activities to the wider public... (Republic of Kenya, 2004, pp.14-15 my emphasis).

The phrase "positive results" in the extract "The campaigns undertaken by AMWIK are already yielding positive results" above points to the Kenyan government's use of praise for the NGOs' lobbying efforts with it (government). As Bhatia (2006) warns, positivity and/or language use seeking to promote a positive image entails a strategy for concealing given ideological differences. As such, the use of praise for the NGOs in the extract above is indicative of the Kenyan government's rhetorical tactic of wanting to project gender equality policies as a collaborative undertaking between it and the women's NGOs.

Remember that just as is the case with the NGOs' texts that were seen to use praise and criticism simultaneously for the Kenyan government (see section 5.4.2), the same is true for the Kenyan government's texts addressed to the women's NGOs. For example, in its report titled "Kenya Human Development Report, 1999," the Kenyan government has this to say about NGO's efforts to promote "Women's Empowerment:"

A number of civil society organisations have been formed and are working toward the advancement of Kenyan women. One of the most active organisations in the area of the political empowerment of Kenyan women is the "Women's Political Caucus." Other active organisations include the Kenya chapter of the Federation of Women Lawyers (FIDA)... Unfortunately, divisions within some of these organisations seem to impede their efforts and reduce their effectiveness (Republic of Kenya, 1999, p.34, emphasis added).

In this excerpt, the proposition "A number of civil society organisations have been formed and are working toward the advancement of Kenyan women" presents the Kenyan government's praise and/or acknowledgement of the NGOs' efforts to promote the interests of women. This is reinforced through the phrase "are working toward the advancement of Kenyan women," which suggests their shared efforts towards the promotion of women's rights. However, the clause "Unfortunately, divisions within some of these organisations seem to impede their efforts and reduce their effectiveness" suggests the Kenyan government's condescending undermining of women's collective efforts by inviting generalisation from the few to the many by association, a well-known ploy of paternalistic authority. This reinforces the idea that the government's practice of praising the women's 
NGOs above is an act of mere rhetoric, strategically tailored to manage interpersonal relations between the Kenyan government and the women's NGOs by taking away with one hand what it has just given with the other.

Another very interesting example showing the Kenyan government's use of criticism against women's NGOs is noted by Michaelson (1994). In this context, Michaelson (1994, p.553) posits that following Professor Wangari Mathai's (i.e. chairperson, Green Belt Movement) opposition against the Kenyan government's announcement to build a $\$ 200$ million 60-story sky-scraper with a 30-foot statue of President Daniel Arap Moi on public land, the Kenyan President, Daniel Arap Moi, responded by criticizing Maathai and other human rights activists as "having insects in their heads," and "wondered why the women of Kenya had not taken any steps to ostracize their 'wayward' colleague."

Other forms of criticism by the Kenyan government can be inferred from President Moi's denunciation of the NGOs' civic education activities to women as a "waste of money," (see 5.4.2 above). From Fairclough's (2003) notion of “value assumptions," President Moi's alleged reference to the civic education activities by the LKWV as "a waste of money," and consequent proposal to invest that money in educating boys, can be said to reflect his "explicit evaluation" of what he considers "desirable" or "undesirable" (Fairclough, 2003, pp.55-57). That is, based on his words stated above, women's empowerment through civic education can be said not to be part of the Kenyan government's policy agenda..

Arguably, this entails his resistance to the "top-down compliance procedures" (Niesche, 2013, p.149) being proposed by the CEDAW committee and pro gender equality policy actors in Kenya.

In Foucauldian terms thus, President Moi's behaviour and language use can be read as an act of counter-conduct, in the sense of "struggle against processes implemented for conducting others" (Foucault, 2007, pp.200-201, cited in Niesche, 2013, p.149). That is, in line with Foucault's view of government as conduct of conduct (Foucault, 1982, p.237) mentioned elsewhere in this study, President Moi's acts can be interpreted in terms of "calculated ways of thinking and acting," that seek to fashion and regulate the conduct or behaviour of the Kenyan population against gender equality policies being proposed by the women's NGOs. This reasoning can be discerned from his advice to the above said group of women that paid him a courtesy call at his office (i.e. State House). In this context, as noted below (see 5.5.5), President Moi is quoted to have told them that they were "good women and they should not associate with the league of women voters" (Konya, 1997, cited in FIDA-Kenya, 1997, p.8). This means that, rather than imposing laws, President Moi is 
deploying tactics, and or/ "strategic games" (Foucault, 1988, pp.129-130), involving manoeuvrings and tactical manipulations of the Kenyan population against the universal gender equality policies.

\subsubsection{Use of irony}

As an indirect response to the NGOs' continued agitation for laws to address gender based violence against women, the Kenyan government enacted the Children's Act of 2001, which banned FGM/circumcision of children below 18 years. This is better illustrated in the Kenyan government's 2007 report titled "Contributing towards efforts to abandon Female Genital Mutilation/Cutting in Kenya: A Situation Analysis.” In this context, the Kenyan government reiterates that:

by ratifying international legal instruments and conventions that condemn FGM/C, Kenya accepts that FGM/C is a violation of the human rights of women and girls, and thereby agrees to an international obligation to end the practice. The Fourth World Conference on Women in Beijing was an important impetus to the Government, NGOs, women's organizations and civil society in general to identify major concerns for women and adopt strategies, for both Government and NGO agencies...The Kenyan Parliament has also enacted the Children Act (No. 8 of 2001) which criminalizes FGM/C on children below 18 years (Republic of Kenya, 2007a, pp.8-9).

From this extract, however, it becomes evident that, though the Kenyan government makes manifest intertextual reference to the United Nations' imperatives concerning the rights of women, the stated policy text actually bans FGM/circumcision only in relation to "children" and /or girls below 18 years, and not women. That is, the text under discussion does not make a legislation banning female genital mutilation under the official gender policies on women, but rather, under the Children's Act, 2001. In other words, though this legislation is made specifically to protect girls under 18 years from female genital mutilation - i.e. considering that people under 18 years in Kenya are constitutionally classified as children (Republic of Kenya, 1998, 2001), it is framed as a women's issue to create the impression of broad spectrum action.

As such, whereas NGOs frame violence against women as a violation of women's rights, the Kenyan government does not dispute this frame, but rather abolishes FGM for 
children under 18 years, and casts it as a matter of women's rights. This can be argued as being an ironical and /or indirect form of the ongoing contestation by the Kenyan government against equality policies. Such a realization endorses Giora's view that irony not only has a beguiling nature, but also "involves pragmatic insincerity" aimed at "self-protection" (Giora, 2001, pp.165-168). In Foucauldian terms, this entails an evasive strategy, and an act of counter-conduct against the NGOs' proposals for policy action to alleviate violence against women.

As part of its strategies for responding to the call for gender equality policies, the Kenyan government also responds to the NGOs' call for gender equality by use of irony enacted through the deployment of substitutive vocabulary. For instance, whereas NGOs' texts demand that the Kenyan government grants Kenyan women their reproductive rights, the Kenyan government responds by recontextualizing this demand as health care services, and reproductive health care. This approach by the Kenyan government is captured by Ngondi-Houghton, who makes reference to the Kenyan constitution by arguing that:

The Draft Constitution, section 61(1) grants everyone the right to health, which includes the right to health care services, including reproductive health care (Republic of Kenya 2005, cited in Ngondi-Houghton, 2005, pp.126-127).

As seen in this extract, the Kenyan government does not address women's reproductive rights, but rather, their rights to health, "health care services," and "reproductive health care." As noted elsewhere in this study (see chapters three and five), Fairclough's notion of intertextuality involves "transformations" (Fairclough, 2013, p.399), enacted through such modes of representation as deletion or addition of given social practices, and substitution of the actual elements by other elements (Leeuwen \& Wodak, 1999, pp.96-98). Based on this understanding, the Kenyan government's text above can be argued to have deployed deletion and substitution modes of representation. This ensures the side-lining of the concept of reproductive rights in its policy texts. This mode of representing the concept of reproductive rights in terms of health care services and reproductive health care, serves to reconstitute its form, thereby diluting its normative force or fidelity as contributing to the transformative gender equality policies being proposed by the women's NGOs and CEDAW.

A similar example demonstrating the Kenyan government's use of irony is given by the African Women and Child Information Network (AWC). In this context, AWC observes that the Kenyan government's education system bans sex education in favour of moral education that teaches moral values and HIV AIDs (AWC, 2004, p.22). Judging from this 
argument, AWC could be suggesting that by banning sex education that is part of women's reproductive rights, the Kenya government could be seeking to ensure that girls and women in general do not receive knowledge concerning their sexuality, which may open up doors to their realization of how their issues are governed based on gendered criteria.

\subsubsection{Divide and rule policy}

Aside from the above said patterns of interaction, the Kenyan government also uses the neo-liberal technique of governance (Ahmed, 2007, p.236) as a means of engaging with the women's NGOs. This is particularly achieved through the use of divide and rule policy, techniques such as cooperation and /or language of partnership (i.e. use of accommodation strategies), and silence.

First, as part of its tactical moves to ensure the lack of a united front by the NGOs against state aggression and indifference to issues of women, the Kenyan government deploys a divide and rule policy. The best example to illustrate this is President Moi's advice below to a delegation of women that visited him in his office. This is cited by FIDA-Kenya in the transcript below from a verbatim report by Beatrice Konya, an employee of the League of Kenya Women Voters:

We had just sent out invitations to our monthly teas and we were due to start collaborating with Maendeleo Ya Wanawake on civic education. During one of his speeches the president is supposed to have said we have a lot of money and we should use it to educate the street boys. He mentioned this three times before we knew. As soon as we knew it we felt we must call a press conference to set the records straight. His statements were very damaging to us because there are a lot of provincial Administrative Officers who listen...We wrote the President a letter introducing ourselves who we are and how we came to be established. We tried to take it to State House but they refused to receive it so we had it delivered to his offices at Harambee House...the letter was delivered on 20 February 1997. He did not reply. Around this time, Elizabeth Masiga had been appointed Permanent Secretary in the Ministry of Education. A contingent of women went to thank him for appointing the new woman permanent secretary. He told them that they were 
"good women and they should not associate with the league of women voters" (LKWV, 1997, cited in FIDA-Kenya, 1997, p.8).

President Moi's advice to women reported in this extract that "they were good women and they should not associate with the League of Women Voters" is an aspect of his use of the divide and rule policy. According to Brainardi and Siplon (2002), governments tend to use a divide and rule policy both as a means of dividing members of given civil society groups, as well as weakening their powers to act.

It should be kept in mind that the above said use of divide and rule policy entails a continuation of similar tactics of rule deployed by the Kenyan government against the women's NGOs in the 1970s and 1980s (Aubrey, 1995, p.101; Mutua 2006, p.10) (see chapter one). As Aubrey and Mutua explained, the Kenyan government under President Moi co-opted Maendeleo Ya Wanaewake Organization, and used it as a tool to condemn and silence other women's NGOs championing human rights and pluralism in Kenya (Aubrey, 1995, p.101). This suggests that as a means to counter the NGOs' joint actions, the Kenyan government responds through particular strategies such as favouritism of one NGO over others, with the aim of neutralizing their powers to act as a united group. The use of undermining all by a logic of association with or extrapolation from the few referred to in 5.5.3 above can also be mentioned in this context.

More interestingly, it is significant to state that this mode of political governance by the Kenyan government did not involve the co-optation of NGOs as institutions per se, but also the NGOs' representatives. That is, as a means to manage increased NGOs' pressure for gender reforms, the Kenyan government resorted to hiring feminist activists and NGOs' representatives into positions of leadership within government institutions. This is illustrated from the excerpt below from a speech titled "Women Political Participation in Kenya" delivered by Faith Kasiva, Programmes Coordinator Women Political Alliance - Kenya, at the East African Women's Leadership Institute of Akina Mama Wa Africa, September $22^{\text {nd }}-$ $3^{\text {rd }}$ October 2003, Entebe Uganda. In this context, Kasiva (2003, p.79, my emphasis) argued that:

The Women's movement in particular has experienced internal and external challenges and changes. Many women have moved into the state... However at this particular historical juncture our movement is divided on the basis of ideology, class, age and political affiliation. It is a fact that our individual and collective ability to influence and participate in political processes has created 
opportunities for some but also excluded others. Some of us have been able to develop and nurture beneficial relationships with the male dominated political elite for personal gains and not collective gains for us all. My observation is that in the post Moi era, the women's movement seems disconnected and no longer has a political strategy. Yet contemporary political practise requires a strong feminist movement to influence and engender the political restructuring process.

From this extract, the phrase "Many women have moved into the state," confirms the negative impact of the Kenyan government's strategy of weakening the women's NGOs' through co-opting some of their representatives into government service. In other words, the co-optation of feminist activists and NGOs' representatives has real practical consequences for the realization of gender equality policies being advocated by CEDAW. A good example to illustrate this involve NARC government's nominations of feminist scholars and advocates of women's rights as MPs to the Kenyan parliament. These include the nominations of Adelina Mwau, Member, Coalition on Violence Against Women (COVAW-Kenya), Professor Julia Ojiambo, Member, Maendeleo Ya Wanawake Organisation (MYWO), and Njoki Ndungu as MPs to the Kenyan parliament (AWC, 2010, p.80). In this context, upon getting nominated to the Kenyan parliament, Ms Njoki Ndungu who had been championing the need for a Sexual Violence Bill to address increased cases of gender-based violence against women had this to say:

When the chance to get into Parliament came, there was nothing as exciting as moving from a lobbyist to an MP... The nomination to Parliament was a pleasant surprise. I did not think that I was a political person. However, I fitted in very well as a member of Parliament (AWC 2010, p.88).

The same trend was noted in 2005, when President Kibaki appointed the Chairperson of the Kenya Women's Political Caucus (currently the Caucus for Women's Leadership), Ms Phoebe Asiyo, as his personal advisor on gender issues (i.e. in relation to the UN Millenium Development Goals meetings in New York).

Terming feminists who enter bureaucracies of government and its management as "femocrats," Deem (1999, p.66) raises the following questions.

(1) Can feminists in these positions use their power to help advance feminist causes? 
(2) Are they able to resist pressures to conform to other kinds of values and to adopt practices and strategies that are inconsistent with their feminisms?

In this context, Deem suggests that by abandoning NGOs' activities and joining government service, such NGOs' representatives become "sell-outs," owing to the fact that they abandon their NGOs' values in pursuit of personal goals (Deem, 1999, p.77). In the Kenyan case therefore, judging from Kasiva's text above, it is arguable that the Kenyan government uses its divide and rule policy, by hiring some of the feminist activists and NGOs' officials in an attempt to weaken their ability for a united front.

\subsubsection{Cooperation/accommodation strategies}

Realizing the need for technical assistance and a good working relationship with the CEDAW committee, the Kenyan government sought the hand of the women's NGOs. This for instance is seen during the face to face oral discussion between the Kenyan officials and the CEDAW committee (see 4.4.2). In this context, it was briefly noted that some of the Kenyan officials engaging the Committee were representatives of the women's NGOs (e.g. FIDA-Kenya and Maendeleo Ya Wanawake Organization). This means that the Kenyan government may have sought the help of NGOs to explain to the committee how gender equality was being implemented in Kenya. In other words, while working in a "contractual relationship" (Ramanath, 2008, p.12) with the Kenyan government's policy makers, the women's NGOs' representatives helped to defend and promote the interests of the Kenyan government. Thus, indirectly, the committee uses the NGOs' representatives' views in such meetings as the measure of the Kenyan government's progress/performance towards implementing gender equality policies. For instance, responding to the issue of violence against women, Martha Koome, a representative of FIDA-Kenya argued that:

Kenya's new Minister of Justice and Constitutional Affairs had demonstrated commitment to the advancement of women's rights and had indicated that he would give priority to bills whose passage through Parliament had been interrupted by the recent election process, such as the Domestic Violence Bill, which would very likely come into effect as early as June 2003. (Committee, 2003a, p.5, emphasis added). 
From this exerpt, Ms Koome's argument that “Kenya's new Minister of Justice and Constitutional Affairs had demonstrated commitment to the advancement of women's rights" reflects the Kenyan government's willingness to implement gender equality policies, including the aforesaid "Domestic Violence Bill." This view is reinforced through the use of the term "commitment," in the verbal phrase "had demonstrated commitment to the advancement of women's rights," above, which suggests the Kenyan governmnt's deliberate efforts to promote the rights of women. Moreover, the verbal phrases "would give priority," and "would very likely come into effect as early as June 2003," can be said to signal the Kenyan government's intention to bring about gender equality in the future. Following Van Dijk's (1997, p.17) explanation about the use of a future oriented language (see 4.4.3), we may argue that Ms Koome's use of futurological language is tailored to raise the Committee's comfort level. This is achieved by triggering the Committee's positive hope with regard to the future policy actions that the Kenyan government has promised to implement. However, notice that Ms Koome's statement under discussion contradicts FIDA-Kenya's criticism of the Kenyan government's lack of political will to bring about gender equality policies (see 5.4.2).

Similarly, responding to the Committee's question regarding any efforts by the Kenyan government to eliminate cultural practices that violate the rights of women, Ms. Olende, a representative of Maendeleo Ya Wanawake Organization argued that:

Female genital mutilation was not practised by all tribes in Kenya, but it was a deeply rooted cultural tradition and represented a significant source of income to those women who performed it. For those reasons, despite the introduction of legislation such as the Children's Act, which would protect many girls, the cultural change necessary to bring about the eradication of the practice would not happen overnight (Committee 2003a, p.8, emphasis added).

According to Kuzio (2015, pp.19 \&61), the linguistic strategy of "grounding" is an important aspect of communication that ought to be taken into consideration. In this context, Kuzio (2015, p.19) notes that as a dialogical model of communication, grounding involves a sequential narration of events and actions that seek to create shared knowledge and/or common ground based on the speaker's worldview. From this perspective, though Ms. Olende explains why the practice of "Female genital mutilation" is hard to eliminate in Kenya in the extract above, i.e. because "it was a deeply rooted cultural tradition," and a "source of income to those women who performed it," the proposition, "For those reasons, despite the introduction of legislation such as the Children's Act, which would protect many 
girls, the cultural change necessary to bring about the eradication of the practice would not happen overnight" can be said to be aimed at grounding the reasons why the Kenyan government ought not to be blamed by the Committee, in relation to the ongoing violation of women's rights. In other words, Ms Olende's statement under discussion can be argued to be tailored to shield the Kenyan government against any blame by the committee for the persistent cultural practices that continue to violate the rights of women.

Following from the aforesaid, we could argue that, partly, the women's NGOs lent themselves to the Kenyan government's techniques of governance, which were at the same time designed to satisfy the committee's queries concerning Kenya's progress towards implementing gender equality policies. In this way, unlike the strong and direct confrontational approaches used by president Moi in earlier years (see 5.5.1), the Kenyan government can be said to have begun to use consultative approaches anchored in the neoliberal strategies of political governance.

In this regard, Sissel advises that accommodation strategies have historically been a "cultural norm" of managing given groups resisting the existing status quo (Sissel, 2001, p.114). Accordingly, the aforesaid changing context in terms of accommodating women's NGOs in policy making can be understood as having been necessitated by the NGOs' ongoing contestations against the Kenyan government's reluctance to implement gender equality policies. This means that the government's inclusion of NGOs in the aforesaid process comprises a hidden form of resistance on the government's part.

\subsubsection{Silence}

The Kenyan government also uses the discursive technique of "silence" (Murphy, 2013, p.15) as one of its discourse devices for interacting with the women's NGOs. According to Niesche (2013, p.155), silence entails a "conscious strategy," and a form of counter conduct to given techniques of governmentality. In this context for example, though the NGOs have historically demanded the implementation of the CEDAW convention and other United Nations' conventions concerning gender equality (see section 5.3.7 above), the Kenyan government continues to ignore such calls discursively through the use of silence. One example showing the use of this style by the Kenyan government is noted by FIDAKenya. In this context, FIDA-Kenya (2006, p.15) posits that though the Kenyan government ratified CEDAW in 1984, "twenty-two years down the line, much still needs to be done in 
terms of implementing the rights entrenched therein."

By the same token, the LKWV (2005, pp.17-35) alleges that the ongoing inequalities amongst Kenyan women are the result of the Kenyan government's failure to implement the recommendations of the Beijing Platform For Action, as well as the recommendations of the 1993 "Task Force for the Review of Laws Relating to Women" (see also section 6.2). In other words, the Kenyan government is still silent on the need to implement the recommendations of the 1993 Task Force for the Review of Laws Relating to Women, as well as the Beijing imperatives obligating national governments to install gender equality policies. This means that the Kenyan government discursively uses silence as a mechanism for backgrounding gender equality issues being demanded by the women's NGOs and other policy actors, thereby denying them space in its official policies. Such a realization explains why Shaw and Eichbaum (2008, pp.7-8) emphasize that policy actions depend largely on the national government's choice to act or not on given policy proposals.

Going back to Niesche's (2013) view stated at the beginning of this subsection, the Kenyan government's alleged silence around gender equality issues can be read as a form of counter-conduct against the NGOs championing gender equality policies in Kenya. It is significant however to note that this state of inaction on the part of the Kenyan government provides a discursive space for the NGOs' ongoing activism and demands for gender equality policies.

Likewise, it has to be pointed out that as part of its use of silence as a discursive strategy for engaging with the women's NGOs, the Kenyan government implements the NGOs' policy demands through partial response - i.e. incrementalist approach to policy making (Shaw \& Eichbaum, 2008). This approach ensures that some of the NGOs' demands remain unattended to via omission enacted discursively through silence. For instance, using the topos of equality (Reisigl \&Wodak, 2001), FIDA-Kenya (1997, pp.29-30) notes that following a heated discussion involving members of parliament, women's NGOs, civil society groups, religious groups and other policy actors in the 1997 constitutional reform agenda, section 33 of the Kenyan constitution concerning nominated MPs was adjusted to take into "account the principle of gender equality" in nominating members of parliament. Whereas this can be taken to signal the fact that one aspect of affirmative action policies proposed by women had been taken up by the Kenyan government, FIDA (1997, p.30) regrets that this never materialised fully as demanded by women, because only "four of the 12 nominated MPs" were women, instead of the expected six. Likewise, following the 1997 women's NGOs' lobbying for constitutional changes in favour of women via the Inter-Parties 
Parliamentary Group (IPPG), section 82 (3) of the Kenyan constitution was adjusted to include the word "sex" in its definition of the concept of discrimination. This is evident in the following excerpt from the Kenyan constitution (Section 82 (3):

In this section the expression"discriminatory" means affording different treatment to different persons attributable wholly or mainly to their respective descriptions by race, tribe, place of origin or residence or other local connections, political opinions, colour, creed or sex... (Republic of Kenya, 1998, 2001, p.42).

In this regard however, using the topos of definition/name interpretation (Reisigl \& Wodak, 2001, pp.76-81; Kwon, Clarke \& Wodak, 2009, p.280), FIDA-Kenya (1997, p.30) explains that though section 82 (3) of the Kenyan constitution was adjusted to include the word "sex" in its definition of the term discrimination as demanded by the women's NGOs, it (the constitution) still retains several discriminatory clauses. This coincides with the Kenyan government's own assertion to the CEDAW committee noted in the previous chapter (see 4.5.1) with regard to the existing discriminatory laws in Kenya, as well as how the Kenyan government was applying the Convention. In this context, the Kenyan government is noted to have reiterated that though amendments to the Kenyan constitution had been made to include sex as the basis for discrimination, the existing legal definition in the Kenyan law did not embrace all the rules and norms of the Convention (Kenya, 2000, p.5). Significantly, it is important to note that up to 2009 , the Kenyan government remains silent on the NGOs' policy demand to adjust the discriminative clauses in the Kenyan constitution. This is evident in the except by AMWIK et al. (2009, p.49, emphasis added) below:

Discrimination against women is rampant in Kenya. The definition of discrimination contained in article 82 of the Constitution of Kenya is not in conformity with the definition contained in Article 1 of the Convention on the Elimination of Discrimination against Women, which takes into account the prohibition of direct and indirect discrimination. A prohibition against discrimination is contained in the Constitution of Kenya in article 82(4(b \&c), but this prohibition against discrimination is subject to various limitations, exceptions and qualifications in article $82(1 \& 2)$. These qualifications make it difficult for women to actualize their right not to be discriminated against on the basis of gender, especially in matters covered by personal law. 
Kuzio (2015, p.98) argues that as an aspect of intertextuality, "Negations can be a means of disagreeing with propositions which are supposed to come from texts that the receivers have already encountered.” Citing Fairclough (2001, p. 128), Kuzio (2015, p.98) states that "Negative assertions" related to particular presupposed "positive assertions" entail a "means of negating these intertextual propositions for manipulative reasons." Likewise, Kuzio (2015, p.98) emphasizes that negation can be semantic or grammatical (i.e. affirmative and negative sentences). Based on these grounds, the negation "not" in the proposition "The definition of discrimination contained in article 82 of the Constitution of Kenya is not in conformity with the definition contained in Article 1 of the Convention" above suggests that the Kenyan government is silent on the need to put into place the necessary policy changes to end the ongoing discrimination against women.

Section 5.5 has examined the discourse of the Kenyan government with regard to its modes of engagement with the women's NGOs. The following section discusses the women's NGOs' understandings of gender equality.

\subsection{Women's NGOs' conceptions of gender (in)equality}

One very interesting feature of the women's NGOs' discourse of women's rights in Kenya is the manner in which their texts weave a path through multiple other discourses (i.e. interdiscursivity). That is, while their texts do, as we have seen, draw heavily on the United Nations' universalist discourse of women's rights to make sense of gender equality, they also mix this, heterogeneously, with an understanding of Kenyan women's rights to gender equality based substantially on their knowledge of discourses that can be termed cultural relativist, as will be discussed in the ensuing sections. This raises awkward questions around political motivation and intellectual conditioning that I will attempt to address as we proceed.

\subsubsection{Kenyan cultural practices and women's dis-empowerment}

From one perspective, it is clearly the case that the NGOs' texts identify the Kenyan people's cultural beliefs and traditions as a barrier to women's realization of gender equality. For instance, with implicit intertextual reference to article 10 (f) of CEDAW that obliges national governments to strive for the "reduction of female students' drop-out rates" (CEDAW, 1981), the LKWV (2005, p.16) reiterates that hundreds of girls are still missing the Free Primary Education because of social and cultural factors like "early and forced 
marriages, and traditional gender attitudes."

Likewise, attributing women's inequality to the existing conceptualization of cultural practices and traditions as permanent and unchangeable, the LKWV emphasizes the need for the Kenyan government not to conceive of culture as a fixed thing. For example, with implicit reference to article 2(f) of CEDAW that calls on national governments to "To take all appropriate measures, including legislation, to modify or abolish" any "customs and practices which constitute discrimination against women," (United Nations, 1981), the LKWV (2005, pp.41) emphasises the need for the Kenyan government to understand culture as a discursive concept that is subject to amendment. In this context, deploying the topos of definition (Reisigl \& Wodak, 2001, pp.76-81), the LKWV (2005, p.41, my emphasis) emphasizes that though culture plays a key role in determining how we perceive the world, it has to be seen as denoting "a set of practices, belief systems, and values that change with time," and therefore "must never be allowed to justify gender-based inequalities." By the same token, the LKWV (2005, p.42, my emphasis) demands that the government:

should collect evidence in the form of testimonies, case studies and statistics on discriminatory cultural practices that are often defended as elements of 'African culture'; ... That the government takes urgent steps to enforce legislation against cultural practices that infringe on the rights of women.

In relation to Fairclough's (2003) concept of deontic modality explained in the previous chapter, Dunmire (2005, p. 498) points out that from an oppositional context, modality serves as a means of contestation, "whether by negotiation or imposition of ideological systems." From this vantage point, the use of the deontic modalitity "must" in the proposition "must never be allowed to justify gender-based inequalities" above can be said to be pointing not only towards what the LKWV considers it to be the Kenyan government's obligation to do, but also its competing or alternative vision of what ought to be done in favour of women. The same can be said to apply to the deployment of the deontic modality "should" in the verbal phrase "should collect evidence in the form of testimonies," including the adjective "urgent," attributed to authoritative discourses (Fairclough 1995) in the extract "urgent steps to enforce legislation against cultural practices that infringe on the rights of women" above. In this context, the verbal phrase "should collect evidence in the form of testimonies" signals the LKWV's “degree of commitment to truth" (Fairclough 2003, p.166), while "urgent" in the proposition "urgent steps to enforce legislation against cultural practices..." spells out the imperative mood in the LKWV's statement, as well as prescribing 
what it (the LKWV) considers important for the Kenyan government to do in favour of women.

Other evidence showing the NGOs' view of cultural practices as constituting a hindrance to women's realization of gender equality is given by Ms Mainga of AMWIK noted above (see 5.4.1). In this context, Ms Mainga (2003, pp.81-83) blames women's inability to participate equitably on the Kenyan government's national media houses. This perception as Mainga (2003, p.82) continues to argue, has to do with the idea of promoting the societal view of women as wives and mothers, and as persons "without decision-making and leadership capacity."

Notice that the alleged behaviour and language use by Mr Njuguna, the court magistrate, who sees men's violence against women as “the African man's way of disciplining his wife" (FIDA Kenya, 1997, p.37), and President Moi's cultural view of women as persons with little minds referred to elsewhere in this chapter, falls within this semantic field. Within this understanding, the extract below by AWC gives a broader picture surrounding the role of culture in women's inability to participate in politics and other decision making positions on equal terms with men in the Kenyan society:

\section{In almost every Kenyan culture, the female is seen as inferior and always} ranked among children...those who venture into the public sphere have their voices drowned by discriminatory sentiments. They are dismissed as children, 'small brains,' divorcees, home breakers, prostitutes and moral decadents. They are asked to return to the Kitchen and homes where they can serve their children and husbands (AWC, 2004, pp.10-11, emphasis added).

As demonstrated in this excerpt, NGOs' texts largely blame the Kenyan cultural practices and traditions for the existing inequality among Kenyan women. According to Kenechukwu, Asemah and Edegoh (2013, p.957), actors can use the persuasive technique of "bandwagon" (i.e. a propaganda device that seeks to persuade the target audience to "believe or do something because 'everybody else' does)" to influence other actors to embrace their world view concerning an issue of political significance. From this perspective, we may argue that the prepositional phrase "In almost every Kenyan culture" in the extract "In almost every Kenyan culture, the female is seen as inferior and always ranked among children ..." above seeks to influence the readers' of their policy texts to the effect that the Kenyan male dominated cultural systems and traditions are largely anti-women, and their issues. 


\subsubsection{Historical factors}

Presenting a rather different perspective, however, Professor Wangari Mathai, the Chairlady, the Green Belt Movement (GBM), blames inequalities among Kenyan women on the process of colonialism and the over-reliance on or "over-use of foreign languages" that do not express the African values and world view (Mathai, 1995, p.15) (see1.3.1). In her view, Mathai (1995, p.15) holds that over-reliance on foreign languages has the potential to alienate people from their cultural norms and identity by de-mystifying and demeaning their personality. Similarly, Mathai (1995, p.17) emphasises that the use of local languages helps to preserve the African "traditional knowledge and spiritual heritage." In conclusion, she emphasizes that:

Cultural liberation will only come when the minds of the people are set free and they can protect themselves from colonialism of the mind. Only that type of freedom will allow them to reclaim their identity, self-respect and destiny (Mathai, 2004)

Mathai's sentiments here seem to echo those of other researchers of human rights in Kenya (see 1.3.1), including transnational feminist scholars of women's rights such as Merry (2006, p.1), who argues that advocacy for women's rights ought to be presented using "local cultural terms." That is, Merry stresses that women's rights have to be presented in local terms (i.e. be remade in the vernacular), so as to be persuasive, and more effective. Thus, following from Merry's argument above, it is arguable that though Mathai espouses the language of rights as the means to women's empowerment and equality with men in society, she (and the Green Belt Movement in general) also endorses the cultural relativist approach to the same rights. As such, though the Green Belt Movement is engaged in advocating women's empowerment and rights (i.e. new normative ideas), it also endorses a cultural relativist approach to their implementation, hence the interdiscursivity that can be seen to characterise the GBM's texts on gender equality.

\subsubsection{Gender equity and equality}

It is of particular significance that, in an attempt to conceptualize the normative discourse of women's rights, several NGOs' texts examined in this study were found to articulate the concept of gender equality simultaneously with those of equity and development. This particular feature was noted, for example, with the LKWV's text titled 
“The Kenya Women's Manifesto" quoted from above. In this context, the LKWV (2005, pp.11-12, my emphasis) stresses that:

The demands in the Manifesto aim at helping to achieve gender equity, equality and women's empowerment. These are a prerequisite to improving the quality of life of women and men and boys and girls... In a nutshell, the Women's Manifesto is a political document and a public declaration of key demands that must be met for Kenya to fully realise its vision for gender equity, equality and women's effective participation in governance and development.

This text epitomizes the overall heterogeneity of the LKWV's discourses of gender equality. This is evident from the act of mixing the discourse of gender equality with the discourses of women's advancement/improvement, "gender equity" and "development" being emphasized by the Kenyan government (i.e. see 6.3). This framing style could be argued to signal the LKWV's realization of the Kenyan government's reluctance to adopt the universalist approach to gender equality policies whole sale, hence the decision to combine its discourse of gender equality with those of "equity" and "development" being mouthed by the Kenyan government. On the other hand, the interdiscursive framing of the LKWV's discourse of gender equality in the Manifesto to include other populist discourses (i.e. that of "governance" and improvement of the Kenyan people's quality of life) can be interpreted both as rhetorically meant to legitimize the LKWV's manifesto through appealing to varied audiences, and as a configuration of style, signalling historical shifts in the LKWV's approach to gender equality policies. This is in view of the fact that the League of Kenya Women Voters has been among the women's NGOs advocating a transformative approach to gender equality policies since its inception in 1992 (Mainga, 2003). The same can be read from the phrase "improving the quality of life of women and men and boys and girls" in the text above, signposting the influence of the Kenyan government's cultural relativist approach to equality that emphasizes the third generation of human rights and/or solidarity rights, emphasized by the African collective approaches to human rights (Delaet, 2006; Ness, 1999).

As Delaet and Ness explain in chapter two (see section 2.2.2), the African people's cultural relativist approaches to rights emphasize human rights as collective rights for all people, women, men, boys and girls, as opposed to the western oriented United Nations' discourse of human rights that emphasize individual rights (Delaet, 2006, p.20; Ness, 1999, p.9). The following text from the Kenyan government's gender policy 2011, is a good 
example to illustrate this African approach to women's rights with the emphasis on men and boys, women and girls, including other groups in society:

The Kenya National Policy on Gender and Development (NPGD), 2000 spells out a policy approach of Gender mainstreaming and empowerment of women and clearly states that it is the right of women, men, girls and boys to participate in and benefit equally from the development process... The vision of the Ministry is "A society where women, men, children and persons with disabilities enjoy equal rights, opportunities and a high quality of life (Republic of Kenya, 2011, pp. 9-10).

From the foregoing discussion, it becomes evident that though the LKWV's texts emphasize the implementation of women's rights using the United Nations' universalist approach, the framing style espoused in this Manifesto seems as well to draw on the cultural relativist approach to gender equality policies. The same can be argued to apply for the LKWV's support for the discourse of development being advocated by the Kenyan government, which to some extent can be interpreted as a government sponsored method of forcing Kenyan women to participate in the development process.

Just like the LKWV's case above, FIDA-Kenya's texts also bear traces of some textual influence from the cultural relativist approaches to gender equality. This is evident in the following extract, which was also stated in 5.4.2 above:

In essence the MDGs have failed to take into account the de facto situation of girls and boys, women and men and to address the gender imbalances that impact on efforts towards achieving gender equality (FIDA-Kenya, 2005, p.20; emphasis added).

From this excerpt, just like the LKWV, FIDA-Kenya talks of "the de facto situation of girls and boys, women and men," reflecting a clear parallel with the Kenyan government's cultural approaches to human rights that emphasises collective/solidarity rights as opposed to individual equality rights.

\subsubsection{Religious discourse}

A similar heterogeneity can be observed when, upon noting the Kenyan government's hard-line stance against gender equality policies during the constitution of Kenya Review 
Process, FIDA-Kenya draws on the topos of religion/culture (Reisgil \& Wodak, 2001) to argue that:

Although the campaign for equal rights between women and men in the Constitutional Review Process (CRP) has realised milestones, some in the society are yet to appreciate the very fact that gender equity and women's' rights are God given. In the Holy Bible for instance, when the daughters of Zelophehad were demanding property and their father was wondering on his succession for he had no son, the Lord God told Moses: "What Zelophehads's daughters are saying is right. You must certainly give them property among their father's relatives, and give their father's inheritance to them" (FIDAKenya, 2005, p.48, my emphasis).

Drawing upon Fairclough's (1992) concept of interdiscursivity, the excerpt above can be said to reflect FIDA-Kenya's "cultural competence," which as Sondergaard states, involves knowing both the prevailing discourses and the ways in which they can be used as cultural premises to legitimize given actions/events, as well as to constitute different identities (Sondergaard, 2002, p.199). This view demonstrates not only the hybrid nature of FIDA-Kenya's texts on gender equality, but also, its double pronged approach to women's rights. This is in view of the fact that its texts on gender equality are based both on the United Nations' universalist approaches, as well as the cultural relativist approaches espoused within the local milieu.

From this vantage point, it can be argued that the NGOs' texts of gender equality are mutually constitutive of both the universal and cultural relativist understandings of women's rights to gender equality. In this way, the universal and cultural relativist understandings of gender equality are complementary, in the sense that the women's NGOs draw on multiple other discourses within their cultural knowledge to make sense of gender equality policies.

In addition, speaking from the transnational feminist rhetorical viewpoint, Dillard and Okpalaoka emphasise that unlike the western feminist discourse, black feminist theorizing draws on the historical and cultural sources which inform the multiplicity of perspectives with which African women view and respond to issues of oppression and domination within and across national contexts (Dillard \& Okpalaoka, 2011, p.150). This is precisely the case with FIDA-Kenya's framing style under discussion.

Evidently, just like the LKWV that articulates the notions of equity and equality together in the same utterance (i.e. see 5.6.3), FIDA-Kenya's extract above also states gender 
equity and women's rights within the same clause. That is, whereas the LKWV's states that its Manifesto presents demands that must be met for Kenya to fully realise its "vision for gender equity, equality and women's effective participation ..." (LKWV, 2005, pp.11-12, my emphasis), FIDA's (2005, p.48, my emphasis) text argues that: "some in the society are yet to appreciate the very fact that gender equity and women's rights are God given." This means that unlike the CEDAW committee that was seen to emphasize the need for the Kenyan government to implement "gender equality" using "a true rights-based approach to women's issues in all areas" (see 4.4.4), the NGOs' texts under discussion tend to embrace both the equality and equity criteria in gender equality policies. This conclusion is further noted in the text below by the Green Belt Movement, which articulates the discourses of culture, equity, development, and people's welfare (i.e. just like the Kenyan government). That is, in her publication titled "The Cracked Mirror," Professor Wangari Mathai, the chairlady, the Green Belt Movement, stresses that:

After working with different Kenyan communities for more than two decades, the Green Belt Movement (GBM), which I led until joining the new Kenyan government in January 2003, also concluded that culture should be incorporated into any development paradigm that has at its heart the welfare of the people. The Green Belt Movement's mission is mobilising community consciousness for self-determination, equity, improved livelihood, security and environmental conservation, using trees as the entry point (Mathai, 2004, p.1, emphasis added)

This understanding resonates with Fairclough's (1992, pp.22-23) emphasis that "the principle of heterogeneity of discourse" is a central element in his concept of intertextuality, and that heterogeneity (i.e. framing style of embedding varied discourses in one text) is an important indicator of "discursive change within wider social and cultural change."

\subsection{Summary}

From the foregoing discussion, NGOs were found to identify the problem of the Kenyan government's misinterpretation of the concepts underlying the normative discourse of gender equality as one of the core issues hindering women's ability to realise their rights. For instance, as noted in 5.4.2 above, FIDA-Kenya cites the Kenyan government's misinterpretation of the concepts of rape and carnal knowledge, as constituting a hindrance to 
the Kenyan law courts' ability to dispense justice in favour of the women victims of genderbased violence. This problem was found to be worsened by the Kenyan government's judges' lack of knowledge and expertise on gender equality and the international standards on women's rights (see 5.4.2 above).

Within this line of argument, NGOs' texts also allege the Kenyan government's misinterpretation of gender equality concepts with regard to women's rights to education. For instance, as noted in 5.4.2 above, FIDA-Kenya (1997, p.20) notes that the Kenyan system of education sees boys' and girls' education as an end in itself, as opposed to being a means to an end, and for achieving "gender equality and social justice." Likewise, FIDA-Kenya (1997, p.20) observes that the Kenyan government's approach to girls' education targets "numbers," rather than the unequal power relations that hinder equal access to quality education for both boys and girls.

In terms of reproductive rights, FIDA-Kenya's (2005, p.21) notes that the Kenyan government's MDG approach to women's reproductive rights focuses on reducing maternal mortality rates, as opposed to achieving women's reproductive rights. Further, FIDA-Kenya (2005, p.21) posits that the Kenyan government's MDG approach to reproductive rights necessitates the view of women solely as "mothers and care givers," rather than as people with rights to their "own health and wellbeing."

Interestingly, FIDA-Kenya's argument above connects with that of scholars on women's reproductive rights in Kenya. For instance, in her study on "the State and Sexuality Politics: An Analysis of Abortion Discourses in Kenya," Njagi (2013, p.202) asserts that:

because women's sexuality is often publicly reduced to their conventional mothering role and conflated with their reproductive capacities (Tamale 2001), Kenyan women's right to choice and sexual freedom is often ignored or swept aside by political elites seeking patronage from religious and traditional leaders."

However, as noted in chapter two, Donnelly (2013, p.103) insists that variations in the interpretation and implementation of rights should be understood as being the result of “differences in human rights practices." Likewise, Johnstone (2005, p.195) observes that the varied interpretations accorded the universal discourse of human rights locally emanates from its (the UN discourse of women's rights') inability to fix a single definition and/or interpretation of women's human rights within the local context. This scenario as Johnstone (2005, p.195) proceeds to explain, allows national governments to act otherwise, though the 
UN's discourse remains the binding glue that holds the divergent viewpoints together.

Similarly, despite the local women's NGOs' apparent adherence to universal gender equality as espoused under CEDAW, it was found that the NGOs' texts also articulate the notion of gender equality interdiscursively with multiple other discourses. As mentioned earlier, it is conceivable that this focus on several other discourses includes, at least in part, a conceptual shift, necessitated by the NGOs' realization of the Kenyan government's reluctance and consequent failure to put in place appropriate policies to grant and promote women's rights to gender equality. But, it needs to be emphasized that, in the final analysis, the adherence to local cultural practices and beliefs appears to be more deep-seated than a mere recourse to rhetorical exigency would suggest. That is, the recurrent NGOs' interdiscursive articulation of gender equality with other discourses in their texts (i.e. the interdiscursive reference to religious beliefs and traditions, equity, development etcetera) can be said to be an inherent and constant feature of their theorizing and way of being. This means that the NGOs' concept of gender (in)equality is to some degree at variance with that of the UN (CEDAW) that was seen to emphasize the human rights approach per se (see 4.4.2).

As this chapter has discussed, despite the NGOs' varied efforts to bring about gender equality policies in Kenya, there seem not to be many changes on the ground. More particularly, despite the women's NGOs' regular demands for changes in policies to enable women's increased participation in politics and decision-making structures, such demands seem to have had little influence on the Kenyan government's hard-line stance against gender equality policies.

Finally, the fact that majority of the women's NGOs' texts seek to legitimize gender equality policies through collaborating with the Kenyan government whilst still operating dialogically with CEDAW's universalist discourse of gender equality is worth mentioning. Drawing on Fairclough's (2001) concept of the dialectics of discourse, this can be taken to signal the fact that a compromise is inevitable, i.e. the need for a middle ground involving the borrowing of perspectives from both the universalist and cultural relativist approaches to women's rights. This is consistent with Donnelly (2013) and other scholars of women's rights discussed in chapter two. 


\section{OFFICIAL STATE POLICY ON GENDER EQUALITY}

\subsection{Introduction}

This chapter seeks to propose that the analyses of Kenya's interactions with NGOs and the Committee on the Elimination of All Forms of Discrimination against Women (CEDAW) in the previous chapters are not the only contexts for understanding the discourse of women's rights to gender equality in Kenya. Rather, it is appropriate here to consider how the Kenyan government's official discourse of gender equality is discursively produced and recontextualized at different levels of policy making. In this context, the present chapter seeks to show how the Kenyan government's official policy on gender equality manages the NGOs' collective demands for gender equality policies in Kenya. This includes examining the extent to which the women's NGOs influence the Kenyan government's public policies concerning women's rights to gender equality. The chapter also explores the different ways in which the Kenyan government construes, as well as recontextualizes the normative discourse of women's rights in its national policy discourses of gender equality.

These objectives will be achieved through a linguistic and intertextual analysis of a chain of documents outlining the Kenyan government's post-Beijing national policy strategy concerning gender equality. These documents are stated in the table below:

Table 1: Official policy documents on gender equality

\begin{tabular}{|l|l|}
\hline No. & Title \\
\hline 1 & The National Gender and Development Policy 2000 \\
\hline 2 & $\begin{array}{l}\text { Kenya Review and Appraisal: Final Report on the Implementation of Beijing } \\
\text { Platform for Action (Beijing }+10)(1994-2004)\end{array}$ \\
\hline 3 & Millennium Development Goals in Kenya: Needs and Costs, 2005 \\
\hline 4 & Kenya Vision 2030, 2007 \\
\hline 5 & Gender Policy 2011 \\
\hline
\end{tabular}

To realise the above stated objective, this chapter seeks to answer the following questions:

(1) How does the Kenyan government recontextualize the normative discourse of women's rights in its national policy discourses of gender equality? 
(2) What linguistic/non-linguistic and rhetorical strategies does the Kenyan government deploy, either for granting or refusing to grant the transformative gender equality policies?

(3) What are the (changing?) conceptions of gender (in)equality that underlie the Kenyan government's policy discourse about women's rights to gender equality?

To shed some light on the Kenyan government's initial official move to address women's rights to gender equality, the first part of this chapter will present a brief overview of the task force to review laws relating to women. This will be followed with a more detailed linguistic and intertextual analysis of the Kenyan government's gender policy texts stated above.

\subsection{Establishment of a task force to review laws relating to women}

As was explained in chapter one, following the Kenyan government's repealing of section 2A of the Kenyan constitution in 1991, Kenyan women and feminist activists took advantage of the opening democratic space to demand the elimination of gender-based discrimination against women, as well as the inclusion of women's issues in the official policy making process. As a response to the women's demands, in 1993, the Kenyan government formed a task force to review all the "laws, regulations, practices, customs and policies that impose constraints on equal enjoyment of rights by women in civil, political, social cultural life or related matters with a view to preparing legislation designed to remove or limit the inequalities referred to" (Republic of Kenya, 2000, p.15). The specific mandate of the task force is captured verbatim from Amos Wako's speech below. That is, while contributing to a discussion of "the Domestic Violence (Family Protection) Bill in the Kenyan Parliament, Mr Amos Wako, the Attorney-General and legal advisor to the Kenyan government had this to say:

It may be recalled that in 1993, I set up a task force to review and make recommendations on all laws relating to women. As part of the burden of that task force, they were to review, not only the existing laws, but also to recommend any new laws that will ensure that women enjoy their rights on an equal footing with men. It was also the specific mandate of the task force, which was ably chaired by Justice Effie Owour, that they should also look into customs, traditions and practices which tend to violate the rights of women. 
That task force did visit all the provinces of Kenya, and some districts, seeking views of Kenyans on this matter... One of the recommendations they made was that, in this country, we should have a Domestic Violence (Family Protection Bill, 2002. In fact, they proceeded to make the job easier for the Government by actually drafting the Bill itself (Hansard, April $24^{\text {th }} 2002$, p.730).

Following on from this, it is worth nothing that the aforesaid task force became the Kenyan government's rallying point in its rhetoric of promoting women's concerns. For instance, the contents of the task force were reiterated by the Minister for culture and social services, Mrs Nyiva Mwendwa, in her inaugural speech at the 1995 Fourth World Conference on Women in Beijing:

I am happy to announce that as part of effective implementation of the Platform for Action, the government of Kenya, in 1993, appointed a Task Force headed by a Senior High Court Woman to review laws and cultural factors that continue to perpetuate discrimination against women. The Task Force is mandated to prepare bills to be tabled in parliament (Republic of Kenya, 1995).

Arguably, this statement can be taken to be indicative of the Kenyan government's intent to promote gender equality policies in Kenya, culminating into the enactment of the National Gender and Development Policy 2000 discussed below.

\subsection{Text 1: The National Gender and Development Policy 2000, Ministry of Gender, Sports, Culture and Social Services}

The National Gender and Development Policy 2000 represents the Kenyan government's first official policy to promote the rights of women. As such, the policy document is addressed to the Kenyan women, women's NGOs, and CEDAW demanding gender equality policies in Kenya. The core concerns of this policy document are explored in the discussion below. 


\subsubsection{Legitimation through forging solidarity with the United Nations' conventions}

In an effort to establish a link between Kenya's policies on gender equality and the universal discourse of women's rights, the national policy on gender and development 2000 opens with a manifest intertextual reference to the 1975-1985 United Nations' Decade for the Advancement of Women:

The UN Decade for the Advancement of Women, proclaimed in 1975, set in motion a process which led to the increased awareness of women's contributions not only to the sustenance but also to the development process (Republic of Kenya, 2000, p.2).

It is arguable that through invoking the United Nations' Decade for Women and placing it in the introductory part of this policy document, the Kenyan policy makers can be said to be seeking to legitimize the new policy through associating it with the well-known normative discourse of women's rights that is linked to the United Nations.

According to Van Leeuwen (2007, p.92), legitimation of a proposition involves ascribing given meanings to justify the imperatives of a given institutional order. In his words, Van Leeuwen (2007, p.92) argues that "Legitimation is always the legitimation of the practices of specific institutional orders." Based on these arguments, it can be said that the aforesaid Kenyan government's legitimation practice above seeks to naturalize the new policy at hand, by presenting it as containing 'given' information.

As Dunmire (2009, p.198) argues, naturalization is usually achieved through presenting policies as being an unescapable "natural response to the given state of the world." In this context, the intertextual reference to "The UN Decade for the Advancement of Women," and its role in setting "in motion a process which led to the increased awareness of women's contributions..." in the excerpt above, can be argued to be indicative of the Kenyan government's intent of wanting to absolve itself from being an agent in the initial process of bringing about equality policies. The verbal phrase "set in motion a process...," in the proposition "set in motion a process which led to the increased awareness of women's contributions not only to the sustenance but also to the development process" above serves to exclude the Kenyan government from the "actional process" (Fairclough 2000) of bringing about gender equality, thereby amplifying the fact that the discourse of women's rights was orchestrated by the United Nations. By so doing, the emerging discourse of women's rights in Kenya is presented as having come about through global processes, rather than as something that is the result of "causal agents" (Fairclough, 2003, p.144), and in this case, through the 
ongoing interactions between the Kenyan government and the other policy actors alluded to in the following excerpt from the policy text under discussion:

The policy is also consistent with the Government's commitment to implementing the National Plan of Action based on the Beijing Platform for Action (PFA). Significantly, the KANU manifesto, and the manifestos of other political parties also address the issue of how a gender perspective can be incorporated into the national development of this country (Republic of Kenya, 2000, p.2).

Interestingly, a closer look at this excerpt reflects that it is an imitative response to a rhetorical question raised previously in the Kenyan parliament by Mrs Asiyo, while contributing to a motion entitled "Implementation of Beijing Platform for Action" in the Kenyan parliament. In this context, Mrs Asiyo is quoted to have argued that:

Even political parties here, both opposition and KANU, are not gender sensitive. Look at all these political parties, what women do they have as their chairladies or even as secretary generals? ...we have to be sensitive to women's issues. Both the opposition and the ruling party should be more sensible and sensitive in the accommodation of women in Kenya (Hansard, 1996, p.2399).

As explained in chapter three, Fairclough's $(1992,1995)$ model of CDA emphasises the need to look at the emergence (historicity) of discourses in terms of the different ways in which they are framed together with elements of other existing discourses. He also believes that it is important to understand how discourses articulate past and current events and actions, as well as how they justify policy actions and proposals, and legitimise imagined change practices and systems (Fairclough, 2013, p.19). From this vantage point, the text above suggests that as an unavoidable global discursive process, the Beijing Declaration and Platform for Action necessitated the "production and intertextual context" (Dunmire, 2005, p.493) that inspired Kenya's enactment of the gender and development policy 2000 that seeks to address women's inequality. In effect, making manifest intertextual references to the United Nations' discourse of women's rights here helps to set up "relations of equivalence" (Fairclough, 2005, p.20) between the United Nations' goals and the Kenyan government's professed policy goals.

In other words, by associating its discourse of women's rights with that of the UN, the 
Kenyan government situates itself in the UN's frame of reference, thereby signposting its unquestioned solidarity with the UN. However, citing Fairclough (1992, p.160), Rivitoi (2008, p.44) notes that producers of texts tend to signal their commitment to a proposition "in the course of their interactions with other people." Further, Rivitoi (2008, p.44) warns that the sense of affinity expressed in such propositions has "little to do with one's commitment to a proposition, but a lot to do with a desire to show solidarity." To some extent therefore, the Kenyan government's manifest intertextual references to the UN's discourse of women's rights can be argued to be rhetorically motivated, probably to afford its official gender policy a universal status, thereby heightening the UN's and other stakeholders' comfort level with regard to its (Kenyan government) commitment towards gender equality.

Other researchers of policy discourse seem to argue that the tendency of associating given policy practices to global processes entails a rhetorical strategy. For instance, Bhatia (2006) argues that rhetorical strategies can be deployed to dull the prevailing ideological differences between various social actors, thereby neutralising deep seated disagreements. On a similar note, Titscher et al. note that attribution of responsibility through such techniques of argumentation as rejection of guilt, scapegoating strategy and playing down through balancing /rationalization constitute part of the techniques commonly used by actors to legitimate or contest particular positions in discourse (Titscher et al., 2000, p.159). It is arguable then that this representation of the Kenyan government's discourse of women's rights as resulting from inevitable global forces (i.e. Beijing Declaration) is a potential device for cushioning any existing ideological differences between the United Nations' normative discourse of women's rights, and the Kenyan government's cultural relativist discourse of women's rights to gender equality. Furthermore, the Kenyan government's policy framing style above seeks to conceal the possibility that this policy document is in fact a by-product of campaigns and contestations over many years by various policy actors agitating for gender equality in Kenya. This reasoning is supported by the following excerpt from the Kenyan parliament. While adding to the above mentioned motion in the Kenyan parliament (refer to the quotation from Mrs Asiyo), Ms Martha Karua, an MP and feminist activist had this to say:

What this motion is calling for is for the government to move a step ahead...We are calling upon the Ministry of Culture and Social Services and the Government to formulate a gender policy which will guide all Government departments and set the pace in this country for women's 
empowerment and for the implementation of the Beijing Platform for Action (Hansard, 1996, p.2507, emphasis added).

From this extract, the proposition "We are calling upon the Ministry of Culture and Social Services and the Government to formulate a gender policy" makes it clear that "the National Gender and Development Policy 2000" under discussion was in part enacted as a response to the Kenyan feminist agitation for gender equality policies.

\subsubsection{Past Kenyan policy regimes}

Using the topos of disadvantage (Grue, 2009; Lindblad \& Popkewitz, 2004; Wodak, 2011), the government's policy text under discussion attributes women's present unequal status in society to previous bad "national and sectoral policies", which in this case are blamed for ignoring issues of women:

Since 1963, national and sectoral policies have had different impacts on Kenyan women and men, and more often than not have overlooked gender concerns. The National Policy on Gender and Development provides a basis for the Government to underscore its commitment to advancing the status of women. The Government of Kenya is determined to address any existing imbalances through policy formulation and implementation taking into account different needs and skills of men and women (Republic of Kenya, 2000, p.2, my emphasis).

From the extract, "The National Policy on Gender and Development provides a basis for the Government to underscore its commitment to advancing the status of women," it is arguable that the core aim of this policy is to promote the advancement of women's social position in society, as opposed to granting them their rights to gender equality.

Through nominalization, the government lays blame on the "national and sectoral policies" (i.e. and not the government itself for instance) for neglecting issues of women. Fairclough defines nominalization as the "conversion of a clause into a nominal or noun" (Fairclough, 1992, p.27). In addition, Fairclough states that the process of nominalization, together with passivization, can be associated with ideological elements of texts, such as that of obscuring agency. In his words, these ideological features of text can allow "the systematic mystification of agency," meaning both permit the agent of a clause to be deleted 
(Fairclough, 1992, p. 27). This suggests that nominalization can be deployed strategically to manipulate the reader by stating the key events of the text in nominal form, thereby omitting the agent responsible for the stated actions. Consequently, Fairclough (2003, p.144) notes that the process of nominalization points to the exclusion of actors in texts. For instance, giving an example of employees that have been dismissed, Fairclough gives the examples below

(i) the management fired them

(ii) they lost their jobs (Fairclough, 2003, p.144)

In this case, text (ii) above is the passive version of text (i), presenting the employees' dismissal as having resulted from some unidentified material process. On these grounds, Fairclough (2003, p.144) argues that nominalization is a potential device for generalizing, and for "abstracting from particular events or sets of events." For this reasons as Fairclough (2003) continues to explain, the process of nominalization plays a significant role both in the genres of "technical discourse" and "governmental discourse." In this context, the excerpt "national and sectoral policies have had different impacts on Kenyan women and men, and more often than not have overlooked gender concerns" above apportions women's inequality to the "national and sectoral policies,"and not to the Kenyan government. By blaming women's inequality on "national and sectoral policies" i.e. for overlooking "gender concerns," the extract under discussion can be argued to be rhetorically aimed at reflecting the Kenyan government as not being directly responsible for women's inequality. In other words, by absolving the Kenyan government from the actional process of causing women's inequality, the extract above can be said to be ideologically motivated, probably to shield the Kenyan government against any moral or political blame for women's inequality.

\subsubsection{Global economic crises and structural adjustment programmes}

Another excerpt from the policy under discussion presents women's inequality as having resulted from a poor economy and global lending agencies:

The sluggish performance of the national economy, made worse by Structural Adjustment Programmes (SAPs), have had a negative impact on the gains made in improving standards of living in general and advancement of women in particular...In this context, women have had to bear greater share of 
responsibility of caring for their families (Republic of Kenya, 2000, p.2, my emphasis).

Arguably, the core message in the text above appears to have been invented to appeal to the feelings of Kenyan women and other actors recovering from the effects of the economic recession, thereby installing itself (government) as the "paternal authority figure" (Davy, 2011, p.8), that is in charge and responsible for matters affecting women in society. This is achieved through identifying "The sluggish performance of the national economy," and "Structural Adjustment Programmes (SAPs)," as the primary factors responsible for women's inequality, thereby projecting itself (government) as being responsible for identifying the core cause of women's inequality in Kenya. In other words, within the context of the National Gender and Development Policy 2000, the government's text above appropriates the notion of "Structural Adjustment Programmes (SAPs)" attributed to the loans provided by the International Monetary Fund (IMF) and the World Bank to countries that experienced economic crises in the 1970s and 1980s (Soeda 2008), both to place the policy within the global perspective, and set the background to the unequal status of women in Kenya. Indirectly, this is a legitimation strategy meant to validate the new policy text.

According to Van Leeuwen (following further the reference in 6.3.1 above), given social practices can be justified through "conformity legitimation," which as he argues, is achieved by comparing or attributing a given proposition to some authority or other actors (Van Leeuwen, 2007, pp.96-97). In addition, Van Leeuwen (2007, p.101) explains that legitimation can be achieved through "theoretical rationality of legitimation," which endeavours to legitimate given practices through making reference to "a natural order of things." In this context, based on theoretical rationalization as Van Leeuwen (2007, p.103) states, social actors seek to legitimize given actions and events in texts, based on some forms of truth explaining how things are. Going by these perspectives, we could argue that to some degree, by attributing women's inequality to the global recession and lending agencies (i.e. World Bank and IMF), the text above seeks not only to legitimize the policy document, but also to naturalize the existing situation of women's unequal status in society by blaming other textual actors.

As Didriksen, Gjesdal and Muller (2013, p.100) contend (see also 4.3.4), causal connectives such as "because," "due to", and "as a result" among others are used to introduce factual cause arguments, thereby reinforcing the textual representation of common values by presenting particular arguments as given. In this way as the researchers proceed to 
argue, causal connectives serve to naturalise given states of affairs in ways that conceal underlying controversies and contestations. Based on Dedriksen, Gjesdal and Muller's arguments above, the use of the causal connective "by" in the clause "by Structural Adjustment Programmes (SAPs)" above seeks to attribute women's inequality to global forces beyond the Kenyan government's control. Beyond this, it is worth noting that in the proposition "the gains made in improving standards of living in general and advancement of women in particular" above, the agent (i.e. probably the Kenyan government) in the actional process of advancing the status of women is elided, and thus informationally backgrounded. From this perspective, it is arguable that the government draws on the discourse of SAPs above attributed to global forces (i.e. global recession and the IMF and World Bank's financial policies) as part of its persuasive strategies to rationalise the state of women, thereby exercising control over their situation by consent. In the light of this argument, we could say that the Kenyan government's text above presupposes that it will be unrealistic to expect the government to make any major difference in the lives of women, beyond its immediate obligation of enacting policy interventions to alleviate their problems. In other words, allusion to global processes as the cause for women's inequality can be taken to be a rhetorical move to depoliticise and/ or downplay expectations concerning what the government may be expected to do to eliminate gender inequality among women, thereby protecting itself against any blame.

According to Rose (1999, p.21), governing draws attention to a multiplicity of historical social problems like wars, diseases, riots, and emergence of new economic regimes around which political problematizations come to form. Further, Rose (1999, p.21) argues that such problematizations never speak for themselves, hence have to be individuated and understood in given ways. This suggests that the Kenyan government could be using global processes as a means for structuring its interventionist policy claims, thereby installing its authority as the planner who knows the particular issues of women, as well as how they ought to be managed.

As noted in chapter two, this scenario tells us why transnational feminist rhetoricians emphasize the need to re-examine the historical and cultural situatedness of meaning, by examining the different ways in which unequal power relations are reproduced across varied contexts enacting gender inequality policies (Hughes, 2002, p.12; Grosz, 2010, p.49).

Ironically, the Kenyan government's expressed uneasy stance about IMF and the World Bank in the text above is not without reason. This is consistent with the Human Rights Watch (1997, p44), who notes that the IMF and the World Bank were largely influenced by 
the international community to suspend aid to Kenya on the basis of its disregard for human rights, thereby forcing the Kenyan government to begin recognizing the concept of human rights in its national policy programmes (Human Rights Watch, 1997, p.34).

\subsubsection{Development processes and women's inequality}

Drawing on the discourse of development, this policy document blames women's inequality on their non-participation in development activities (ironically, given that an increase in participation has been one of the leading demands of the women's NGOs). This is demonstrated below:

Whereas the planning and policy making processes recognise that it is the right of men and women to participate and benefit equally from development initiatives, this has often not been the case ...The policy advocates for new departures and strategies... It promotes a more cost-effective way of managing resources and ensuring sustainable development. This will ensure better targeting of marginalised groups and their integration into mainstream of development (Republic of Kenya, 2000, pp.4-5, my emphasis).

According to Lindblad and Popkewitz (2004, p. xviii), the topoi of exclusion and reform entails a strategy deployed by authors to support given forms of thinking, thereby persuading readers to come to some consensus about the intended actions. Further, the researchers posit that the strategy of exclusion serves to individualize and personalize people through categorization. On these grounds, the argument above that the new policy seeks to "ensure better targeting of marginalised groups and their integration into mainstream of development" presupposes that women's inequality could be due to their exclusion and/or absence from development activities, thereby suggesting that women themselves are to blame for their unequal status in society. This is deduced from the fact that the excerpt under discussion conceals through nominalization (Fairclough, 1992, p.27) whoever could be responsible for the aforesaid exclusionary policies, including the provision of the necessary conditions needed for their (women's) realisation of their rights.

Another good example to illustrate the Kenyan government's framing framing style with regard to women's rights can be discerned from the text below: 
Beyond lack of effective participation in the economy, women have made little progress in politics... Women do not often offer themselves for elective posts for reasons that have been thoroughly discussed by many scholars...

(Republic of Kenya, 2005, p.63, emphasis added)

From this excerpt, the proposition "Women do not often offer themselves for elective posts for reasons that have been thoroughly discussed by many scholars" shows the Kenyan government's view of women's inequality as being self-determined. In this context, the negation "not," in the phrase "women do not often offer themselves..." above indicates the Kenyan government's underlying assumption regarding the low participation of women in politics and other decision making structures. This interpretation can also be inferred from the fact that the policy texts under discussion do not mention men as missing from the development process, thereby suggesting that they are already actively involved.

According to Van Leeuwen (2007, p.104), making reference to a people's attributes in texts entails a legitimatory act. This means that the act of attributing women's inequality to their non-involvement in development activities is a device for legitimizing the policy text under discussion.

On the other hand, pushing women to take part in development unearths the regulative role of the Kenyan government's policy discourse of women's rights, which in this case functions as a tool designed to manage and control the conduct of Kenyan women to given political ends. As Fairclough (Fairclough, 2005, p.56) argues, discourses have a role in constituting and consolidating political and socio-economic structures, where for instance women in this study become a resource for achieving given state goals.

From the feminist perspectives, as True (2013, p.127) explains, emphasizing the inclusion of women into the development process as a prerequisite for their empowerment reflects an instrumentalist conceptualization of gender equality anchored in the essentialist argument that women's participation in development can reduce gender inequality.

Moreover, the phrase "cost-effective way of managing resources and ensuring sustainable development" in the excerpt above signals how issues of women are interpreted in “individualistic and utilitarian" (Skilling, 2010, p.46) terms, where women's services are targeted for the benefit of the exploitative capitalist actors (Harrington, 2013, p.53). This reasoning is spelt out in the extract "This will ensure better targeting of marginalised groups and their integration into mainstream of development" above. This reveals the underlying logic in the Kenyan government's gender policy under discussion, i.e. that of seeing women 
as an "untapped resource" (Moser, 2012) that can provide a contribution to economic development, as opposed to viewing them as individuals with rights to equality.

As Lemke (2002) notes, Foucault's view of the art of government is not limited to the notion of politics as a separate entity from the economy. Rather, Foucault sees the state as an economic government constituted both by politics and the market logic (Lemke, 2002, p.57). In this context, as Lemke (2002, p.58) proceeds to explain, Foucault sees power of the economy as involving technologies of production and exploitation/utilization of human labour to enhance the accumulation of capital necessary for sustaining the state (i.e. political economy). As such, Lemke (2002, p.58) emphasizes the need to see the notion of economy as a governmental practice that characterises postmodern materialism. Viewed from this perspective, the terms "cost-effective," "managing resources," "development initiatives," and "sustainable development" from the discourses of management and development used in the excerpt above can be said to be indicative of the fact that the Kenyan government's policy discourse of women's rights is anchored in a liberal logic of governing. Going by Barry, Osborne and Rose's argument (see chapter 2 for more details), the choice of a liberal logic of governing here suggests the delimiting of excessive governmental intervention (Burchell, 1996, p.23). This delimiting of government is achieved through the "responsibilization and empowerment" (Barry, Osborne \& Rose, 1996, p. 12) of women to take charge of their own lives, rather than depending on welfare support from the national government. This is precisely what Foucault terms as the techniques of self-regulation (i.e. technologies of the self), whereby as Jonathan (2012, p.13) explains, individuals are encouraged to adopt an entrepreneurial attitude towards themselves, including making rational choices and decisions concerning their own individual lives. However, from a feminist perspective as Hatton and Trautner (2013, p.66) say, feminist activists continue to emphasize that any exploration of gender issues ought to move past the notions of individual choice, to analyse "the social forces that shape and constrain it."

\subsubsection{Culture and women's rights}

Drawing on the topos of culture (Reisigl \& Wodak, 2001) to make sense of women's rights, the policy document argues through narration that the empowerment of women and their advancement in society is directly hampered by the existing cultural beliefs and practices. In this context, the policy text states that: 
Gender relations in Kenya have been moulded by a combination of factors that draw from the influence of various traditions, customs and cultural practices, levels of education and awareness, economic development and emerging patterns of social organisation, besides legislation. The socio-cultural attitudes held by both men and women, the socialisation processes and women's perception of their own status, roles and rights are of particular significance in determining the status of women. Since young children are socialised by women at a very early age, they can change their attitudes or perpetuate negative perceptions...Women are perceived to be dependent on men and the roles accorded to men carry a higher status compared to those of women. This means that men have more rights than women (Republic of Kenya, 2000, p.4).

According to Leichty (2013), culture involves a clash between competing views of social reality. Moreover, Leichty sees a cultural topos as a set of coherent premises that support a given way of interacting and of perceiving the world. In conclusion, Leichty (2013, p.38) notes that such premises involve both perceptions of reality, and value assessments of what is considered desirable and good. From this perspective, it is arguable that the Kenyan government seeks to legitimize its policy actions concerning gender equality by invoking the authority of the Kenyan culture and traditions that espouse a cultural relativist approach to the rights of women. In other words, the Kenyan government's reference to the traditions, customs, cultural practices and socio-cultural attitudes in the excerpt above could be part of its (Kenyan government's) textual strategy tailored at privileging cultural thinking over other alternative ways of knowing, thereby undercutting the larger goal of achieving transformative gender equality policies.

What is more, by invoking the role of women in socializing children, the Kenyan policy makers could be suggesting that bringing about the suggested gender equality policies is highly likely to hurt children who depend on their mothers as care givers. This view is further evidenced in the policy document through the repeated emphasis of women's roles within the home. The following excerpt is a good example to illustrate this view:

The crucial role of women as providers and promoters of family and community health has been well acknowledged in various Government documents. Women actively participate and often manage several activities that affect the health and wellbeing of their families (Republic of Kenya, 2000, p.28). 
This scenario explains why the transnational researcher and scholar of women's rights, Coomaraswamy (1997, p.1260) emphasizes that though the universal discourse of human rights is a powerful tool with which to criticize states:

Nonetheless, insofar as it concerns a woman's private life, it is actually in many societies quite a weak discourse, particularly in the context of family and community relations. While international human rights law moves forward to meet the demands of the international women's movement, the reality in many societies is that women's rights are under challenge from alternative cultural expressions.

Ideologically speaking, such a construal conjures up an image of women as persons preoccupied with matters of the home, where their primary responsibility is taking care of children. This strategy that seeks to present women's roles as merely involving child upbringing poses a challenge through normalizing (Fairclough, 1992) women's position in society. Simply put, the Kenyan government seems to have a strategy that seeks to normalize this particular role of women. This understanding finds support in Padamsee's observation that policy makers can strategically package and present given cultural meanings to achieve particular ideological goals (Padamsee, 2009, p.419).

Further, it could be argued that by presenting women's current roles of caring for children as important or good, the Kenyan government's policy text plays a significant function in enslaving women by denying them the opportunity to participate in the public sphere on equal terms with men. As noted in chapter 4, this explains why the CEDAW Committee contests the Kenyan government's policy framing practices that construe women's role as being in the private sphere/home per se.

Along similar lines, the text's characterization of women's roles in relation to household chores underlies the on-going global discourse regarding the public and private domains. In this context, transnational feminist rhetoricians and researchers of women's rights argue that culture and traditions of the world have always posed problems to the realization of women's rights. For instance, as stated in chapter two, Coomaraswamy (1999) and Gould (2004) emphasize that cultures and other traditional practices tend to be seen as belonging to the private sphere of life, hence outside of the purview of human rights protection. In addition, they posit that such cultural practices continue to be invoked as a means for justifying the subordinate position of women in society. Contrary to this position, however, Fairclough (1995, p.137) proposes that our modern society is post-traditional, 
meaning that traditions ought to be justified against alternative possibilities, and /or thinking, instead of being taken as given. He thus emphasises the need to establish or take positions/identities that are "built up through a process of negotiation," instead of being assumed as "a feature of given positions and roles" (Fairclough, 1995, p.137), i.e. as is the case in the text under discussion. On a similar note, drawing both on Foucauldian poststructuralist perspectives and critical hermeneutics that emphasize "self-reflection," Bacchi (2013) emphasizes the need to strive for critical understandings that transcend strategic framings. In her view, such framing styles are tailored to achieve given political objectives. As a solution to this problem, she emphasizes the need to embrace reflexive writing practices that foster our capacity to re-examine our own normative/cultural assumptions (Bacchi, 2013, p.19).

\subsubsection{Alternative vocabulary and the characterization of women}

Another striking feature of the National Gender and Development Policy 2000 is the characterization of women as "a population category with special needs" (Republic of Kenya, 2000, p.2). That is, this text signals the fact that the Kenyan government's national policy on gender is still anchored in the 1970s "Women In Development theory (WID)," which as Mukhopadhyay, Steehouwer and Wong (2006, p.10) note, emphasised the inclusion of women in the development process, but without disturbing the existing unequal power relations between men and women in society. This means that though the Beijing Declaration gave the framework for "putting women and gender" (Mukhopadhyay, Steehouwer \& Wong, 2006, p.13) at the centre of development policies, the Kenyan government's national policy on gender equality is yet to do the same. That is, its "integrationist" approaches to gender equality that emphasise the inclusion of women in development, have not been incorporated within the Beijing Declaration's "transformatory perspective" (Mukhopadhyay, Steehouwer \& Wong, 2006, p.13) that seeks to transform the existing unequal power relations between men and women in society.

The aforesaid feeling is enhanced further through the repeated use of terms associated with the above said 1970s WID approaches to development. In its own terms, the Kenyan government argues that:

The Policy reflects and builds upon past experiences and commitment of the Government, NGOs, religious organisations, donor communities and 
especially the women themselves to the need for such a policy. They are inspired by valuable experiences of Women in Development (WID) activities undertaken during and after the United Nations Women's Decade, 1975 1985(Republic of Kenya, 2000, p.5, emphasis added).

In this context, the commonly used substitutive vocabularies from the WID discourse deployed in the policy under discussion (i.e. in place of those provided by the United Nations discourse of gender equality) include parity, mainstreaming gender issues, increasing participation, improvement, advancement, advancement of women,progress, advancing, gender responsive, gender issues, gender concerns, gender activities, women's concerns, women's issues, status of women, right of men, mainstreaming gender, mainstreaming of the needs and concerns of men and women, enhance women's roles, needs of women, roles of women, women's specific needs, empowerment of people, women's economic opportunities, increase, women's access, involvement of women, gender sensitive human rights, promoting, women participation, participation of women, gender-specific concerns, gender disparity, status of men, women and children, status of the female child, women's development, and gender relations among others (Republic of Kenya, 2000, pp.2-39).

The italicised terms in the following extracts from the policy document under discussion will illustrate the point:

(i) The National Policy on Gender and Development provides a basis for the Government to underscore its commitment to advancing the status of women (ibid, p.2)

(ii) Since independence, the Kenya Government has demonstrated concern for the welfare and special needs of women (ibid, p.2).

(iii) The National Gender and Development Policy will provide a framework for advancement of women (ibid, p.3)

(iv) ther Government Ministries also set up special units that were aimed at addressing women issues and subsequently gender concerns in their respective sectors (ibid, p.3)

(v) The development of technologies relevant to the roles of women in agricultural production and food processing has significantly lagged behind (ibid, p.7)

(vi) Effective coordination and collaboration between sectoral Ministries to enhance women's roles is generally lacking (ibid, p.8) 
(vii) The Committee on Gender and Development (CGD) will address issues of gender relations (ibid, p.34)

In this way, despite presenting the new policy text as having originated with the United Nations' discourse of women's rights, extracts (i) to (vii) above demonstrate that Kenyan policy makers may have been careful with regard to their choice of terms associated with gender equality. Likewise, the use of such terms as advancing the status of women, concern for the welfare and special needs of women, advancement of women, addressing women issues, and enhance women's roles among others above signal the fact that the main thrust for the policy text is to ensure the improvement of women's welfare, rather than the promotion of their rights to equality.

Notice that these terms are used in place of the specific human rights vocabulary deployed in the Beijing Declaration and Platform for Action (United Nations, 1995, p.11-74). These can be infered from the following extracts:

(i) In order to realize equality, development and peace, there is a need to fully respect these rights and freedoms (ibid, p.11)

(ii) 10 years after the Nairobi Conference, equality between women and men has still not been achieved (ibid, p.11)

(iii) The advancement of women and the achievement of equality between women and men are a matter of human rights and a condition for social justice (ibid, p.14)

(iv) The Platform for Action recognizes that women face barriers to full equality and advancement (ibid, p.16)

(v) Education is a human right and an essential tool for achieving the goals of equality, development and peace (ibid, p.23)

(vi) Women's right to the enjoyment of the highest standard of health must be secured throughout the whole life cycle in equality with men (ibid, p.32)

(vii) The human rights of women include their right to have control over and decide freely and responsibly on matters related to their sexuality (ibid, p.33)

(viii) Violence against women both violates and impairs or nullifies the enjoyment by women of their human rights and fundamental freedoms (ibid, p.45)

(ix) Equality in political decision-making performs a leverage function without which it is highly unlikely that a real integration of the equality dimension in government policy-making is feasible (ibid, p.74) 
As noted in these extracts, it is arguable that unlike the Kenyan government that uses the aforesaid alternative vocabulary, the United Nations/Beijing Declaration uses disciplinary terms that characterise the transformative discourse of women's rights. These include equality, rights and freedoms, advancement of women, achievement of equality between women and men, human rights, social justice, full equality and advancement, goals of equality, women's right, equality with men, the human rights of women, human rights and fundamental freedoms, equality in political decision-making, and equality dimension (See ixiii above). From this perspective, we could argue that the Kenyan governmnt's use of the aforesaid alternative terms serves the rhetorical role of pulling readers of "The Gender and Development Policy 2000" out of purely gender equality concerns, into the realm of cultural relativism. This negates the provisions of the "Beijing +5 Resolution" (i.e. resolution passed during a special session convened by the UN General Assembly in June 2000 to review and appraise progress made in implementing the Beijing Declaration and Platform for Action). In this context, the UN recommended that "efforts towards ensuring women's advancement" ought to combine a focus on "women's conditions and basic needs with an holistic approach based on equal rights," (paragraph 37, United Nations, 2000).

The aforesaid emphasis on women's advancement/progress rather than equality unearths the irony that though the National Gender and Development Policy 2000 makes explicit reference to the United Nations human rights instruments, it is in reality anchored in the assumptions of the 1970s discourses of development.

As noted in chapters three and four, Fairclough (2003, p.55) emphasises that intertextuality is "selective with respect to what is included and what is excluded" from the events and actions represented in a text. Within this frame of reference, Fairclough notes that in any representation, the speaker or writer can decide what discourse or aspects of discourse to include and/or exclude, as well as what to foreground or background (Fairclough, 1995, p.4). Moreover, in common with Van Leeuwen and Wodak's (1999) recontextualizing strategies discussed in chapter four (see 4.4.1), Blackledge (2006, p.64) and Fairclough (2001, p.13) emphasize that while being recontextualized, social events get reconfigured in their new contexts through such mechanisms as substituting given elements for others, and addition or deletion of some aspects of the borrowed concepts. In this respect as Chouliaraki and Fairclough (1999) stress, the process of recontextualization involves the "suppression and filtering of some meaning potentials of a discourse" (Chouliaraki \& Fairclough, 1999 cited in Blackledge, 2006, p.64), so as to deny it the ability to neutralize, and thus colonize other discourses. In this sense, by using alternative terms in place of the discipline-specific human 
rights vocabulary underlying the normative discourse of women's rights, the policy text under discussion can be said to signal the Kenyan government's reluctance and/or discomfort with the transformative discourse of gender equality, as well as the existing ideological controversies between the normative discourse of women's rights and the Kenyan government's relativist/alternative version of it.

Evidently, the use of the aforesaid alternative/substitutive vocabulary feeds into the transnational feminist rhetoricians' view (see 2.4.6). In this case, Dingo (2012) emphasizes that as the universal meaning of gender equality in the Beijing declaration continues to travel across the globe, its meaning continues to change as determined by the needs and interests of the policy makers within their contexts of practice. These shifts in meaning, as Dingo proceeds to argue, explain why policy actors are under obligation to examine the different ways in which ideas are connected to policies within and across borders. Such an understanding, as Dingo posits, is reason enough as to why feminist academics and other scholars dealing with issues of women ought to focus on how ideas are interlinked in policies across borders. This plays a role in helping us to determine the different forms of influences that could impact on policy decisions within their contexts of implementation (Dingo, 2012, pp.6-7).

From Foucault's perspective of governmentality, the replacement of the terms underlying the normative discourse of gender equality with alternative vocabulary can be read in terms of resistances and tensions in regard to the application of the universal rights of women in Kenya. According to Foucault (1978), power and resistance exist together in all networks of power relationships. In his words, as noted earlier, Foucault (1978, p.95) emphasizes that "where there is power, there is resistance," meaning that power and resistance constitute one another and are omnipresent in the power network. In this view of power, Foucault (1978, pp.93-94) emphasizes the need to understand that in as far as "power is everywhere," it is not an entity that is acquired, held and exercised from a dominant source (i.e. individual, groups or institutions), but rather a thing that is "exercised from innumerable points." This suggests that power is constituted both by those who support it, as well as those who oppose or resist it (Rouse, 2005, p.112). This scenario could precisely be the case with the Kenyan government's decision to use alternative terms above in place of those given in the universal discourse of women's rights, probably to retain the fidelity of its cultural relativist approach to gender equality policies. To some extent though, this can be read as a form of resistance and/or "counter-conduct" (Foucault, 2007) against the universalist 
approaches to gender policies being proposed by the CEDAW Committee and the human rights-based women's NGOs in Kenya as discussed in the two previous chapters.

\subsection{Text 2: Kenya review and appraisal: final report on the implementation of Beijing Platform for Action (Beijing +10) (1994 - 2004), June 2004.}

This report is both a "review and appraisal" (Republic of Kenya, 2004, p.1) of the Kenyan government's progress and identified obstacles in its efforts to implement the Beijing Declaration and Platform for Action in Kenya during the period 1994-2004.

\subsubsection{Appeals to universality}

Like other government policy texts discussed above, this report opens with a manifest intertextual reference to the UN's imperatives concerning women's rights to gender equality:

This report presents a review and appraisal of the implementation of the Beijing Declaration and Platform for Action (BPFA) in Kenya during the period 1994-2004. It evaluates the implementation measures taken within the context of the further actions recommended by the Special Session of the UN General Assembly (2000) on the BPFA and is guided by the priorities of the African Plan of Action 2000-2004 (APA)... Coming at a time when Kenya is now under a new political regime, the National Rainbow Coalition (NARC) Government, following the general elections held in December 2003, the report also reflects the gains and achievements made in the pursuit of the Millennium Development Goals (Republic of Kenya, 2004, p.1).

Sowinska (2013, p.14) argues that credibility is normally enacted through making "appeals to universally acknowledged values" as well as denouncing their "conceptual oppositions.” By making manifest intertextual references to the international human rights covenants, the Kenyan government can be said to be wanting to secure the confidence of the above stated policy actors, to the fact that it is fulfilling its obligation in implementing the universal rights of women. In this context, to give hope to the desperate Kenyan women and other policy actors agitating for gender equality policies, the report states that:

Despite difficult economic conditions facing the country the NARC government has made considerable efforts to implement several measures 
aimed at enhancing the welfare of women and children to the benefit of the majority of the poor and disadvantaged groups. The introduction of free primary education in January 2003 in fulfilment of one of NARC's key election pledges, for instance, was a major milestone in the implementation of one of the critical areas of concern in the country and a great opportunity for achieving one of the most important Millennium Development Goals (MDGs) (Republic of Kenya, 2004, p.2, my emphasis).

This excerpt unearths the fact that the report is interdiscursively juxtaposed with other populist discourses (i.e. discourses designed to appeal to multiple audiences/constituencies of interest to the Kenyan government) competing for attention within the policy document, hence the hybrid nature of the Kenyan government's report. This is achieved through mixing the discourses of "the NARC government" and its "key election pledges" with those of "the welfare of women" (i.e. attributed to the Beijing Declaration and Platform for Action), including those of "the poor and disadvantaged groups," "introduction of free primary education," "Millennium Development Goals, and "the critical areas of concern in the country"in the extract above.

\subsubsection{Interdiscursity in the service of competing interests}

In line with Fairclough's notion of interdiscursivity, as Adie emphasizes, the presence of multiple competing discourses in a policy text creates the need to examine the different ways in which governments could be exercising power through official policies, in ways that seek to hegemonize and privilege given social practices at the expense of others (Adie, 2008, p.262). In this context, the invocation of the NARC government and its "key election pledges" above indicates the dialogical stance espoused by the Kenyan government's report, probably of wanting to give credit to the current government's policy actions, thereby justifying the legitimacy of its policy texts.

Of concern here is the fact that the Kenyan government's text above seeks to enhance the welfare of women and children, as opposed to granting women their rights to gender equality. This feeling is heightened further through the prevalent use of terms related to the neoliberal discourse of development (Sharma, 2008), as opposed to those associated with the transformative discourse of gender equality. As Sharma puts it, "development is indeed a powerful mode through which subaltern subjects are named and normalized...third world 
women have been largely depicted within development literature as victims who have 'needs' and 'problems'..." (Sharma, 2008, p.xxiv). These are illustrated in the following extracts from the policy document under investigation.

(i) The NARC government has made considerable efforts to implement several measures aimed at enhancing the welfare of women and children

(ii) The 1995 United Nations Conference on Women recognized the important role of the media in enhancing women's development and advancement

(iii) Women empowerment is closely linked to their legal status in society

(iv) Currently Women's Bureau... is the national machinery for the advancement of women (Republic of Kenya, 2004, pp. 2-28, my emphasis).

These include the use of alternative terms such as "welfare of women and children," "women's development and advancement," "Women empowerment," and "the advancement of women"in texts (i)-(iv). Notice that the deployment of similar vocabularly was seen in our analysis of the National Gender and Development Policy 2000, where terms such as gender issues, welfare of women and children, needs and concerns of men and women, gender equity, women empowerment, issues of women and women affairs among many more are commonly used in place of the universal human rights vocabulary that characterise the discourse of women's rights (see 6.3.6). This framing style was found in 6.3.6 above to be contrary to that used in texts by the United Nations, i.e. the Beijing Declaration and Platform For Action, where terms such as the advancement of women are used simultaneously with achievement of equality between women and men, human rights, social justice, and full equality among many more. This can be inferred from the following two extracts from the Beijing Declaration and Platform For Action (United Nations 1995, pp.14-16) stated in 6.3.6 above, which I also restate below to illustrate this point.

(i) The advancement of women and the achievement of equality between women and men are a matter of human rights and a condition for social justice (, p.14)

(ii) The Platform for Action recognizes that women face barriers to full equality and advancement (United Nations 1995, p.16)

From this perspective, it is arguable that the Kenyan government's preference for the aforesaid alternative terms over the human rights vocabulary underlying gender equality or 
women's rights (i.e. that are sparingly used in this report) signals one significant issue worth mentioning. That is, this tendency reflects the fact that Kenyan policy makers have a clear understanding regarding the power of such words from the transformative discourse of women's rights, hence their calculative move of using alternative vocabulary that suits their ideological interests within their context of policy practice. Implicitly, by omitting the actual terms that characterize the universal discourse of gender equality seen above, the Kenyan policy makers marginalize the UN's discourse of women's rights as not being suitable and relevant to their interests.

\subsubsection{Economic discourse}

The above stated interdiscursive and/or hybrid nature of the report under discussion is also evidenced through tutorials enacting the neoliberal discourse of economic growth and its accompanying values and norms. In this context for instance, the Kenyan government gives a tutorial concerning how the status of the economy determines men's and women's ability to participate in public affairs, including the idea that a well performing economy enhances women's opportunities and ability to "effectively participate in and contribute to the national economy and the welfare of communities and households in which they live" (Republic of Kenya, 2004, p.1). According to Van Leeuwen (2007, p.107), legitimation can be achieved by providing stories. As such, the story concerning how the poor performing economy has enhanced women's inequality can be said to be a rhetorical strategy aimed at legitimizing the policy text under discussion.

Moreover, by emphasizing economic growth, the excerpt above signals the fact that though this report seeks to appraise the Kenyan government's progress towards implementation of Beijing Platform for Action, its policies on gender equality are articulated with the neoliberal discourses of improved productivity, economic growth and change of lifestyles. In Faircloughian terms, the aforementioned are part of the neoliberal discourse of the knowledge economy that stresses the values of competitiveness and efficiency (Fairclough, 2005a, pp.11-12). Consistent with Foucault's concept of the "neoliberal rationality of government" (Gordon, 1991, p.44), economic growth and women's contribution to development become the means for addressing women's inequality. This is reflected in the text above emphasizing women's contribution to the national economy and support for their families, as opposed to granting them their rights to gender equality. The same understanding is amplified as the report proceeds to document how the poor performing economy tends to 
affect women more than men, owing to their varied roles as "mothers, wives, food providers, care providers, heads of households and workers" (Republic of Kenya, 2004, p.1). This further presents the Kenyan government's conceptualization of women's inequality as being tied to the status of the economy, including the fact that their empowerment is linked to their traditional roles as mothers and home care takers within the community. However, this characterization of women as mothers and care givers is strongly contested by the CEDAW Committee (see chapter four) including feminist advocates for gender equality.

A similar framing style is reflected in "Kenya vision 2030," a long-term policy blue print that spells out the Kenyan government's aspiration to reduce gender disparities between men and women by the year 2030 (Republic of Kenya 2007b, p.i). In relation to women's economic empowerment and political leadership, the policy document states that:

Women are disadvantaged in accessing labour markets and productive resources...Furthermore, given that women play a critical role in the socioeconomic development of any nation, there is an urgent need to remove all obstacles that hinder their contribution to national development" (Republic of Kenya 2007b, p.133).

In this excerpt, the proposition "given that women play a critical role in the socio-economic development of any nation" reflects the Kenyan government's view of women's inequality as being necessitated by their non-participation in "the socio-economic development" of their nation. This understanding is heightened through the call to "remove all obstacles that hinder their contribution to national development" above. However, the invocation of women's issues together with such terms as labour markets, productive resources, socio-economic development, and national development in the extract under discussion, can be said to be indicative of the Kenyan government's emphasis on women's contribution to economic growth, as opposed to championing gender equality policies. This is made clear in the statement, "given that women play a critical role in the socio-economic development of any nation," in the extract under discussion, which reveals the Kenyan governmnt's underlying assumption regarding the position of women.

Another example to demonstrate the point under discussion can be evidenced in the Kenyan government's "Gender Policy 2011," which states that: "it is the right of women, men, girls and boys to participate in and benefit equally from the development process... Gender equality is therefore an agenda for development effectiveness" (Republic of Kenya, 2011, pp.9-11, emphasis added). From this excerpt, though the government declares that 
"women, men, girls and boys" have an equal right to take apart in, and "benefit equally from the development process," the proposition "Gender equality is therefore an agenda for development effectiveness" makes clear the core aim of this gender policy is ensuring the involvement of women in the development process, where their energies and skills are required to bring about "development effectiveness."

\subsubsection{Re-invention of government}

Going a step further, the report under discussion in this chapter declares that:

Kenya's priorities have not changed much from the previous ones. The ordering and emphasis, however, have changed, following the realization by the NARC administration that without widening democratic space in the economy, little can be achieved under the critical areas identified under the Beijing Declaration, among other policy objectives (Republic of Kenya, 2004, p.2, my emphasis)

Fairclough (2001) argues that texts are never neutral, but laden with given ideological perspectives that seek to establish or maintain a particular discourse as being the dominant one within specific social domains. In this context, the argument above about re-ordering and change of government's focus and priority areas of policy for implementation has the ideological aim of boasting. This boasting is aimed at creating a good image of the new government to the various policy actors concerned with the rights of women. Similar cases of boasting (i.e. positive self-presentation) are evident in the policy text. The boastful language is enacted through the repeated use of such terms as marked progress, achievement, considerable progress, impressive gains, marked improvement, positive achievement, positive results, strong positive correlation, and some level of success among others. Such a language is evident in the statements below:

(i) Considerable progress has been made in Kenya in the implementation of the BPFA since the last review in $2000 \ldots$ (Republic of Kenya, 2004, pp.3\&6)

(ii) Women's participation in politics and decision making...Marked progress has been made in this area although more still remains to be done ... (Republic of Kenya, 2004, p.4)

(iii) there has been a marked improvement in the nomination of MP's. Out of the twelve nominated MP's, $41.7 \%$ were women compared to $8.3 \%$ in 1992 
(Republic of Kenya, 2004, p. 26)

According to Shaw and Eichbaum (2008, p.7), public policy texts are normally framed in the positive, and in ways that seek to reflect the need to "bring about an improvement in a state of affairs." For Bhatia (2006, p.180), "positivity statements" are commonly used in policy texts to suggest the government's progress towards achieving given policy objectives. Also, Bhatia (2006, p.180) says that positivity is normally used as a strategy "to achieve common ground or mutual understanding between two ideological opposites," as well as to propose a promising future relationship. In this context, the use of the positive reinforcement phrases such as "considerable progress," "marked progress" and "marked improvement" in texts (i) to (iii) above, point to the Kenyan governments strategy of wanting to enact its progress towards meeting the Beijing imperatives. This is strategically aimed at affording itself an affable relationship with the United Nations, through disguising any underlying ideological differences that could stir feelings of disagreement with the normative understandings of gender equality.

In Faircloughian terms, by using such positive terms to justify Kenya's past and present policy actions, the Kenyan government affords its cultural relativist discourse of women's rights some hegemonic status over other competing universalist understandings of women's rights. According to Foucault (1990, p.95), power relations are both intentional and non-subjective, meaning that all forms of power are exercised with a multiplicity of aims and objectives. This means that the various forms of knowledge produced by power are never neutral, but rather imbued with the varied aims and perspectives of their producers seeking to conduct and control their recipients' behaviour to particular ways of reasoning. In many respects, the use of positivity terms above points to the Kenyan government's deliberate aim of seeking to persuade, and thus conduct other policy actors' feelings to the idea that it (Kenyan government) is moving towards implementing gender equality policies.

Similarly, though the Kenyan government makes regular intertextual references to the Beijing Platform for Action to suggest the existing close relations between its discourse of gender equality and the United Nations' universalist discourse of women's rights, it emerges that this was a textual strategy to ensure that sufficient background knowledge in the normative discourse of women's rights is established, as prerequisite for covering any mismatches of knowledge within its relativist discourse of gender equality that could contradict the mainstream understandings of gender equality. This is seen in its (Kenyan government's) contemporaneous policy text titled "Millennium Development Goals in 
Kenya: Needs and Costs, 2005." In this case, while appraising its progress in implementing affirmative action policies in the context of "Gender Equality" and "Women's Empowerment," the Kenyan government asserts that: "The Government is implementing some affirmative actions ...However, affirmative actions are selectively implemented without a grand plan for gender equity in all facets of human life..." (Republic of Kenya, 2005, pp.86-88, my emphasis).

By asserting authoritatively that affirmative action policies are implemented selectively in the text above, it becomes clear that the Kenyan government is not only using its discourse of women's rights to engage with the United Nation's discourse of equality, but also as a strategy for asserting what it considers appropriate within its national borders. Furthermore, the text under discussion suggests that the Kenyan government has the "authority to act unilaterally" (Bhatia, 2006, p.188), in determining which aspects of gender equality to implement or not.

\subsubsection{Legitimizing policy through topos of numbers}

A similar effect as the one stated above is realised through the use of the topos of numbers (Reisigl \& Wodak, 2001; Wodak, 2011). For instance, in explaining its achievements in granting gender equality policies, the Kenyan government deploys the topos of numbers to argue that the percentage of women joining the Kenyan parliament had grown from 4.1 percent to 8.1 percent between 1997 and 2002 (Republic of Kenya, 2004, p.4). In its words, the government explains that "following the 2002 General Elections, the number of women Members of Parliament (MPs) doubled from 9 in the 1997 elections to 18 in 2002, an increase from $4.1 \%$ to $8.1 \%$ of the total number of MPs" (Republic of Kenya, 2004, p.4, emphasis added).

Concerning the issue of women's education, the report uses the topos of numbers (Reisigl \& Wodak, 2001) to argue that the enrolment of girls and boys was "close to parity" in pre-primary education, which stood at 49.9 percent for girls and 50.1 percent for boys (Republic of Kenya, 2004, p.5). This can be inferred from the extract below:

From 1995, girls' enrolment accounted for $48.7 \%$ of the total enrolment. This close-to-parity share between the girls' and boys' enrolment was witnessed in the subsequent years, reaching 49.9 percent for girls and 50.1 percent for boys... (Republic of Kenya 2004, p.20, emphasis added) 
According to Reisigl and Wodak as was emphasized in chapter three, topoi function as legitimizing devices that justify the movement or transition from an argument or arguments to a given conclusion or claim (see 3.5.3.2) (Reisigl \& Wodak, 2001, p.75; Wodak, 2011, p.42).

Notice that the Kenyan government uses a similar framing style in its periodical reports to the CEDAW Committee to emphasise its progress in addressing women's inequality. For instance, in its 2006 combined fifth and sixth periodic reports to CEDAW, the Kenyan government uses the topos of numbers (Reisigl \& Wodak, 2001, p.75) to emphasize its progress towards increasing the number of women in politics and other decision-making structures. In this context, the Kenyan government stresses that:

Of the 210 elected members of parliament in 2003, 10 (4.8\%) were women as compared to 4 (1.9\%) of 210 in $1997 \ldots$ In 2005 women formed $42.2 \%$ of

District Magistrates... (Kenya, 2006, pp.21-23, emphasis added)

Based on these arguments, it is arguable that the Kenyan government uses the topos of numbers in the texts above to suggest its consistent progress towards granting gender equality policies. This is aimed at enacting a sense of consensus with the other policy actors agitating for gender equality policies in Kenya. However, as Bhatia (2006) warns above, language use seeking to promote a positive image (positivity) entails both a strategy of evasion, as well as a means for concealing given ideological differences. In a similar vein, Van Leeuwen (2007, p.95) stresses that actors can use scientific voice (i.e. topos of numbers attributed to given scientific findings) to endorse given propositions as being a good idea, hence their legitimation within given contexts of practice. This means that in order to convince other policy actors concerning its professed efforts to grant Kenyan women their equality rights, the Kenyan government opts to use the topos of numbers which carries some sense of recommendation for the stated policy outcomes.

\subsubsection{Managing anticipated policy actions through re-stating present and future policy initiatives}

Pursuing a similar strategy noted in chapter five, the report proceeds to enumerate a number of policy initiatives that have been established to enhance the realization of women's rights. For instance, among other initiatives, the report identifies: (1) the introduction of affirmative action policies; (2) the National Policy on Gender and Development approved in 2000; (3) creation of principal commissions, and new laws relating to the critical areas of 
concern to the Beijing Declaration (Republic of Kenya, 2004, pp.3-29). To add some “evidential strength" (Chang \& Mehan, 2008, p.470) to its proclaimed policy initiatives, the Kenyan government promises further that the adoption of the new constitution "will enable the government to effectively implement most issues on gender equity, women's economic rights and their independence" (Republic of Kenya, 2004, p.8). Of interest here is the use of the terms "will" and "effectively." That is, whereas "will" presents the government as one capable of predicting the future policy outcomes, the grammatical choice of the term "effectively" stated above enhances the feeling and expectations of that foreseen future when women's inequality will be no more. In line with Fairclough's $(1992,1995)$ perspective of hegemony, the authoritativeness of the Kenyan government's report draws from the policy makers' ability to foresee the future, when issues of women's inequality will be addressed by new policy actions to be put into place. However, the prevalent use of a future oriented language noted here and elsewhere in this study raises questions as to why the Kenyan government presents future policy options as the only possible means for addressing the existing problems of gender inequality amongst Kenyan women. This raises our sceptism concerning the certainty of such policy promises. In Foucauldian terms, the Kenyan government's routine use of futurological language to suggest future policy actions entails part of its technologies of government. Such technologies of government as Miller and Rose put it, are deployed to fashion, "normalize," and "instrumentalize" the conduct, decisions, and aims of others, so as to achieve particular political ends (Miller and Rose, 1990, p.8).

Commenting on the tendency of restating past statements, Fairclough emphasizes that repeated summarising of past policy proposals, policy achievements, and the impeding challenges entail "a management of language" (Fairclough, 2015, p.386). This management of language, as Fairclough holds, operates through selecting given representations of discourse that seek to achieve consent. Along similar lines, Bhatia (2006, p.185) argues that the tendency of repeating and/or recycling similar statements (e.g. the Kenyan government's tendency of restating similar policy initiatives noted in the previous two chapters) entails a strategy in political discourse that is commonly used to avoid offering any significant input, thereby limiting any chances of arousing hostility. As such, Bhatia (2006, p.193) emphasizes the need to know that the tendency of repeating similar policy actions in discourse is an evasive strategy, one that is strategically deployed by actors wanting to avoid contradictions, through reinforcing what has been previously stated, as well as for avoiding to say more than it is planned. 


\subsubsection{Governing through the rhetoric of working with NGOs}

Following from this overview, and in what can be said to be a further move to afford the Kenyan government's national discourse of women's rights some sense of credibility, the report stresses the need for working in partnership with NGOs and other civil society actors, so as to achieve the MDGs. For instance, with intertextual reference to the Beijing Declaration's particular emphasis on the role of the media in promoting the rights of women (Art. 239, United Nations, 1995), the report states:

To address the poor media portrayal of women, the media in Kenya, through lobbying by various women organizations such as Maendeleo ya Wanawake Organization (MYWO), the National Council of Women in Kenya (NCWK), the Federation of Women Lawyers (FIDA) and the Association of Media Women in Kenya (AMWIK), religious organizations and the Government, have developed media programmes in support of the key roles women play in the society. Generally, the campaigns against bad practices that impact negatively on participation of women in development are undertaken through advocacy and awareness creating activities using television and radio programmes and the print media. The campaigns undertaken by AMWIK are already yielding positive results... To increase women's representation and coverage in media, AMWIK and government policies being followed by media training institutions, are geared towards encouraging girls to join journalism through lectures at schools (Republic of Kenya, 2004, pp.14-15).

This excerpt seeks to legitimize the Kenyan government's policy discourse as a product of deliberation between different policy actors. According to Shaw and Eichbaum (2008, p.7), policy decisions are the aftermath of processes of discussion, consultation, and negotiation involving "interactions between different policy actors." On these grounds, by invoking NGOs here, the report indicates the Kenyan government's aim of wanting to project the implementation of gender equality as a collaborative endeavour between NGOs and itself. Ironically, as noted in chapter 4, the preparation of the Kenyan government's policy reports was raised by the CEDAW Committee, meaning that the framing style in the text above could be part of the feedback to satisfy the Committee's queries over the non-involvement of NGOs in policy making processes concerning women's rights.

One other interesting issue is the Kenyan government's praises for the NGOs in the extract above. However, Ho (2011, p.2542) notes that praising someone for his or her actions 
or behaviour entails a rhetorical strategy with a persuasive intent. From this vantage point, it is arguable that by praising and enmeshing its policy text above with the voice of NGOs, the Kenyan government's report seeks to win the support and confidence of these NGOs. Such support and confidence with the NGOs is necessary to secure the Committee's approval. This is in view of the Committee's proposal reported in chapter 4 that the Kenyan government ought to involve women's NGOs in its efforts to implement gender equality policies (see section 5.4.2). Indirectly, from Foucault's concept of conduct of conduct (Foucault, 1982, 1994) discussed early in this study, by co-opting the NGOs' voice here, the Kenyan government can be said to be wanting to silence any opposition from feminist activists seeking to install a transformative discourse of gender equality. In other words, by praising the success of its collaborative efforts with the women's NGOs noted above, the Kenyan government can be said to be seeking to conduct the NGOs through their professed policy actions, thereby appealing to their emotions, as well as anaesthetising their dissenting voices contesting women's inequality in Kenya. Moreover, owing to the CEDAW Committee's demands seen in chapter 4 for the Kenyan government to work in partnership with the women's NGOs (see 4.3.3), it is arguable that the Kenyan government's praise for NGOs above underlies its logic of wanting to counter the women's movement, and thus disrupt the Committee's plans of wanting to install gender equality policies in Kenya. As such, its strategy of praising NGOs outside of its interaction with the Committee can be read in terms of its evasive strategies of seeking to evade being conducted by the Committee and the women's NGOs. This can be said to entail an aspect of counter-conduct-(Foucault, 2007), achieved by exploiting the window of opportunity offered by NGOs promoting women's rights. As a result, this framing style helps the Kenyan government to amplify and increase the visibility of its cultural relativist discourse of gender equality over other proposed alternatives.

What is interesting though, is the manner in which the Kenyan government adopts the language of working in partnership (Ahmed, 2007) with the women's NGOs on gender equality issues. This can be inferred from the way Kenyan policy makers use intertextuality creatively to merge the Kenyan government's policy text with that of the women's NGOs, in ways that seek to blend and blur boundaries between them. This is evident in the text "To increase women's representation and coverage in media, AMWIK and government policies being followed by media training institutions..." above. According to Bhatia (2006, p.181), juxtaposing texts from two ideologically opposed discourses entails a rhetorical strategy for projecting shared interests and a common responsibility for achieving a given set of 
objectives. Also, Bhatia (2006, p.183) argues that terms such as "good," "positive," and "candid" have a slippery quality that conceals "any differences of opinion on critical issues." This suggests that the use of the noun phrase "positive results" in the excerpt "The campaigns undertaken by AMWIK are already yielding positive results" above points to the Kenyan government's strategic aim of seeking both to appease the women's NGOs, as well as to cushion any ideological differences between the women's NGOs and the Kenyan government. This means that the Kenyan government's manifest intertextual references to the women's NGOs above are part of its rhetorical moves to anaesthetize their dissenting voices, thereby facilitating some consensus between them. Remember that it is in this sense that Fairclough advises that orders of discourse involve "the social regulation of linguistic and semiotic difference or variation" (Fairclough, 2013, p.382).

\subsubsection{Hybrid governance mechanisms}

From another perspective, it can be argued that the Kenyan government's praise for and language of working with the women's NGOs entails a "hybrid governance mechanism" (Perkins, 2009, p.403), seeking to project a united front on gender equality policies. This form of governing is achieved by creating an impression of a shared affable, and cooperative working relationship between the Kenyan government and the women's NGOs. In effect, this strategy serves to manage and conceal any existing differences between them that go back a long way.

As Rose (1999, p.15) argues, governance entails a strategy, tactic, process and procedures for regulating, fashioning and exercising authority over others within particular discursive settings. Moreover, Rose (1999, p.16) notes that governance endeavours to focus on the "nature, problems, means, actions, manners, techniques and objects by which actors place themselves under the control, guidance, sway and mastery of others, or seek to place other actors, organizations, entities or events under their own sway." On a similar note, Muller (2013, p.33) explains that analysis of government involves a grasp of its calculations, knowledges invoked, techniques of government, how the object being governed is conceived, and the desired ends of such arrangements. In this context, Muller (2013, p.33) reiterates that every mentality and/or rationality of government entails a discursive space involving calculations aimed at managing and regulating the conduct of others towards a given understanding of "how things are or how they ought to be." On these grounds for instance, though the report under discussion enacts a good working relationship between the Kenyan 
government and the Women's NGOs that support the UN's gender equality policies, the Kenyan government identifies the "problematic experiences in alliancing" (Vaara, Kleymann \& Seristo, 2004, p.21) with the same NGOs:

Although these organizations are active in addressing gender issues and concerns in development, interactions between them and policy makers are not strong and require improvement (Republic of Kenya, 2004, p.29).

This extract signals an indirect acknowledgment of the existing antagonistic relations between the Kenyan government and the women's NGOs as described in chapter 5. According to Vaara, Kleymann and Seristo, the identification of "partnering problems as implementation issues" (Vaara, Kleymann \& Seristo, 2004, p. 21) is a discursive strategy for legitimating the need to work in partnerships, which also strategically and naturally serves to insulate specific ideas that have already been decided. Further, the trio say that enacting the lack of cooperation and the acceptance of the need to work in partnerships entails one of the coordination and/or management mechanisms for asserting authority and control over the particular policy decisions in question (Vaara, Kleymann \& Seristo, 2004, p.21). This reinforces my earlier point in 6.4.7 above that the government's act of praising the women's NGOs is an act of rhetoric, strategically tailored to manage interpersonal relations between the Kenyan government and the women's NGOs.

Rhetorically speaking, these praises are tailored at cushioning any negative feelings and/or disagreements between them. Moreover, this implies that both the Kenyan government and the women's NGOs are still "struggling opposites" (Bhatia 2006, p.181) trying to find a common ground. Such an understanding unveils the ambivalent feelings underlying the government's communicative intent.

\subsubsection{Mixing promotional genres within official discourse}

Going back to the issue of women's rights to education discussed in 6.4 .5 above, the report nominates the introduction of the cost-sharing policy in education, i.e. the "arrangement whereby the costs of the programme or project are shared by the involved parties, according to an agreed upon formula" (Wambugu \& Mokoena, 2013, pp.441-442) and the lack of financial and material resources as part of the major factors impeding women's equitable participation in education (Republic of Kenya, 2004, p.6). Against this limitation, the report states: 
It is however, pleasing to note that, the government is aware of this. The action being taken is moving at a fairly slow pace and we are urging the concerned authority to move faster in these areas to arrest the otherwise worrying trend of things in this area (Republic of Kenya, 2004, p.6, my emphasis).

According to Bhatia (2006, p.188), emotive vocabulary plays a significant role in persuading, as well as in creating an impression of some drive or passion and support for a given cause. In this sense, the use of emotive terms like "pleasing," "aware," "fairly slow," and "worrying trend of things" above, are meant to amplify the government's level of felt concern and commitment to gender equality issues. In Faircloughian terms, the use of these terms can be said to reflect the government's use of informal /casual language that characterise popular speech. As Fairclough (1992, p.279) argues, mixing of formal and informal language in texts is one feature of publicity/promotional genres that characterise the discourses of marketing and advertisement. Further, Fairclough (1992, p.279) insists that informal language is used to communicate a sense of simplicity, hence a rhetorical device to minimise imposition of one's authority. In this context, Fairclough (2013, p.388) says that communicative styles that seek to mix formal and informal speech constitute political strategies of "posturing and evasions" that characterise the public language of politics/political discourse. As such, Fairclough (2000, p.183) advises that the tendency of mixing promotional genres within official discourses has to be seen as encompassing "textual work of controlling and regulating social relations and interactions. Based on these understandings, the use of informal language through such terms as "pleasing," "fairly slow pace," and "worrying trend of things" in the excerpt above entails one of the textual strategies deployed by the Kenyan government to texture its policy texts on women's rights in ways that serve to evade making total commitment to grant women their rights to gender equality.

\subsection{Findings}

In this chapter, I undertook to examine how the Kenyan government recontextualizes the universal discourse of women's rights in its national policy texts on gender equality. In this context, the discussion sought to answer the following questions: 
(1) How does the Kenyan government recontextualize the normative discourse of women's rights in its national policy discourses of gender equality?

(2) What are the (changing?) conceptions of gender (in)equality that underlie the Kenyan government's policy discourse about women's rights to gender equality?

(3) What linguistic and rhetorical strategies does the Kenyan government deploy, either for granting or refusing to grant the transformative gender equality policies?

In the ensuing discussion, it is worth nothing that question three above has not been discussed separately, but rather in terms of how the aforesaid linguistic and rhetorical strategies are used both in making sense of the notion of gender equality, as well as in recontextualizing the normative discourse of women's rights in Kenya. These objectives were achieved as follows.

\subsubsection{Question 1: Recontextualization of the normative discourse of women's rights to gender equality.}

From all the examples of texts examined above, it became evident that the Kenyan government makes repeated manifest intertextual references to the United Nations' imperatives concerning the rights of women. That is, many of the texts analysed indicate the Kenyan policy makers' aim of seeking to create and cultivate a sense of solidarity between the Kenyan government's cultural relativist, and the UN's universalist discourses of women's rights, hence the intended belief in the legitimacy of Kenya's discourse of women's rights to gender equality (e.g. see 6.3.1).

Another mode of recontextualization was found to involve the use of promotional language (see 6.4.9 above) tailored at affording the Kenyan government a favourable reputation and/or image, thereby managing the behaviour of other policy actors towards believing its professed concern to implement equality policies. This was seen to be realized through the use of: (1) the language of working in partnership with the Women's NGOs in promoting gender equality policies in Kenya; (2) positivity terms and topoi enacting Kenya's progress towards achieving equality policies (see 6.4.5 and 6.4.7).

A further key feature of the Kenyan government's discourse of gender equality is the 
notion of interdiscusivity. That is, the findings from the policy texts analysed above confirm that the Kenyan government's official policy discourse of gender equality includes not just the normative discourse of gender equality, but also other populist discourses. This was particularly noted in section 6.4.2 and 6.4.3 where the policy text examined made numerous explicit references to the neoliberal discourse of development, ruling parties (i.e. KANU and NARC) and their symbols of governance, opposition parties, and national elections among other discourses. What is more, unlike the CEDAW Committee's texts analysed in chapter 4 that present women as the centre of focus for gender equality policies, the Kenyan government's policy texts examined above reveal that Kenyan policy makers have a tendency of stating women and children, including men, boys, girls, the poor and disadvantaged groups as the focus of their policies on gender equality. This means that by stating women interdiscursively with other actors such as men, children, disabled persons and disadvantaged groups, the Kenyan policy makers do replace women as the core focus of the Kenyan government's gender equality policies. As was suggested in chapter two, the above said scenario can be said to be indicative of the Kenyan policy makers' influence from the African approach and mode of rights as being collective (i.e. solidarity rights applying to all persons in society), hence their view of women as a collective group of persons with particular social problems. This conclusion is not negated by the fact that the Beijing +5 Resolution mentioned above also emphasises that "Policy-making processes require the partnership of women and men at all levels," and that "Men and boys should also be actively involved and encouraged in all efforts to achieve the goals of the Platform for Action and its implementation" (paragraph 58, United Nations, 2000).

It is worth mentioning at this point that though the UN's discourse of women's rights is presented as the "strategic nodal discourse for imagining, operationalizing and actualizing" (Fairclough, 2005a, p.14) Kenya's discourse of women's rights, the findings from this study confirm that the Kenyan government does not embrace the universal discourse of women's rights wholesale. This is demonstrated in this study through such recontextualizing strategies as omission of the key terms underlying the transformative discourse of gender equality, in favour of alternative/substitutive vocabulary that suits the needs and interests of the Kenyan policy makers (see 6.3.6 and 6.4.2). For instance, the Kenyan government's National Gender and Development Policy 2000 and Kenya Review and Appraisal: Final Report on the Implementation of Beijing Platform for Action (Beijing +10) (1994 - 2004) report above operate within this framework/strategy, characterised with explicit references to the Beijing Declarations' imperatives, while simultaneously enacting policy practices that deny voice to 
the normative discourse of women's rights through substituting its vocabulary with alternative terms. As stated in chapter three, Fairclough emphasises that changes in the wording of a text often culminate in changes in meanings, as well as creation of new lexical structures (Fairclough, 1992, p.191). In a similar vein, Muntigl proposes that "Changes in the linguistic form of policy are also related to changes in its content" (Muntigl, 2000, p.2). This means that by replacing the core terms underlying the normative discourse of women's rights with alternative terms, the Kenyan government seeks to reduce its modal strength, hence constraining its influence within Kenya. As such, by using alternative vocabulary in place of that given by the UN, the Kenyan government demonstrates its discomfort with the wholesale adoption of the universal discourse of women's rights, hence an act of counter-conduct calling for the need for different approaches to issues of women in Kenya. The same case applies to the use of evasive strategies realised through the use of strategic vagueness, topoi of numbers, positivity terms, generalization and abstraction achieved through nominalization, and repeated listing of past policy initiatives in the policy texts analysed in this section of the thesis. From Foucault's (2007) concept of counter-conduct, the use of such strategies in Kenya's official policy texts on gender equality can be argued to point to the Kenyan government's defence strategy, hence an act of counter-conduct against the normative discourse of women's rights that seeks to colonize its national discourse of women's rights to gender equality.

In the context of Fairclough's (1992) notion of hegemony, the use of substitutive vocabulary and other recontextualizing strategies noted above introduces the oppositional logic, as well as ideological controversies underlying the Kenyan government's official policy discourse of women's rights to gender equality. Furthermore, my assumption is that this watered-down version of gender equality is either neglected, or has not been subjected to critical questioning by the Kenyan feminist activists and other policy actors agitating for women's rights to gender equality in Kenya.

More interestingly, from the texts analysed above, it was found out that the Kenyan government's official discourse of women's rights to gender equality is recontextualised in ways that tend to emphasize the role of the national government in determining matters of women. In other words, the Kenyan government's gender equality policies examined here demonstrate Kenyan policy makers' tendency of seeking to territorialise and/or place emphasis on the Kenyan national space (i.e. national sovereignty), as a separate and distinct entity dependent upon the Kenyan government's power to decide on how to determine and govern issues affecting the Kenyan population, including women and their struggle for 
equality policies. This aspect is evidenced above (see section 6.3.5), where the Kenyan government's National Gender and Development Policy 2000 was found to be drawing on the topos of culture (Reisigl \&Wodak, 2001), both to legitimise and install its cultural relativist approach to women's rights to gender equality. This approach was also found to be standing in opposition to CEDAW's universalist perspectives discussed in chapter five.

A similar textual style that was found to be tailored to emphasize Kenya as a separate territorial space within which equality policies are to be made unilaterally without the consent of other policy actors involves the use of categorical assertions. A case in point is the assertion that "affirmative actions are selectively implemented without a grand plan for gender equity in all facets of human life" discussed above (see 5.5.1 and 6.4.4), which confirms the Kenyan government's power to decide unilaterally both how, and which aspects of gender equality are to be implemented or not, without concern for the greater goal of gender equality in all areas of women's life. As stated elsewhere in this study, assertions implicitly seek to emphasize how other policy actors, more so, women's NGOs and the UN, ought to understand and interpret issues of women within Kenya.

In Foucauldian terms, the use of assertions here can be interpreted as an indirect warning to those championing the implementation of the transformative gender equality policies in the Kenyan context that falls within the Kenyan government's area of jurisdiction. Likewise, it should be clear from this assertion that the Kenyan government insists on implementing "gender equity," as opposed to gender equality that was proposed by the committee in chapter five. This is demonstrated in the clause "gender equity in all facets of human life" in the excerpt above.

However, as noted in chapter two, Foucault criticizes the application of totalitarian approaches that seek to side-line alternative ways of thinking. Also, as noted in chapter two, the emphasis on applying a purely cultural relativist approach to human rights has been criticised by many scholars of human rights like Ibhavvoh (2004, p.26) and Peereboom (2004, p.13), who emphasize that permitting each national government to implement its own version of rights will allow many oppressive regimes to continue violating the rights of their people as they wish, by maintaining given oppressive cultural practices and traditions that cushion and perpetuate oppression and inequality. Similar sentiments have been raised by transnational feminist activists and researchers of women's rights, who as Merry (2006, p.74) and Coomaswamy (1999, p.168) explain, blame cultures and traditions steeped in cultural relativism for promoting discrimination against women in society. In this context, though Donnelly (1989, p.129) like several other scholars (see chapter two for more details) accepts 
that the application of human rights from their context of practice can increase their validity, he equally criticizes strict cultural relativism and instead proposes the need for a compromise, one that allows policy makers some limited space to apply their cultural relativist approaches to human rights, while at the same time making reference to their fundamental moral universality. In his words, Donnelly (2013, p.103) insists that:

The ways in which these rights are interpreted and implemented, however, so long as they fall within the range of variation consistent with the overarching concept, are matters of legitimate variation.

Likewise, Donnelly (2013, p.103) stresses that these variations in interpretation and implementation should not be mistaken to mean the rejection of human rights, but rather the result of "differences in human rights practices." Endorsing a similar view, transnational feminist scholars of women's rights such as Dempsey, Parker and Krone (2011, p.204) have critiqued the "dangers of adopting a universal conception of women to address different forms of discrimination and privilege." As such, arguing that categories of class, gender, sexuality, race and religion cause interlocking forms of domination and control, the trio emphasize the need for a relational/intersectional approach to women's issues, one that provides "a vantage point to see the ways women's experiences of inequality differ from place to place" (Dempsey, Parker \& Krone, 2011, p.204).

Also, the fact that the Kenyan government asserts the need for a cultural relativist approach to gender equality while simultaneously invoking the UN's imperatives ( i.e. to legitimize its discourse of gender equality) point to Donnelly's recommendation above, concerning the need to balance between the cultural relativist and universalist approaches to women's rights. In effect, this may also help to eliminate both the principle of bureaucracy embedded in the Kenyan government's rhetoric of gender equality, which as noted above, is enacted through such strategies as the use of futurological language and deployment of promotional language through mixing of formal and informal language which were found to be tailored to controlling and regulating social relations and interactions between the Kenyan policy makers and other policy stakeholders (Fairclough, 2000, p.183).

\subsubsection{Question 2: Conceptualizations of the notion of gender (in)equality}

The Kenyan government's policy texts concerning women studied in this chapter present Kenya's policies on women's rights as a thing that emanated from global processes 
triggered by the United Nations, as opposed to something that resulted from given "causal agents" (Fairclough, 2003, p.144). This stance was more pronounced in the majority of the extracts drawn from "the National and Development Policy 2000" and "Kenya Review and Appraisal: Final Report on the Implementation of Beijing Platform for Action (Beijing +10 ) (1994 - 2004)," examined above, which attributed the Kenyan government's national policies on gender equality to the Beijing Declaration and Platform for Action.

Along similar lines, the Kenyan government's policy discourse under discussion was found to attribute women's inequality to external forces such as the global recession, bad lending policies by IMF and the World Bank, including bad national policies that exclude women from participating equally with men both in public service and other decision making structures. This understanding was well exhibited in the Kenyan National Gender and Development Policy 2000 examined above (see the early subsections of 6.3). This mode of recontextualization was also found to be used as a rhetorical strategy, both for legitimizing the policy text in question, as well as for exonerating the Kenyan government from any political or moral blame for women's unequal status in society. From the feminist perspectives, as True (2013, p.127) was reported above as stating, emphasizing women's involvement in development processes as a means to their equality policies was found to be indicative of the Kenyan government's instrumentalist understanding of gender equality, based on the positivist view that women's involvement in development could reduce instances of gender inequality among women.

From the foregoing discussion, it was also noted that Kenya's discourse of gender equality is articulated interdiscursively with other discourses such as the neoliberal discourses of improved productivity, economic growth and change of lifestyles (Fairclough, 2005a, p.11), which emphasize economic growth as a means for women's empowerment. As a result, this framing style was found to present the Kenyan government's construal of women's contribution to development as a means for addressing their inequality. That is, from Fairclough's $(1992,2003)$ notion of presupposition, the Kenyan government's policy texts examined in this chapter present the view that women's empowerment is only achievable through enabling them to become economically independent and stable in society. This understanding was reflected in extracts from the Kenyan government's policy texts analysed above (see 6.3.5 and 6.4.3), which emphasize that women's contribution to national development is significant for supporting the economy and their families, as mothers and care providers within their households. The best example demonstrating this view was noted above, in the Kenyan government's argument that women's involvement in the development 
process was a "cost-effective way of managing resources and ensuring sustainable development," which as well reflects the Kenyan government's interpretation of women's issues from an "individualistic and utilitarian" perspective (Skilling, 2010, p.46), in terms of their contribution to the economy, as opposed to their rights to equal participation in the public sphere of their life.

Similarly, these arguments were found to promote the view that: (1) gender inequality is a property of women themselves as individuals in society, i.e. owing to their characterization as "a population category with special needs" in 6.3 .6 above, and the fact that the policy texts analysed in this chapter do not attribute gender inequality to men in the same way they do to women; (2) policies on women are largely anchored in "integrationist" approaches to gender equality that emphasise the inclusion of women in development, as opposed to the Beijing Declaration's "transformatory perspective" (Mukhopadhyay, Steehouwer \& Wong, 2006, p.13) that endeavours to transform the existing asymmetrical power relations between men and women in society; (3) the interdiscursive articulation of gender equality to include other discourses, such as that of development and economic growth among others, was noted to be indicative of the Kenyan government's understanding of gender equality as being one amongst many other concerns competing for governmental policy intervention.

By the same token, the policy texts analysed in this section reveal the Kenyan government's conceptualization of gender equality in terms of promoting women's social and economic status in society, as opposed to granting them their right to gender equality. This was particularly noted in sections 6.3.6 and 6.4.3 above. The text analysed was found to privilege the use of terms such as gender equity, welfare and special needs of women, needs and concerns of women, women empowerment, advancing the status of women, advancement of women, improvement, advancement, progress, women's economic opportunities, women's access, women's development, gender relations, among many more. This revelation unearths the irony that though the Kenyan government's policy discourse of gender equality make regular explicit intertextual references to the UN's imperatives to suggest its support for the transformative discourse of gender equality, its national policies on gender equality are tailored towards improving women's welfare, as opposed to granting them their rights to equality. Moreover, this suggests that the Kenyan government's policy texts on gender equality are anchored in the assumptions of the 1970s Women in Development theory (WID), which as Parisi (2012, p. 576) emphasizes, looked at the effects of economic development on the status of women, but without questioning the traditional roles assigned to women that 
were also the source of their oppression. In effect as Parisi (2012, p.576) continues to argue, this approach violates the core aims of the 1975-1985 Decade for the Advancement of Women, whose central objective was to ensure fair representation of women as subjects rather than objects of development, as well as CEDAW's non-discrimination principle (CEDAW 1981, Art.1) that underlies true equality between men and women.

At the same time, the preceding discussion unearths the Kenyan government's relational conception of women's rights to gender equality. That is, in a number of the cases examined above, it became evident that the Kenyan policy makers tend to articulate issues of women in relation to their roles as child care takers. A good example to explain this view is evident in section 6.3.5 above, where the National Gender and Development Policy 2000 draws on the topos of culture (Reisigl \& Wodak, 2001) to invoke the role of women in socializing children. The same understanding is evident in section 6.4.1 above, where the report in question states the NARC government's efforts to promote "the welfare of women and children to the benefit of the majority of the poor and disadvantaged groups" (Republic of Kenya, 2004, p.2). A similar observation is made by Mitullah (2003, pp.216-217), a researcher on women's rights in Kenya, who emphasizes that:

Most development approaches in Kenya have tended to support women within their traditional roles concentrated mainly within the household and involving homecare-based services... these areas ...limit women to their traditional roles, which are known to be problematic in respect to mainstreaming women in governance and overall development...

Regrettably, though, this construal of women as caretakers was found to present the Kenyan government's essentialist understanding of culture as an existing particular way of life specific to the Kenyan women per se, and one that is not subject to change. Also, the reference to the Kenyan cultural norms and traditions was found to be part of the Kenyan government's gatekeeping practices of wanting to prevent the state policy from being colonized by the normative discourse of women's rights, hence the perpetuation of the existing cultural relativist gender equality policies. This reasoning is consistent with Padamsee's (2009, p.418) emphasis that:

Perhaps the most profound influences of culture arise from its embeddedness in the institutions, routines, purposes, and language of policy making. From this background position, it helps perpetuate existing patterns of policy 
practice, shapes the conditions under which policy actors perceive a need for change, and informs the path of policy discussion.

What is more, as noted above, policy framing practices that present women's role as caretakers have been strongly contested by feminist scholars of women's rights, who as Coomaraswamy (1999, p.170) and Gould (2004, p.147) stress, claim that cultures and other traditional practices tend to treat women's issues as belonging to the private sphere of life that is outside of human rights protection.

In addition, results from our discussion in this chapter suggest that the Kenyan policy makers view gender equality as an issue to be realized in the future. This understanding can be deduced from regular use of a future oriented language, which signposts gender equality as something in the pipeline. In a similar vein, by privileging futurological language through the use of what Fairclough (2003, p.167) calls "the socially ratified power of prediction" associated with priests, prophets, politicians and governments, the Kenyan policy makers can be said to be communicating the idea that gender equality policies are within the Kenyan government's abilities to grant at its own chosen time. However, questions abound as to how actionable the Kenyan government's future policy promises are, considering that the problem of gender inequality among women is "incubating within the present" (Anderson, 2010, p.780), where curative policy interventions are ignored in favour of the anticipated future that may never come. This interpretation is consistent with Muntigl's (2000, p.10) view that the weaker modal form "will be" (e.g. as the one commonly used in the Kenyan government's policy texts above), suggests less possibility of carrying out the stated policy actions.

The same reasoning can be argued to apply to assertions, whose use can be said to be seeking to emphasize the Kenyan government's power and authority to decide on which aspects of gender equality to grant or not to. This was seen particularly with the text above asserting that affirmative action policies in Kenya are selectively done without regard to any set international standards. Against this background, however, Donnelly (1989) (see 2.2.3) advises on the need for policy makers to draw a balance, by implementing human rights with regard to their fundamental moral universality (i.e. by applying the universal human rights), while allowing some space for the cultural relativist perspectives. In this context, Donnelly (2013, p.104) argues against radical or absolute universality or relativism, and emphasizes that:

both relativity and universality are essential to international human rights. The crucial work, then, is to identify the ways in which human rights both are and 
are not both relative and universal and to avoid either treating the universal as if it were relative or falsely universalizing the particular.

Along similar lines, Angle (2002) emphasizes that this approach of mixing relativist and universalist perspectives helps to account for the varied roles and motives of policy makers within their contexts of practice, thereby helping to check against sociocultural practices that violate and hinder the realization of equality between men and women in society.

\subsection{Summary}

From the foregoing discussion, it becomes apparent that the CEDAW committee's and NGOs' textually mediated calls for gender equality policies necessitated the Kenyan government's production of different "genres of government" (Fairclough, 2000, p.172). These include the chain of policy genres such as the gender and development policy 2000, and the subsequent appraisal report for government on gender equality issues.

Likewise from the findings in this study, it emerged that though the Kenyan government trumpets the language of working in partnerships with the women's NGO, this should not be mistaken to suggest a shift in its (Kenyan government's) policy making process (i.e. from a closed circle of government as the primary maker of policies on women, to working in partnerships with the women's NGOs). Instead, it was noted that the recurrent use of the language of working in partnership with NGOs' is part of the Kenyan government's strategies to defuse the NGOs' demands for equality policies. This means that the NGOs' pressures for gender equality play a major role in terms of texturing (i.e. serving as discursive resources for the Kenyan government's inventing of new terms and language for use in its policy documents on gender equality), as opposed to bringing about gender equality policies. 


\section{CONCLUSION}

This study set out to examine the intertextual interactions amongst different policy actors involved in the process of implementing women's rights to gender equality in Kenya.This was achieved through a linguistic and intertextual analysis of the policy texts produced by the relevant discourse communities: United Nations' bodies in charge of women's rights (i.e. the Committee for CEDAW), the Kenyan government, and women's NGOs. The policy texts from each of these institutions/discourse communities were analysed both in their own right and in their interrelations (see chapters 46), so as to understand what is going on at various levels of textual interaction. Specifically, the goal was to get to know the different ways in which the policy actors from these institutions/discourse communities interpret and recontextualize the normative notion of gender equality.

A comparative intertextual approach to Fairclough's $(1992,1995)$ three-tier model of CDA was used to consider and explore how gender equality policies are appropriated and recontextualized by the policy actors within their contexts of practice.

Fairclough's method was supplemented with theoretical perspectives from Bakhtin's $(1981,1986)$ theory of dialogism, Reisigl and Wodak's (2001) theory of argumentation (i.e. topoi), Foucault's $(1982,1991)$ theory of governmentality, including philosophical insights from transnational feminist rhetorical theory (Ackerly, 2001; Dingo, 2012; Ferree \& Mueller, 2004).

\subsection{Findings Summary}

This study was designed to answer the following research questions:

RQ1.What are the (changing?) conceptions of gender (in)equality that underlie the Kenyan government's, NGOs' and the United Nations' policy texts about women's rights to gender equality?

RQ2. What strategies/modes of engagement (i.e. linguistic/non-linguistic and rhetorical) do the UN/CEDAW Committee, the Kenyan government, and women's NGOs adopt in their policy texts on gender equality? 
RQ3. What implications do the intertextual relations between the women's NGOs and government hold for the Kenyan government's policy and practices concerning gender equality for women?

RQ4. What implications do the textual interactions between the UN/CEDAW Committee and the Kenyan government hold for the realization of gender equality policies in Kenya?

These questions are discussed below with illustrative examples from each of the cases studied.

\subsubsection{Findings Summary for RQ1: Conceptions of gender (in)equality}

Chapter four sought to investigate the textual interactions between the CEDAW Committee and the Kenyan government. To examine their interactions, the study drew on Bakhtin's $(1981,1986)$ theory of dialogism (i.e. authoritative and internally persuasive discourses). The analysis shows that the CEDAW Committee raised questions to the Kenyan government, and the Kenyan government responded to these questions through several interactions culminating in an assessment and recommendations from the committee. It was noted that the Committee's core aim was to uncover both the Kenyan government's progress in implementing gender equality policies, and the disciplinary knowledge of Kenyan policy makers concerning the key concepts underlying women's rights to gender equality. From their textual interactions, it was established that whereas the CEDAW Committee emphasizes the implementation of gender equality using the human rights approach per se (see section 4.4.4), the Kenyan government's policy texts were seen to adopt simultaneously the human rights criterion, and multiple other discourses (e.g. development and Kenyan people's cultural practices and traditions) that characterise its cultural relativist approach to gender equality. Based on Fairclough's $(1992,1995)$ perspective of sociocultural practice, the findings showed that Kenyan policy makers regularly draw on the cultural beliefs and traditions that seek to contribute to how gender equality policies ought to be interpreted in Kenya. Among these cultural practices are women's domestic roles as "baby care takers." A good case showing the Kenyan government's concept of women's domestic roles as “baby care takers" was demonstrated in section 6.3.5. In this regard, the analysis showed that whereas Kenyan policy makers talk from the context of the United Nations' discourse of women's rights to explain Kenya's progress towards implementing gender equality, they do 
so while simultaneously maintaining a dialogic gaze at the cultural beliefs and practices of the Kenyan people. In other words, though they speak from the normative perspective of women's rights, they creatively re-route their policy statements to encompass the Kenyan people's cultural values and beliefs concerning the position and roles of women in society.

The research findings also showed that the CEDAW Committee blames women's inequality in Kenya on such factors as discriminative laws against women (see 4.4.3 and 4.5.5), oppressive cultural beliefs and practices (see 4.5.2), and the Kenyan government's mis-translation/misinterpretation of the gender equality concepts and initiatives emanating from the United Nations (see 4.4.4 and 4.6.2).

On its part, in addition to blaming women's inequality on social practices such as poverty, economic crises, biased previous policy regimes, and low economic status among women (see 6.3.2, 6.3.3, and 6.3.4 and 6.4.3), the Kenyan government's policy texts were found to attribute gender inequality to women's non-participation in development activities within the public sphere (see 6.3.4). Notice the contradiction, however, that whereas the Kenyan government blames women's inequality on their non-participation in development activities, its policy makers (see section 6.3.5) were found to use language imbued with cultural beliefs and norms that seek to limit women's participation in the public sphere of their life. This finding illustrates Fairclough's (2001) emphasis on the role of CDA in pointing out contradictions in discourse.

From the analysis of the NGOs' policy texts about gender equality, it was noted that just like the Kenyan government's texts, the NGOs' texts were also drawing on both the human rights approach (i.e. universalist criterion), as well as the Kenyan cultural beliefs and practices concerning women's roles and position in society (see 5.6.1 and 5.6.4). This included their interdiscursive references to historical factors, notions of equity and equality, religious discourse, and oral traditions as part of the social practices that inform their approaches to gender equality policies in Kenya (see 5.6.2 to 5.6.5). According to Freeman, Chinkin and Rudolf (2012, p.18), whereas "equity" is based on the "subjective notions of fairness," "equality" is "a human right," and thus "a legal obligation" that cannot be avoided. As such, it was realised that unlike the CEDAW Committee whose texts were seen to stick solely to the universal approach to gender equality (see 4.4.4), both the Kenyan government and the women's NGO's texts on gender equality were found to be drawing on both the United Nations' universal discourse of gender equality, and the cultural relativist understandings of the Kenyan people. It was therefore concluded that both the normative discourse of women's rights, and the Kenyan people's cultural beliefs about women, do 
influence and shape both the Kenyan government's, and women's NGOs' policy practices concerning gender equality.

It should be pointed out at this juncture that the Kenyan government's and NGOs' approaches to gender equality were found to cohere with the recommendations of the transnational researchers and scholars of human rights, who emphasise the need to mix both the universalist and cultural relativist approaches to the implementation of human rights. For instance, as noted in chapter 2, the majority of scholars such as Angle (2002), Brems (2001), Clapham (2007), Donnelly (2013), and Zeleza (2004), do emphasize the need to mix the universal criteria with the cultural relativist approaches to human rights, so as to enhance the "validity", "legitimacy," and "acceptability" of the human rights discourse across cultures. On a similar note, Donnelly (2013, p.104) stresses that "Both relativity and universality are essential to international human rights." The same applies to the transnational feminist rhetoricians, who as Dempsey, Parker and Krone (2011, p.211) argue, stress that while privileging local scale action for issues affecting women, policy actors are under obligation to adopt "a hybrid strategy that shifts between the particular and the universal."

In reaching this conclusion, however, I do not discount the fact that the Kenyan government's and NGOs' texts were seen to be drawing on the socio-cultural practices of the Kenyan people for different purposes. That is, the data analysis showed that whereas Kenyan policy makers use policy statements imbued with cultural norms and values that seek to deny and limit women's rights to political participation on equal terms with men (see 4.4.6 and 6.3.5), NGOs' texts were seen to criticise this approach by encouraging the need for the Kenyan government both to abolish oppressive cultural practices, as well as embrace policy practices that see culture as dynamic and fluid, as opposed to a fixed and unchanging entity. Likewise, NGOs' texts were seen to draw on the Kenyan people's cultural beliefs and practices for two significant reasons. First, from the research findings in this study, it was noted that the NGOs' practices of drawing on the cultural beliefs and practices of the Kenyan people was part of the core features that characterize the heterogeneity of their discourses of gender equality (see 5.6.3, and 5.6.4). In this context, it was noted that the NGOs' invocation of the Kenyan cultural discourse was suggestive of their knowledge (i.e. cultural competence, Sondergaard, 2002, p.199) of the prevailing discourses, and the different ways in which such discourses could be utilized as cultural premises to legitimize particular policy actions in favour of women (see 5.6.2, 5.6.3, and 5.6.4).

Then, it was proposed that the NGOs' framing style that involves the act of juxtaposing the discourse of gender equality with multiple other cultural discourses such as 
those of "development," "welfare of the people," and "gender equity" among others, was suggestive of the NGOs' realization of the Kenyan government's reluctance to adopt the universalist approach to gender equality wholesale, hence their decision to begin combining their discourse of gender equality with those of "equity," "development" and "welfare of the people," being articulated by the Kenyan government (see 5.6.3, and 5.6.4). In this way, the NGOs' interdiscursive use of language under discussion can also be viewed in the context of their changing conceptions of gender equality. This is in terms of their getting to know the interests of the other policy actors (i.e. the Kenyan government, and its populist discourses). Such an understanding explains their consequent shift to language choices in terms of what could be listened to, and acted upon, owing to the Kenyan government's resistance to the transformative gender equality policies. This, could be precisely the reason why Fairclough, Mulderrig \& Wodak (2011, p.370) emphasize that "We can only make sense of the salience of discourse in contemporary social processes by recognizing that discourse and society/culture are mutually constitutive," and that every instance of language use makes its own small contribution to reproducing and/or transforming society and culture, including power relations.

\subsubsection{Findings Summary for RQ2: Strategies/modes of engagement deployed by policy actors}

This question examined the modes of engagement (i.e. linguistic/non-linguistic, and rhetorical strategies), in terms of the functions or roles they play in revealing the nature of the policy actors' social practices concerning gender equality. The analysis of these features showed that both the Kenyan government and the CEDAW Committee drew on forms of language that sought to regulate and control how the notion of gender equality ought to be understood and implemented. For instance, it was noted that whereas the Committee uses deontic modality aimed at expressing power, authority, and the need for Kenya to implement gender equality in the here and now, the Kenyan government was seen to privilege the use of categorical assertions and futurological language (Fairclough, 2003) indexing its chosen time of bringing about the anticipated gender equality policies (see 4.4.7 and 4.3.3). In addition, whereas the Kenyan government's policy texts addressed to the CEDAW Committee were found to draw on strategies such as weasel terms (see 4.3.2), and strategic vagueness (see 4.3.5) among others as a means of evading and/or navigating the call for gender equality, the 
Committee's texts were seen to draw largely on such modes of engagement as evidentiality, and question and answer (see 4.4.2), as well as verbal and mental process clauses (see 4.4.2 and 4.5.2). These were found to be used by the Committee both as a strategy for persuading, and as devices for countering the Kenyan government's evasive strategies.

On its part, the Kenyan government was found to use such strategies as adversarial address, categorical assertions, imitative/reformulated discourse, irony, praise mixed with criticism, divide and rule policy, accommodation strategies, and silence (see 5.5.1 to 5.5.8). Through the analysis of the Kenyan government's choice and use of language in its policy texts addressed to the United Nations and other policy actors in Kenya, it emerged that it invokes the United Nations conventions and treaties concerning women's rights rhetorically, for purposes of establishing solidarity with the United Nations, as opposed to implementing the normative gender equality policies (see 6.3.1 and 6.4.4).

Similarly, in their texts meant for the Kenyan government, NGOs' texts were found to be deploying strategies of engagement such as training and consciousness-raising programmes, praise mixed with criticism, authoritative texts, evidentiality, cooperation, shaming through comparison, narrative intertextuality, gap in knowledge-filling pattern, adversarial forms of address, and strategies of self- and other-presentation (see 5.4.2 5.4.10). These were particularly meant for such functions as invalidating the Kenyan government's concept of, and commitment to, gender equality, as well as legitimizing the NGOs' alternative perspective concerning the implementation of gender equality.

\subsubsection{Findings Summary for RQ3: Implications of intertextual relations between NGOs and government for Kenyan government's policy practices on gender equality}

As was said earlier, though the CEDAW Committee emphasizes the need for the Kenyan government to work in partnership with the women's NGOs in implementing gender equality policies, this has not come to pass fully in the Kenyan case. In this context, as institutions and/or discourse communities, NGOs in this study were found to have attempted to intervene in terms of trying to put in place programmes meant to promote Kenyan women's realization of gender equality. However, from the research analysis in chapter 5, it emerged that, despite the NGOs continued lobbying for support from the Kenyan officials (i.e. police officers, news editors, and legislators/MPs), as a means of promoting the Kenyan 
government's responsiveness to issues of women, such a strategy seems to have failed to translate the NGOs' goals into official policy on gender equality. Instead, it was found that the Kenyan government has largely ignored the majority of the proposals from the women's NGOs, such as the need to adopt affirmative action policies wholesale, and women's citizenship rights (e.g. see 4.5.5 and 5.4.2). In this regard, my research found that though the Kenyan government acts in ways showing its readiness to work with the NGOs in bringing about gender equality (e.g. through its recurrent use of the language of working in partnership with NGOs), it never takes an active role in promoting the NGOs efforts to implement gender equality policies. Instead, the Kenyan government keeps on employing mechanisms of power (e.g. delaying tactics through irony, silence...) tailored to delaying the installation of such policies. Thus, though women's NGOs have helped the Kenyan government to identify areas of concern for governmental attention with regard to issues of women, this has not engendered an epistemological shift, i.e. from the phase of recognizing the existence of women's rights, to that of implementing them. In other words, though the NGOs under discussion have managed to dialogue with, and partly capture, the Kenyan government's attention to gender equality concerns, this has largely worked at the level of text, in terms of providing themes for inclusion in government policy texts on women's rights, as opposed to granting such rights. This finding coincides with Weldon and Htun's (2013, p.245) view stated elsewhere in this study, that though the involvement of women's NGOs plays a significant role in identifying crucial areas of concern for government action, their participation with national governments does not foster much change towards issues of women.

Further, this study reveals that women's NGOs in Kenya are yet to become more directly involved in the policy making process concerning women's rights. In this context, though the women's NGOs' representatives were seen to be part of the Kenyan government's official delegation to the CEDAW Committee, it appears that they were co-opted strategically (see 5.5.6) as part of the Kenyan government's managerial schemes of wanting to appear to be working collaboratively with the NGOs to promote the realization of gender equality policies. The NGOs' continued outcry against the lack of women in politics and other decision-making positions (see 5.4.3) attests to this claim.

As Maguire and Hardy $(2006,10)$ argue, discourses not only constrain us by structuring the spaces within which we operate, but also offer us the requisite resources with which to mobilize given understandings and interpretations that are not only capable of changing institutions, but also justifying particular practices that are commensurate with our 
interests. In this context, citing Phillips et al., they emphasize that texts are weapons that agents in struggle use in their discursive strategies "to produce new institutions or delegitimate existing institutions" (Phillips et al., 2004, cited in Maguire \& Hardy, 2006, pp.910). Based on this understanding, I would argue that the Kenyan women's NGOs involved in talks with the CEDAW Committee could have seized this discursive opportunity to: (1) foreground, and thus invalidate the Kenyan government's limiting forms of knowledge concerning gender equality discussed in section 5.4.2; and (2), highlight the Kenyan government's longstanding pattern of failing to respond to the women's policy demands noted by the Committee in chapter 4. By so doing, they could have helped to foreground the existing understandings that continue to oppress women, thereby triggering collective action with the Committee, to challenge and disrupt such understandings at an earlier stage. Instead, as noted in chapter 5 (see 5.5.6), they offered themselves to be used by the Kenyan government against their own interests that remain unattended to until the present moment. Likewise, NGOs' representatives could have taken advantage of this occasion to highlight, and thus contextualize any problematic modes of engagement deployed by the Kenyan government that is known to them (i.e. divide and rule policy and adversarial address, see 5.5.1 to 5.5.6) that continue to hinder the promotion of gender equality. This approach is also in line with the Foucauldian feminist poststructuralist thought espoused in this study (see 2.5.1), which endeavours to expose games of truth and power, thereby destabilizing fixed identifications/forms of knowledge that are at odds with alternative forms of thinking (Newman, 2005, p.1). Also, citing Foucault (1982, p.785), Healy (1999, p.117) reiterates the Foucauldian perspective of transformation as involving the idea of not discovering "what we are," but rather, to "refuse what we are," i.e. by contextualizing and disrupting fixed identities that stand in opposition to social change. In other words, as Healy (1999, p.118) posits, poststructuralist thought emphasizes that discourses have "real, or material effects", which demands that activists have to critically reflect on how they define who they are, and what they do.

\subsubsection{Findings Summary for RQ4: Implications of intertextual relations between NGOs and government for Kenyan government's policy practices on gender equality}

Engaging national governments in mainstreaming gender equality policies sits at the centre of the United Nations' organizations with responsibility for policies relating women's 
rights. The findings from the analysis of the textual interactions between the CEDAW Committee and the Kenyan government might contribute to explaining why the Committee has not been able to foster the installation of gender equality in Kenya. For instance, the research findings confirm that Kenya's modes of interaction with the Committee are riddled with evasive strategies meant both to delay and avoid the implementation of gender equality policies in Kenya. These evasive strategies were also found to be in response to the CEDAW Committee's strategies of engagement (linguistic and rhetorical), that sought to regulate and control how the notion of gender equality ought to be understood and implemented in Kenya (see 4.4.4).

Arguably, by opposing and circumventing the United Nations' normative discourse of women's rights, the Kenyan government's modes of interaction could be pointing to the need for an approach to gender equality that recognizes the broader historical, cultural and sociopolitical variations that underpin the efforts of varied policy actors that both interpret and seek to implement gender equality policies differently. This reasoning is consistent with Foucault's $(1982,2007)$ notions of "conduct of conduct," and "counter-conduct" noted earlier in this study, which as Davidson notes, go beyond the "purely negative act of disobedience", to signal citizens' rejection of given kinds of governmental direction (Foucault, 2007, p.200, cited in Davidson, 2011, p.27). Foucault argues:

if resistance were nothing more than the reverse image of power, it wouldn't resist; in order to resist one must activate something 'as inventive, as mobile, as productive' as power itself (Foucault, 2001, p. 267, cited in Davidson, 2011, p.27)

In this endeavour, against falling into the trap of either the cultural relativist stance that emphasizes cultural norms and values of different social groups, or the universalist notions that privilege "standards of the dominant group as the norm" Walby (2013, p. 44), one of the transnational feminist scholars of human rights, emphasizes the need to embrace the power of argumentation and negotiation based on facts and theoretical insights as the basis for tendering claims on gender equality. As seen in chapter 2, some scholars and transnational feminist researchers of human rights like Friedman (2003) and Merry (2001) emphasize the urgent need for the application of the universal human rights of women with specific reference to their particular contexts of practice, where matters of interpretation and implementation are at issue. A similar argument is stated by Fairclough and Wodak (1997, 
p.273), whose quote we have already seen above (see 7.1.1, last para.) and which I repeat here:

$$
\begin{aligned}
& \text { We can only make sense of the salience of discourse in contemporary social } \\
& \text { processes and power relations by recognizing that discourse constitutes } \\
& \text { society and culture, as well as being constituted by them. Their relationship, } \\
& \text { that is, is a dialectical one. This entails that every instance of language use } \\
& \text { makes its own small contribution to reproducing and/or transforming } \\
& \text { society and culture, including power relations. That is the power of } \\
& \text { discourse; that is why it is worth struggling over. }
\end{aligned}
$$

As such, in line with the UN's/CEDAW Committee's objectives of promoting gender equality within the local milieu, this study reveals that by embedding its universalist discourse of women's rights with cross-cultural ideas concerning women, the CEDAW Committee and other interested policy actors would stand a better chance of enhancing the legitimacy of such rights, including their wide acceptance across cultures. Further, such an approach may reduce the ideological struggles between the Committee and the Kenyan government, thereby eliminating one of the core factors that continue to prevent Kenya and the UN from speaking as a single voice in favour of gender equality policies in Kenya.

In relation to this understanding therefore, our research findings confirm that the Committee is yet to appreciate the idea that gender equality constitutes a contested space with attendant tensions arising from different conceptions within varied contexts of practice. In other words, it is yet to view the Kenyan government's cultural relativist/competing discourse of women's rights as another way of conceiving gender equality, as opposed to being irrelevant cultural claims that stand in opposition to the universal understandings of women's rights to gender equality. This argument draws on the cultural beliefs brought on board by Kenyan policy makers (see 6.3.5), who, as argued in chapter 6, drew on Kenyan cultural beliefs and practices to explain the position of Kenyan women in relation to their equality rights with men.

Likewise, although many scholars such as Bunch (1990), Charlesworth and Chinkin (2013), and Coomaraswany (1999) praise the CEDAW Convention's imperatives for engendering policy changes concerning women's rights globally, the findings from the ongoing discussion confirm that the Committee has only textual power, and that it lacks enforcement powers to ensure the implementation of the universal rights of women within the local milieu. This was particularly noted from its text-oriented modes of communication with 
the Kenyan government, which were seen to draw on mental processes, and deontic modalities aimed both at persuading, managing, and countering the Kenyan government's evasive strategies to gender equality policies. Based on this revelation, my line of argument is that the committee's reliance on textual modes of interaction per se with the Kenyan government cannot bring about gender equality policies expected by Kenyan women. In this context, its is arguable that the Committee ought to come up with a pragmatic mix of other approaches and/or mechanisms to promote the realization of women's rights in Kenya. For instance, it may have to carry out more collaborative seminars and workshops with the Kenyan government's policy makers. This approach would afford members the opportunity to meet regularly with the Kenyan government's policy makers within their contexts of practice. In my view, and from the findings of this study, seminars and workshops would help both the Committee's and the Kenyan government's policy makers to share ideas concerning gender equality based on their applicability within the local milieu. This suggestion rests on the assumption that without sufficient support from the Kenyan government's policy makers from within their context of practice, gender equality policies based on the normative discourse of women's rights alone will continue to be resisted, thereby derailing further the implementation of gender equality.

Further, such an understanding would promote interactions that allow the Committee and the Kenyan national policy makers to operate in an environment that foregrounds the possibility of collaborative thinking with regard to women's rights, rather than insisting on the need to reproduce authoritative understandings (i.e. universal or cultural relativist) that continue to generate differences that divide and promote resistance to gender equality policies.

\subsection{Methodological implications}

This section outlines the methodological contributions of my study.

First, the findings from the comparative intertextual approach to Fairclough's (1992, 1995) model of CDA espoused in this study provides a very useful framework for getting to understand how global concepts like gender equality are interpreted, understood, and recontextualized by different social actors within their varied contexts of practice, including their ideological goals, and the discourses they draw upon to make sense of such concepts. As such, the intertextual approach also helps us understand how institutional relationships, based solely on texts, are managed, resisted, and negotiated. 
Second, the intertextual approach gives testimony to the different ways in which Fairclough's model of CDA promotes the assemblage of varied methodological and theoretical approaches for making sense of the object of study. That is, the research findings in this study were made available for consideration through a mix of analytical approaches and theoretical insights. These were drawn from Bakhtin's (1981) theory of internally persuasive discourse, and authoritative discourses, Reisigl and Wodak's (2001), and Kwon, Clarke and Wodak's (2009) theory of argumentation, i.e. topoi, Chilton and Schaffner's (2006), and Van Leeuwen and Wodak's (1999) theory of legitimation, Foucault's (1982, 1991) theory of governmentality, and the transnational feminist rhetorical theory. These were used to complement the intertextual approach to CDA adopted in this study. The mixing of theoretical and methodological approaches was particularly significant in enhancing reflexive thinking and "critical questioning" (Fairclough 2013) of the different ways in which policy actors in the research interpret and recontextualize gender equality policies within their contexts of practice.

Third, based on the second contribution above, the current study provides linguists, discourse analysts and other researchers in the social sciences with the means of using the comparative intertextual approach to Fairclough's model of CDA for triangulating both methodological and theoretical approaches as they theorise and analyse their research data within varied fields of interdisciplinary research. This is consistent with Barker et al. (2008, p.280), Fairclough (2013, p.178), and Muntigl (2000, p.3) who emphasize the need for researchers to mix and/or triangulate theoretical and methodological approaches, as a means for enhancing the rigor (i.e. reliability and validity) of their research analyses through making sense of their subjects of study from a variety of perspectives.

Fourth, the research analysis shows that the majority of the policy actors' modes of engagement are manifested textually through varied linguistic indicators, such as the NGOs' use of strategies of "self- and other-presentation" seen in section 5.4.10. More significantly, the linguistic and rhetorical analysis was able to identify the particular patterns of language use that were habitually used (e.g. recurrent use of assertions and futurological language by the Kenyan government), including the different ways in which such linguistic choices were exploited to exercise varied forms of power and control. This includes the role of linguistic/rhetorical analysis that helped to reveal contradictions in Kenya's policy discourse of gender equality discussed in this study. Such a realization, I would argue, could not have been possible in this study if I had taken a non-linguistic approach.

Finally, the analysis of the textual interactions amongst the Kenyan government, the 
UN/CEDAW Committee, and NGOs enabled me to explore the particular roles played by the policy actors involved in the process of implementing gender equality policies in Kenya. For instance, as noted in section 4.4, I analysed textual interactions emanating from face to face meetings involving questions from the CEDAW Committee and answers from the Kenyan government's policy makers/officials. This was done particularly to understand these policy actors' discursive practices evident from their choice and use of language concerning gender equality. The same effect was realised through the inclusion of texts from the Kenyan MPs' verbatim statements from the Kenyan parliament. Similarly, the NGOs' texts in chapter 5 showed the different ways in which the Kenyan government is presented as serving the role of an instigator of social practices that affect women by denying them their rights to gender equality. This approach played a crucial role in bringing to the fore the varied understandings of gender equality espoused by the policy actors involved in Kenya's discourse of gender equality. As Van Leeuwen (2003, p.13) puts it, although "The texts which discourse analysts analyse form part of social practices," and "realize all or some of the actions that constitute the social practices," "they tell us nothing about the agents and patients of the actions, or about their place and time.” Similarly, citing Wodak (2006), Leitch and Palmer (2010, p.1198) argue that though CDA endeavours to examine the concepts of power and domination at the micro level of "discourse and social practice," "Linking of interactions associated with their creation and interpretation" has "remained a significant challenge within CDA." The current study fills this gap through its employment of a dense intertextual analysis that shows the links between the varied policy actors involved in the implementation of women's rights in Kenya, including unveiling their goals, interpretations, and modes of recontextualizing the notion of gender equality within their contexts of practice. In this context, the analyses in chapters 4, 5, and 6 reveal the agents and/or policy actors involved in Kenya's discourse of women's rights, and their textual interactions and interpretations of the notion of gender (in)equality. Such information, as I argue, emphasizes the particular significance of the transdisciplinary approach adopted in this study, and as recommended in Fairclough's $(1992,1995)$ intertextual approach to CDA.

\subsection{Theoretical implications}

This study makes the following seven theoretical contributions.

First, the theoretical insight from this study is that for any major policy changes on gender equality to occur within the local milieu, the UN and other policy stakeholders have to 
overcome resistance from national governments. In other words, the UN/CEDAW Committee is under obligation to identify the specific conditions that generate resistance, hence its ability to come up with better mechanisms for overcoming reversals and/or policy redirections by national governments. That is, to overcome this resistance, there is need for the active participation of the key individuals and/or policy actors with the right skills, knowledge, and ability to circumvent both the normative and cultural relativist constraints stated above.

Second, the discourse-based analysis approach to gender equality used in this study provides an avenue for a broader view of the particular assumptions associated with representations of gender equality in Kenya's discourse of women's rights. This means that, the findings from this study provide another key avenue for beginning to grasp the different discourses and discursive struggles in Kenya's discourses of gender equality, including their underlying contradictions. This particular knowledge offers another theoretical angle to the existing literature on gender equality policies in Kenya.

Third, my findings on the different modes of engagement between the Kenyan government and the women's NGOs (see 5.4 and 5.5) provide significant lessons to the advocates of gender equality policies (e.g. women's NGOs in this study), in terms of revealing how policy actors relate, including the particular modes of engagement that suit given contexts of policy practice. These include establishing the appropriate strategies for countering and navigating varied forms of resistance from the Kenyan government with regard to the implementation of gender equality policies. For instance, my discussion of silence as one of the Kenyan government's mode of engagement with the NGOs (see 5.5.7), would alert women activists and other human rights-based NGOs in Kenya to be aware of this strategy within the context of human rights practice. This would enable them to demand the Kenyan government's sensitivity to the critical demands concerning human rights, which have previously remained unarticulated in policy practice by the Kenyan government. The same applies to utilizing shared modes of engagement such as cooperation strategies used by NGOs and the Kenyan government (see 5.4.5 and 5.5.6), both for raising awareness and identifying areas of interest that impact their common positions within the larger social network of their existence. In effect, this will help to eliminate the existing oppositional feelings amongst them, as well as creating a favourable climate for political dialogue in favour of women's concerns.

Fourth, the research analysis confirms that one major hindrance to the attainment of gender equality in Kenya lies in the differing interpretation amongst the parties involved, including the Kenyan government's mis-translations of the discursive concepts underlying 
the notion of gender equality (see CEDAW Committee's, and NGOs' criticisms of the Kenyan government's concept of gender equality in 4.4.4, and 5.4.2). This points to the idea that part of the solution to women's inequality could be in establishing a common and /or shared conceptual clarity around the key terms underlying gender equality policies.

Fifth, the conceptual model of the intertextual chain of communication (i.e. intertextual governmentality) (see 4.4) between the CEDAW Committee and the Kenyan government is yet another contribution of this study. The model endeavours to convey the centrality of Foucault's $(1982,1991,2007)$ theory of conduct of conduct, and counter conduct in making sense of the ongoing textual interactions between the UN and the Kenyan government. The conceptual model suggests that the intertextual interactions between the Kenyan government and the Committee are characterized by contestations and power struggles that continue to hinder the realization of gender equality policies in Kenya.

Sixth, owing to the crucial role of texts in institution-building processes (Phillips et al. 2004, cited in Maguire \& Hardy, 2005, p.25), and in the process of engendering social change (Fairclough 2005), the current research shows the significant role of linguistic and rhetorical analyses, particularly for exposing the contradictory institutional practices characterizing Kenyan women's NGOs' operations, which continue to work against their own goals of bringing about change in favour of women.

Finally, in the context of the ongoing debates between the universalist and cultural relativist approaches to gender equality discussed in chapter 2, the NGOs' and Kenyan government's use of cultural discourses that are particular to the Kenyan context in this study (see chapters 5 and 6), can be said to be pointing to the need for the CEDAW Committee and other advocates of the transformative gender equality policies in Kenya to consider the need to incorporate both the cultural relativist and universal criteria for implementing women's rights to gender equality, as opposed to taking a purely human rights approach to the same as advocated for by the UN/CEDAW Committee. This conclusion draws support from Whaites's (2000, p.131) view that the state (e.g. Kenya) is the legally enforceable vehicle for effecting social change and equality. Such an understanding suggests that gender equality policies are only possible through acknowledging and reconceptualising the interests of the Kenyan government, while implementing the rights of women. The same understanding finds support in Fairclough's (2001, p.20) emphasis on the need for discourse analysts to focus on "what people have in their heads and draw upon when they produce and interpret texts," including the "values", "beliefs," and "assumptions" they espouse.

Likewise, the mixing of cultural relativist and universalist perspectives to the 
implementation of human rights has been noted to be advantageous in two significant ways. First, Angle (2002) says that mixing the aforesaid approaches has the advantage of accommodating the different roles and intent of policy makers within their contexts of practice, thereby reducing their acts of resistance against the implementation of human rights. Second, a pragmatic mix of the universalist and cultural relativist perspectives concerning gender equality is likely to engender an increased sense of "ownership," and "responsibilization" (Lemke 2002, p.53) of the national government's policy makers (e.g. Kenyan policy makers in this study), thereby enhancing their in-built free will to promote gender equality policies

However, it is significant to note that the findings of this study are directly applicable to the implementation of gender equality within the Kenyan context. This scenario raises problems with regard to the extent to which the research findings can be generalizable to other related studies within and outside Kenya. At the same time, though, I must emphasize that this does not mean that results from this research cannot be relevant to other sociocultural settings, particularly, African countries characterized with varied cultural beliefs and practices akin to those witnessed in Kenya.

\subsection{Future research}

The understandings from the findings of this study can be used by future researchers wishing to investigate the extent to which Kenya's policy practices and conceptions of gender equality cohere with the global trends that emphasize the universality of women's rights to gender equality.

As noted in chapter 2, this study draws on Foucault's $(1982,1991)$ theory of governmentality, and the transnational feminist rhetorical theory (Ackerly 2001; Dingo 2012; Ferree \& Mueller 2004). These theories focus on issues of power, domination, and resistance that were significant for making sense of the subject of my research. Given the centrality of their philosophical insights in this study, I would highly recommend future research on women's rights using insights from these theories. This will unveil the opportunity for a discursive comparison, further refining the research methods used in my study. 


\section{REFERENCES}

Aalberts, Tanja E. (2012). patterns of global governmentality and sovereignty. In Stefano G. \& Neumann I. (Eds.), The diffusion of power in global governance: International Political economy meets Foucault (229-255). London: Palgrave Macmillan

Achieng, Judith (2001, March 8th). Politics-Kenya: President Moi’s remarks spoil women's day. Inter Press Service News Agency. Retrieved from: http://www.ipsnews.net/2001/03/politics-kenya-president-mois-remarks-spoilwomens-day.

Ackerly, Brooke (2001). Women's human rights activists as cross-cultural theorists. International Feminist Journal of Politics, 3(3), 311-346.

Akerstrom, Malin, Yakhlef Sophia \& Basic Goran (2015) Successful Collaboration and Collaboration Obstacles in Police, Border, and Coast Guard Cooperation. Sweden: Lund University

Adie, Lenore (2008). The hegemonic positioning of 'smart state' policy. Journal of Education Policy, 23(3), 251-264.

Ahmad, Azreen Zeti (2012). PR and CSR: Malaysian perspectives. Unpublished PhD thesis, University of Sterling.

Ahmed, Sara (2007). The language of diversity. Ethnic and Racial Studies, 30(2), 235-256.

Ainsworth, Susan \& Hardy Cynthia (2004) Critical discourse analysis and identity: why bother?. Critical Discourse Studies, 1(2), 225-259

AMWK et al., (2009). Beijing +15-how far have we come, how far to go? : assessing the implementation of the Beijing Platform for Action in Kenya, November 2009. Nairobi: FEMNET

Anderson, B. (2010). Preemption, precaution, preparedness: anticipatory action and future geographies. Progress in Human Geography, 34(6), 777-798.

Angle, Stephen C. (2002). Human Rights and Chinese Thought. UK: Cambridge University Press.

Atanga, Lilian Lem (2010). Gender, discourse and power in the Cameroonian Parliament. Cameroon: Langaa RPGG.

Aubrey, Lisa Marie (1995). The politics of development cooperation: African NGOs and 
their relational environment: a study of Maendeleo Ya Wanawake Organization in Kenya. Unpublished $\mathrm{PhD}$ thesis, Ohio State University.

AWC (2004). Women's rights as human rights in Kenya: a contradiction between policy and practice. Occasional Paper Number 01/2004. Norway: Norwegian Church Aid

AWC (2010) Beyond Numbers: Narrating the Impact of Women's Leadership in Eastern Africa. Nairobi: The African Woman and Child Features Service

Bacchi, Carol (2013). The issue of intentionality in framing theory: the need for reflexive framing. In Lombardo E., Meier P., \& Verloo M (Eds.), The discursive politics of gender equality: stretching, bending and policy-making (19-35). United Kingdom: Routledge

Baker, Paul, Gabrielatos Costas, Khosravinik Majid, Anowski K. Michael, McEnery Tony \& Wodak Ruth (2008). A useful methodological synergy? Combining critical discourse analysis and corpus linguistics to examine discourses of refugees and asylum seekers in the UK press. Discourse and Society, 19(3), 273-306.

Bhatia, Aditi (2006). Critical Discourse analysis of political press conferences. Discourse and Society, 17 (2), 173-203).

Bhatia, Vijay \& Zhengrui Han (2012). Comparative genre analysis of Chinese legal judgements and arbitration awards. In Bhatia Vijay, Garzone Giuliana \& Degano Chiara (Eds.), Arbitration awards: generic features and textual realizations (192- 217). UK: Cambridge Scholars publishing.

Bakhtin, Michael. (1981). The dialogic imagination. Austin: University of Texas Press.

Bakhtin, Michael. (1986). Speech genres and other late essays. Austin: University of Texas Press

Ball, Stephen J. (1998). Big policies/small world: an introduction to international perspectives in education policy, Comparative Education, 34 (2), 119-130.

Ball, Stephen J. (2006). Education policy and social class: the selected works of Stephen J. Ball. USA/Canada: Routledge.

Ball, Arnetha F. \& Freedman Sarah Warshauer (2004). Ideological becoming: Bakhtinian concepts to guide the study of language, literacy, and leaning. In Ball F., A. \& 
Freedman S., W. (Eds.), Bakhtinian perspectives on language, literacy, and leaning (3-33). UK: Cambridge University Press

Baraza, Nancy (2008). Lost between rhetoric and reality: what role for the law and human rights in redressing gender inequality? Nairobi. Kenya Law Review, 2, 1-9

Barker, Chris \& Galasinski Dariusz (2003). Cultural studies and discourse analysis: a dialogue on language and identity. London: Sage Publications Ltd.

Barry, Andrew, Osborne Thomas \& Rose Nikolas (1996). Introduction. In Barry Osborne T. \& Rose N. (Eds.), Foucault and Political Reason (1-18). Chicago: The University of Chicago Press

Bazerman, C. (2004) Intertextuality: how texts rely on other texts. In Bazerman C. \& Prior P. (Eds.), What writing does and how it does it: an introduction to analyzing texts and textual practices (83-96). Mahwah, NJ: Lawrence Erlbaum Associates.

Bellier, Irene (2005). Anthropology of institutions and discourse analysis: Looking into Interdiscviplinarity. In Wodak Ruth \& Chilton Paul (Eds.), A New agenda in (Critical) Discourse Analysis (243-267). Amsterdam/Philadelphia: John Benjamins Publishing Company

Bernstein, B. (1990). The structuring of pedagogic discourse. USA/Canada: Routledge.

Bernstein, B. (1996). Pedagogy, symbolic control and identity: theory, research, critique. London: Taylor and Francis.

Besley Tina 2002). Foucault and the turn to narrative therapy. British Journal of Guidance and Counselling, 30(2), 125-143.

Binkley, Sam (2009). The work of neoliberal governmentality: temporality and ethical substance in the tale of two dads. Foucault Studies, (6), 60-78.

Blackledge, Adrian (2005). Discourse and power in a multilingual world. Amsterdam/Philadelphia: John Benjamins Publishing Company.

Blackledge, Adrian (2006). The racialization of language in British political discourse. Critical Discourse Studies, 3(01), 61-79.

Blain, Michael (2005). The politics of victimage: power and subjection in a US anti-gay campaign. Critical Discourse Studies, 2(1), 31-50. 
Blommaert, Jan \& Bulcaen Chris (2000). Critical discourse analysis. Annu. Rev. Anthropol. (29), 447-466

Blommaert, Jan (2005) Discourse: a critical introduction. UK: Cambridge University Press

Bourdieu, P. and Wacquant, L. (2001). New-liberal speak: notes on the new planetary vulgate. Radical Philosophy, 105, 2-5

Brainardi, Lori A., \& Siplon Patricia (2002). The internet and NGO-government relations: injecting chaos into order. Public Administration and Development, 22(1), 63-72

Brems, Eva (2001) Human rights: universality and diversity. Netherlands: Martinus Nijhoff Publishers

Brown, Charlotte (1997). Universal human rights: a critique. The International Journal of Human Rights, 1(2), 41-65

Brown, William (2008). To Discipline without destruction: the multifaceted profile of the child in proverbs. In Bunge Marcia, J., Fretheim Terence E. \& Gaventa Beverly Roberts (Eds.), The child in the Bible (63-81). USA: Wm. B. Eerdmans Publishing Co.

Bunch, Charlotte (1990). Women's rights as human rights: toward a re-vision of human rights. Human Rights Quarterly, 12(4), 486-498.

Bunch, Charlotte (2001). Women's human rights: the challenges of global feminism and diversity. In Dekoven M. (Ed.), Feminist locations: global and local, theory and practice (129-146). New Jersey \& London: Rutgers University Press.

Burchell, Graham (1996) Liberal government and techniques of the self. In Barry Andrew, Osborne Thomas \& Rose Nikolas (Eds.), Foucault and political reason: liberalism, neo-liberalism and rationalities of government (19-36). Chicago: the University of Chicago Press

Cairney, Paul (2012). Understanding public policy: theories and issues. UK: Palgrave Macmillan

Candlin, Christopher \& Maley, Yon, (1997. Intertextuality and interdiscursivity in the discourse of alternative dispute resolution. In Gunnarsson B., Linell, P., \& Nordberg, B. (Eds.), The Construction of Professional Discourse (201-222). London: Longman 
CEDAW Committee (1993). Concluding comments of the Committee on the Elimination of Discrimination against Women, Kenya: combined initial and second periodic report, 18th January - 5th February 1993; Supplement No. 38 (A/48/38)

CEDAW Committee (2003a). Consideration of reports submitted by state parties under article 18 of the Convention: combined third and fourth periodic report of Kenya, $6^{\text {th }}$ February 2003, 10: am.

CEDAW Committee (2003b). Consideration of reports submitted by state parties under article 18 of the Convention: Combined third and fourth periodic report of Kenya, $6^{\text {th }}$ February, 2003,3:pm

CEDAW Committee (2003) Report of the Committee on the Elimination of Discrimination against Women: Official Records of the General Assembly, Fiftyeighth Session, 20 March 2003.

Chang, Gordon C. \& Mehan Hugh B. (2008). Why we must attack Iraq: Bush's reasoning practices and argumentation system. Discourse and Society, 19 (4), 453-482

Charlebois, Justin M. (2010).The Discursive Construction of Hegemonic and Pariah femininities in the Spoken Accounts of a group of Japanese women. Unpublished $\mathrm{PhD}$ thesis, Lancaster University.

Charlesworth, H., \& Chinkin, C. (2013). The new United Nations "gender architecture": a room with a view? Max Planck Yearbook of United Nations Law Online, 17(1), 1-60

Chege, Fatuma \& Sifuna Daniel (2006) Girls' and Women's Education in Kenya: Gender Perspectives and Trends. Nairobi: UNESCO

Chilton, Paul \& Schaffner, Christina (2006). Discourse and politics. In Van Dijk Teun (Ed.), Discourse as social interaction (206-230). London: Sage Publications Ltd.

Chouliaraki, Lilie \& Fairclough, Norman (1999). Discourse in late modernity. Edinburgh: Edinburgh University Press.

Chovanec, Jan (2012). Implicit meaning and racism in political advertising. In Navratilova D. Olga \& Povolna Renata (Eds.), Discourse interpretation: approaches and applications (55-78). UK: Cambridge Scholars Publishing

Clapham, A. (2007). Human rights: very short introduction. Ney York: Oxford University Press. 
Collins, Dana, Falcón Sylvanna, Lodhia Lodhia \& Talcott Molly (2010). New directions in feminism and human rights. International Feminist Journal of Politics, 12(3-4), 298-318

Coomaraswamy, Radhika (1997). Reinventing international law: women's rights as human rights in the international community. Commonwealth Law Bulletin, 23(3-4), 12491262

Coomaraswamy, Radhika (1999). Reinventing international law: women's rights as human rights in the international community. In Peter Van Ness (Ed.), Debating human rights: critical essays from the the United States and Asia. Canada/USA: Routledge.

Cooper, Marilyn M., and Selfe Cynthia L. (1990). Computer conferences and learning: authority, resistance, and internally persuasive discourse. College English, 52(8), 847-869.

Cox, J. W., \& Hassard, J. (2010). Discursive recontextualization in a public health setting. The Journal of Applied Behavioral Science, 46(1), 119-145.

Centre for rights education and awareness (2007). Status of women and girls in Kenya: urgent need to uphold human rights. Nairobi: CREAW

Davidson, Arnold I. (2011). In praise of counter-conduct. History of the Human Sciences, $24(4), 25-41$

Davy, Debbie (2011). Selling strong medicine: the rhetoric of Ontario's harmonized sales tax, paper presented at Professional Communication Conference (IPCC), on 17-19 Oct. 2011, Cincinnati, OH, USA

Dean, Mitchell (2002) 'Liberal government and authoritarianism.' Economy and Society, 31 (1), 37-61

Dean, M. (1999, 2010) Governmentality: Power and Rule in Modern Society. Los Angeles, CA: Sage

Dean, Mitchell (2010) Governmentality: Power and Rule in Modern Society. London: Sage Publications Ltd.

Death, Carl (2010) Counter-conducts: a Foucauldian analytics of protest. Social Movement Studies: Journal of Social, Cultural and Political Protest, 9(3), 
$235-251$.

Deem, Rosemary (1999). Power and resistance in the academy: the case of women academic managers. In Whitehead Stephen \& Moodley Roy (Eds.). Transforming managers: gendering change in the public sector (66-83). London: UCL Press Ltd

Delaet, D. L. (2006). The global struggle for human rights: universal principes in world politics. USA: Thomson Wadsworth.

DeJaeghere, Joan, Parkes Jenny \& Unterhalter Elaine (2013). Gender justice and education: linking theory, policy and practice. International Journal of Educational Development, 33(6), 539-545.

Dejaeghere, Joan \& Wiger Pellowski, Nancy (2013). Gender discourse in an NGO education project: openings for transformation toward gender equality in Bangladesh. International Journal of Education and Development, 33 (6), 557-565

Dempsey, Sarah E., Parker Patricia \& Krone Kathleen (2011) Navigating socio-spatial difference, constructing counter-space: insights from transnational feminist praxis. Journal of International and Intercultural Communication, 4(3), 201220.

Didriksen, Anders Alvsaker \& G\& Gjestedal, Anje, Muller (2013) On what is not said and who said it: argumentative connectives in Nicolas Sarkosy's speeches to the European Parliament. In Flottum Kjersti (Ed.), Speaking of Europe: discourse approaches to politics, society and culture (85-110). Amsterdam: John Benjamin's B.V.

Dillard, Cyntia B. \& Okpalaoka, Chinwe (2011. The sacred and spiritual nature of endarkened transnational feminist praxis in qualitative research. In Denzin K. Norman \& Lincoln Yvonna (Eds.), The Sage Handbook of qualitative research (147-162). London: Sage Publications Ltd.

Dingo, Rebecca (2012). Networking arguments: rhetoric, transnational feminism, and public policy making. USA: University of Pittsburgh Press. 
Donelly, Jack (1989). Universal human rights in theory and practice. Ithaca : Cornell University Press.

Donelly, Jack (2013). Universal human rights in theory and practice (3rd Ed.). USA: Cornell University Press

Dunmire, Patricia (2005). Pre-empting the future: rhetoric and ideology of the future in political discourse. Discourse \& Society, 16(4), 481-513

Dunmire, Patricia (2009). 9/11 changed everything': an intertextual analysis of the Bush doctrine. Discourse and Society, 20(2), 195-222.

Dunn, Yo (2015). Using critical discourse analysis to interpret educational policy on school exclusion in England and Wales. In Smeyers Paul, Bridges David, Burbules Nicholas \& Grffihs Morwenna (Eds.), International Handbook of interpretation in educational research (pp. 285-314). New York \& London: Springer Science \& Business Media B.V.

Eggins, Suzanne. (2004). An Introduction to systemic functional linguistics. London: Continuum International Group.

Evans, Bev \& Thomas Pete (2011). Recontextualizing Policy: discourse and social practices in enacting policy initiatives. 11th international Conference on Organizational Discourse, Terra Firma, Terra Nova, Terra incognita, 9th - 11th July, 2011. Fairclough, Norman (1989). Language and power. England: Longman Group Limited. Fairclough, Norman (1992) Discourse and social change. Cambridge: Polity Press Fairclough, Norman (1993) CDA and the marketization of public discourse: the universities. Discourse and Society 4(2), 133-168

Fairclough, Norman. (1995). Media discourse. London: Edward Arnold

Faircough, Norman (1996). Border crossings: discourse and social change in contemporary societies. British Studies in Applied Linguistics, 10, 3-17.

Faircloug, Norman \& Wodak Ruth (1997). Critical discourse analysis. In T. A. Van Dijk (Ed.), Introduction to discourse studies (258-284). London: Sage. 
Fairclough, Norman and Wodak Ruth (1997). Critical discourse analysis. In T. van Dijik (Ed.), Discourse studies: a multidisciplinary introduction. London: Sage Publications

Fairclough, Norman (2000). Discourse, social theory, and social research: the discourse of welfare reform. Journal of Sociolinguistics 4(2), 163-95.

Fairclough, Norman (2001). Critical discourse analysis as a method in social scientific research. In Wodak Ruth \& Meyer Michael (Eds.), Methods of critical discourse analysis. London: Sage Publications

Fairclough, Norman. (2003). Analysing discourse: textual analysis for social research. London: Routledge.

Fairclough, Norman (2004). Critical discourse analysis and change in management discourse and ideology: a transdisciplinary approach to strategic critique. Retrieved January 11, 2006 from http://www.ling.lancs.ac.uk/staff/norman/paper5.doc

Fairclough, Norman. (2005a) Discourse in the process of social change: "transition" in Central and Eastern Europe. British and American Studies, 11, 9-34.

Fairclough, Norman. (2005b) Critical discourse analysis in transdisciplinary research. In Wodak Ruth \& Chilton Paul (Eds.), A new agenda in (critical) discourse analysis (5369). Amsterdam/Philadelphia: John Benjamins Publishing Company.

Fairclough, Norman, Simon Pardoe, and Bronislaw Szerszynski. (2006). Critical discourse analysis and citizenship. In Hausendorf Heiko \& Bora Alfons (Eds.), Analysing citizenship talk: social positioning in political and legal decision-making processes (98-123). Amsterdam/ Philadelphia: John Benjamins Publishing Company.

Fairclough, Norman (2006). Semiosis, ideology and mediation: a dialectical view. In Lassen Inger, Strunck Jeanne \& Vestergaar Torben (Eds.), Mediating ideology in text and image: ten critical studies (19-36). Amsterdam/Philadelphia: John Benjamins Publishing Company.

Fairclough, Norman (2009). A dialectical- relational approach to critical discourse analysis in social research. In Wodak Ruth \& Meyer Michael (Eds.), Methods of critical discourse analysis. London: Sage Publications Ltd. 
Fairclough, Norman \& Wodak Ruth (2010) Recontextualizing European higher education policies: the cases of Austria and Romania. Critical Discourse Studies, 7 (1), 1940.

Fairclough, Norman, Muldering Jane \& Wodak Ruth (2011). Critical discourse analysis. In Van Dijk Teun, A. (Ed.) Discourse studies: a multidisciplinary introduction (357378). London: Sage Publications Ltd.

Fairclough, Norman (2013). Critical discourse analysis: the critical study of language (2nd Ed.). New York: Routledge.

Fairclough, Norman (2015). Language and power (3rd Ed.). London/New York: Routledge Farrell, Amy \& McDermott Patrice (2005) Claiming Afghan women: the challenge of human rights discourse for transnational feminism. In Hesford Wendy S. \& Kozol Wendy (Eds.), Just advocacy/women's human rights, transnational feminism, and the politics of representation (33-55). USA: Rutgers University Press

Feng, Dezheng and Wignell Peter (2011). Intertextual voices and engagement in TV advertisements. Visual Communication 10, 565-588.

Ferree, Myra Marx \& Mueller Carol McClurg (2004). Feminism and the women's movement: a global perspective. In Snow David A., Soule Sarah \& Kriesi Hans Peter (Eds.), The Blackwell Companion to Social Movements (576-607). Australia: Blackwell Publishing Ltd

Ferree, Marx Myra (2006). Globalization and feminism: opportunities and obstacles for activism in the global arena. In Ferree Marx Myra \& Tripp Aili Mari (Eds.), Global feminism: transnational women's activism, organizing, and human rights (323). New York \& London: New York University Press

FIDA-Kenya (1997) Bado mapambano-Kenyan women demand their rights: the 1997 FIDA-(K) annual report on the legal status of Kenyan women. Nairobi: FIDA-Kenya FIDA-Kenya (2004). Parliamentary survey report. Nairobi: FIDA-Kenya FIDA-Kenya (2005). Towards the promise of gender equality...will the Millennium Development Goals take us there? : 2005 Annual Report, Kenya. Nairobi: FIDAKenya 
FIDA-Kenya (2006). Report of a baseline survey on the level of awareness and impact of CEDAW on rural women in Kenya. Nairobi: FIDA-Kenya

FIDA-Kenya (2007). A shadow report to the 5th and 6th combined report of the Government of the Republic of Kenya, on the international Convention on the Elimination of all Forms of Discrimination against Women (CEDAW), presented to the 39th Session of the United Nations Committee on the Elimination of all Forms of Discrimination against Women, 23th July -10th August 2007, New York, USA

Fity Ovesen Rasmus, Bengtsson Emilie \& Moraes Miriam Leite (2008) Wangari Maathai, Unbowed, A Memoir. The Analysis of the Ideological Visions of a Contemporary Kenyan Woman. PhD Dissertation, Roskilde University.

Foucault, Michel (1972). The Archeology of knowledge and the discourse on language. New York: Pantheon

Foucault Michel (1978). The history of sexuality, vol. 1: an introduction, trans. Hurley R. New York: Random House

Foucault, Michel (1982). The subject and power. Critical Inquiry, 8 (4), 777-795

Foucault, Michel (1982). The subject and power. In Dreyfus H. L. \& Rabinow P. (Eds.), Michel Foucault: beyond structuralism and hermeneutics (208-226). New York: Harvester Wheatsheaf

Foucault, Michel (1981). The order of discourse. In Young R. (Ed.), Untying the text: a poststructural anthology (48-78). Boston, MA: Rutledge\& Kegan Paul

.Foucault, Michel (1988). The ethic of care for the self as a practice of freedom. In Bernauer J. \& Rasmussen D. (Eds.), the final Foucault (1-20). Boston: MIT Press.

Foucault, Michel (1991). Governmentality. In Burchell Graham, Gordon Colin \& Miller 'Peter (Eds.), The Foucault Effect (1-51). Great Britain: Harveter Wheatsheaf.

Foucault, Michel (1994) the subject and Power. In Scott John Power (Ed.), Critical concepts (218-233). London: Routledge

Foucault, Michel (1997). Ethics, subjectivity and truth. In Rabinow Paul (Ed.), The essential works of Michel Foucault 1954-1984. New York: The New Press Foucault, Michel (2007). Security, territory, population: lectures at the college de France (1977-1978). Basingstoke: Palgrave. 
Foucault, Michel (2008) The Birth of biopolitics: lectures at the college de France 1978-79. New York: Palgrave Macmillan

Freeman, Marsha A, Chinkin, Christine, Rudolf Beate (2012). The UN Convention on the Elimination of All Forms of Discrimination against Women: a commentary. UK: Oxford University Press

Fregoso, Rosa-Linda (2006). 'We want them alive!': the politics and culture of human rights. Social Identities, 12(2), 109-138.

Friedman, Elizabeth J. (2003). Gendering the agenda: the impact of the transnational women's rights movement at the UN Conferences of the 1990s. Women's studies international forum, 26 (4), 313-331

Ganesh, Shiv, Zoller Heather \& Cheney George (2005). Transforming resistance, broadening our boundaries: critical organizational communication meets globalization from below. Communication Monographs, 72 (2), 169-191

Gathigi, H. Wnjiru (2000). The impact of women groups activities on the role and status of women's activities: a study of Ngong division, Kajiado district. Unpublished M.A thesis, University of Nairobi.

Gee, P. James. (1999). An introduction to discourse analysis: theory and method. London: Routledge.

Gelb, Joyce (2003. Gender policies in Japan and the United States: comparing women's movements, rights and politics. New York: Palgrave Macmillan

Giora, Rachel (2001). Irony and discontent. In Schram Dick \& Steen Gerald (165-184), The psychology and sociology of literature. Amsterdam\& Philadelphia: John Benjaminss Publishing Company

Gramci, Antonio (1971). Selection from the prison notebooks. New York: NY International Publishers

Grewal, Inderpal (1999). 'Women's rights as human rights': feminist practices, global feminism, and human rights regimes in transnationality. Citizenship Studies, 3(3), $337-354$ 
Grewal, B. S. (2008). Neoliberalism and discourse: case studies of knowledge policies in the Asia-Pacific. Unpublished PhD thesis, Auckland University of Technology

Grue, Jan (2009). Critical discourse analysis, topoi and mystification: disability policy documents from a Norwegian NGO. Discourse Studies, 11(3), 305-328

Goldberg, Michelle (2006). Discursive policy webs in a globalisation era: a discussion of access to professions and trades for immigrant professionals in Ontario, Canada. Globalisation, Societies and Education, 4(1), 77-102

Gordon, Colin (1991) Governmental rationality: an introduction: In Graham Burchell, Colin Gordon and Peter Miller (Eds.) The Foucault effect: studies in governmentality (151). Hemel Hempstead: Harvester Wheatsheaf

Gould, Carol., C. (2004). Globalizing democracy and human rights. United Kingdom: Cambridge University Press

Guo, Xiaotian (2006). Verbs in the written English of Chinese learners: a corpus-based comparison between non-native speakers and native speakers. Unpublished $\mathrm{PhD}$ thesis, University of Birmingham.

Grosz, Elizabeth (2010). The untimeliness of feminist theory. NORA-Nordic Journal of Feminist and Gender Research, 18(1), 48-51

Gieryn, Thomas (1999). Cultural boundaries of science: credibility on the line. Chicago, IL/London: University of Chicago Press

Haahr, Jens Henrik \& Walters William (2005). Governmentality and political studies. European Political Science 4(3), 288-300

Halliday, K. Michael (1978). Language as social semiotic. London: Edward Arnold

Halliday, K. Michael (1985). An introduction to functional grammar. London: Edward Arnold

Harrington, Carol (2013). Governmentality and the power of transnational women's movements. Studies in Social Justice, 7 (1), 47-63

Harsock, Nancy (1990) Foucault on power: theory for women: In Nicholson (Ed.), Feminism/postmodernism. New York/London: Routledge

Hart, Christopher (2011). Legitimizing assertions and the logico-rhetorical module: 
evidence and epistemic vigilance in media discourse on immigration. Discourse Studies, 13(6), 751-769.

Hart, Christopher (2013). Argumentation meets adapted cognition: manipulation in media discourse on immigration. Journal of Pragmatics 59, 200-209

Harpur, Paul (2009). Labour rights as human rights: worker's safety at work in Australian-based supply chains. Unpublished $\mathrm{PhD}$ thesis, Queensland University of Technology

Hatton, Erin \& Trautner Mary Nell (2013). Images of powerful women in the age of 'choice feminism.' Journal of Gender Studies, 22(1), 65-78

Healy, Karen (1999). Power and activist social work. In Pease Bob and Fook Jan (Eds.), Transforming social work practice: postmodern critical perspectives (pp. 115-135). London/New York; Routledge

Hoey, Michael (2001). Textual interaction: an introduction to written discourse analysis: Routledge: London/New York

Hodge Robert \& Kress Gunther (1988) Social semiotics. Oxford: Cornell University Press

Ho, Victor (2011). What functions do intertextuality and interdiscursivity serve in request email discourse? Journal of Pragmatics 43(10), 2534-2547

Hughes, Christina (2002). Key concepts in feminist theory and research: Chicago. Sage. Human Rights Watch (1997) Human Rights Watch world report 1997. Human Rights Watch. New York

Human Rights Watch (2003) interview with Ann Gathumbi; Coordinator Coalition on Violence against Women, October, 17, 2002. Human Rights watch, 15 (5) (A)

Human Rights Watch (2011). World report events of 2010. USA: Human Rights Watch Hyland, Ken (2004). Disciplinary discourses: social interactions in academic writing. USA: The University of Michigan Press

Hyland, Ken (1999). Disciplinary discourses: writer stance in research articles. In Candlin Christopher \& Hyland Ken (Eds.), Writing texts, processes and practices (99-121). London/New York: Routledge

Hyndman, Jennifer (2004). Mind the gap: bridging feminist and political geography through geopolitics. Political Geography, 23(3), 307-322 
Ibhawoh, Bonny (2000). Between culture and constitution: Evaluating the cultural legitimacy of human rights in the African State. Human Rights Quarterly,22 (3), 838-860

Ibhavvoh, Bonny (2004). Restraining universalism: Africanist perspectives on cultural relativism in the human rights discourse. In Zeleza P. \& McConnaughay P. (Eds.), Human rights, the rule of law, and development in Africa (21-39). Philadelphia: University of Pennsylvania Press

Inda, Jonathan Xavier (2005). Anthropologies of modernity: Foucault, governmentality, and life politics. USA: Blackwell Publishing Ltd

Ivanic, Roz (1998). Writing and identity: the discoursal construction of identity in academic writing. Amsterdam: John Benjamins

Jaworski, Adam \& Coupland Nikolas (2006). The discourse reader (2nd Ed.). USA: Routledge

Jessop, Bob (2000). The crisis of the national spatio-temporal fix and the ecological dominance of globalizing capitalism. International Journal of Urban and Regional Research, 24(2), 323-360.

Jessop, Bob. (2004). Critical semiotic analysis and cultural political economy. Critical Discourse Studies, 1 (2), 159-174

Jessop, Bob (2006). From micro-powers to governmentality: Foucault's work on statehood, state formation, statecraft and state power. Political Geography, 26 (1), 34-40.

Jianguo, W.U. (2011). Understanding interdiscursivity: a pragmatic model. Journal of Cambridge Studies, 6(2-3), 95-115

Jivanjee, Pauline \& Tebb Susan (1999). Visions of community women and children in the developing and developed worlds. International Social Work 42(1), 27-38. Sage Publications: London, Thousand Oaks, CA and New Delhi (Accessed, 27th Sept, 2012

Jonathan, Joseph (2012). The social in the global: social theory, governmentality and global politics. Cambridge: Cambridge University Press

Jones, Rodney H. (2010) Creativity and discourse. World Englishes, 29(4), 467-480.

Jonstone, Ian (2005). The power of interpretive communities. In Barnett Michael 
and Duvall Raymond (Eds.), Power in global governance (1-32). UK: Cambridge University Press

Jorgensen, Kenneth Molberg (2007) Power without glory: a geneology of a management decision. Denmark: Copenhagen Business School Press

Jørgensen, Marianne W., \& Phillips Louise J. (2002). Discourse analysis as theory and method. London: Sage Publications Ltd

Junefelt, Karen (2007). Rethinking egocentric speech: towards a new hypothesis. New York: Nova Science Publishers, Inc.

Kamau, Nyokabi (2010). Women and political leadership in Kenya. Nairobi: Heinrich Boll Stiftung

Kameri-Mbote, Patricia \& Kiai, W (1993). The women's movement in Kenya: an overview. In Khasiani, A.S \& Njiro, E.I. (Eds.), The women's movement in Kenya (7-20). Nairobi: AAWORD

Kameri-Mbote, Patricia (2001). Violence against women in Kenya. Geneva: International Environmental Law Research Centre: IELRC Working Paper 2000-1

Kameri- Mbote, Patricia (2006). Women, land rights and the environment: the Kenyan experience. Development, 49 (3), 43-48

Kasiva, Faith (2003). Women political participation in Kenya" paper presented at The East African Women's Leadership Institute of Akina Mama Wa Africa, September 22nd 3rd October 2003, Entebe Uganda

Keats, Patrice A. (2009). Multiple text analysis in narrative research: visual, written, and spoken stories of experience. Qualitative Research, 9 (2), 181-195

Keck, Margaret \& Sikkink Kathryn (1998). Activists beyond borders. Ithaca: Cornell University Press.

Kenya (2000) Consideration of reports submitted by states parties under article 18 of the Convention on the Elimination of All Forms of Discrimination against Women: third and fourth periodic reports of states, Kenya, 14th February, 2000 
Kenya (2006) Consideration of reports submitted by States parties under article 18 of the Convention on the Elimination of All Forms of Discrimination against Women: Combined fifth and sixth periodic reports of States, Kenya, 16th October, 2006

Kilderry, Anna Dorothea (2012). Teacher decision making in early childhood education. Unpublished PhD thesis, Queensland University of Technology

Kim, Mary Shin. (2011). Negotiating epistemic rights to information in Korean conversation: an examination of the Korean evidential marker-tamye. Discourse Studies, 13(4), 435-459.

Kitetu, Catherine (1998). An examination of classroom discourse practices and the construction of gendered identities in a Kenyan secondary school. Unpublished $\mathrm{PhD}$ thesis. UK. University of Lancaster.

Kopiyo, Getrude (1994). Can the law secure women's rights? Situation of violence against Kenyan women. In Klemb Ludigera (Ed.), Women challenge violence: experiences from Eastern and Southern Africa. Dar es Salaam: Friedrich Ebert Stiftung.

Kress, Gunther (2001). From Saussure to critical sociolinguistics: the turn towards a social view of language. In Wetherell Margaret, Taylor Stephane \& Yates Simeon J. (Eds.), Discourse theory and practice (29-38), The reader. London: Sage Publications Ltd

Kristeva, Julia (1980). Desire in language: a semiotic approach to literature and art. New York: Columbia University Press

Kristeva, Julia (1986). Word, dialogue and novel. In Toril Moi (Ed.), The Kristeva reader (34-61). Oxford: Blackwell.

Kotthoff, Helga (2002). Irony, quotation, and other forms of staged intertextuality: double or contrastive perspectivation in conversation. In Karl Graumann and Werner Kallmeyer (Eds.), Perspective and perspectivation in discourse. Amsterdam: Benjamins B.V

Kuzio, Anna (2015). Exploitation of Schemata in Persuasive and Manipulative Discourse in English, Polish and Russian. UK: Cambridge Scholars Publishing

Kwon, Winston, Clarke Ian \&Wodak Ruth (2009). Organizational decision-making, 
discourse, and power: integrating across contexts and scales. Discourse and Communication, 3(3), 273-302

Lapakko, David (2014). Argumentation: critical thinking in action (3rd Ed.) USA: iUniverse

Larner, Wendy (2006). Neoliberalism: policy, ideology, governmentality. In Marieke de Goede (Ed.) International political economy and poststructural politics (199-218). UK: Palgrave Macmillan

Lassen, Inger (2004). Ideological resources in biotechnology press releases: patterns of theme/rheme and given/new. In: Young Lynee and Harrison Claire (Eds.), Systemic functional linguistics and critical discourse analysis (264-279). London/New York: Continuum

Laher, Yumna (2014). Pageant politics: framing gendered images of women in leadership, politikon. South African Journal of Political Studies, 41(1), 103-120.

Leichty, Greg (2013). Cultural topoi. In Heath Robert (Ed.), Encyclopedia of public relations (238-240). London: Sage Publications, Inc.

Leitch, Shirley \& Palmer Ian (2010). Analysing texts in context: current practices and new protocols for critical discourse analysis in organization studies. Journal of Management Studies, 47(6), 1194-1212

Lemke, Jay L. (1992). Intertextuality and educational research. Linguistics and Education, 4(3), 257-267

Lemke, Thomas (2001). 'The birth of bio-politics': Michel Foucault's lecture at the Collège de France on neo-liberal governmentality. Economy and society, 30(2), 190-207.

Lemke, Thomas (2002). Foucault, governmentality, and critique, rethinking marxism. A Journal of Economics, Culture and Society, 14(3), 49-64

Lemke, Thomas (2010). Foucault's hypothesis: from the critique of the juridico-discursive concept of power to an analytics of government. Parrhesia, 9, 31-43

Linell, Per (1998). Discourse across boundaries: on recontextualizations and the blending of voices in professional discourse. Text, 18(2), 143-158. 
Lindblad, Sverker\& Popkewitz Thomas S. (2004). Educational restructuring: (re) thinking the problematic of reform. In Lindblad Sverker and Popkewitz Thomas S. (Eds.) Educational restructuring: international perspectives on traveling policies (vii-xxxi). USA: Information Age Publishing Inc.

Livnat, Zohar (2012). Dialogue, science and academic writing. Amsterdam: John Benjamins B.V

LKWV (2005). The Kenya women's Manifesto. Nairobi: Friedrich Ebert Stiftung. Locke, Terry (2004). Critical discourse analysis. London: Continuum International Publishing Group

Lombardo E., Meier P., \& Verloo M. (2013). Stretching and bending gender equality: a discursive politics approach. In Lombardo E. Meier P. \& Verloo M. (Eds.), The discursive politics of gender equality: stretching, bending and policy-making (118). United Kingdom: Routledge

Lowndes, Anthony Peter (2001). Exploring intertextuality: a study of a teacher's implementation of the key stage 1 reading SATs. Unpublished PhD Dissertation, the Open University.

Machin, David \& Mayr Andrea (2012). How to do critical discourse analysis. London: Sage Publications Ltd

Maguire, Steve and Hardy, Cynthia (2006) The emergence of new global institutions: a discursive perspective. Organization Studies, 27(1), 7-29

Mainga, Rita (2003). Engendering the political process in Kenya using the media, paper presented at the East African women's leadership institute of Akina Mama Wa Africa, September 22nd -3rd October 2003, Entebe Uganda

Manisha, Desai (2005). Transnationalism: the face of feminist politics post-Beijing. UK: UNESCO

Martin, James R. \& White Peter (2005). The language of evaluation. New York: Palgrave Macmillan.

Martin, James R. \& Rose David (2007). Working with discourse. Meaning beyond the clause. London/New York: Continuum 
Masaki, Katsuhiko (2007). Power, participation, and policy: the "emancipatory" evolution of the elite-controlled" policy process. United Kingdom: Lexington Books

Mathai, Wangari (1995). Bottle-necks of development in Africa, speech presented at the 4th United Nations' Conference for Women in Beijing, China, August 30th -15th September 1995

Mathai, Wangari (2004). The cracked mirror. Resurgence Magazine, 11th November, 2004 Matogo, Joyce Njeri (2010) The Impact of customs and sexual practices on young Maasai women's ability to negotiate their sexual and reproductive health in relation to HIV/AIDS in Loitokitok, Kenya. Unpublished M.A thesis, UNITEC New Zealand

Matusov, Eugene (2007), Applying Bakhtin scholarship on discourse in education: a critical review essay. Educational Theory, 57(2), 215-237

McBride, Dorothy \& Mazur Amy (2012) Gender machineries worldwide. Background paper for the world Development repoty 2012. The World Bank

Mcenery Tony \& Hardie Andrew (2012) Corpus Linguistics: Method, Theory and practice. UK: Cambridge University Press

Mclaren, Margaret A. (2002). Feminism, Foucault and embodied subjectivity. New York: State University of New York Press.

Merlingen, Michael (2010). From governance to governmentality in CSDP: towards a Foucauldian research agenda. Journal of Common Market Studies, 49 (1), 149-169

Merry, Engle Sally (2001) Women, violence, and the human rights system. In Agosin Marjorie (Ed.), Women, gender and human rights: a global perspective (8397). New Jersey: Rutgers University Press

Merry, Sally Engle (2006). Transnational human rights and local activism: mapping the middle. American Anthropologist, 108 (1), 38-51

Messer, Ellen (1993). Anthropology and human rights. Annual Review of Anthropology, 22, 221-249.

Michaelson, Marc (1994). Wangari Maathai and Kenya's Green Belt Movement: 
exploring the evolution and potentialities of consensus movement mobilization. Social problems, 41 (4), 540-561

Miller, Peter \& Rose Nikolas (1990). Governing economic life. Economy and Society, 19(1), 1-31

Miller, Peter \& Rose Nikolas (1992). Political power beyond the state: problematics of government. The British Journal of Sociology, 43 (2), 173-205

Miller, Carol \& Ravazi Shahrashoub (1995). From WID to GAD: conceptual shifts in the women and development discourse. Occasional Paper I, February 1995, United Nations Research Institute for Social Development: United Nations Development Programme, Switzerland

Miller, Peter \& Rose Nikolas (2010). Political power beyond the State: problematics of government. The British Journal of Sociology, 61(1), 271-303

Mitullah, Winnie (2003). Gender inclusion in transition politics: a review and critique of women's engagement. In Mbai C. Odhiambo and Oyugi O. Walter (Eds.), The politics of transition in Kenya: from KANU to NARC. Nairobi: Heinrich Böll Foundation.

Moghadam, Valentine (2000). Transnational feminist networks: collective action in an era of globalization. International Sociology, 15(1), 57-85.

Mohanty, Chandra Talpade (2003). "Under Western eyes" revisited: feminist solidarity struggles through anticapitalist struggles. Signs, 28 (2), 448-535.

Mona, Lilja \& Stellan Vinthagen (2014). Sovereign power, disciplinary power and biopower: resisting what power with what resistance? Journal of Political Power, 7 (1), $107-126$

Morley, David G., (2000). Syntax in functional grammar: an introduction to lexicogrammar in systemic linguistics. London: Continuum

Moser, Caroline O., (2012) Gender Planning and development: Theory, Practice and Training. London/New York: Routledge 
Moss, Jeremy (1998). Introduction: the later Foucault. In Moss Jeremy (Ed.), The later Foucault (1-17). London: Sage Publications Ltd.

Mukhopadhyay, Maitrayee, Steehouwer Gerard \& Wong Franz (2006). Politics of the possible: gender mainstreaming and organizational change: experiences from the field. United Kingdom: Oxfam

Muller, Hissink (2013). The place where streams seek ground: towards a new territorial governmentality: the meaning and usage of the concept of territorial cohesion in the European Union. Published PhD thesis, the University of Amsterdam.

Mulila-Matei, Asumpta K. (2014). Discourse, gender identity and gender power relations in fiction: a critical discourse analysis and systemic functional grammar reading of Wamitila's unaitwa nani? Unpublished PhD thesis, University of Nairobi

Muntigl, Peter (2000). The European Union: policy-making through organizational discursive practices. In Muntigl Peter, Weiss Gilbert and Wodak Ruth (Eds.), The European Union discourses on unemployment: an interdisciplinary approach to employment policy-making and organizational change (1-27). Amsterdam: John Benjamins B.V

Muntigl, Peter (2002). Politicization and depoliticization: employment policy in the European Union. In Chilton Paul and Schaffner Christina (Eds.), Politics as text and talk (4580). Amsterdam /Philadelphia: John Benjamins B.V

Murphy, Alexandra (2013). Discursive frictions: power, identity, and culture in an international working partnership. Journal of International and Intercultural Communication, 6(1), 1-20

Muthuki, Janet (2006). Challenging patriarchal structures: Wangari Maathai and the Green Belt Movement in Kenya. Agenda: Empowering Women for Gender Equity, 20 (69), 83-91

Mutua, Makau (1995). The ideology of human rights. Virginia Journal of international Law, $36,589-657$

Mutua, D. Athena (2006). Gender equality and women's solidarity across religious, ethnic, and class differences in the Kenyan constitutional review process. William and Mary Journal of Women and the Law, 13, 001

Nagar, Richa \& Swarr Amanda Lock (2010). Theorizing transnational feminist praxis. 
Albany: State University of New York Press.

Nash, Kate (2002). Human rights for women: an argument for 'deconstructive equality.' Economy and Society, 31(3), 414-433.

Ness, Peter Van (1999). Debating human rights: critical essays from the United States and Asia. London: Routledge.

Njagi, Jane Wambui (2013). The state and sexual politics: an analysis of abortion discourses in Kenya. Unpublished $\mathrm{PhD}$ thesis, the University of Waikato

Niesche, Richard (2013). Foucault, counter-conduct and school leadership as a form of political subjectivity. Journal of Educational Administration and History, 45(2), 144-158.

Ngondi-Houghton, Connie (2005). The state of human rights in Kenya: a baseline survey report (main report). Nairobi: Kenya National Commission of Human Rights and Ministry of Justice and Constitutional Affairs

Ndambuki, Jacinta (2010). Discursive representation of women's interests and needs in Makueni district. Unpublished PhD thesis, University of Witwatersrand

Newman, Saul (2005). Power and politics in poststructuralist thought. New theories of the political. New York: Routledge

Norton, Bonny (1997). Critical discourse research. In Hornberger N.H. \& Corson D. (Eds.) Encyclopedia of language and education, Vol.8: research methods in language and education (207-216). Boston/London: Kluwer academic Publishers

Norton, Bonny (2010). Language and identity. In Hornberger Nancy H. and Mckay Sandra Lee (Eds.) Sociolinguistics and language education: new perspectives on language and education. UK: Multilingual Matters.

Nzomo, Maria (1993). The Kenyan women's movement in a changing political context. In Khasiani S. A. and Njiro E.I. (Eds.), The women's movement in Kenya (131149). Nairobi: Association of African Women for Research and Development

Nzomo, Maria (1994). The status of women's human rights in Kenya and strategies to overcome inequalities. A Journal of Opinion 22(2), 17-20 
Nzomo, Maria (1995). The political economy of the African crisis: gender impacts and responses. International Journal, 51(1), 78-102

Nzomo, Maria (1997). Kenyan women in politics and public decision making. In Mikell Gwendolyn (Ed.), African feminism: the politics of survival in Sub-Saharan Africa (232-256). Philadelphia: University of Pennsylvania Press.

Nylund, Anastasia (2011). Connecting discourses of language and place in Washington. In Ryan Sullivant (Ed.), Proceedings of the nineteenth annual symposium about language and society. Texas Linguistics Forum, 54, 120-129

Onsarigo, Beatrice N. (2005). Factors influencing women's participation in democratization and electoral processes in Kenya: a case study of Gusii women 1992-1997. In Kasongo Lumumba T. (Ed.), Liberal democracy and its critics in Africa (76-98). Dakar: CODESRIA Books

Ondicho, Tom G. (2000). Battered women: a socio-legal perspective of their experiences in Nairobi. African Study Monographs, 21(1), 35-44,

Padamsee, Tasleem J. (2009). Culture in connection: re-contextualizing ideational processes in the analysis of policy development. Social Politics: International Studies in Gender, State and Society, 16(4), 413-445.

Palli, Pekka, Vaara Eero \& Sorsa Virpi (2009). Strategy as text and discursive practice: a genre-based approach to strategizing in city administration. Discourse and Communication, 3 (3) 303-318

Parisi, Laura (2002). Feminist praxis and women's human rights. Journal of Human Rights, 1(4), 571-585.

Parker, Ian (2014). Discourse dynamics (Psychology Revivals): critical analysis for social and individual psychology. New York: Routledge.

Patrona, Marianna (2013). 'We change or we sink': discursively constructing the voter's dilemma in a pre-election interview with the Greek Prime Minister. In Ekström Mats and Tolson Andrew (Eds.), Media talk and political elections in Europe and America (13-40). London: Palgrave Macmillan

Peerenboom, Randall (2004). Human rights and rule of law: What's the relationship? Geo. J. Int'l L., 36, 809 
Phillips, Nelson \&Hardy Cynthia (1997). Multiple identities: discourse, legitimacy and resources in the UK refugee system. Organization, 4(2), 159-185

Phillips, David \& Ochs Kimberly (2003). Processes of policy borrowing in education: Some explanatory and analytical devices. Comparative Education, 39(4), 451-461

Phillips, Nelson, Thomas Lawrence \& Hardy Cynthia (2004) 'Discourse and institutions'. Academy of Management Review 29(4), 1-18

Perkins, Harold A. (2009). Out from the (Green) shadow? Neoliberal hegemony through the market logic of shared urban environmental governance. Political Geography, 28(7), $395-405$

Presbey, Gail M. (2013). Women's empowerment: the insights of Wangari Maathai. Journal of Global Ethics, 9(3), 277-292

Prestidge, Paul (2010). It's a partnership: yeah, right! An analysis of discourses of partnership between government and community organisations in New Zealand (1999-2008). Unpublished M.A thesis, Auckland University of Technology

Prior, Paul. (1995). Tracing authoritative and internally persuasive discourses: a case study of response, revision, and disciplinary enculturation. Research in the Teaching of English, 29(3), 288-325

Powell, Marie (2005). A Rights-based approach to gender equality and women's rights. Canadian Journal of Development Studies, 26(1), 605-617

Queen, Mary (2008). Transnational feminist rhetorics in a digital world. College English, 70(5), 471- 489.

Rai, Shirin M. (2003). Institutional mechanisms for the advancement of women: mainstreaming gender, democratizing the state?. In Rai S. M. (Ed.) Mainstreaming gender, democratizing the state. Institutional Mechanisms for the Advancement of Women (15-39). UK/USA: Transaction Publishers

Rahimi, Forough \& Riasati Mohammad Javad (2011). Critical discourse analysis: scrutinizing ideologically-driven discourses. International Journal of Humanities and Social Science, 1 (16), 107 -112 
Ramanath, Ramya (2008). Limits to institutional isomorphism: examining internal processes in NGO-Government interactions. Non-profit and Voluntary Sector Quarterly, 20 (10), 1-26

Ransom, John S. (1997). The Politics of subjectivity: Foucault's discipline. USA: Duke University Press

Rayner, Timothy (2007). Foucault Heidegger: philosophy and transformative experience. London: Continuum international Publishing Group

Reisigl, Martin \&Wodak Ruth (2001). Discourse and discrimination: rhetorics of racism and antisemitism. London/New York: Routledge

Rensfeldt, Bergviken A. (2010). Opening higher education: discursive transformations of distance and higher education government. Unpublished $\mathrm{PhD}$ thesis, University of Gothenburg

Republic of Kenya (1995). Statement by Hon Nyiva Mwendwa, Minister for Culture and Social Services to the Fourth UN World Conference on Women, 8th September 1995

Republic of Kenya (1996). National Assembly official report (Hansard) October 30th 1996

Republic of Kenya (1999) Kenya human development report, 1999. Nairobi: UNDP

Republic of Kenya (1999). National Assembly official report (Hansard), Wednesday 8th December, 1999

Republic of Kenya (2000). The National Gender and Development Policy 2000 Nairobi: Ministry of Gender, Sports, Culture and Social Services.

Republic of Kenya (1998, 2001). The constitution of Kenya Review Act, 1997, Kenya Gazette Supplement No. 73 (Acts No.7), 30th December 1998, Nairobi

Republic of Kenya (2002). National Assembly Official Report (Hansard) April 24th 2002 Republic of Kenya (1995). Statement by Hon Nyiva Mwendwa, Minister for Culture and Social Services to the Fourth UN World Conference on Women, 8th September 1995 Republic of Kenya (2004). Kenya review and appraisal: final report on the implementation 
of Beijing Platform for Action, (Beijing +10) (1994 - 2004), June 2004. Nairobi: Ministry of Gender, Sports, Culture, and Social Services

Republic of Kenya (2005). National Assembly Official Report (Hansard), Thursday 24th March, 2005

Republic of Kenya (2005). Millennium Development Goals in Kenya: needs and costs. Nairobi: Ministry of Planning and National Development

Republic of Kenya (2007a). Contributing towards efforts to abandon female genital mutilation/cutting in Kenya. Nairobi: Ministry of Gender, Sports, Culture and Social Services

Republic of Kenya (2007b). Kenya vision 2030. Nairobi: Ministry of Planning and National Development

Republic of Kenya (2011). Gender policy 2011. Nairobi: Ministry of Gender, Children and Social Development

Rivitoi, Andrea Deciu (2008). Talking the (political) talk: Cold war refugees and their political legitimation through style. In Johnstone C. and Eisenhart B. (Eds.), Rhetoric in detail: discourse analyses of rhetorical talk and text (33-56). Amsterdam: John Benjamins Publishing Company

Rogers, Rebecca, Malancharuvil-Berkes Elizabeth, Mosley Melissa, Hui Diane \& O'Garro Glynis (2005). Critical discourse analysis in education: a review of the literature. Review of Educational Research, 75(3), 365-416

Rose, Nikolas (1999). Powers of freedom: reframing political thought. UK: Cambridge University Press

Rose, Nikolas \& Rabinow Paul (2003). Foucault today. In Rabinow P. \& Rose N. (Eds.) The essential Foucault: selections from the essential works of Foucault, 1954-1984 (1-30). New York: New Press

Rouse, Joseph (2005). Power/knowledge.In Gutting Gary (Ed.), The cambridge companion to Foucault (95-122). New York: Cambridge University Press

Saarinen, Taina (2007). Quality on the move: discursive construction of higher education policy from the perspective of quality. Published PhD thesis, University of Jyvaskyla 
Saarinen, Taina (2008) Persuasive presuppositions in OECD and EU higher education policy documents. Discourse Studies, 10 (3), 341-359.

Salleh, Ariel (1988). 'Living with nature: reciprocity or control.’ In Engel J.R and Engel J.G. (Eds.), Ethics of environment and development (245 - 253). Tuscon: University of Arizona Press

Sawick, Jana (1991). Disciplining Foucault: feminism, power, and the body. London/New York : Routledge

Singh, Kirti (199by4). 'Obstacles to women's rights in India.' In Cook R. J. (Ed.), Human rights of women: national and international perspectives. Philadelphia: University of Pennsylvania Press

Sharma, Aradhana \& Gupta Anil (2006). The anthropology of the state. A reader. USA: Blackwell Publishing Ltd

Sharma, Aradhana (2008). The logics of empowerment: development, gender and governace. London/Minneapolis: University of Minnesota Press

Shavji, Issa. G. (2004). Concept of human rights in Africa. London: CODESRIA Book Series Shaw, Richard \& Eichbaum Chris (2008.) Public policy in New Zealand: institutions, processes and outcomes. New Zealand: Pearson Education New Zealand

Selby, D. (1987). Human rights. Cambridge/New York: Cambridge University Press

Schmitz, Daniel W. (1999). Transitional activism and political change in Kenya and Uganda. In Risse Thomas and Ropp Stephen (Eds.), The power of human rights: international norms and domestic change (39-77). UK: Cambridge University Press

Sissel, Peggy (2001). When "accommodation" is resistance: towards a critical discourse on the politics of adult education. In Cervero R. M. Cervero, Courtenay B. C., and Monaghan C. H. (Eds.), The Cyril Houle scholars in adult and continuing education program global research perspectives: volume 1 (103-116). USA: University of Georgia,

Skilling, Peter (2010). New Zealand's fifth labour government (1999--2008): a new partnership with business and society? Labour History: A Journal of Labour and Social History, (98), 39-53. 
Smith, Jennifer L. (2007). Critical discourse analysis for nursing research. Nursing Inquiry, $14(1), 60-70$

Sondergaard, Dorte Marie (2002). Poststructuralist approaches to empirical analysis. International Journal of Qualitative Studies in Education, 15 (2), 187-204

Soeda, Yasuko (2008). Education toward improving the quality of life of women: impact of a community-based organization in rural Kenya. Unpublished MA Thesis, University of Oregon

Solin, Anna (2004). Intertextuality as mediation: on the analysis of intertextual relations in public discourse. Text 24(2) 267-296

Stevanovic, Melisa \& Perakyla Anssi (2012). Deontic authority in interaction: the right to announce, propose, and decide. Research on Language and Social Interaction, 45(3), 297-321

Sondergaard, Dorte Marie (2002). Poststructuralist approaches to empirical analysis. International Journal of Qualitative Studies in Education, 15 (2), 187-204

Sowinska, Agnieska (2013). A critical discourse approach to the analysis of values in political discourse: the example of freedom in President Bush's State of the Union addresses (2001-2008). Discourse and Society 24 (6), 1-18

Sullivan, Paul (2012). Qualitative data Analysis using a dialogical approach. London: Sage Publications Ltd

Tamale, Sylvia (2001). Think globally, act locally: using international treaties for women's empowerment in East Africa. Agenda, 16(50), 97-104.

Tardy, Christine M. (2011). Genre analysis. In Hayland Ken and Paltridge Brian (Eds.), The continuum companion to discourse analysis (54-68). London/New York: Continuum International Publishing Group

Talbot, M. (2007). Media discourse: representation and interaction. Edinburgh: Edinburgh University Press.

Thongori Judy (2003) Incorporating women's rights into the new constitution. In Republic of Kenya, Report of the Constitution of Kenya Review Commission (pp.184-187), Vol. 5 (10), April, 2003 
Titscher Stefan, Meyer Michael, Wodak Ruth \& Vetter Eva (2000). Methods of text and discourse analysis. London: Sage Publications Ltd

True, Jacqui (2013). Trading in gender equality: gendered meanings in EU trade policy. In Lombardo E., Meier P., and Verloo M. (Eds.), The discursive politics of gender equality stretching, bending and policy making (p.121-136). London: Routledge

Tuler, Seth (2000) Forms of talk in policy dialogue: distinguishing between adversarial and collaborative discourse. Journal of Risk Research, 3(1), 1-17

United Nations (1981). Convention on the Elimination of All Forms of Discrimination against Women (CEDAW)

United Nations (1995). Beijing Declaration and Platform for Action, 4th World Conference on Women, Beijing

United Nations (1998). "Report to the Economic and Social Council": Secretary-General's Report to ECOSOC

United Nations (2000). United Nations Millennium Declaration: Resolution adopted by the General Assembly, fifty-fifth session, September 2000

United Nations (2000). Five-year review of the implementation of the Beijing Declaration and Platform for Action (Beijing + 5) held in the General Assembly, 5 - 9, June 2000

Unterhalter, E., J. Karlsson, V. Dieltiens, J. Onsongo, A. North, H. Makinda, and C. Yates. 2011. Gender, education and global poverty reduction initiatives. Report on C omparative case studies in Kenya, South Africa and selected global organisations. London: Institute of Education

Vaara, E. (2013). Struggles of legitimacy in mediatized society. Paper presented at “Connecting Rigor and Relevance in Institutional Analysis' Conference," Harvard Business School, June 2-4, 2013.

Vaara Eero, Kleymann Birgit \& Seristo Hannu (2004). Strategies as discursive constructions: the case of airline alliances. Journal of Management Studies, 41(1), 1-35

Van Dijk, Teun (1997). Discourse as interaction in society. In Van Dijk Teun (Ed.), Discourse as social interaction: discourse studies (17-37). London: Sage Publications Ltd 
Van Dijk, Teun A. (2000). On the analysis of parliamentary debates on immigration. In Reisigl M. \& Wodak R. (Eds.), The semiotics of racism. Approaches to critical discourse analysis (85-103). Vienna: Passagen Verlag,

Van Dijk, Teun (2001) Critical discourse analysis. In Schiffrin D., Tannen D. and Hamilton H. (Eds.), The handbook of discourse analysis. Oxford: Blackwell

Van Dijk, Teun (2006). Ideology and discourse analysis. Journal of Political Ideologies, $11(2), 115-140$

Van Dijk, Teun (2011). The study of discourse. In Van Dijk, T. (Ed..), Discourse studies. London: Sage

Van Eemeren, Frans H., Houtlosser Peter, \& Henkemans Fransisca S. (2007) Argumentative Indicators in Discourse. A Pragma-Dialectical Study. Netherlands: Springer

Van Leeuwen, Theo \& Wodak Ruth (1999). Legitimizing immigration control: a discoursehistorical analysis. Discourse Studies, 1(1), 83-118

Van Leeuwen, Theo (2005). Introducing social semiotics. London New York: Routledge

Van Leeuwn, Theo (2007). Legitimation in discourse and communication. Discourse and Communication, 1(1), 91-112

Van Leeuwn, Theo (2008) Discourse and practice: new tools for critical discourse analysis. New York: Oxford University Press

Van Leeuwen, Theo \& Kress Gunther (2011). Discourse semiotics. In Van Dijk Teun (Ed.), Discourse studies. London: Sage Publications Ltd

Vidovich, Lesley (2007). Removing policy from its pedestal: some theoretical framings and practical possibilities. Educational Review, 59(3), 285-298

Volkova, Viktoria (2012). A systemic functional approach to applied linguistic article conclusions. Published M.A Thesis, Carleton University

Walby, Sylvia (2013). Beyond the politics of location: the power of argument in gender equality politics. In Lombardo E., Meier P., and Verloo M. (Eds.), The discursive politics of gender equality: stretching, bending and policy-making (3651). United Kingdom: Routledge 
Waller, Lloyd (2006). Introducing Fairclough's critical discourse analysis methodology for analyzing Caribbean social problems: going beyond systems, resources, social action, social practices and forces of structure or lack thereof as units of analysis. Social action, social practices and forces of structure or lack thereof as units of analysis. Journal of Diplomatic Language, 3(1), 1-19

Walsh, Janet (2005). Women's property rights violations in Kenya. In Alston and Robinson (Eds.), Human rights and development: towards mutual reinforcement. New York: Oxford University Press

Wambugu, Jedidah \& Mokoena Sello (2013) Education Financing in Kenya: Parents' Perceptions about the Implementation of the Cost-Sharing Policy in Secondary School Education. Mediterranean Journal of Social Sciences, 4 (13), 441-446

Wang, Wei (2008). Intertextual aspects of Chinese newspaper commentaries on the events of 9/11. Discourse Studies, 10(3), 361-381.

Waterton, Emma, Smith Laurajane \& Campbell Gary (2006). The utility of discourse analysis to heritage studies: the Burra charter and social inclusion. International Journal of Heritage Studies, 12 (4), 339-355

Welch, Claude Emerson (1995) protecting human rights in Africa: strategies and roles of non-governmental organizations. Philadelphia: University of Pennsylvania Press

Weldon, Laurel S. \& Htun Mala (2012). Fixing women or fixing the world? 'Smart economics,' efficiency approaches, and gender equality in development. Gender and Development, 20 (3), 517-529

Whaites, Alan (2000). Let's get civil society straight: NGOs, the state, and political theory. In Eade Deborah (Ed.), Development, NGOs and civil society. a development in practice reader (124-141). UK: Oxfam GB

Wodak, Ruth (1995). Critical linguistics and critical discourse analysis. In Verschueren, J. et al. (Eds.), Handbook of pragmatics: manual (204-210). Amsterdam: John Benjamins

Wodak, Ruth (1997). Critical discourse analysis and the study of doctor-patient interaction. In Gunnarsson B., Linell, P., and Nordberg, B. (Eds.), The construction of Professional discourse (173-199). London: Longman 
Wodak, Ruth \& Busch Brigitta (2004). Approaches to media texts: In Downing D.H., McQuil Denis, Schlesinger Philip and Wartella Ellen (Eds.) The sage handbook of media studies (105-122). California: Sage Publications

Wodak, Ruth. (2001) What CDA is about-a summary of its history, important concepts and its development.' In Wodak, R. \& Meyer M. (Eds.), Methods of Critical Discourse Analysis. London: Sage

Wodak, Ruth (2006). Mediation between discourse and society: assessing cognitive approaches in CDA. Discourse Studies, 8(1), 179-190

Wodak, Ruth (2011). Critical discourse analysis. In Hayland Ken and Paltridge Brian (Eds.), The continuum companion to discourse analysis (38-53). London/New York: Continuum International Publishing Group

Wodak, Ruth (2011). The discourse of politics in action: politics as usual. London: Palgrave Macmillan

Wuerffel, Kristin N. (1998). Discriminating among rights: a nation's legislating a hierarchy of human rights in the context of international human rights customary law. Valparaiso University Law Review, 33(1), 369-412.

Zeleza, Paul Tiyambe (2004). The struggle for human rights in Africa. In Zeleza P. and McConnaughay P. (Eds.), Human rights, the rule of law, and development in Africa. Philadelphia: University of Pennsylvania Press

Yieke, Felicia (2004). Language use and sexual harassment at work places. Culture Today, $6(2)$

Yell, Susan (2005). Critical discourse analysis and social semiotics: re-thinking text and discourse in media and communication research. In Kwamena Kwansah-Aidoo (Ed.), Topical issues in communication and media research (9-23). New York: Nova Science Press

Zwingel, Susanne (2005). How do international women's norms become effective in domestic contexts?. An analysis of the Convention on the Elimination of all Forms of Discrimination against Women (CEDAW). Unpublished PhD thesis, University of Bochum 